Argonne National Laboratory

9700 South Cass Avenue

Argonne, Illinois 60439

\title{
EFFECT OF VISCOSITY ON SEISMIC RESPONSE
} OF WASTE STORAGE TANKS

by

Yu Tang, R. Aziz Uras, and Yao-Wen Chang

Reactor Engineering Division

June 1992

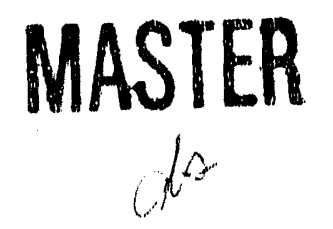




\section{TABLE OF CONTENTS}

$\underline{\text { Page }}$

ABSTRACT $\ldots \ldots \ldots \ldots \ldots \ldots \ldots \ldots \ldots \ldots \ldots \ldots \ldots \ldots \ldots \ldots \ldots$

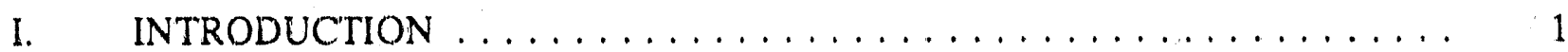

II. LIQUID-TANK SYSTEM AND INPUT GROUND MOTIONS . . . . . . . 2

III. FLUSTR COMPUTER CODE $\ldots \ldots \ldots \ldots \ldots \ldots \ldots$

IV. SYSTEM RESPONSE TO HARMONIC EXCITATIONS $\ldots \ldots \ldots \ldots$

A. Small Tank $\ldots \ldots \ldots \ldots \ldots \ldots \ldots \ldots \ldots \ldots \ldots \ldots$

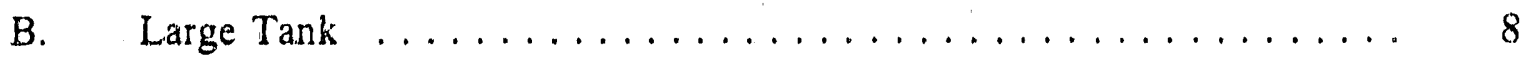

C. Equivalent Viscous Damping ..................... 9

V. SYSTEM RESPONSE TO EARTHQUAKE MOTIONS $\ldots \ldots \ldots \ldots \ldots \ldots$

VI. EFFECT OF INTEGRATION TIME STEP ON SYSTEM RESPONSE . . . . 13

VII. CONCLUSIONS .......................... 14

ACKNOWLEDGMENTS $\ldots \ldots \ldots \ldots \ldots \ldots \ldots \ldots \ldots \ldots \ldots \ldots \ldots$

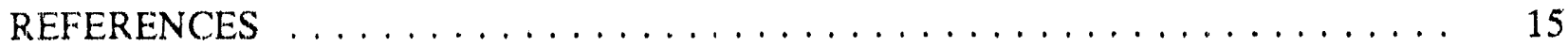

APPENDIX A. Basic Equations and Solution Algorithm in FLUSTR Code . .... . A-1

A.1 Governing Equations for p-V Formulation $\ldots \ldots \ldots \ldots$ A-1

A.2 Finite Element Formulation $\ldots \ldots \ldots \ldots \ldots$ A-3

A.3 Matrix Governing Equations ............... A-4

A.4 Solution Algorithm $\ldots \ldots \ldots \ldots \ldots \ldots \ldots \ldots$ A $\ldots \ldots \ldots \ldots$

Appendix B. Comparison of FLUSTR Code Predictions with Experimental Data . . B-1

B.1 Code Validation . . . . . . . . . . . . . . . B-1 


\section{TABLE OF CONTENTS (Cont'd)}

Page

Appendix C. Time History Plots of the Sloshing Wave Height and Hydrodynamir Pressures for the Case of $\mu=60 \mathrm{cP}$ for Base Motion $1 \ldots \ldots \ldots$.

Appendix D, Time History Plots of the Sloshing Wave Height and Hydrodynamic Pressures for the Case of $\mu=200 \mathrm{cP}$ for Base Motion $1 \ldots \ldots$. 


\section{LIST OF TABLES}

No.

Title

Page

$1 \quad$ Sloshing Wave Height, Total Pressure, Impulsive Pressure, Dia. of Tank = 40";

Harmonic Excitation: Amplitude $=1 \mathrm{in} . \mathrm{sec}^{2}$, Freq. $=0.915 \mathrm{~Hz} \ldots \ldots \ldots$

II Sloshing Wave Height, Total Pressure, Impuisive Pressure, Din. of Tank = 40";

Harmonic Excitation: Amplitude $=1 \mathrm{in} . / \mathrm{sec}^{2}$, Freq. $=1.53 \mathrm{~Hz} \ldots \ldots \ldots 17$

III Sloshing Wave Height, Total Pressure, Impulsive Pressure, Dia. of Tank = 40";

Harmonic Excitation: Amplitude $=1 \mathrm{in} . / \mathrm{sec}^{2}$, Freq. $=2 \mathrm{~Hz} \ldots \ldots \ldots$

IV Sloshing Wave Height, Total Pressure, Impulsive Pressure, Dia. of Tank $=40^{\prime \prime}$;

Harmonic Excitation: Amplitude $=1$ in. $/ \mathrm{sec}^{2}$, Freq. $=3 \mathrm{~Hz} \ldots \ldots \ldots$

V Sloshing Wave Height, Total Pressure, Impulsive Pressure, Dia, of Tank = 40";

Harmonic Excitation: Amplitude $=1 \mathrm{in} . / \mathrm{sec}^{2}$, Freq. $=5 \mathrm{~Hz} \ldots \ldots \ldots \ldots$

VI Sloshing Wave Height, Total Pressure, Impulsive Pressure, Dia. of Tank = $50 \mathrm{ft}$; Harmonic Excitation: Amplitude $=1 \mathrm{in} . / \mathrm{sec}^{2}$, Freq. $=0.233 \mathrm{~Hz} \ldots \ldots \ldots$

VII Sinshing Wave Height, Total Pressure, Impulsive Pressure, Dia. of Tank = $50 \mathrm{ft}$; Harmonic Excitation: Amplitude $=1 \mathrm{in} . / \mathrm{sec}^{2}$, Freq. $=0.5 \mathrm{~Hz} \ldots \ldots \ldots 22$

VIII Equivalent Viscous Damping Factor, $\zeta \ldots \ldots \ldots \ldots \ldots \ldots$

IX Comparison of Impulsive Pressure (psi) Distribution Along the Wall for Base

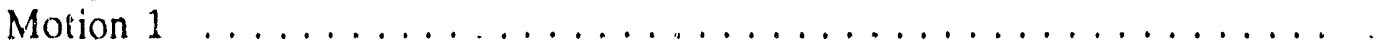

X Comparison of Maximum Convestive Pressure (psi) Distribution Along the Wall

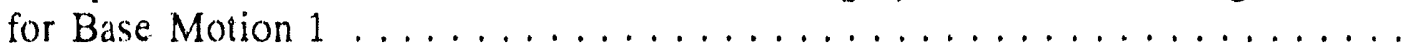

XI Comparison of Maximum Total Pressure (psi) Distribution Along the Wall for

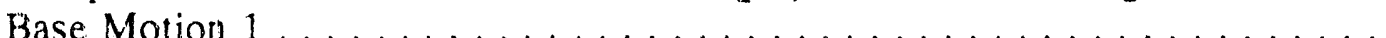

XII Comparison of Sloshing Wave Height, Base Shear and Base Moments for Base

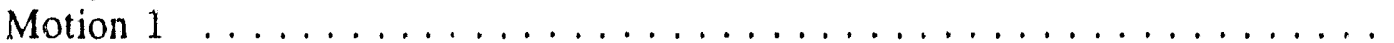

XIII Comparison of Impulsive Pressure (psi) Distribution Along the Wall for Base Motion 2 


\section{LIST OF TABLES (Cont'd)}

No.

Title

Page

XIV Comparison of Maximum Convective Pressure (psi) Distribution Along the Wall for Base Motion $2 \ldots \ldots \ldots \ldots \ldots \ldots \ldots \ldots \ldots \ldots$

XV Comparison of Maximum Total Pressure (psi) Distribution Along the Wall

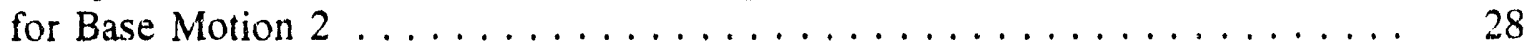

XVI Comparison of Sloshing Wave Height, Base Shear and Base Moments for

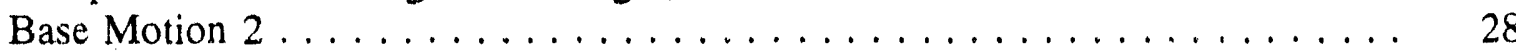

XVII Comparison of Impulsive Pressure $\left(\mathrm{psi} \times 10^{-2}\right)$ Obtained with Different

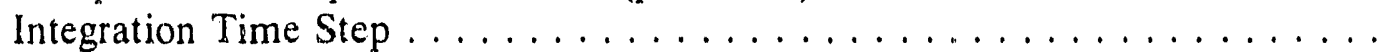

XVIII Comparison of Vertical Displacement (in.) and Total Pressure $\left(\mathrm{psi} \times 10^{-2}\right)$ Obtained with Different Integration Time Step $\ldots \ldots \ldots \ldots \ldots \ldots \ldots$ 


\section{LIST OF FIGURES}

No.

Title

Page

1 Finite Element Model of the Small Liquid-Tank System . . . . . . . . . . .

2 Sloshing Wave Heights as a Function of Time for Fluid Viscosity, $\mu=60,200,1000$ and $10,000 \mathrm{cP}$ Due to Resonant Harmonic Excitation

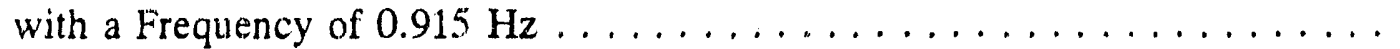

3 Sloshing Wave Height as a Function of Time for Fluid Viscosity, $\mu=0$ Due to Resonant Harmonic Excitation with a Frequency of $0.915 \mathrm{~Hz} \ldots \ldots$

4 Total Hydrodynamic Pressures at Fluid Elements 1, 133, 331 and 529 for the Case of $\mu=200 \mathrm{cP}$ Due to Resonant Harmonic Excitation with a

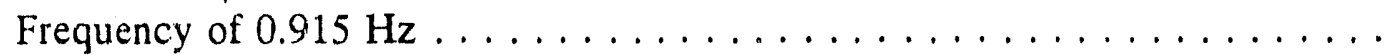

5 Impulsive Pressures at Fluid Elements 1, 133, 331 and 529 for the Case of $\mu=200 \mathrm{cP}$ Due to Resonant Harmonic Excitation with a Frequency of

6 Sloshing Wave Heights as a Function of Time and FFT Plot for Fluid Viscosity, $\mu=60$ and $200 \mathrm{cP}$ Due to Non-Resonant Harmonic Excitation with a Frequency of $5 \mathrm{~Hz} \ldots \ldots \ldots \ldots \ldots \ldots \ldots \ldots$

7 Sloshing Wave Heights as a Function of Time and FFT Plot for Fluid Viscosity, $\mu=1000$ and $10,000 \mathrm{cP}$ Due to Non-Resonant Harmonic Excitation with a

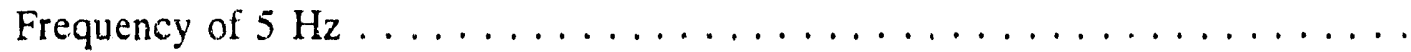

8 Sloshing Wave Heights as a Function of Time for Fluid Viscosity, $\mu=60,200$, 1000 , and $10,000 \mathrm{cP}$ Due to Resonant Harmonic Excitation with a Frequency of $1.53 \mathrm{~Hz}$

9 Finite Element Model of the Large Liquid-Tank System

10 Sloshing Wave Height as a Function of Time at Node 131 of the Large Tank for the Case of $\mu=10,000 \mathrm{cP}$ Due to Resonant Harmonic Excitation with a Frequency of $0.233 \mathrm{~Hz}$

11 Time History and FFT of Base Motion $1 \ldots \ldots \ldots \ldots \ldots$

12 Time History and FFT of Base Motion 2 


\title{
EFFECT OF VISCOSITY ON SEISMIC RESPONSE \\ OF WASTE STORAGE TANKS
}

by

Yu Tang, R. Aziz Uras, and Yao-Wen Chang

\begin{abstract}
The dynamic response of liquid-storage tanks subjected to harmonic excitations and earthquake ground motions has been studied. A rigid tank of negligible mass, rigidly supported at the base having a diameter of $50 \mathrm{ft}$. and fluid height of $20.4 \mathrm{ft}$. was used in the computer analysis. The liquid is assumed to have a density of $1.5 \mathrm{~g} / \mathrm{ml}$. Viscosity values, $\mu=60,200$, 100 , and $10,000 \mathrm{cP}$, were used in the numerical analyses to study the effects of viscosity on sloshing wave height, impulsive and corrvective pressure on the tank wall, base shear and base moments.

Harmonic excitations as well as earthquake ground motions were used as input motions. The harmonic excitations used in the analyses covers a wide range of frequencies, including both the resonant and non-resonant frequencies. Two earthquake motions were used. One matches the Newmark-Hall median response spectrum and is anchored at $0.24 \mathrm{~g}$ for a rock site with a damping of $2 \%$ and a time duration of $10 \mathrm{~s}$. The other is the 1978 Tabas earthquake which had a peak ZPA of $0.81 \mathrm{~g}$ and a time duration of $29 \mathrm{~s}$. A small tank, about $1 / 15$ the size of the typical waste storage tank, was used in the harmonic excitation study to investigate the effect of viscosity on the response of liquid-storage tanks and how the viscosity effect is affected by the size of the storage tank.

The results of this study show that for the typical waste storage tank subjected to earthquake motions, the effect of viscosity on sloshing wave height and impulsive and convective pressures is very small and can be neglected. For viscosity effect to become noticeable in the response of the typical waste storage tank, the waste viscosity must be greater than $10,000 \mathrm{cP}$. This value is far greater than the estimated viscosity value of the high level wastes, which may range from 60 to $200 \mathrm{cP}$ for some tanks.
\end{abstract}




\section{INTRODUCTION}

The dynamic response of liquid-storage tanks subjected to earthquake ground motions has been the subject of numerous studies in the past thirty years. Housner's papers on dynamic pressures on accelerated fluid containers [1] and dynamic behavior of water tanks [2] are examples of early works dealing with liquid-storage tanks. An excellent review of that subject can be found in the paper of Veletsos [3]. However, most of the studies were focused on the tanks that contained only one liquid and that the liquid can be considered as incompressible and inviscid. Because of their inherent simplicity, the methods developed based on the assumption of inviscid fluid have been widely used in industry for the design of liquid.storage tanks. Thus, the effect of viscosity on the dynamic response of liquid-tanks is often ignored. This is justified for water-storage tanks because water has a very small viscosity value.

Recently, DOE-EM has initiated a high-level waste tank safety program. One of the objectives of the safety program is to develop seismic design and evaluation criteria for use in assessing the seismic response of existing underground high level waste (HLW) storage tanks and for use as design guides for new underground HLW storage tanks. As the high level waste is quite viscous, use of the methods based on inviscid assumption becomes questionable. Thus, one of the tasks in the DOE seismic design and evaluation program for underground waste storage tanks is to study the effect of viscosity on the dynamic response of the tank. As is well known, if viscosity is to be included in the analysis, the governing equations become very complicated, and in most cases, closed form solutions are unattainable. Therefore, it is necessary to use computer codes to solve the equations numerically.

Argonne National Laboratory (ANL) has been deeply involved in developing methodology for the seismic analysis for advanced liquid metal reactor (LMR) designs, including the very large diameter (70-75 ft.) primary sodium tanks used in large LMR plants. These large diameter tanks are thin-walled and are quite similar to the thin-walled underground waste storage tanks now being studied for seismic upgrading by DOE-EM.

Under the funding and direction of DOE-NE, ANL has developed a computer code, FLUSTR-ANL [4], that can be used to perform seismic analysis of the large reactor tanks, including the determination of sloshing wave heights and hydrodynamic pressures on the tank wall as well as on the components located within the tank. The FLUSTR-ANL computer code 
has been extensively validated by using experimental data obtained from sloshing tests [5] conducted by the Electric Power Research Institute (EPRI) and the Japanese Central Research Institute of Electric Power Industry (CRIEPI). Thus Argonne was chosen by DOE-EM to use the FLUSTR-ANL computer code to study the effect of viscosity on seismic response of underground HLW storage tanks. This report describes the results of the FLUSTR analysis.

\section{LIQUID-TANK SYSTEM AND INPUT GROUND MOTIONS}

The liquid-tank system studied is a typical HIJW tank currently existing in the DOE sites. It is a rigidly supported circular cylindrical steel tank having a diameter of $50 \mathrm{ft}$ and fluid height of $20.4 \mathrm{ft}$. The waste is assumed to have a density of $1.5 \mathrm{~g} / \mathrm{ml}$. The values of the dynamic (absolute) viscosity, $\mu$, considered in the study are 60,200,1000 and 10,000 centipoise (cP). (Note: 1 centipoise $=0.01$ dyne-s $/ \mathrm{cm}^{2}=0.0000209 \mathrm{lb}-\mathrm{s} / \mathrm{ft}^{2}$.) The response quantities examined include the sloshing wave height, the convective component of the hydrodynamic pressure, the impulsive component of the hydrodynamic pressure and the associated base shear and base moments.

Two earthquake acceleration time histories are used in the study. One is a ten-second synthetic time history whose response spectrum matches the Newmark-Hall median response spectrum with a damping value of $2 \%$ of critical and is anchored to the ZPA of $0.24 \mathrm{~g}$. The other is the 29-second longitudinal component of the September 16, 1978 Tabas earthquake in Iran which has a peak acceleration of $0.81 \mathrm{~g}$.

Also, the response of the liquid-tank system subjected to harmonic excitations was studied. In addition, a small tank, about $1 / 15$ the size of the typical waste storage tank, was used in the harmonic excitation study to examine the effect of viscosity on the response of the liquidtank system. It should be mentioned that the original workscope of this study was to study only two viscosity values, i.e. $\mu=60$ and $200 \mathrm{cP}$, and for one time history, which is only require satisfy the Newmark-Hall median response spectrum anchored at $0.24 \mathrm{~g}$ for a rock site with a damping of $2 \%$. The workscope was later expanded to include all the above conditions to gain an improved understanding of the viscosity effect on the dynamic response of liquid-tank systems. 


\section{FLUSTR COMPUTER CODE}

The FLUSTR-ANL computer code was developed by the Engineering Mechanics Program staff in the Reactor Engineering Division of Argonne National Laboratory. It is a 3-D finite element computer code for fluid-structure interaction analysis involving large displacements. It can be used to perform static and dynamic analyses on solids, fluids and structures. The fluid can be considered to be compressible and viscous. The code has an option to use Lagrangian, Eulerian or arbitrary Lagrangian-Eulerian meshes to solve the complicated fluid problem involving large free surface motion, nonlinear sloshing, and flow around a sharp corner. It has an implicit-explicit mesh partition algorithm and is very efficient for long time-duration seismic analyses. There are twelve different elements in the element library. The governing equations for the fluid, weak form of the governing equations, fluid-structure interaction equations, matrix equations and solution algorithm are given in Appendix A.

The major coding of the FLUSTR-ANL code has been verified by comparing code predictions with known analytical solutions, such as Housner's solution on sloshing of simple rigid tanks [2] and Fritz's solution for two concentric cylinders [6]. Validation of the code against experimental data was accomplished in 1987 [5] using the results obtained from sloshing tests conducted in 1984-87 by EPRI and CRIEPI. This latter validation, comparing code predictions with experimental data, is given in Appendix B. It should be noted that the liquid used in EPRI/CRIEPI sloshing tests was low viscosity water. Thus, validation of the code should be limited to liquids of low to moderate viscosities.

\section{SYSTEM RESPONSE TO HARMONIC EXCITATIONS}

As stated earlier, the purpose of this study is to investigate the effect of viscosity on the response of underground HLW storage tanks when subjected to earthquake ground motions. The response functions to be examined include the sloshing wave height, the hydrodynamic pressure, the base shear and base moments. However, before studying the effect of viscosity on these response functions using earthquake ground motions as input, it is instructive to examine first how these functions will be affected by viscosity if the input motion is harmonic. Since an earthquake motion can be viewed as a series of harmonic excitations with different frequencies, the results of harmonic analysis can provide insight into the problem. 
The harmonic excitations used in the analysis covers a wide range of frequencies, including both the resonant and non-resonant frequencies. It is expected that when the excitation frequency coincides with the sloshing frequencies, the effect of the viscosity on the response would be significant for the sloshing wave and hydrodynarnic pressure, whereas for non-resonant frequencies, the effect would not be significant. The relative importance of the effect of viscosity on the response of the liquid-tank system can be assessed by examining the duration time of excitation needed for the system to reach the steady state response and the magnitude of the amplitude of the response quantities. For a typical HLW tank described in Section II, i.e., a tank diameter of $50 \mathrm{ft}$. and height of the contained liquid of $20.4 \mathrm{ft}$., the first sloshing frequency is $0.233 \mathrm{~Hz}$. Thus, one hundreil cycles of harmonic excitations will take $429 \mathrm{~s}$ of time. When a resonant harmonic excitation is applied, it may require, depending on the magnitude of the fluid viscosity, several hundred cycles of oscillations for the response functions to reach the steady state. If each analysis requires 100 cycles of harmonic excitation, the computation cost would be very expensive. Therefore, a small size liquid-tank system was used for the study of viscosity effect under harmonic excitations. The typical HLW tank was also used in the harmonic excitation study to examine how the viscosity effect is affected by the size of the storage tank.

\section{A. Small Tank}

The small tank used herein has a diameter of $40^{\prime \prime}$, which is about $1 / 15$ the size of the typical waste storage tank. It contains 18 " of liquid. Thus, it has about the same height/radius $(\mathrm{H} / \mathrm{R})$ ratio as the typical waste storage tank. The first and second sloshing frequencies of the small tank are 0.915 and $1.53 \mathrm{~Hz}$, respectively.

The finite element model of the small tank is shown in Fig. 1. It has 486 regular fluid elements and 162 thin fluid elements. The thin fluid elements, 0.25 in. thick, are placed at the inierface of the regular fluid elements and the tank wall. The tank wall is assumed to be rigid and is rigidly supported at the base. Thus the boundary conditions for fluid elements at the tank wall are assumed to be fixed in all three directions $(r, \theta, z)$. The input harmonic accelerations are sinusoidal waves. The amplitude of the maximum acceleration is scaled to $1 \mathrm{in} . / \mathrm{sec}^{2}$, which is aboui $1 / 100$ th of $0.24 \mathrm{~g}$. The frequency of the harmonic accelerations is an input parameter. Five different values are used in this study. Two are the resonant frequencies of the sloshing 
modes, i.e., $f=0.915$ and $1.53 \mathrm{~Hz}$; the other three frequencies are non-resonant frequencies, i.e., $\mathrm{f}=2,3$ and $5 \mathrm{~Hz}$. Four viscosity values, $\mu$ (absolute viscosity) $=60,200,1000$ and 10,000 cP, are used in the study. The use of four viscosity values is to provide some validation of the code for highly viscous liquids by establishing the reasonableness of the results from the parametric study.

Figure 2 shows the sloshing wave heights (vertical displacement at node 131) as a function of time for $\mu=60,200,1000$ and $10,000 \mathrm{cP}$. The input harmonic accelerations have a frequency of $0.915 \mathrm{~Hz}$ which is in resonance with the frequency of the first sloshing mode. As can be seen, for $\mu=60 \mathrm{cP}$ the sloshing wave height is increasing over a long period of time, reaching the steady state oscillation at $\mathrm{t}=126 \mathrm{~s}$. For $\mu=10,000 \mathrm{cP}$, sloshing wave height reaches the steady state oscillation very quickly, in less than 10 seconds of time. For purposes of comparison, the sloshing wave height as a function of time for $\mu=0$ is shown in Fig. 3, where the amplitude of the wave height is increasing linearly with the time.

The hydrodynamic pressure can be divided into two components: impulsive and convective [1]. The characteristics of the two components are quite different. We shall use the results of the case $\mu=200 \mathrm{cP}$ to illustrate the differences between the two components. Since the values of convective presures cannot be obtained directly from the computer output, the value of the total pressure (impulsive plus convective) is used here to compare with that of the impulsive pressure. The total pressures at fluid elements 1 (free surface), 133 (two-third liquid height), 331 (one-third liquid height) and 529 (bottom of tank) for the case of $\mu=200 \mathrm{cP}$ are shown in Fig. 4. It can be seen that the time history of the total hydrodynamic pressure has the same shape as that of the sloshing wave height. The time histories of the impulsive pressures for fluid elements 1, 133, 331 and 529 for the case of $\mu=200 \mathrm{cP}$ are shown in Fig. 5, where the shape of the impulsive pressure time history is quite different from that of the sloshing wave height. The amplitude of the impulsive pressure does not increase with time. It oscillates in unison with the applied harmonic excitation and reaches the maximum value at the very first cycle of excitation. This phenomena has also been observed in the inviscid fluids [3]. Comparing the peak value of the total pressure at each location with the corresponding value of the impulsive pressure, it is noted that the magnitude of impulsive pressure as a whole is still very small compared with the total pressure. Thus, the total pressures shown in Fig. 4 can be 
considered to be the convective pressures. This explains why the timewise variations of the total pressure are the same as those of the sloshing wave height.

For non-resonant harmonic excitations, as expected, the sloshing wave height does not increase with time. This can be seen from the time history of the sloshing wave shown in Figs. 6 and 7, where the viscosity of the liquid is $\mu=60,200,1000$ and $10,000 \mathrm{cP}$ and the harmonic excitation frequency is $5 \mathrm{~Hz}$. The FFT plots of these sloshing wave time histories are also shown in Figs. 6 and 7. It can be seen from these FFT plots that these time histories also contain the motion corresponding to the first sloshing mode, $f=0.915 \mathrm{~Hz}$. This is caused by the initial conditions and will eventually die out when the response reaches the steady state. It should be noted that in the non-resonant excitations, the vertical displacement of the excited sloshing motions is quite small compared with that uf the sloshing motions occurring in the resonant excitations.

For the purpose of comparison, the sloshing wave height (vertical displacement at node 131) and the total and impulsive pressures at various fluid elements along the tank wall for $\mu=$ 60. 200, 1000 and $10,000 \mathrm{cP}$ are tabulated in Tables I to $\mathrm{V}$ for harmonic excitations with frequencies of $0.915,1.53,2.0,3.0$ and $5.0 \mathrm{~Hz}$, respectively. The data listed in the tables are those of steady state response after the cessation of the influence of the initial conditions.

The data given in Table I reconfirms the previous observation of Figs, 4 and 5 that the sloshing motion is amplified such that the convective component of the hydrodynamic pressure is dominant in the total hydrodynamic pressure. For the surface elements, or near-surface elements, the ratio of total pressures of two liquids with different viscosity values is about the same as that of the sloshing wave height. For impulsive pressures, the variations of pressure magnitude along the tank depth are rather small. The smallest impulsive pressure is at the surface fluid element, whereas the largest impulsive pressure occurs at the bottom of the tank. However, the magnitude of impulsive pressure as a whole is still very small compared with the lotal hydrodynamic pressure. Furthermore, the magnitude of the impulsive pressure does not change much with different values of viscosity. For $\mu=60,200$, and $1000 \mathrm{cP}$, they are almost the same. For $\mu=10,000 \mathrm{cP}$ the impulsive pressure does increase slightly. This is probably due to the effect of the high viscosity which prevents the fluid to move freely. 
Using the frequency equation from the nonviscous fluid analysis, the second sloshing frequency of the small tank is $1.62 \mathrm{~Hz}$. However, the computer results indicated that the second sloshing frequency of the finite element model was $1.53 \mathrm{~Hz}$, not $1.62 \mathrm{~Hz}$ as predicted by the potential theory. Therefore, in the harmonic excitation study, a harmonic excitation with a frequency of $1.53 \mathrm{~Hz}$ was used. Figure 8 shows the sloshing wave heights (vertical displacement at node 1.31) as a function of time for $\mu=60,200,1000$ and $10,000 \mathrm{cP}$. Like the first resonant excitation, the magnitude of the sloshing wave height in second resonant excitation is increasing with time for a long duration. This is especially true for liquids having low viscosity value such as $\mu=60$ and $200 \mathrm{cP}$. For $\mu=1000 \mathrm{cP}$ the steady state oscillation of the response functions was reached relatively quickly, at $\mathrm{t}=30 \mathrm{~s}$. However, the values of the sloshing wave height in steady state oscillation for all values of viscosity, i. e. $\mu=60,200,1000$ and $10,000 \_\mathrm{P}$ under the second resonant harmonic excitations are much lower than those in the first resonant harmonic excitations. This is because the second sloshing mode has a much smaller participation factor than that of the first sloshing mode. Thus, the sloshing wave associated with the second mode is not amplified as much as that for the first mode. The sloshing wave height shown in Fig. 8 consists of two oscillating waves. One is the oscillation of the second sloshing mode which was caused mainly by the input harmoric excitation and the other is the nscillation of the first sloshing mode which was caused by the initial conditions. As pointed out earlier, the oscillations caused by initial conditions will die out quickly when the steady state is reached. This is clearly shown in Fig. 8. It can be seen from Table. II that the convective pressure is dominant only near the fluid surface. Also, the decay rate for the convective component associated with the second sloshing mode along the depth is much faster than for the first mode. As a result, the pressure away from the surface is not dominated by the convective pressure. Some of the data given in Table II show that the total pressures are less than the impulsive pressures. This is because of the phase difference between the impulsive and convective components which results in a reduction in the total pressure.

As expected, Tables III through $V$ show that for non-resonant harmonic excitations, the sloshing wave heights are much smaller than those presented in Tables I and II, as are the magnitudes of the total hydrodynamic pressures. However, the magnitudes of the impulsive 
pressures remain the same. In other words, the magnitude of the impulsive pressure does not depend on the frequency of the harmonic excitations.

\section{B. Large Tank}

Figure 9 is the finite element model of the large liquid-tank system, which is the same as the typical waste storage tank described in Section II. The model has the same number of fluid elements as the small tank except the thicknesses of the horizontal layers are no longer uniform. The use of non-uniform meshes is to improve the accuracy of pressure calculations. Thus, for fluid elements having large hydrodynamic pressures, a finer mesh is used. Again, thin fluid elements are placed at the interface of the regular fluid elements and the tank wall. The thickness of the thin fluid elements is $5.0 \mathrm{in}$. Two harmonic excitations were used. One has a frequency of $0.233 \mathrm{~Hz}$, which is in resonance with the frequency of the first sloshing mode. The other has a frequency of $0.5 \mathrm{~Hz}$, which is a non-resonant harmonic excitation. The amplitude of the harmonic acceleration is again scaled to $1 \mathrm{in.} / \mathrm{sec}^{2}$.

Figure 10 is the time history of the sloshing wave height at node 131 at the free surface for the case of $\mu=10,000 \mathrm{cP}$ subjecied to a harmonic excitation with a frequency of $0.233 \mathrm{~Hz}$. It can be seen that the sloshing wave height reaches the steady state oscillation very slowly. It requires more than 100 cycles of harmonic excitations and 437 seconds of time to reach that state. This indicates that the viscosity effect in a large tank is unimportant. Thus, for viscosity values below $10,000 \mathrm{cP}$, i.e. $\mu=60,200$ and $1000 \mathrm{cP}$, the numerical analyses were nor performed. Table VI lists the sloshing wave height and total and impulsive pressures in various fluid elements along the tank wall for the case of $\mu=10,000$ under resonant harmonic excitations.

As mentioned earlier, under non-resonant harnonic excitations the response functions such as the sloshing wave height and the total pressure do not rapidly increase with time as those under resonant harmonic excitations. Thus the steady state values of these functions can be whained from analysis with only 20 to 30 cycies of harmonic excitations. Table VII gives the values of the sloshing wave height, and the total and impulsive pressures at different fluid elements along the tank wall for the cases of $\mu=60,200,1000$, and $10,000 \mathrm{cP}$ for a nonresonant harmonic excitation with a frequency of $0.5 \mathrm{~Hz}$. 


\section{Equivalent Viscous Damping}

Viscous damping is the phenomenon by which mechanical energy is dissipated into internal thermal energy. Here we shall use the concept of viscous damping to characterize the effect of fluid viscosity. This section describes how an equivalent viscous damping can be derived to represent the effect of fluid viscosity. It should be noted that this is not the exact method of analysis for evaluation of fluid viscosity, but rather to provide a means to interpret the effects of fluid viscosity in terms of the terminology that engineers are more familiar with.

Consider a linear, single-degree-of-freedom system with viscous damping and subjected to an external excitation. The equation of motion is given by

$$
\ddot{x}+2 \xi \omega_{n} \dot{x}+\omega_{n}^{2} x=\omega_{n}^{3} u(t)
$$

where $\mathrm{x}$ is the displacement, $\dot{\mathrm{x}}$ the velocity, $\ddot{\mathrm{x}}$ the acceleration, $\omega_{\mathrm{n}}$ is the natural frequency of undamped oscillation in radians per second, $\zeta=c / c_{c}=$ damping factor, $c_{c}=2 m \omega_{n}=$ critical damping coefficient and $u(t)$ is the excitation function. If the excitation is harmonic, with frequency $\omega$ and applitude $u_{0}$, and

$$
u(t)=u_{0} \cos \omega t
$$

then the response at steady state is given by

$$
x=x_{0} \cos (\omega t+\phi)
$$

in which

$$
\frac{x_{0}}{u_{0}}=\frac{1}{\sqrt{\left[1-\left(\frac{\omega}{\omega_{n}}\right)^{2}\right]^{2}+\left(2 \zeta \frac{\omega}{\omega_{n}}\right)^{2}}}
$$

and

$$
\tan \phi=\frac{2 \zeta \frac{\omega}{\omega_{n}}}{1-\left(\frac{\omega}{\omega_{n}}\right)^{2}}
$$


The term $\frac{x_{0}}{u_{0}}$ is called the amplification factor (A.F.). It is a function of the frequency ratio $\frac{\omega}{\omega_{n}}$ and the damping factor $\zeta$. $\phi$ is the phase angle. The maximum value of $\frac{x_{0}}{u_{0}}$ occurs when

$$
\frac{\omega}{\omega_{n}}=\sqrt{1-2 \zeta^{2}}
$$

and is given by

$$
\frac{x_{0}}{u_{0}}=\frac{1}{2 \zeta \sqrt{1-\zeta^{2}}}
$$

For the small and large tanks under harmonic excitation with an amplitude of $1 \mathrm{in} / \mathrm{sec}^{2}$ applied at the base of the tank, the corresponding amplitudes of the input excitation for the sloshing motion at node 131, using Eq. (C-37) of Ref. 3, are 0.0433 in. and 0.65 in., respectively, for the first mode of sloshing vibration. Using the steady state values of the maximum sloshing wave height obtained from the harmonic analysis, the amplification factor, A.F. and damping factor, $\zeta$, values for various values of viscosity are listed in Table VIII.

As can be seen from Table VIII, the size of the tank plays an important role in the determination of the equivalent viscous damping factor. In small tanks, such as 40 " in diameter, the equivalent viscous damping factor for fluids having a viscosity value of $10,000 \mathrm{cP}$ is $13 \%$, whereas in large tanks, such as $50 \mathrm{ft}$. in diameter, the equivalent viscous damping factor for fluids having a viscosity value of $10,000 \mathrm{cP}$ is only $0.47 \%$. This is to be expected because in viscous flows, the viscosity effect is appreciable only in a narrow region surrounding the fluid boundaries. This narrow region near the solid-fluid boundaries is called the boundary layer. When motion is started in a viscous fluid, the flow is essentially irrotational in the first instants. Since the fluid at the boundaries has zero velocity relative to the boundaries, there is a steep velocity gradient from the boundary into the flow. This velocity gradient sets up the boundary shear forces that reduce the flow relative to the boundary. As time goes on, the continual action of shear stress tends to slowdown additional fluid particles, causing the thickness of the boundary 
layer to increase. Calculations of boundary layer growth are very complex and are beyond the scope of this study.

It should be pointed out that the viscosity values for small and large tanks listed in Table VIII are not totally unrelated. In considering two geometrically similar flow situations Reynolds found that they would be dynamically similar if the dimensionless group $\frac{u \ell \rho}{\mu}$ is the same for both cases, where $u$ is a characteristic velocity, $\ell$ a characteristic length, $\rho$ the mass density, and $\mu$ the viscosity. This group is now called the Reynolds number, $R$. The true values of the characteristic velocity $u$ and length $\ell$ for the small and large tanks are difficult to compute, but they are related by similarity law as follows,

$$
\frac{\ell_{s}}{\ell_{L}}=\frac{1}{\lambda}
$$

and

$$
\frac{u_{s}}{u_{L}}=\frac{1}{\sqrt{\lambda}}
$$

where the subscripts $s$ and $L$ represent small and large tanks, respectively and $\lambda$ is the scale factor. For $\lambda=15$, ul of the large tank is $\mathbf{5 8 . 0 9 5}$ times larger than ul of the small tank. Since the mass density of the liquid in small and large tanks remains the same, the only way to make the two systems dynamically similar is to increase the viscosity of the liquid in the large tank by a factor of 58.095 . Thus, $10,000 \mathrm{cP}$ viscosity in the large tank is dynamically similar to $172 \mathrm{cP}$ viscosity in the small tank. It is reasonable that the calculated $\zeta$ value for $\mu=10,000 \mathrm{cP}$ for the large tank lies between the cases of $\mu=60$ and $200 \mathrm{cP}$ for the small tank.

It can be concluded from the results of the harmonic excitation study that the effect of viscosity on the sloshing motion and hydrodynamic pressure in a typical HL.W storage tank is very small and can be neglected if the viscosity value of the contained liquid is less than 10,000 cP. If a single-degree-of-freedom system can be used to approximate the sloshing motion, then for $\mu=10,000 \mathrm{cP}$ or less, the equivalent viscous damping factor, $\zeta=\frac{\mathrm{c}}{\mathrm{c}_{\mathrm{c}}}$, in the typical waste 
storage tank is less than $0.5 \%$. If the waste storage tank size is very small, say $40^{\prime \prime}$ in diameter, the effect of viscosity on the hydrodynamic pressure can also be neglected for fluid viscosity value below $200 \mathrm{cP}$.

\section{SYSTEM RESPONSE TO EARTHQUAKE MOTIONS}

For earthquake excitations, only the response of the large tank is examined. Two acceleration time histories are used in the study. The first is a 10-second synthetic record whose response spectrum matches the Newmark-Hall median response spectrum anchored at $0.24 \mathrm{~g}$ with a damping of $2 \%$. The other is a 29 -second real earthquake record, occurring at Tabas, Iran on September 16,1978, with a peak acceleration of $0.81 \mathrm{~g}$. For discussion purposes, the first time history is referred to as Base Motion 1, and the second time history is referred to as Base Motion 2. The plots of these two time histories and their FrTs are shown in Figs. 11 and 12, respectively.

The response quantities examined are the sloshing wave height, the convective pressure, and the impulsive pressure and the associated base shear and moments. Five values of viscosity are used in the study. They are: $\mu=0,60,200,1000$ and 10,000 cP. The maximum imp.lsive, convective and total pressures exerted on the wall of the tank subjected to Base Motion 1 for the five values of viscosity are presented in Tables IX, $\mathrm{X}$ and $\mathrm{XI}$, respectively. As mentioned earlier, the convective pressures are not readily available from the computer output. They must be calculated by subtracting the impulsive pressure from the total pressure. It should be mentioned that the impulsive pressures given in Table IX were taken at the time of maximum ground acceleration. The convective and total pressures listed in Tables $\mathrm{X}$ and $\mathrm{XI}$ are the absolute maximum values of these pressures which may not occur at the same time. The associated sloshing wave heights for the five cases analyzed in this study are listed in Table XI, and the impulsive components of the base shear and base moments above and below the tank base mat are presented in Table XII. Examining the values presented in Tables IX, X, XI and XII, it can be concluded that the effect of viscosity on the dynamic response of the typical HLW tank is negligible. This is to be expected because it has been demonstrated in the harmonic analysis that the equivalent viscous damping for the values of viscosity considered is less than $0.5 \%$. The time-history plots of the sloshing wave height at node 131, and the impulsive, convective and 
total pressures at various elements along the depth of the tank, under the excitation of Base Motion 1, are in Appendices $\mathrm{C}$ and $\mathrm{D}$ for the cases of $\mu=60$ and $200 \mathrm{cP}$, respectively.

The data presented in Tables XIII, XIV, XV and XVI for Base Motion 2 are the counterparts of the data presented in Tables IX, X, XI and XII, respectively. Again, the variation of the response quantities with different values of viscosity is quite small.

\section{EFFECTS OF INTEGRATION TIME STEP ON SYSTEM RESPONSE}

One of the concerns in the numerical analysis is the choice of the optimal integration time step. If the integration time step used in the numerical analysis is too large, the accuracy of the numerical solution will degenerate. On the other hand, if the integration time step is too small, the cost of numerical computations will be high due to unnecessary computations. This section deals with the determination of the optimal integration time step. The approach used in this study is to compare the results of several computer runs with different integration time step values. The tank system chosen for this study is the small tank described in Section IV.A where the viscosity of the high-level waste is assumed to be $1000 \mathrm{cP}$. Several different integration time steps were used in the analysis. For example, in the harmonic excitations of $f=0.915 \mathrm{~Hz}$ and $1.53 \mathrm{~Hz}, \Delta t=0.02 \mathrm{~s}$ and $0.01 \mathrm{~s}$ were used; in the harmonic excitation of $f=2.0 \mathrm{~Hz}, \Delta t=0.02$ $\mathrm{s}, 0.01 \mathrm{~s}$ and $0.005 \mathrm{~s}$ were used; in the harmonic excitations of $\mathrm{f}=3.0 \mathrm{~Hz}, \Delta \mathrm{t}=0.01 \mathrm{~s}$ and 0.005 $s$ were used; in the harmonic excitations of $f=5 \mathrm{~Hz}, \Delta t=0.01 \mathrm{~s}, 0.005 \mathrm{~s}$ and $0.0025 \mathrm{~s}$ were used. The results of this study are given in Tables XVII and XVIII, where Table XVII compares the impulsive pressure and Table XVIII compares the sloshing wave height and total pressure.

Table XVII shows that the values of impulsive pressure obtained from two computer runs with different integration time steps are practically the same. Table XVIII shows that the differences in total pressure between different computer runs with different integration time steps are quite small, within $1 \%$ range. The largest percentage difference in sloshing wave height for harmonic excitations of $0.915 \mathrm{~Hz}$ and $1.53 \mathrm{~Hz}$ between integration time steps of $0.02 \mathrm{~s}$ and 0.01 $\mathrm{s}$ is only $3 \%$; for harmonic excitations of 2 and $3 \mathrm{~Hz}$ between integration time steps of $0.01 \mathrm{~s}$ and $0.005 \mathrm{~s}$, it is only $1 \%$; for harmonic excitation of $5 \mathrm{~Hz}$ between integration time steps of 0.01 $\mathrm{s}$ and $0.005 \mathrm{~s}$, it is $6 \%$, however the percentage decreases to $0.1 \%$ cutting the time step down to $0.0025 \mathrm{~s}$. This indicates that for low harmonic excitations, i.e., $\mathrm{f}=0.915 \mathrm{~Hz}$ and $1.53 \mathrm{~Hz}$, an 
integration time step of $0.02 \mathrm{~s}$ appears to be appropriate. For harmonic excitations in the range of 2 to $3 \mathrm{~Hz}$, an integration time step of $0.01 \mathrm{~s}$ is adequate. For higher harmonic excitations, above $5 \mathrm{~Hz}$, an integration time step smaller than $0.01 \mathrm{~s}$ may be more adequate for a better accuracy. The time step $0.005 \mathrm{~s}$ yields the converged results.

\section{CONCLUSIONS}

It can be concluded from the results of this study that for typical waste storage tanks the effect of viscosity on sloshing wave height, impulsive and convective pressures is very small and can be neglected for earthquake motions that are being considered in the seismic upgrading by DOE-EM for the thin-walled underground HLW storage tanks. This is also true for large earthquakes, such as the 1978 Tabas earthquake which had a peak acceleration of $.81 \mathrm{~g}$ and a time duration of $29 \mathrm{~s}$. It should be pointed out that the size of the liquid-tank system plays an important role in the determination of viscosity effect. For viscous effect to be influential in response analysis of typical waste storage tanks, the viscosity value of the waste must be greater than $10,000 \mathrm{cP}$. This value is far greater than the estimated viscosity value of the high level wastes which is in the range of 60 to $200 \mathrm{cP}$. Even though only limited cases have been examined in this study, it is believed that the conclusions drawn from this study are quite general.

\section{ACKNOWLEDGMENTS}

The authors wish to thank Professor C. S. Yeh of the University of Michigan, and Drs. C. Y. Wang and D. C. Ma and Mr. Ralph Seidensticker of Argonne National Laboratory for helpful discussions during the performance of this work.

This work was performed in the Engineering Mechanics Program of the Reactor Engineering Division of Argonne National Laboratory under the auspices of the U.S. Department of Energy, Contract No. W-31-109-ENG-38. The funding for this study was provided by DOEEM Office. The DOE program manager was Mr. Howard J. Eckert. 


\section{REFERENCES}

1. Housner, G. W., "Dynamic Pressures on Accelerated Fluid Containers," Bulletin of the Seismological Society of America, Vol. 47, No. 1, January 1957, pp. 15-35.

2. Housner, G. W., "The Dynamic Behavior of Water Tanks," Bulletin of the Seismological Society of America, Vol. 53, No. 2, February 1963, pp. 381-387.

3. Veletsos, A. S., "Seismic Response of Design of Liquid Storage Tanks," Guidelines for the Seismic design of Oil and Gas Pipeline Systems, Technical Council on Lifeline Earthquake Engineering, ASCE, pp. 255-370 and 443-461.

4. Chang, Y. W., Ma, D. C., Gvildys, J. and Liu, W. K., "Seismic Analysis of LMR Reactor Tanks," Nuclear Engineering and Design, Vol. 106, 1988, pp. 19-33.

5. "Seismic Sloshing of Pool-Type Liquid Metal Reactors," EPRI/CRIEPI Joint Study Report, June 1987.

6. Fritz, R. J., "The Effects of Liquids on the Dynamic Motions of Immersed Solids," Journal of Engineering for Industry, Transactions of ASME, Vol. 94, February 1972, pp. 167-173. 
Table I. Sloshing Wave Height, Total Pressure, Impulsive Pressure

Dia. of Tank $=40^{\prime \prime}$; Harmonic Excitation: Amplitude $=1 \mathrm{in} . / \mathrm{sec}^{2}$, Freq. $=0.915 \mathrm{~Hz}$

\begin{tabular}{|c|c|c|c|c|c|}
\hline \multirow{2}{*}{\multicolumn{2}{|c|}{ Response Function }} & \multicolumn{4}{|c|}{ Viscosity, cP } \\
\hline & & 60 & 200 & 1000 & 10,000 \\
\hline \multicolumn{2}{|c|}{$\begin{array}{l}\text { Sloshing Wave Height, in. } \\
\text { (vert. disp. at node 131) }\end{array}$} & 6.332 & 2.829 & 0.6807 & 0.1684 \\
\hline \multirow{10}{*}{$\begin{array}{c}\text { Total } \\
\text { Pressure, } \\
\text { psi } \times 10^{-2}\end{array}$} & Element 1 & 29.37 & 13.13 & 3.155 & 0.7704 \\
\hline & 67 & 24.75 & 11.07 & 2.665 & 0.7562 \\
\hline & 133 & 20.92 & 9.366 & 2.248 & 0.5913 \\
\hline & 199 & 17.68 & 7.916 & 1.894 & 0.4839 \\
\hline & 265 & 15.25 & 6.834 & 1.637 & 0.4480 \\
\hline & 331 & 13.52 & 6.058 & 1.446 & 0.3710 \\
\hline & 397 & 12.37 & 5.547 & 1.333 & 0.3896 \\
\hline & 463 & 11.57 & 5.190 & 1.241 & 0.3226 \\
\hline & 529 & 11.15 & 5.004 & 1.207 & 0.3639 \\
\hline & 595 & 11.13 & 4.997 & 1.240 & 0.2844 \\
\hline \multirow{10}{*}{$\begin{array}{l}\text { Impulsive } \\
\text { Pressure, } \\
\text { psi } \times 10^{-2}\end{array}$} & Element 1 & 0.0467 & 0.0466 & 0.0468 & 0.0657 \\
\hline & 67 & 0.0879 & 0.0878 & 0.0885 & 0.0927 \\
\hline & 133 & 0.1192 & 0.1192 & 0.1201 & 0.1448 \\
\hline & 199 & 0.1449 & 0.1449 & 0.1459 & 0.1500 \\
\hline & 265 & 0.1634 & 0.1634 & 0.1641 & 0.1857 \\
\hline & 331 & 0.1766 & 0.1766 & 0.1776 & 0.1792 \\
\hline & 397 & 0.1851 & 0.1851 & 0.1854 & 0.2064 \\
\hline & 463 & 0.1911 & 0.1911 & 0.1918 & 0.1915 \\
\hline & 529 & 0.1941 & 0.1941 & 0.1938 & 0.2105 \\
\hline & 595 & 0.1940 & 0.1943 & 0.1915 & 0.1799 \\
\hline
\end{tabular}


Table II. Sloshing Wave Height, Total Pressure, Impulsive Pressure

Dia. of Tank $=40 "$; Harmonic Excitation: Amplitude $=1 \mathrm{in} / \mathrm{sec}^{2}$, Freq. $=1.53 \mathrm{~Hz}$

\begin{tabular}{|c|c|c|c|c|c|}
\hline \multirow{2}{*}{\multicolumn{2}{|c|}{ Response Function }} & \multicolumn{4}{|c|}{ Viscosity, cP } \\
\hline & & 60 & 200 & 1000 & 10,000 \\
\hline \multicolumn{2}{|c|}{$\begin{array}{l}\text { Sloshing Wave Height, in. } \\
\text { (vert. disp. at node } 131 \text { ) }\end{array}$} & 1.032 & 0.4675 & 0.08032 & 0.008397 \\
\hline \multirow{10}{*}{$\begin{array}{c}\text { Total } \\
\text { Pressure, } \\
\text { psi } \times 10^{-2}\end{array}$} & Element 1 & 2.599 & 1.238 & 0.2601 & 0.04427 \\
\hline & 67 & 1.215 & 0.5951 & 0.1481 & 0.03336 \\
\hline & 133 & 0.5544 & 0.2866 & 0.1070 & 0.08322 \\
\hline & 199 & 0.2466 & 0.1434 & 0.1041 & 0.09010 \\
\hline & 265 & 0.1035 & 0.1175 & 0.1248 & 0.1354 \\
\hline & 331 & 0.1141 & 0.1256 & 0.1347 & 0.1301 \\
\hline & 397 & 0.1511 & 0.1464 & 0.1503 & 0.1645 \\
\hline & 463 & 0.1715 & 0.1540 & 0.1527 & 0.1485 \\
\hline & 529 & 0.1810 & 0.1621 & 0.1611 & 0.1717 \\
\hline & 595 & 0.1983 & 0.1561 & 0.1373 & 0.08195 \\
\hline \multirow{10}{*}{$\begin{array}{l}\text { Impulsive } \\
\text { Pressure, } \\
\text { psi } \times 10^{-2}\end{array}$} & Element 1 & 0.0468 & 0.0468 & 0.0466 & 0.0552 \\
\hline & 67 & 0.0878 & 0.0878 & 0.0880 & 0.0947 \\
\hline & 133 & 0.1192 & 0.1192 & 0.1193 & 0.1349 \\
\hline & 199 & 0.1448 & 0.1449 & 0.1451 & 0.1532 \\
\hline & 265 & 0.1634 & 0.1634 & 0.1634 & 0.1773 \\
\hline & 331 & 0.1766 & 0.1766 & 0.1769 & 0.1834 \\
\hline & 397 & 0.1851 & 0.1851 & 0.1850 & 0.1976 \\
\hline & 463 & 0.1911 & 0.1911 & 0.1913 & 0.1961 \\
\hline & 529 & 0.1942 & 0.1941 & 0.1938 & 0.2033 \\
\hline & 595 & 0.1942 & 0.1944 & 0.1934 & 0.1979 \\
\hline
\end{tabular}


Table III. Sloshing Wave Height, Total Pressure, Impılsive Pressure

Dia. of Tank $=40$ "; Harmonic Excitation: Amplitude $=1 \mathrm{in} / \mathrm{sec}^{2}$, Freq. $=2 \mathrm{~Hz}$

\begin{tabular}{|c|c|c|c|c|c|}
\hline \multirow{2}{*}{\multicolumn{2}{|c|}{ Resporse Function }} & \multicolumn{4}{|c|}{ Viscosity, $\mathrm{cP}$} \\
\hline & & 60 & 200 & 1000 & 10,000 \\
\hline \multicolumn{2}{|c|}{$\begin{array}{l}\text { Sloshing Wave Height, in. } \\
\text { (vert. disp. at node } 131 \text { ) }\end{array}$} & 0.02815 & 0.0238 & 0.0166 & 0.001742 \\
\hline \multirow{10}{*}{$\begin{array}{c}\text { Total } \\
\text { Pressure, } \\
\text { psi } \times 10^{-2}\end{array}$} & Element 1 & 0.06906 & 0.05047 & 0.03325 & 0.04188 \\
\hline & 67 & 0.05592 & 0.04149 & 0.03111 & 0.03945 \\
\hline & 133 & 0.0972 & 0.0850 & 0.07652 & 0.1043 \\
\hline & 199 & 0.1277 & 0.1174 & 0.1096 & 0.1165 \\
\hline & 265 & 0.1501 & 0.1412 & 0.1343 & 0.1566 \\
\hline & 331 & 0.1647 & 0.1571 & 0.1511 & 0.1545 \\
\hline & 397 & 0.1750 & 0.1678 & 0.1618 & 0.1820 \\
\hline & 463 & 0.1816 & 0.1749 & 0.1696 & 0.1710 \\
\hline & 529 & 0.1849 & 0.1782 & 0.1730 & 0.1887 \\
\hline & 595 & 0.1852 & 0.1789 & 0.1758 & 0.1444 \\
\hline \multirow{10}{*}{$\begin{array}{l}\text { Impulsive } \\
\text { Pressure, } \\
\text { psi } \times 10^{-2}\end{array}$} & Element 1 & 0.0467 & 0.0467 & 0.0466 & 0.0524 \\
\hline & 67 & 0.0877 & 0.0877 & 0.0878 & 0.0941 \\
\hline & 133 & 0.1190 & 0.1191 & 0.1192 & 0.1307 \\
\hline & 199 & 0.1446 & 0.1446 & 0.1449 & 0.1526 \\
\hline & 265 & 0.1631 & 0.1631 & 0.1633 & 0.1742 \\
\hline & 331 & 0.1762 & 0.1763 & 0.1766 & 0.1833 \\
\hline & 397 & 0.1848 & 0.1848 & 0.1848 & 0.1946 \\
\hline & 463 & 0.1907 & 0.1907 & 0.1910 & 0.1967 \\
\hline & 529 & 0.1938 & 0.1938 & 0.1937 & 0.2009 \\
\hline & 595 & 0.1944 & 0.1941 & 0.1937 & 0.1965 \\
\hline
\end{tabular}


Table IV. Sloshing Wave Height, Total Pressure, Impulsive Pressure

Dia. of Tank = 40"; Harmonic Excitation: Amplitude $=1 \mathrm{in} / \mathrm{sec}^{2}$, Freq. $=3 \mathrm{~Hz}$

\begin{tabular}{|c|c|c|c|c|c|}
\hline \multirow{2}{*}{\multicolumn{2}{|c|}{ Response Function }} & \multicolumn{4}{|c|}{ Viscosity, cP } \\
\hline & & 60 & 200 & 1000 & 10,000 \\
\hline \multicolumn{2}{|c|}{$\begin{array}{l}\text { Sloshing Wave Height, in. } \\
\text { (vert. disp. at node 131) }\end{array}$} & 0.01533 & 0.008265 & 0.006724 & 0.003714 \\
\hline \multirow{10}{*}{$\begin{array}{c}\text { Total } \\
\text { Pressure, } \\
\text { psi } \times 10^{-2}\end{array}$} & Element 1 & 0.0582 & 0.02715 & 0.02032 & 0.03565 \\
\hline & 67 & 0.00992 & 0.07346 & 0.06746 & 0.07583 \\
\hline & 133 & 0.1297 & 0.1081 & 0.1029 & 0.1137 \\
\hline & 199 & 0.1539 & 0.1358 & 0.1314 & 0.1394 \\
\hline & 265 & 0.1714 & 0.1558 & 0.1520 & 0.1611 \\
\hline & 331 & 0.1835 & 0.1698 & 0.1666 & 0.1734 \\
\hline & 397 & 0.1915 & 0.1790 & 0.1760 & 0.1833 \\
\hline & 463 & 0.1970 & 0.1853 & 0.1827 & 0.1878 \\
\hline & 529 & 0.2000 & 0.1887 & 0.1860 & 0.1908 \\
\hline & 595 & 0.2000 & 0.1889 & 0.1863 & 0.1875 \\
\hline \multirow{10}{*}{$\begin{array}{l}\text { Impulsive } \\
\text { Pressure, } \\
\text { psi } \times 10^{-2}\end{array}$} & Element 1 & 0.0468 & 0.0468 & 0.0466 & 0.0491 \\
\hline & 67 & 0.0879 & 0.0878 & 0.0878 & 0.0925 \\
\hline & 133 & 0.1193 & 0.1193 & 0.1192 & 0.1263 \\
\hline & 199 & 0.1449 & 0.1449 & 0.1449 & 0.1515 \\
\hline & 265 & 0.1634 & 0.1634 & 0.1634 & 0.1700 \\
\hline & 331 & 0.1766 & 0.1766 & 0.1767 & 0.1827 \\
\hline & 397 & 0.1853 & 0.1851 & 0.1850 & 0.1905 \\
\hline & 463 & 0.1911 & 0.1911 & 0.1911 & 0.1957 \\
\hline & 529 & 0.1943 & 0.1942 & 0.1940 & 0.1974 \\
\hline & 595 & 0.1942 & 0.1944 & 0.1943 & 0.1960 \\
\hline
\end{tabular}


Table V. Sloshing Wave Height, Total Pressure, Impulsive Pressure Dia. of Tank $=40$ "; Harmonic Excitation: Amplitude $=1 \mathrm{in} / \mathrm{sec}^{2}$, Freq. $=5 \mathrm{~Hz}$

\begin{tabular}{|c|c|c|c|c|c|}
\hline \multirow{2}{*}{\multicolumn{2}{|c|}{ Response Function }} & \multicolumn{4}{|c|}{ Viscosity, $\mathrm{cP}$} \\
\hline & & 60 & 200 & 1000 & 10,000 \\
\hline \multicolumn{2}{|c|}{$\begin{array}{l}\text { Sloshing Wave Height, in. } \\
\text { (vert. disp. at node 131) }\end{array}$} & 0.007322 & 0.003397 & 0.002348 & 0.001812 \\
\hline \multirow{10}{*}{$\begin{array}{c}\text { Total } \\
\text { Pressure, } \\
\text { psi } \times 10^{-2}\end{array}$} & Element 1 & 0.05991 & 0.04399 & 0.03881 & 0.03983 \\
\hline & 67 & 0.09886 & 0.08583 & 0.08174 & 0.08394 \\
\hline & 133 & 0.1287 & 0.1176 & $0.11+3$ & 0.1161 \\
\hline & 199 & 0.1529 & 0.1437 & 0.1408 & 0.1437 \\
\hline & 265 & 0.1704 & 0.1625 & 0.1600 & 0.1618 \\
\hline & 331 & 0.1827 & 0.1757 & 0.1736 & 0.1761 \\
\hline & 397 & 0.1908 & 0.1844 & 0.1824 & 0.1833 \\
\hline & 463 & 0.1964 & 0.1904 & 0.1886 & 0.1902 \\
\hline & 529 & 0.1993 & $0.19: 36$ & 0.1917 & 0.1914 \\
\hline & 595 & 0.1995 & 0.1938 & 0.1923 & 0.1886 \\
\hline \multirow{10}{*}{$\begin{array}{l}\text { Impulsive } \\
\text { Pressure, } \\
\text { psi } \times 10^{-2}\end{array}$} & Element 1 & 0.0468 & 0.0468 & 0.0467 & 0.0464 \\
\hline & 67 & 0.0879 & 0.0878 & 0.0878 & 0.0899 \\
\hline & 133 & 0.1193 & 0.1193 & 0.1191 & 0.1210 \\
\hline & 199 & 0.1448 & 0.1448 & 0.1448 & 0.1482 \\
\hline & 265 & 0.1635 & 0.1634 & 0.1633 & 0.1652 \\
\hline & 331 & 0.1766 & 0.1766 & 0.1766 & 0.1794 \\
\hline & 397 & 0.1852 & 0.1851 & 0.1850 & 0.1861 \\
\hline & 463 & 0.1911 & 0.1911 & 0.1912 & 0.1929 \\
\hline & 529 & 0.1942 & 0.1942 & 0.1941 & 0.1939 \\
\hline & 595 & 0.1946 & 0.1944 & 0.1947 & 0.1914 \\
\hline
\end{tabular}


Table VI. Sloshing Wave Height, Total Pressure, Implilsive Pressure Dia. of Tank $=50 \mathrm{ft}$; Harmonic Excitation: Amplitude $=1 \mathrm{in} . / \mathrm{sec}^{2}$, Freq. $=0.233 \mathrm{~Hz}$

\begin{tabular}{|c|c|c|}
\hline \multirow{2}{*}{\multicolumn{2}{|c|}{ Response Function }} & Viscosity, $c P$ \\
\hline & & 10,000 \\
\hline \multicolumn{2}{|c|}{$\begin{array}{l}\text { Sloshing Wave Height, in. } \\
\text { (vert. disp. at node 131) }\end{array}$} & 68.68 \\
\hline \multirow{10}{*}{$\begin{array}{c}\text { Total } \\
\text { Pressure, } \\
\text { psi } \times 10^{-2}\end{array}$} & Element 1 & 275 \\
\hline & 67 & 210 \\
\hline & 133 & 176 \\
\hline & 199 & 155 \\
\hline & 265 & 144 \\
\hline & 331 & 137 \\
\hline & 397 & 132 \\
\hline & 463 & 129 \\
\hline & 529 & 129 \\
\hline & 595 & 128 \\
\hline \multirow{10}{*}{$\begin{array}{l}\text { Impulsive } \\
\text { Pressure, } \\
\text { psi } \times 10^{-2}\end{array}$} & Element 1 & 0.914 \\
\hline & 67 & 1.78 \\
\hline & 133 & 2.19 \\
\hline & 199 & 2.42 \\
\hline & 265 & 2.55 \\
\hline & 331 & 2.63 \\
\hline & 397 & 2.68 \\
\hline & 463 & 2.71 \\
\hline & 529 & 2.72 \\
\hline & 595 & 2.74 \\
\hline
\end{tabular}


Table VII. Sloshing Wave Height, Total Pressure, Impulsive Pressure

Dia. of Tank $=50 \mathrm{ft}$; Harmonic Excitation: Amplitude $=1 \mathrm{in} / \mathrm{sec}^{2}$, Freq. $=0.5 \mathrm{~Hz}$

\begin{tabular}{|c|c|c|c|c|c|}
\hline \multirow{2}{*}{\multicolumn{2}{|c|}{ Response Function }} & \multicolumn{4}{|c|}{ Viscosity, cP } \\
\hline & & 60 & 200 & 1000 & 10,000 \\
\hline \multicolumn{2}{|c|}{$\begin{array}{l}\text { Sloshing Wave Height, in. } \\
\text { (vert. disp. at node } 131 \text { ) }\end{array}$} & 1.00 & 1.00 & .986 & .910 \\
\hline \multirow{10}{*}{$\begin{array}{c}\text { Total } \\
\text { Pressure, } \\
\text { psi } \times 10^{-2}\end{array}$} & Element 1 & 2.300 & 2.296 & 2.271 & 2.016 \\
\hline & 67 & 2.444 & 2.440 & 2.421 & 2.222 \\
\hline & 133 & 2.758 & 2.755 & 2.740 & 2.580 \\
\hline & 199 & 2.931 & 2.929 & 2.915 & 2.776 \\
\hline & 265 & 3.030 & 3.028 & 3.016 & 2.887 \\
\hline & 331 & 3.085 & 3.083 & 3.071 & 2.950 \\
\hline & 397 & 3.122 & 3.120 & 3.109 & 2.992 \\
\hline & 463 & 3.145 & 3.143 & 3.132 & 3.018 \\
\hline & 529 & 3.153 & 3.151 & 3.139 & 3.025 \\
\hline & 595 & 3.154 & 3.152 & 3.141 & 3.029 \\
\hline \multirow{10}{*}{$\begin{array}{l}\text { Impulsive } \\
\text { Pressure, } \\
\text { psi } \times 10^{-2}\end{array}$} & Element 1 & 0.9153 & 0.9152 & 0.9149 & 0.9131 \\
\hline & 67 & 1.7765 & 1.7765 & 1.7762 & 1.7761 \\
\hline & 133 & 2.1849 & 2.1847 & 2.1843 & 2.1829 \\
\hline & 199 & 2.4162 & 2.4162 & 2.4161 & 2.4166 \\
\hline & 265 & 2.5496 & 2.5495 & 2.5490 & 2.5473 \\
\hline & 331 & 2.6255 & 2.6255 & 2.6256 & 2.6252 \\
\hline & 397 & 2.6767 & 2.6766 & 761 & 2.6744 \\
\hline & 463 & 2.7086 & 2.7086 & 2.7085 & 2.7075 \\
\hline & 529 & 2.7186 & 2.7185 & 2.7178 & 2.7149 \\
\hline & 595 & 2.7195 & 2.7194 & 2.7186 & 2.7136 \\
\hline
\end{tabular}


Table VIII. Equivalent Viscous Damping Factor, $\zeta$

\begin{tabular}{||c|c|c|c|c|c|c|c||}
\hline \multicolumn{5}{|c|}{ Small Tank } & \multicolumn{5}{c||}{ Large Tank } \\
\hline Dia $=40 ", u_{0}=.0433$ in. & \multicolumn{3}{c||}{ Dia, $u_{0}=0.650$ in. } \\
\hline Viscosity, cP & $\mathrm{X}_{0}$, in. & A.F. & $\zeta, \%$ & Viscosity, cP & $\mathrm{X}_{0}$, in. & A.F. & $\zeta, \%$ \\
\hline 60 & 6.33 & 146.2 & .342 & & & & \\
\hline$(172)$ & & & & 10,000 & 68.68 & 105.66 & .473 \\
\hline 200 & 2.83 & 65.36 & .765 & & & & \\
\hline 1000 & .681 & 15.73 & 3.180 & & & & \\
\hline 10,000 & .168 & 3.88 & 12.995 & & & & \\
\hline
\end{tabular}

Table IX. Comparison of Impulsive Pressure (psi) Distribution Along the Wall for Base Motion 1

\begin{tabular}{||c|c|c|c|c|c|}
\hline \multirow{2}{*}{ Height, in } & \multicolumn{5}{|c|}{ Viscosity, cP } \\
\cline { 2 - 6 } & 0 & 60 & 200 & $10^{3}$ & $10^{4}$ \\
\hline 220.8 & 0.848 & 0.848 & 0.848 & 0.848 & 0.847 \\
\hline 172.8 & 1.645 & 1.645 & 1.645 & 1.645 & 1.645 \\
\hline 133.8 & 2.023 & 2.023 & 2.023 & 2.023 & 2.022 \\
\hline 103.8 & 2.237 & 2.237 & 2.237 & 2.237 & 2.237 \\
\hline 78.8 & 2.360 & 2.360 & 2.360 & 2.360 & 2.360 \\
\hline 59.8 & 2.431 & 2.431 & 2.431 & 2.431 & 2.431 \\
\hline 41.8 & 2.478 & 2.478 & 2.478 & 2.478 & 2.477 \\
\hline 23.8 & 2.508 & 2.508 & 2.508 & 2.508 & 2.508 \\
\hline 9.8 & 2.517 & 2.517 & 2.517 & 2.517 & 2.516 \\
\hline 2.4 & 2.518 & 2.518 & 2.518 & 2.518 & 2.519 \\
\hline
\end{tabular}

Note: Maximum pressure at different heights may not occur at the same time. 
Table X. Comparison of Maximum Convective Pressure (psi) Distribution Along the Wall for Base Motion 1

\begin{tabular}{|c|c|c|c|c|c|}
\hline \multirow{2}{*}{ Height, in } & \multicolumn{5}{|c|}{ Viscosity, cP } \\
\cline { 2 - 6 } & 0 & 60 & 200 & $10^{3}$ & $10^{4}$ \\
\hline 220.8 & 0.877 & 0.877 & 0.877 & 0.876 & 0.862 \\
\hline 172.8 & 0.648 & 0.648 & 0.647 & 0.647 & 0.639 \\
\hline 133.8 & 0.535 & 0.535 & 0.535 & 0.534 & 0.526 \\
\hline 103.8 & 0.470 & 0.470 & 0.470 & 0.469 & 0.465 \\
\hline 78.8 & 0.433 & 0.433 & 0.433 & 0.433 & 0.427 \\
\hline 59.8 & 0.412 & 0.412 & 0.412 & 0.412 & 0.408 \\
\hline 41.8 & 0.398 & 0.398 & 0.398 & 0.397 & 0.392 \\
\hline 23.8 & 0.389 & 0.389 & 0.389 & 0.389 & 0.385 \\
\hline 9.8 & 0.386 & 0.386 & 0.386 & 0.386 & 0.380 \\
\hline 2.4 & 0.386 & 0.386 & 0.386 & 0.386 & 0.385 \\
\hline
\end{tabular}

Note: Maximum pressure at different heights may not occur at the same time. 
Table XI. Comparison of Maximum Total Pressure (psi) Distribution Along the Wall for Base Motion 1

\begin{tabular}{||c|c|c|c|c|c||}
\hline \multirow{2}{*}{ Height, in } & \multicolumn{5}{|c|}{ Viscosity, cP } \\
\cline { 2 - 6 } & 0 & 60 & 200 & $10^{3}$ & $10^{4}$ \\
\hline 220.8 & 1.211 & 1.211 & 1.211 & 1.210 & 1.197 \\
\hline 172.8 & 1.700 & 1.700 & 1.700 & 1.699 & 1.689 \\
\hline 133.8 & 1.984 & 1.984 & 1.984 & 1.984 & 1.984 \\
\hline 103.8 & 2.193 & 2.193 & 2.193 & 2.193 & 2.193 \\
\hline 78.8 & 2.316 & 2.316 & 2.316 & 2.316 & 2.316 \\
\hline 59.8 & 2.383 & 2.383 & 2.383 & 2.383 & 2.383 \\
\hline 41.8 & 2.432 & 2.432 & 2.432 & 2.432 & 2.432 \\
\hline 23.8 & 2.459 & 2.459 & 2.459 & 2.459 & 2.459 \\
\hline 9.8 & 2.471 & 2.471 & 2.471 & 2.471 & 2.471 \\
\hline 2.4 & 2.466 & 2.466 & 2.466 & 2.466 & 2.465 \\
\hline
\end{tabular}

Note: Maximum pressure at different heights may not occur at the same time.

Table XII. Comparison of Sloshing Wave Height, Base Shear and Base Moments for Base Motion 1

\begin{tabular}{||l|c|c|c|c|c|}
\hline \multirow{2}{*}{\multicolumn{1}{|c|}{ Response Function }} & \multicolumn{5}{|c|}{ Viscosity, cP } \\
\cline { 2 - 6 } & 0 & 60 & 200 & $10^{3}$ & $10^{4}$ \\
\hline Sloshing Wave Height, in. & 22.42 & 22.42 & 22.41 & 22.40 & 22.22 \\
\hline Base Shear, ${ }^{*}$ lb. & $4.29 \times 10^{5}$ & $4.29 \times 10^{5}$ & $4.29 \times 10^{5}$ & $4.29 \times 10^{5}$ & $4.29 \times 10^{5}$ \\
\hline $\begin{array}{l}\text { Base Moment Above Mat, } \\
\text { lb.-in. }\end{array}$ & $3.62 \times 10^{7}$ & $3.62 \times 10^{7}$ & $3.62 \times 10^{7}$ & $3.62 \times 10^{7}$ & $3.62 \times 10^{7}$ \\
\hline $\begin{array}{l}\text { Base Moment Below Mat, }{ }^{*} \\
\text { lb.-in. }\end{array}$ & $8.43 \times 10^{7}$ & $8.43 \times 10^{7}$ & $8.43 \times 10^{7}$ & $8.43 \times 10^{7}$ & $8.43 \times 10^{7}$ \\
\hline
\end{tabular}

*Impulsive component only. 
Tal KIII. Comparison of Impulsive Pressure (psi) Distribution Along the Wall for Base Motion 2

\begin{tabular}{|c|c|c|c|c|c|}
\hline \multirow[b]{2}{*}{ eight, in } & \multicolumn{5}{|c|}{ Viscosity, $\mathrm{cP}$} \\
\hline & 0 & 60 & 200 & $10^{3}$ & $10^{4}$ \\
\hline 220.8 & 2.871 & 2.871 & 2.871 & 2.871 & 2.870 \\
\hline 172.8 & 5.572 & 5.572 & 5.572 & 5.572 & 5.571 \\
\hline 133.8 & 6.852 & 6.852 & 6.852 & 6.852 & 6.852 \\
\hline 103.8 & 7.578 & 7.578 & 7.578 & 7.578 & 7.578 \\
\hline 78.8 & 7.996 & 7.996 & 7.996 & 7.996 & 7.996 \\
\hline 59.8 & 8.234 & 8.234 & 8.234 & 8.234 & 8.234 \\
\hline 41.8 & 8.395 & 8.395 & 8.395 & 8.395 & 8.388 \\
\hline 23.8 & 8.495 & 8.495 & 8.495 & 8.495 & 8.492 \\
\hline 7.8 & 8.526 & 8.526 & 8.526 & 8.526 & 8.518 \\
\hline 2.4 & 8.529 & 8.529 & 8.529 & 8.529 & 8.529 \\
\hline
\end{tabular}

$\therefore$ Impulsive pressure is at time of maximum ground acceleration. 
Table XIV. Comparison of Maximum Convective Pressure (psi) Distribution Along the Wall for Base Motion 2

\begin{tabular}{|c|c|c|c|c|}
\hline \multirow{2}{*}{ Height, in. } & \multicolumn{4}{|c|}{ Viscosity, cP } \\
\cline { 2 - 5 } & 60 & 200 & $10^{3}$ & $10^{4}$ \\
\hline 220.8 & 2.137 & 2.136 & 2.130 & 2.068 \\
\hline 172.8 & 1.587 & 1.587 & 1.582 & 1.538 \\
\hline 133.8 & 1.333 & 1.333 & 1.330 & 1.294 \\
\hline 103.8 & 1.182 & 1.181 & 1.178 & 1.144 \\
\hline 78.8 & 1.093 & 1.092 & 1.090 & 1.062 \\
\hline 59.8 & 1.042 & 1.041 & 1.038 & 1.007 \\
\hline 41.8 & 1.007 & 1.007 & 1.004 & 0.979 \\
\hline 23.8 & 0.986 & 0.985 & 0.982 & 0.953 \\
\hline 9.8 & 0.979 & 0.979 & 0.976 & 0.953 \\
\hline 2.4 & 0.978 & 0.977 & 0.974 & 0.940 \\
\hline
\end{tabular}

Note: Maximum pressure at different heights may not occur at the same time. 
Table XV. Comparison of Maximum Total Pressure (psi) Distribution Along the Wall for Base Motion 2

\begin{tabular}{||c|c|c|c|c||}
\hline \multirow{2}{*}{ Height, in. } & \multicolumn{5}{|c|}{ Viscosity, cP } \\
\cline { 2 - 5 } & 60 & 200 & $10^{3}$ & $10^{4}$ \\
\hline 220.8 & 3.755 & 3.754 & 3.750 & 3.702 \\
\hline 172.8 & 5.491 & 5.491 & 5.491 & 5.496 \\
\hline 133.8 & 6.791 & 6.791 & 6.791 & 6.793 \\
\hline 103.8 & 7.525 & 7.525 & 7.525 & 7.528 \\
\hline 78.8 & 7.949 & 7.949 & 7.949 & 7.950 \\
\hline 59.8 & 8.189 & 8.189 & 8.190 & 8.193 \\
\hline 41.8 & 8.352 & 8.352 & 8.352 & 8.353 \\
\hline 23.8 & 8.453 & 8.453 & 8.453 & 8.457 \\
\hline 9.8 & 8.485 & 8.485 & 8.485 & 8.485 \\
\hline 2.4 & 8.488 & 8.488 & 8.489 & 8.496 \\
\hline
\end{tabular}

Note: Maximum pressure at different height may not occur at the same time.

Table XVI. Comparison of Sloshing Wave Height, Base Shear and Base Moments for Base Motion 2

\begin{tabular}{||l|c|c|c|c|c||}
\hline \multirow{2}{*}{\multicolumn{1}{|c|}{ Response Function }} & \multicolumn{5}{|c||}{ Viscosity, cP } \\
\cline { 2 - 6 } & 0 & 60 & 200 & $10^{3}$ & $10^{4}$ \\
\hline Sloshing Wave Height, in. & 55.72 & 55.72 & 55.69 & 55.55 & 53.92 \\
\hline Base Shear, ${ }^{*}$ lb. & $1.45 \times 10^{6}$ & $1.45 \times 10^{6}$ & $1.45 \times 10^{6}$ & $1.45 \times 10^{6}$ & $1.45 \times 10^{6}$ \\
\hline $\begin{array}{l}\text { Base Moment Above Mat, } \\
\text { lb.-in. }\end{array}$ & $1.23 \times 10^{8}$ & $1.23 \times 10^{8}$ & $1.23 \times 10^{8}$ & $1.23 \times 10^{8}$ & $1.23 \times 10^{8}$ \\
\hline $\begin{array}{l}\text { Base Moment Below Mat, } \\
\text { lb.-in. }\end{array}$ & $2.85 \times 10^{8}$ & $2.85 \times 10^{8}$ & $2.85 \times 10^{8}$ & $2.85 \times 10^{8}$ & $2.85 \times 10^{8}$ \\
\hline
\end{tabular}

*Impulsive component only. 


\begin{tabular}{|c|c|c|c|c|c|c|c|c|c|c|c|}
\hline & 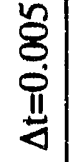 & 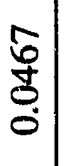 & $\begin{array}{l}\stackrel{\infty}{\infty} \\
\stackrel{\infty}{0} \\
\dot{0}\end{array}$ & $\begin{array}{c}n \\
\\
\sigma\end{array}$ & $\frac{a}{j}$ & 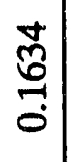 & $\begin{array}{c}8 \\
\stackrel{8}{0} \\
\frac{1}{0}\end{array}$ & $\frac{\sqrt{n}}{\infty}$ & $\frac{\sqrt{3}}{2}$ & $\begin{array}{l}\overrightarrow{1} \\
\stackrel{+}{-1} \\
0\end{array}$ & 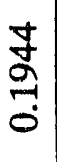 \\
\hline & 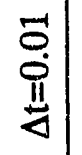 & 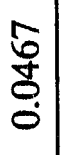 & $\begin{array}{l}\infty \\
\infty \\
0 \\
0\end{array}$ & 完 & $\frac{\infty}{\stackrel{+}{Z}}$ & $\begin{array}{c}m \\
\tilde{m} \\
\tilde{0} \\
0\end{array}$ & $\begin{array}{l}8 \\
\frac{8}{9} \\
0\end{array}$ & $\begin{array}{l}0 \\
\infty \\
\infty \\
0 \\
0\end{array}$ & $\begin{array}{l}\frac{y}{1} \\
\frac{1}{0} \\
0\end{array}$ & $\begin{array}{l}\frac{1}{4} \\
\frac{2}{0}\end{array}$ & $\frac{\pi}{5}$ \\
\hline & $\begin{array}{l}2 \\
8 \\
0 \\
\frac{11}{4}\end{array}$ & 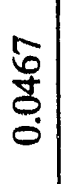 & $\begin{array}{l}9 \\
0 \\
0 \\
0\end{array}$ & 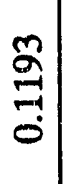 & $\frac{q}{\dot{f}}$ & 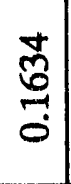 & $\frac{5}{0}$ & 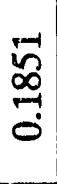 & $\begin{array}{l}\overline{-1} \\
\frac{\sigma}{0} \\
0\end{array}$ & $\begin{array}{l}\overrightarrow{+} \\
\stackrel{5}{a} \\
\dot{0}\end{array}$ & 㝵 \\
\hline & $\begin{array}{l}-1 \\
0 \\
\dot{\pi} \\
\dot{u}\end{array}$ & $\begin{array}{l}0 \\
0 \\
0 \\
0 \\
0\end{array}$ & 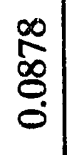 & $\begin{array}{c}\Omega \\
\frac{2}{0} \\
0\end{array}$ & $\frac{g}{\mathfrak{g}}$ & 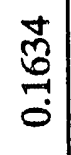 & $\frac{5}{6}$ & $\begin{array}{l}\mathscr{0} \\
\infty \\
\infty \\
0\end{array}$ & $\begin{array}{l}= \\
\sigma \\
0 \\
0\end{array}$ & $\begin{array}{l}\frac{P}{2} \\
\stackrel{2}{0}\end{array}$ & $\frac{m}{2}$ \\
\hline & $\begin{array}{l}0 \\
0 \\
01 \\
y\end{array}$ & $\begin{array}{l}0 \\
\dot{0} \\
0 \\
0\end{array}$ & $\begin{array}{l}8 \\
0 \\
0 \\
0 \\
0\end{array}$ & $\underset{0}{\stackrel{8}{\Xi}}$ & $\begin{array}{l}\frac{5}{5} \\
\stackrel{5}{0}\end{array}$ & $\begin{array}{l}n \\
\tilde{n} \\
\\
0\end{array}$ & $\frac{8}{5}$ & $\frac{\sqrt{n}}{\infty}$ & 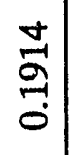 & $\frac{8}{\stackrel{+}{2}}$ & 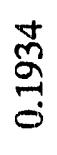 \\
\hline & $\begin{array}{l}\delta \\
0 \\
0 \\
\frac{11}{4}\end{array}$ & $\begin{array}{l}0 \\
0 \\
\vdots \\
0 \\
0\end{array}$ & $\begin{array}{l}\infty \\
\stackrel{\infty}{0} \\
0 \\
0\end{array}$ & 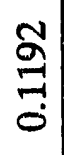 & $\frac{g}{\mathbb{Z}}$ & 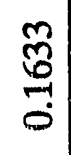 & $\begin{array}{l}0 \\
\frac{8}{2} \\
0\end{array}$ & $\begin{array}{l}\underset{+}{\infty} \\
\stackrel{1}{0}\end{array}$ & 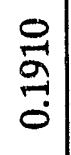 & $\frac{\hat{m}}{a}$ & $\frac{n}{\tilde{m}}$ \\
\hline$\tilde{n}$ & $\begin{array}{l}\tilde{0} \\
\dot{0} \\
\stackrel{11}{4}\end{array}$ & $\begin{array}{l}1 \\
0 \\
0 \\
0 \\
0\end{array}$ & $\begin{array}{l}-1 \\
\infty \\
0 \\
0 \\
0\end{array}$ & $\frac{2}{\stackrel{2}{二}}$ & $\frac{\widetilde{Z}}{\stackrel{\Xi}{*}}$ & 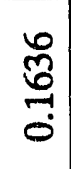 & 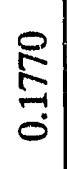 & $\begin{array}{l}-1 \\
\infty \\
0 \\
0\end{array}$ & $\begin{array}{l}\frac{d}{\sigma} \\
\stackrel{-1}{0}\end{array}$ & 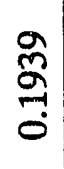 & 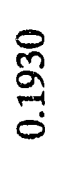 \\
\hline$\pi$ & $\begin{array}{l}\text { d } \\
\dot{0} \\
\stackrel{11}{4}\end{array}$ & $\begin{array}{l}0 \\
0 \\
0 \\
0 \\
0\end{array}$ & $\begin{array}{l}8 \\
\infty \\
0 \\
0 \\
0 \\
0\end{array}$ & $\begin{array}{l}\stackrel{2}{=} \\
\tilde{\sigma}\end{array}$ & 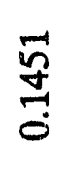 & \begin{tabular}{l}
\multirow{心}{6}{} \\
$\stackrel{-}{0}$ \\
$\dot{0}$
\end{tabular} & $\begin{array}{l}0 \\
0 \\
0 \\
0 \\
0\end{array}$ & $\begin{array}{l}\stackrel{0}{n} \\
\stackrel{\infty}{0} \\
0\end{array}$ & 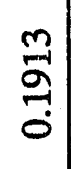 & 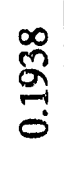 & 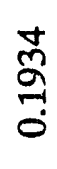 \\
\hline$\stackrel{n}{-1}$ & 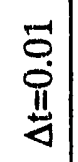 & $\begin{array}{l}a \\
\dot{p} \\
\dot{0} \\
0\end{array}$ & $\begin{array}{l}0 \\
\infty \\
0 \\
0 \\
0\end{array}$ & 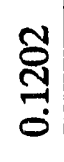 & $\frac{8}{8}$ & $\frac{\substack{0 \\
0}}{0}$ & $\underset{F}{5}$ & 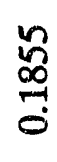 & $\frac{a}{a}$ & 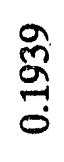 & $\frac{N}{a}$ \\
\hline II & $\begin{array}{l}0 \\
0 \\
0 \\
\\
\forall\end{array}$ & $\begin{array}{l}\infty \\
0 \\
⿱ 亠 乂 \\
0 \\
0\end{array}$ & $\begin{array}{l}n \\
\infty \\
\infty \\
0 \\
0\end{array}$ & 芯 & $\begin{array}{l}0 \\
n \\
0 \\
0\end{array}$ & $\underset{0}{\overparen{J}}$ & $\begin{array}{l}0 \\
E \\
0\end{array}$ & $\begin{array}{l}\text { पे } \\
\stackrel{\infty}{-1} \\
0 \\
0\end{array}$ & $\begin{array}{l}\infty \\
0 \\
0 \\
0\end{array}$ & $\frac{\infty}{2}$ & $\frac{n}{a}$ \\
\hline & $\begin{array}{l}n \\
\hat{c} \\
\dot{d} \\
\dot{w} \\
\stackrel{g}{\Xi}\end{array}$ & 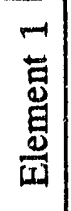 & $\sqrt{6}$ & $\stackrel{m}{m}$ & g & బ & $\vec{m}$ & S్ & ఝூ & ్ㅐㄱ & ñ \\
\hline 它 & 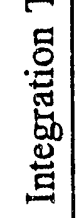 & \multicolumn{10}{|c|}{ 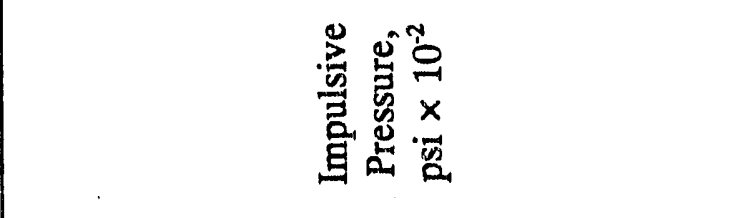 } \\
\hline
\end{tabular}




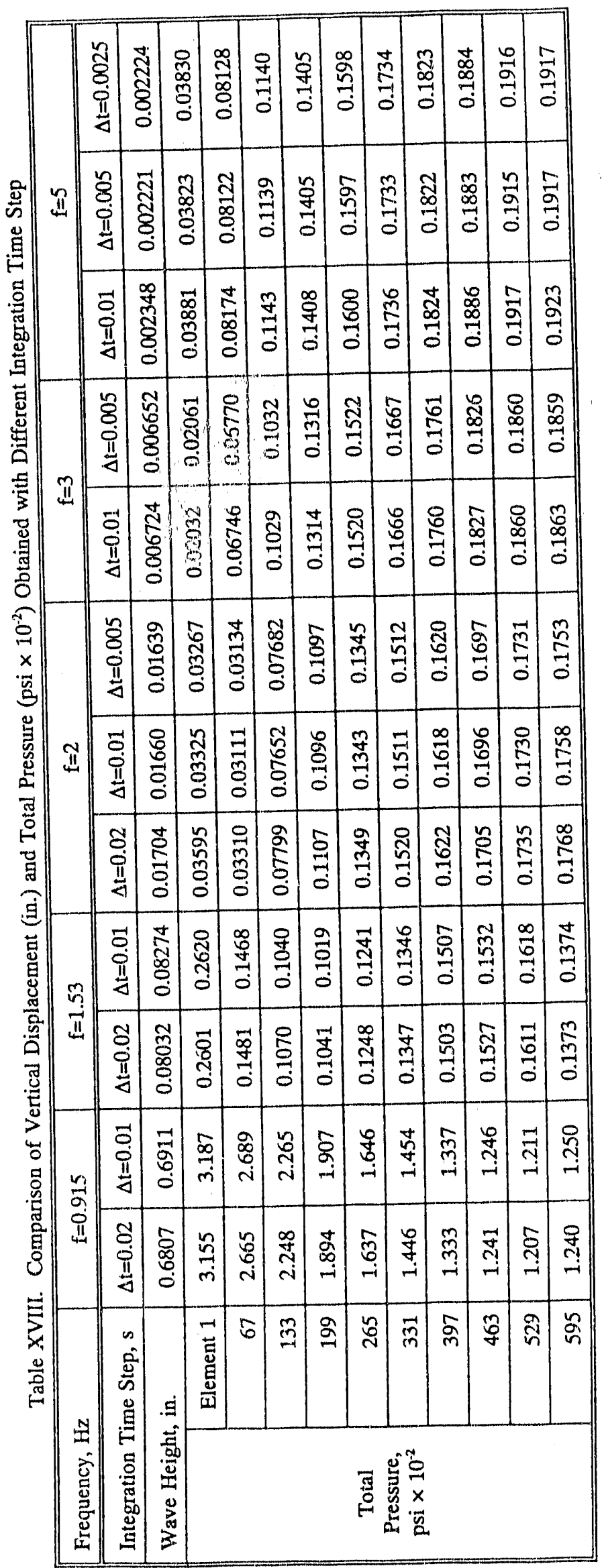




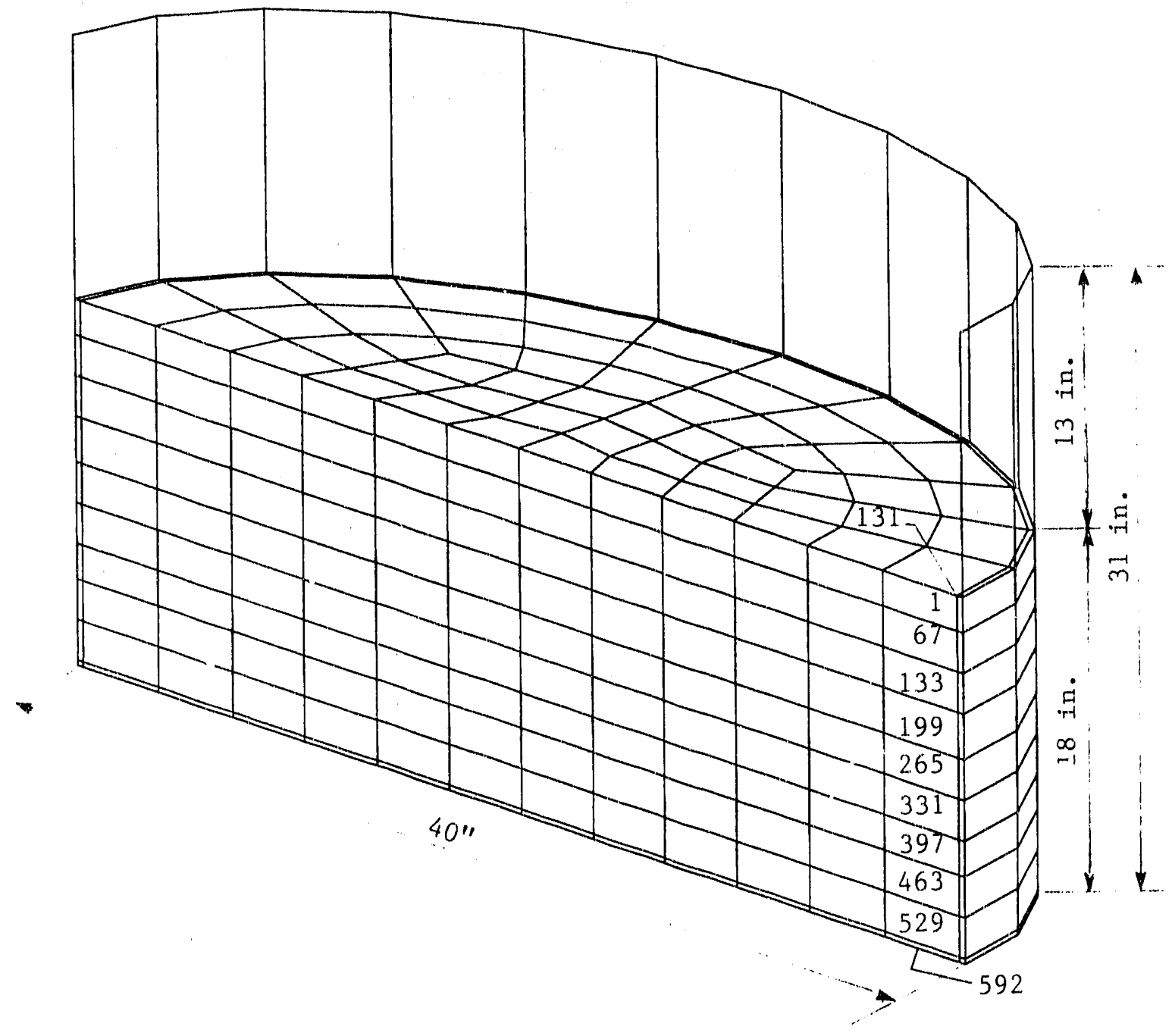

Fig. 1. Finite Element Mode1 of the Small Liquid-Tank System 
VERTICAL DISPLACEMENT AT NODE 131(waste, 60cp)

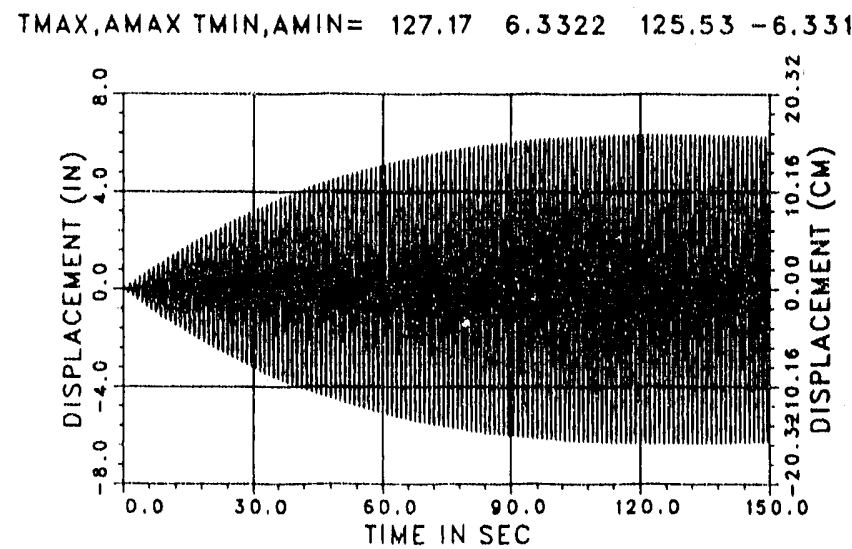

VERTICAL DISPLACEMENT AT NODE 131(waste, 1000cp)

TMAX,AMAX TMIN,AMIN $=\begin{array}{lllll}51.94 & 0.6808 & 47.02 & -0.6807\end{array}$

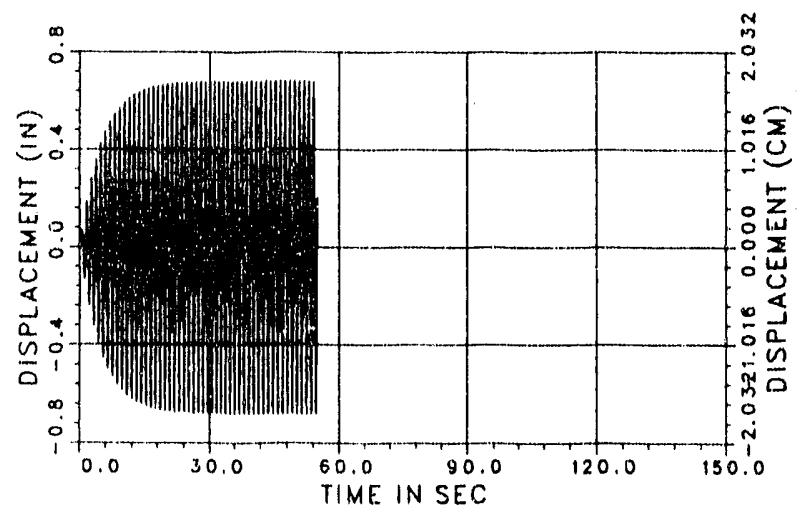

VERTICAL DISPLACEMENT AT NODE 131(wasto, $200 \mathrm{cp}$ )

TMAX, AMAX TMIN,AMIN $=102.11 \quad 2.8294 \quad 103.75 \quad-2.8294$

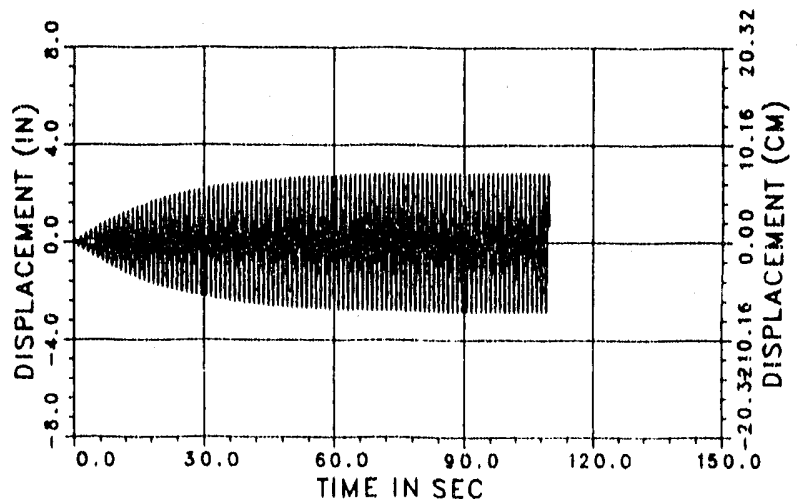

VERTICAL DISPLACEMENT AT NODE 131 (waste, 10000cp) TMAX, AMAX TMIN, AMIN $=6.16 \quad 0.1684 \quad 6.70-0.1682$

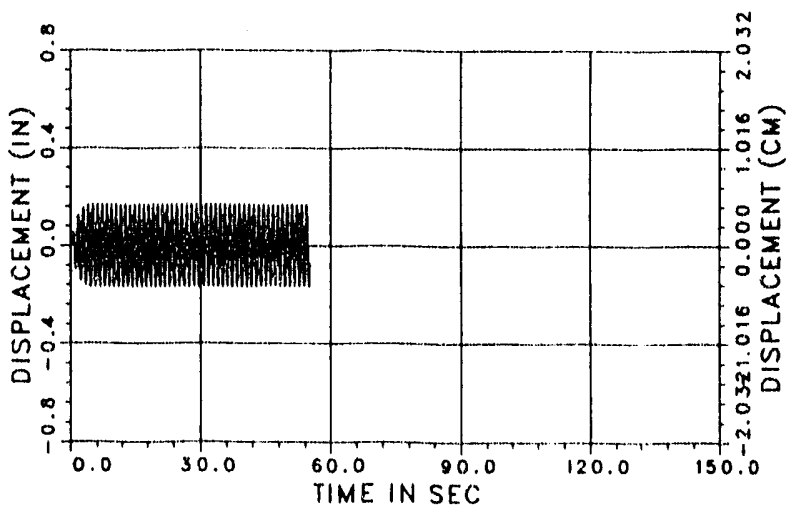

Fig. 2. Sloshing Wave Heights as a Function of Time for Fluid Viscosity, $\mu=60,200,1000$ and $10,000 \mathrm{cP}$ Due to Resonant Harmonic Excitation with a Frequency of $0.915 \mathrm{~Hz}$ 

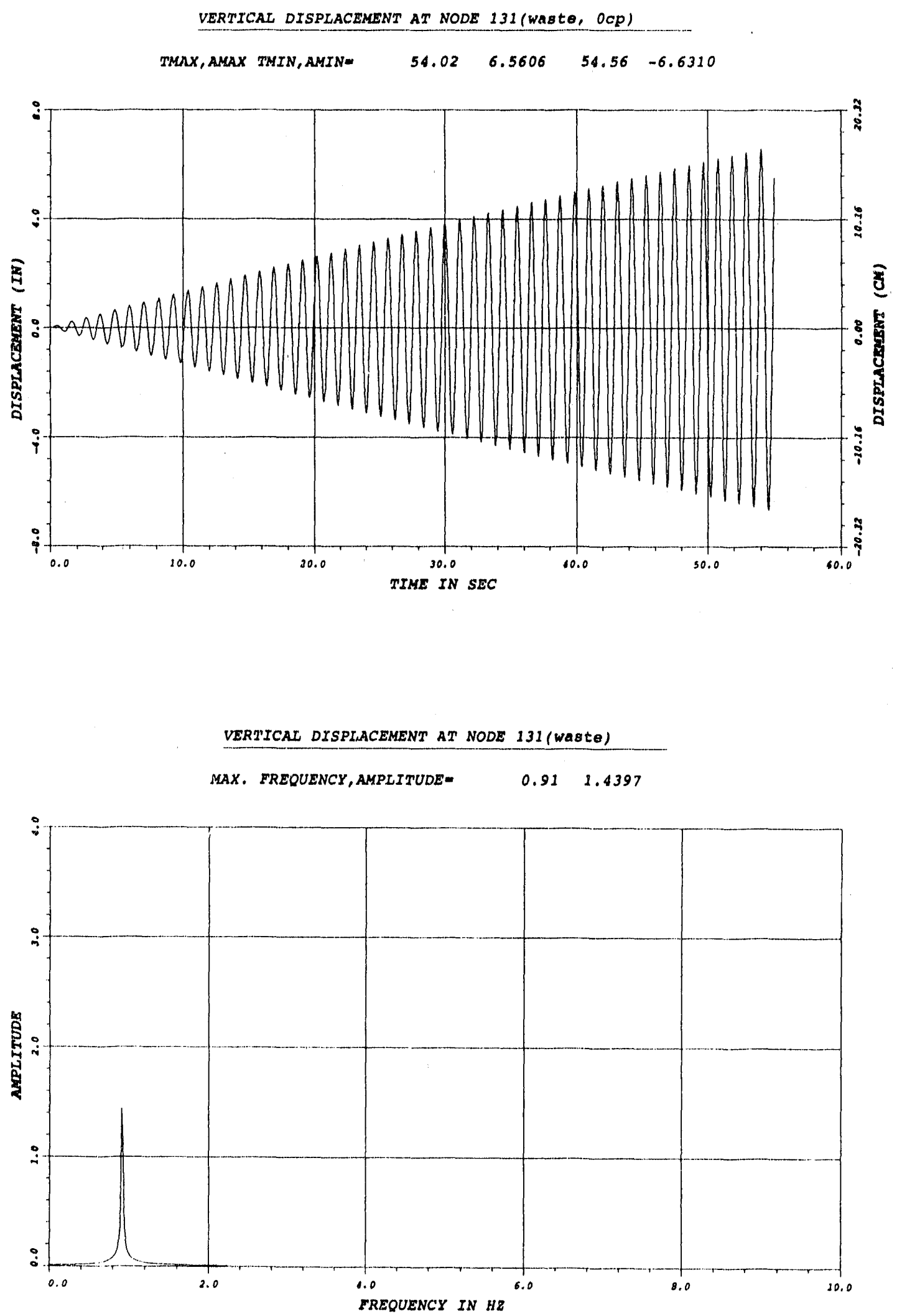

Fig. 3. Sloshing Wave Height as a Function of Time for Fluid Viscosity, $\mu=0$ Due to Resonant Harmonic Excitation with a Frequency of $0.915 \mathrm{~Hz}$ 
TMAX,AMAX TMIN,AMIN $=107.57 \quad 0.1313 \quad 109.21=0.1313$ TMAX, AMAX TMIN, AMIN=: $104.29 \quad 0.0937 \quad 105.93-0.0937$
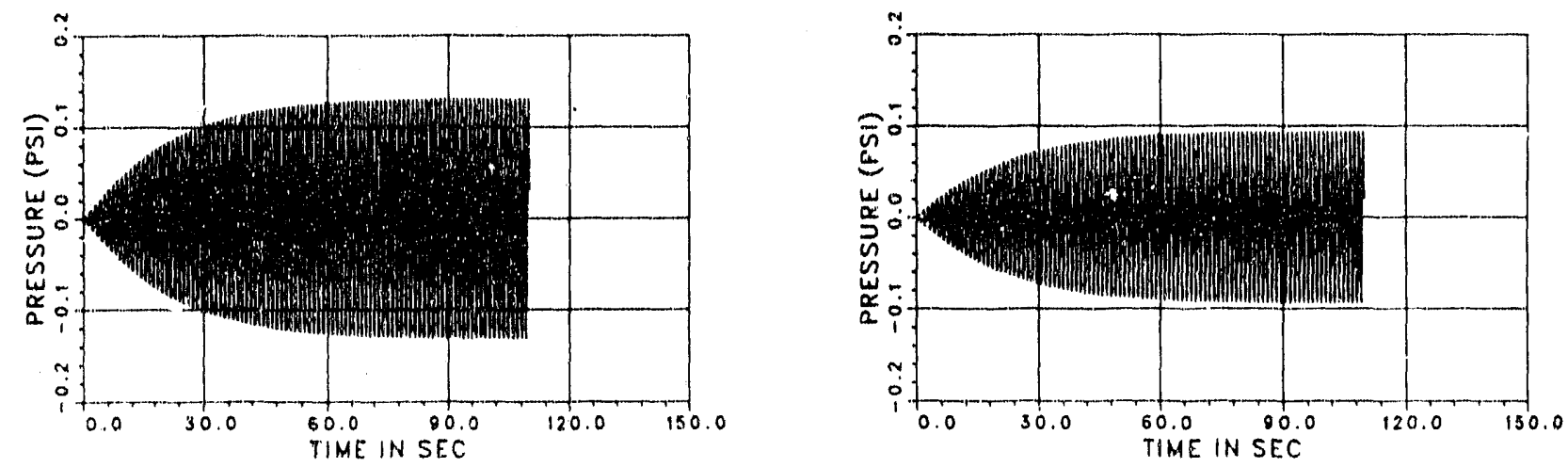

TMAX,AMAX TMIN,AMIN $=109.75 \quad 0.0606 \quad 108.11-0.0606$ TMAX,AMAX TININ,AMIN= $106.47 \quad 0.0500108 .11-0.0500$
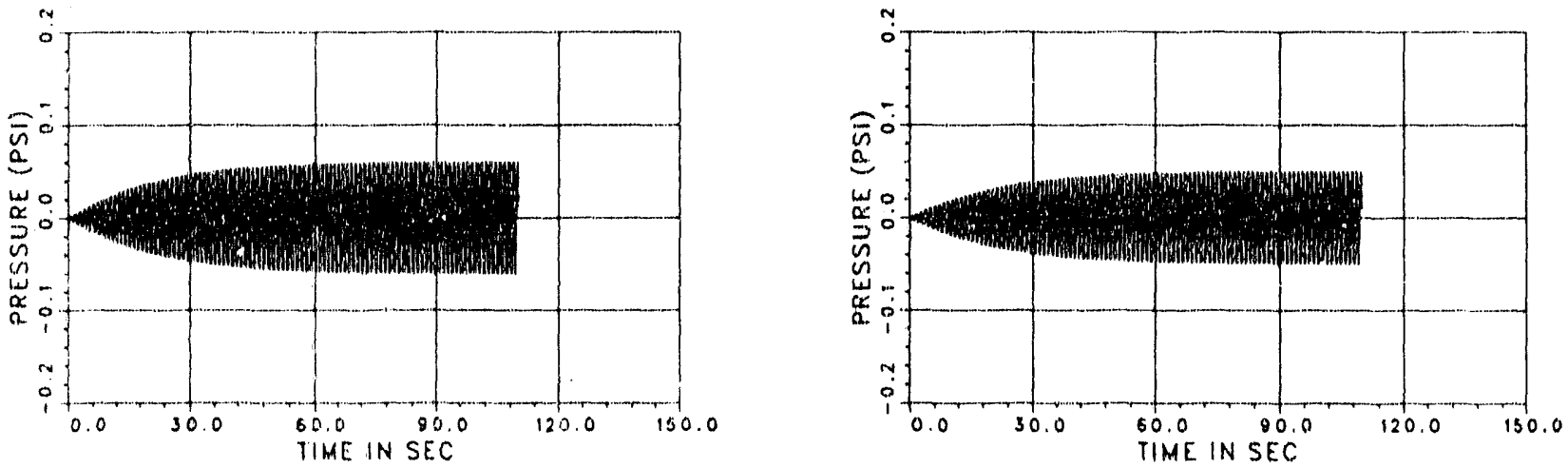

Fig. 4. Total Hydrodynamic Pressures at Fluld Elements 1, 133, 331 and 529 for the Case of $11=200$ cP Due to Resonant Harmonic Excitation with a Frequency of $0.915 \mathrm{~Hz}$ 
PRESSURE AT ELEMENT 1(waste, 200cP)

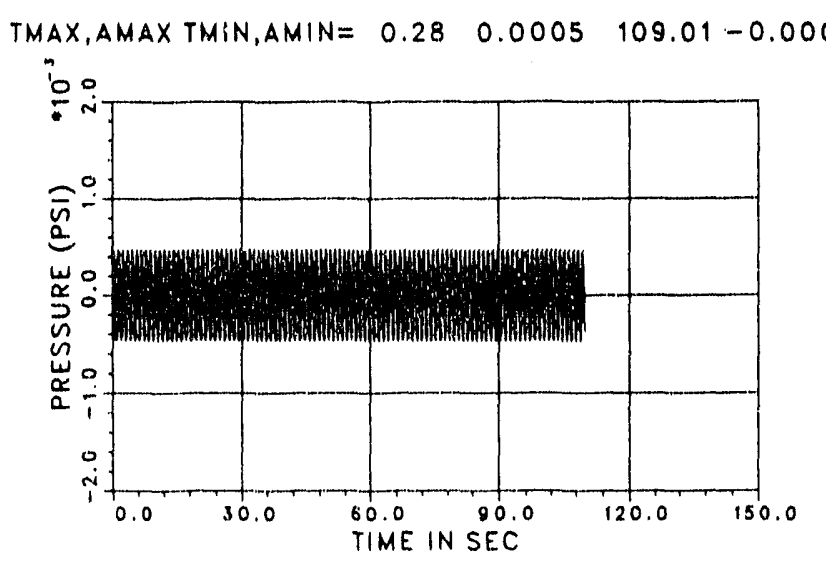

PRESSURE AT ELEMENT 331 (wasto, 200cp)

TMAX, AMAX TMIN,AMIN $=0.28 \quad 0.0018 \quad 7.38-0.0018$

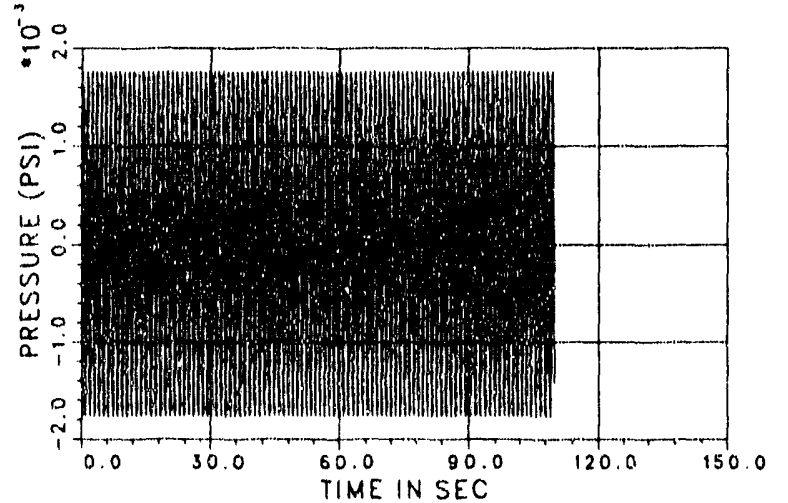

PRESSURE AT ELEMENT 133 (waste, 200cP)

TMAX, AMAX, TMIN, AMIN $=0.28 \quad 0.0012 \quad 105.73-0.0012$

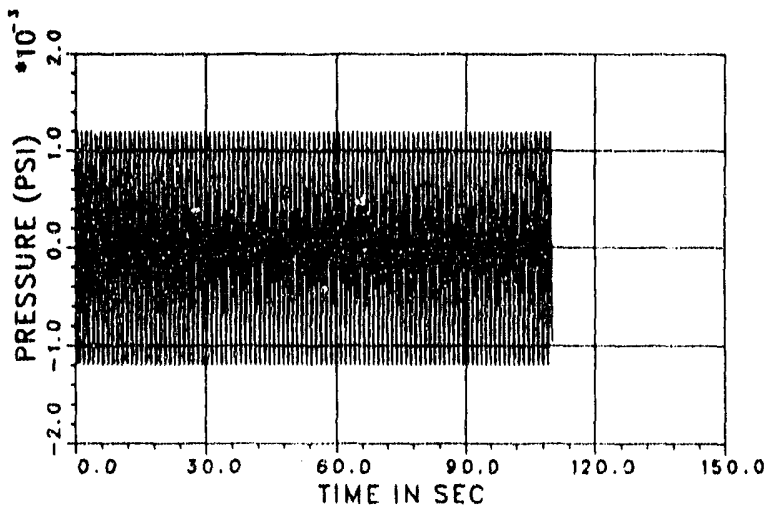

PRESSURE AT ELEMENT 529(woste, 200cp)

TMAX, AMAX TMIN, AMIN $=2.46 \quad 0.0019 \quad 102.45 \cdots 0.0019$ io

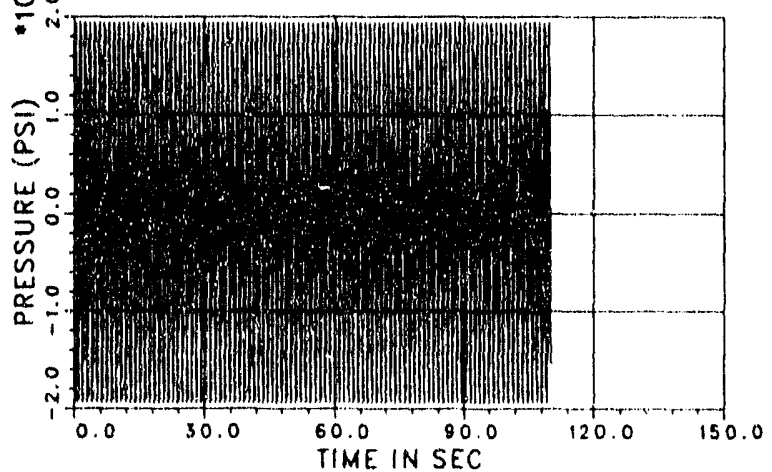

Fig. 5. Impulsive Pressures at Fluid Elements 1, 133, 331 and 529 for the Case of $\mu=200 \mathrm{cP}$ Due to Resonant Harmonic Excitation with a Frequency of $0.915 \mathrm{~Hz}$ 
VERTICAL DISPLACEMENT AT NODE 131 (waste, 60cp)

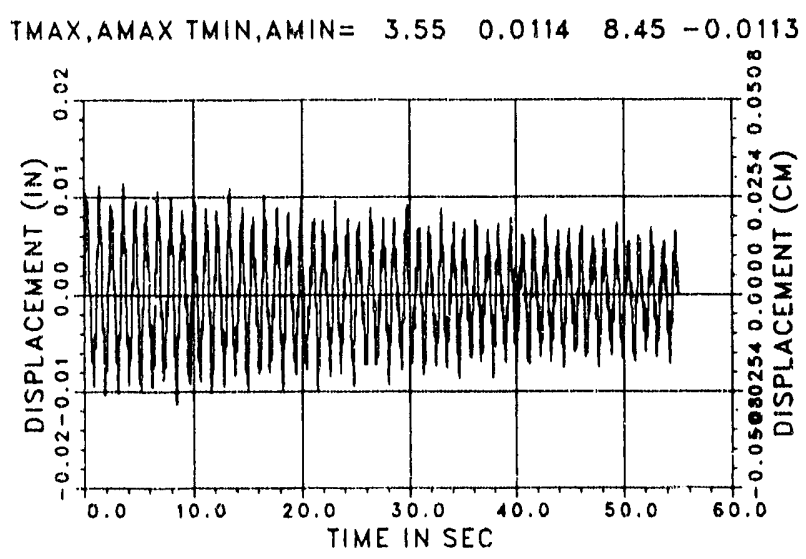

VERTICAL DISPLACEMENT AT NODE 131 (waste. 200cp)

TMAX, AMAX TMIN,AMIN= $1.35 \quad 0.0107 \quad 1.86 \cdots 0.0101$

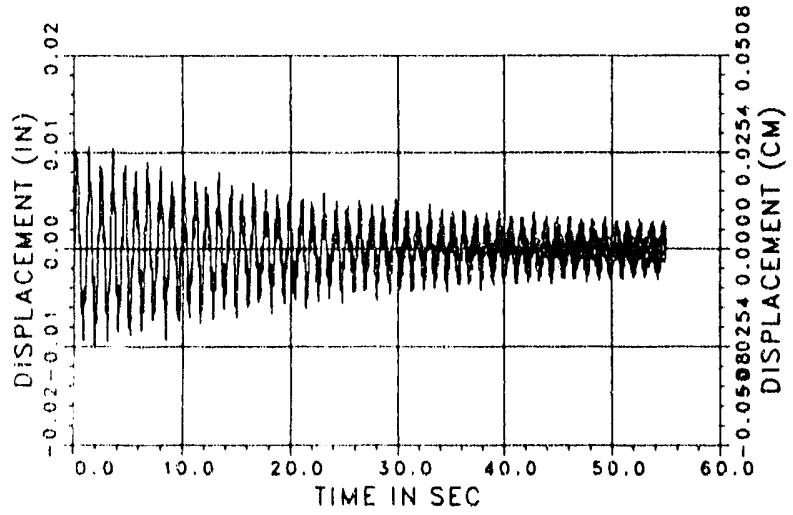

VERTICAL DISPLACEMENT AT NODE 131(waste)

MAX. FREQUENCY, AMPLITUDE $=0.910 .0021$

io

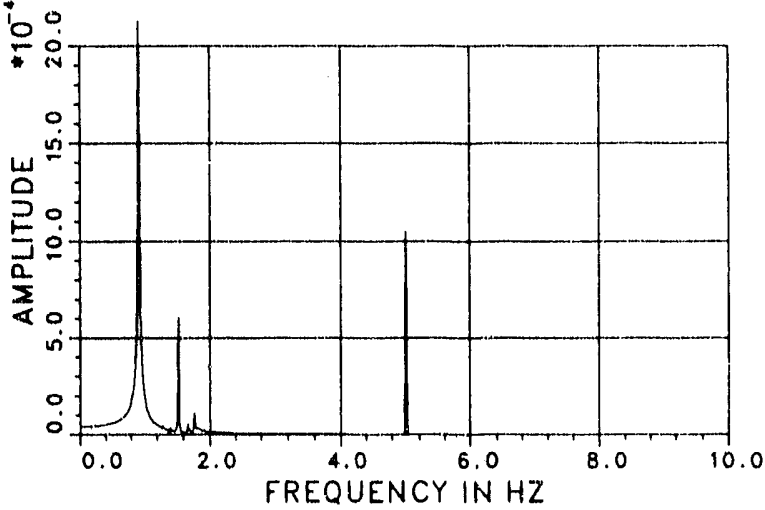

VERTICAL DISPLACEMENT AT NODE 131(waste)

MAX. FREQUENCY, AMPLITUDE $=0.910 .0013$

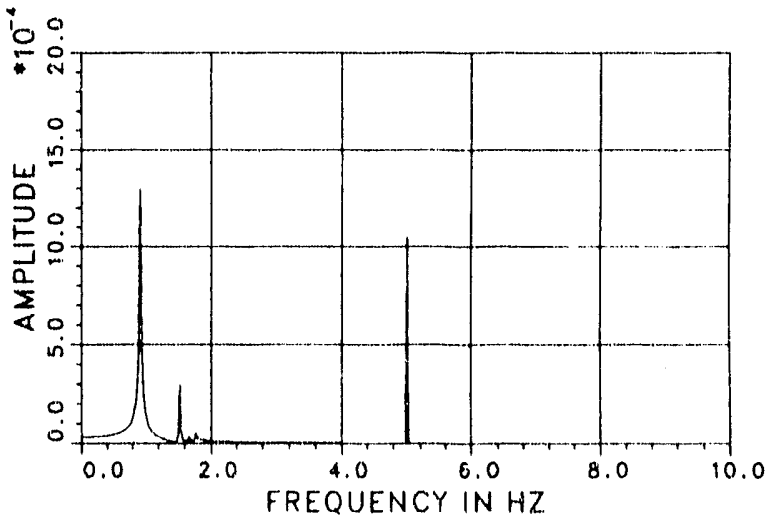

Fig. 6. Sloshing Wave Heights as a Function of Time and FFT Plot for Fluid Viscosity, $\mu=60$ and $200 \mathrm{cP}$ Due to Non-Resonant Harmonic Excitation with a Frequency of $5 \mathrm{~Hz}$ 
VERTICAL DISPLACEMENT AT NODE 131(wasto, $1000 \mathrm{cp}$ )

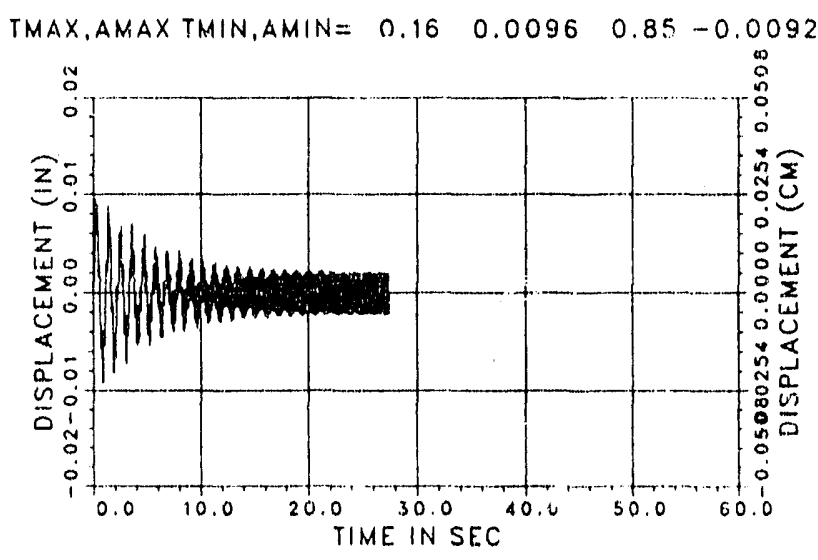

VERTICAL DISPLACEMENT AT NODE 131 (wosto, $10000 \mathrm{cP}$ )

TMAX, AMAX TMIN,AMIN $=0.33 \quad 0.0079 \quad 1.03-0.0063$

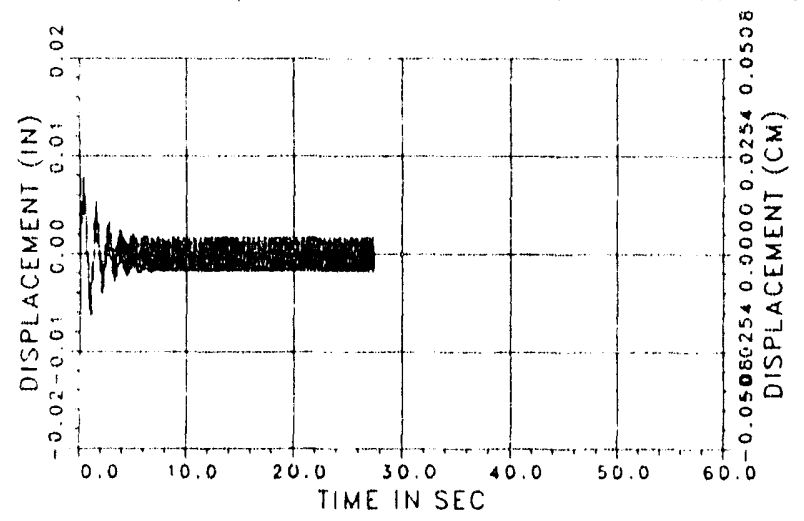

VERTICAL DISPLACEMENT AT NODE 131(wasto)

MAX. FREQUENCY,AMPLITUDE $=0.910 .0008$

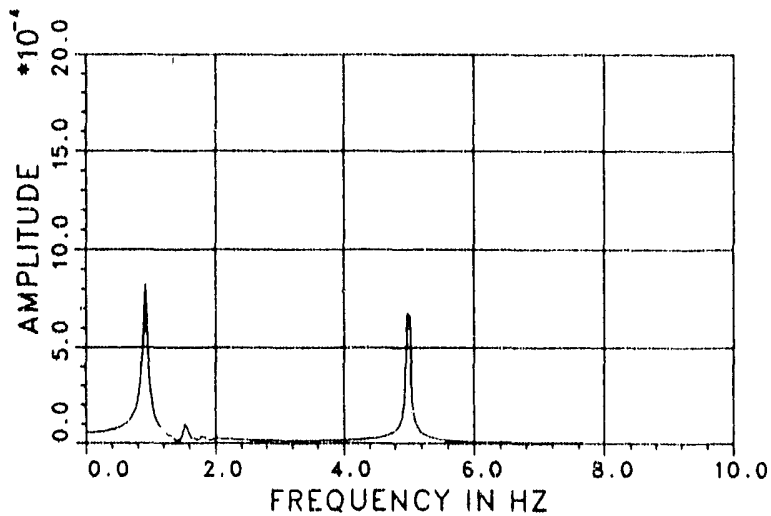

VERTICAL DISPLACEMENT AT NODE 131(waste)

MAX. FREQUENCY,AMPLITUDE $=4.98 \quad 0.0006$

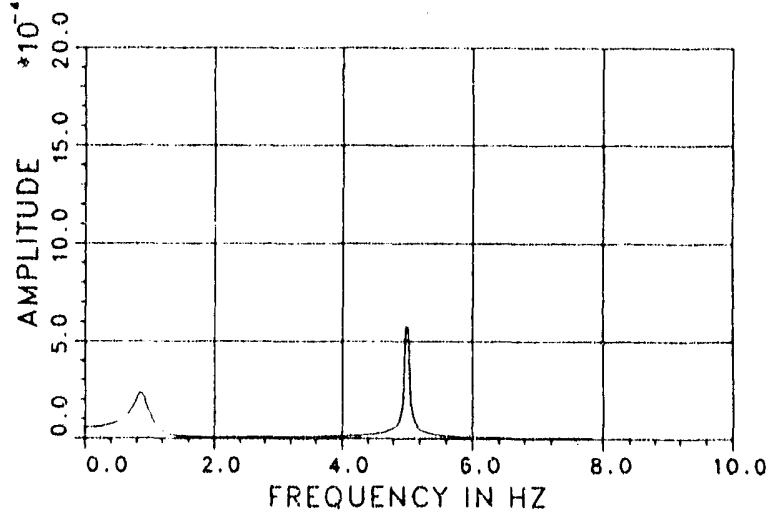

Fig. 7. Sloshing Wave Heights as a Function of Time and FFT Plot for Fluid Viscosity, $\mu=1000$ and $10,000 \mathrm{cP}$ Due to Non-Resonant Harmonic Excitation with a Frequency of $5 \mathrm{~Hz}$ 
VERTICAL DISPLACEMENT AT NODE 131(wasto, 60cP)

TMAX, AMAX TMIN,AMIN $=90.62 \quad 1.0541 \quad 88.98-1.0540$

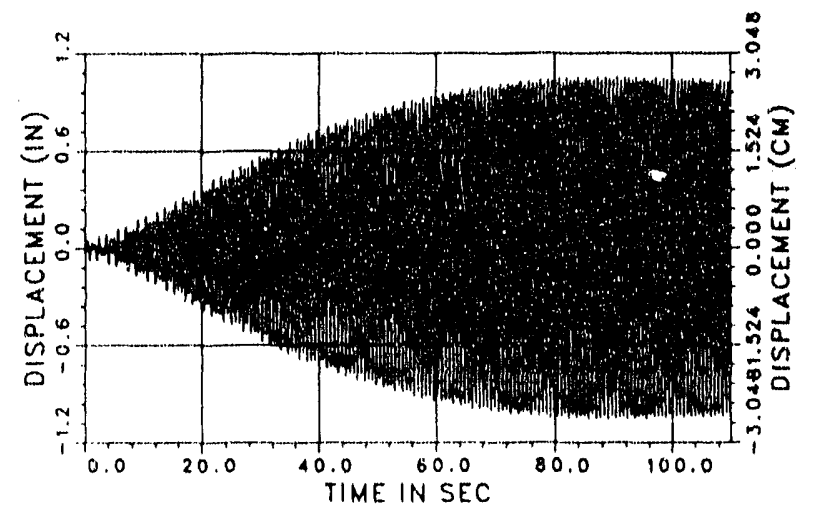

VERTICAL DISPLACEMENT AT NODE 131(wasto, $1000 \mathrm{cp}$ )

TMAX,AMAX TMIN,AMIN $=38.28 \quad 0.0804 \quad 43.18-0.0803$

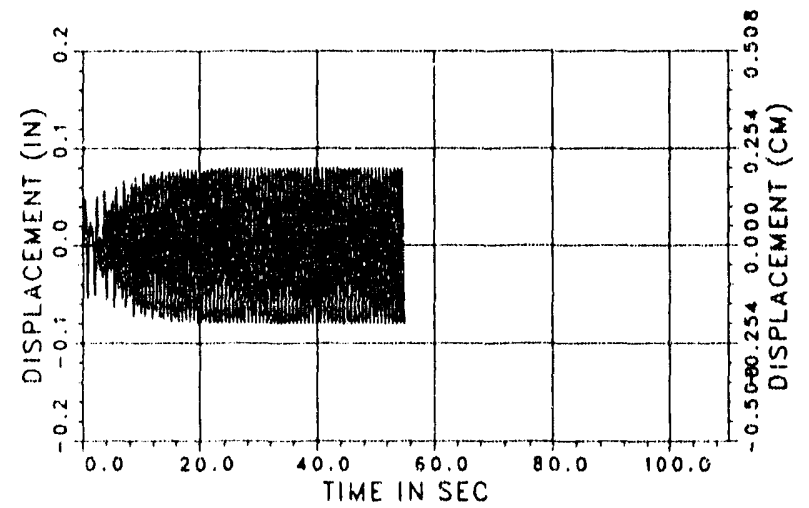

VERTICAL DISPLACEMENT AT NODE 13i(waste, 200cp)

TMAX, AMAX TMIN, AMIN $=87.32 \quad 0.4692 \quad 88.96-0.4696$

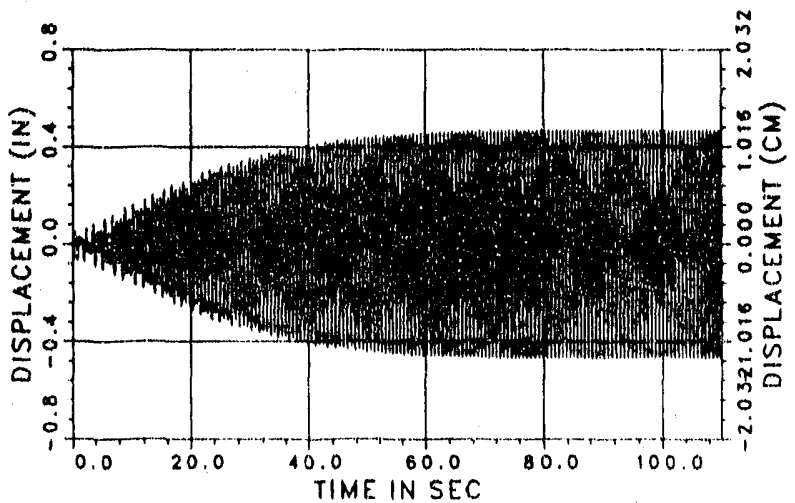

VERTICAL DISPLACEMENT AT NODE 131 (waste, 10000cp) TMAX, AMAX TMIN, AMIN $=0.44 \quad 0.0314 \quad 0.90-0.0299$

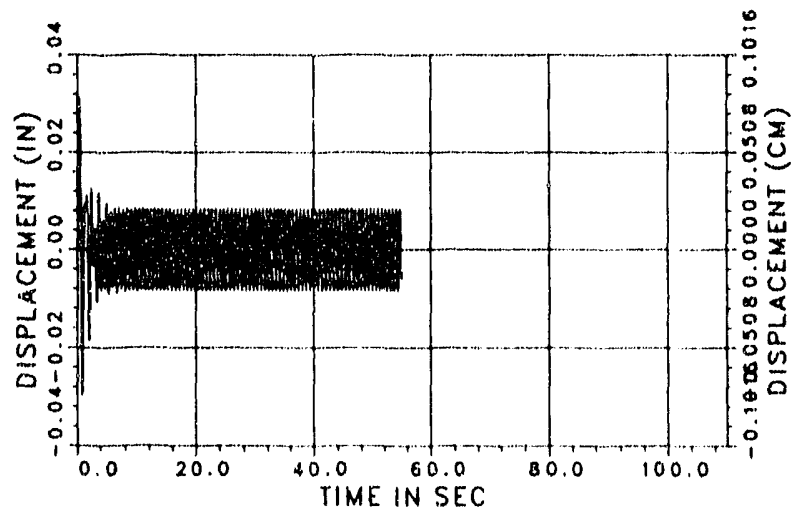

Fig. 8. Sloshing Wave Heights as a Function of Time for Fluid Viscosity, $\mu=60,200,1000$ and $10,000 \mathrm{cP}$ Due to Resonant Harmonic Excitation with a Frequency of $1.53 \mathrm{~Hz}$ 


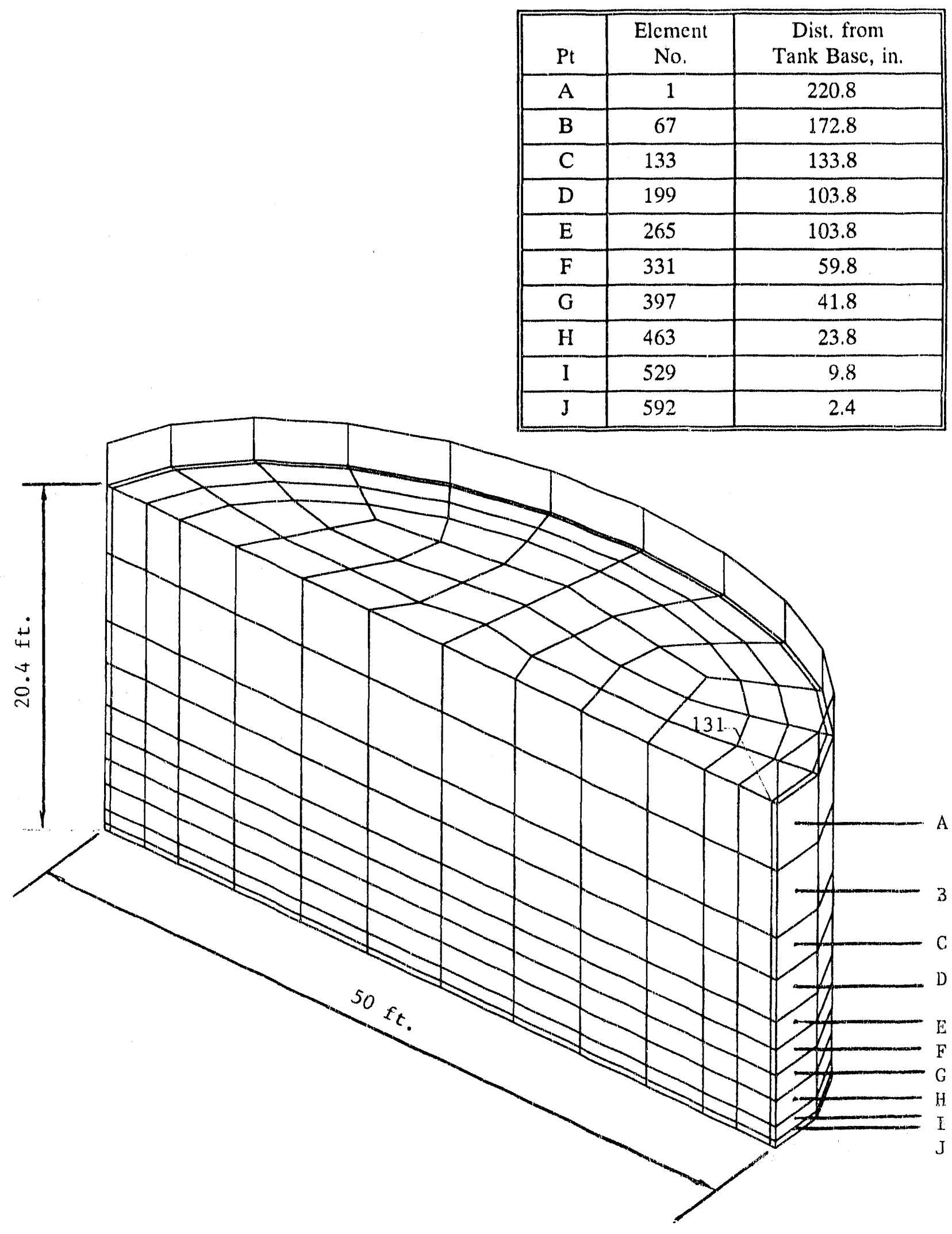

Fig. 9. Finite Element Model of the Large Liquid-rTank System 


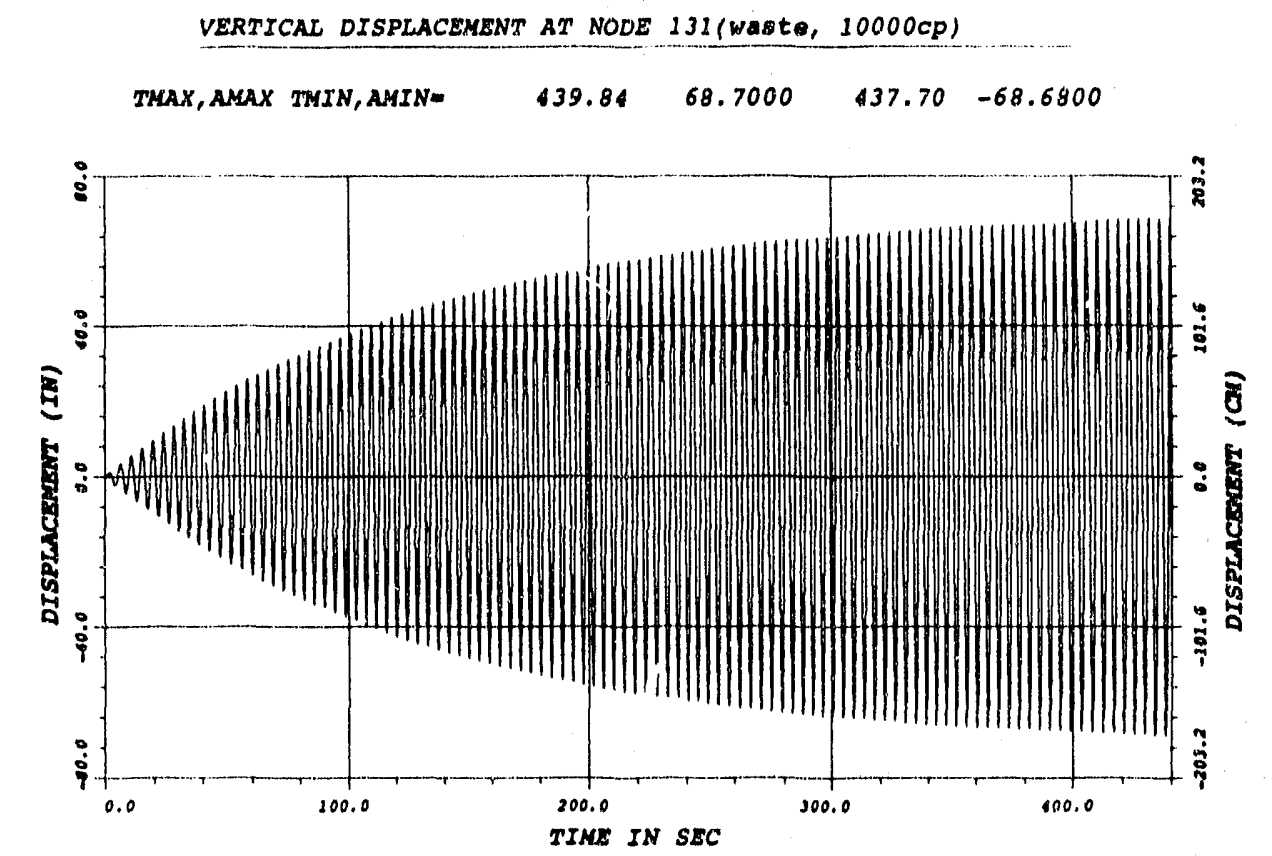

VERTICAL DISPLACEMENT AT NODS 131 (wate)

MAX. FREQUENCY, AMPLITUDE= $\quad 0.23 \quad 18.1076$

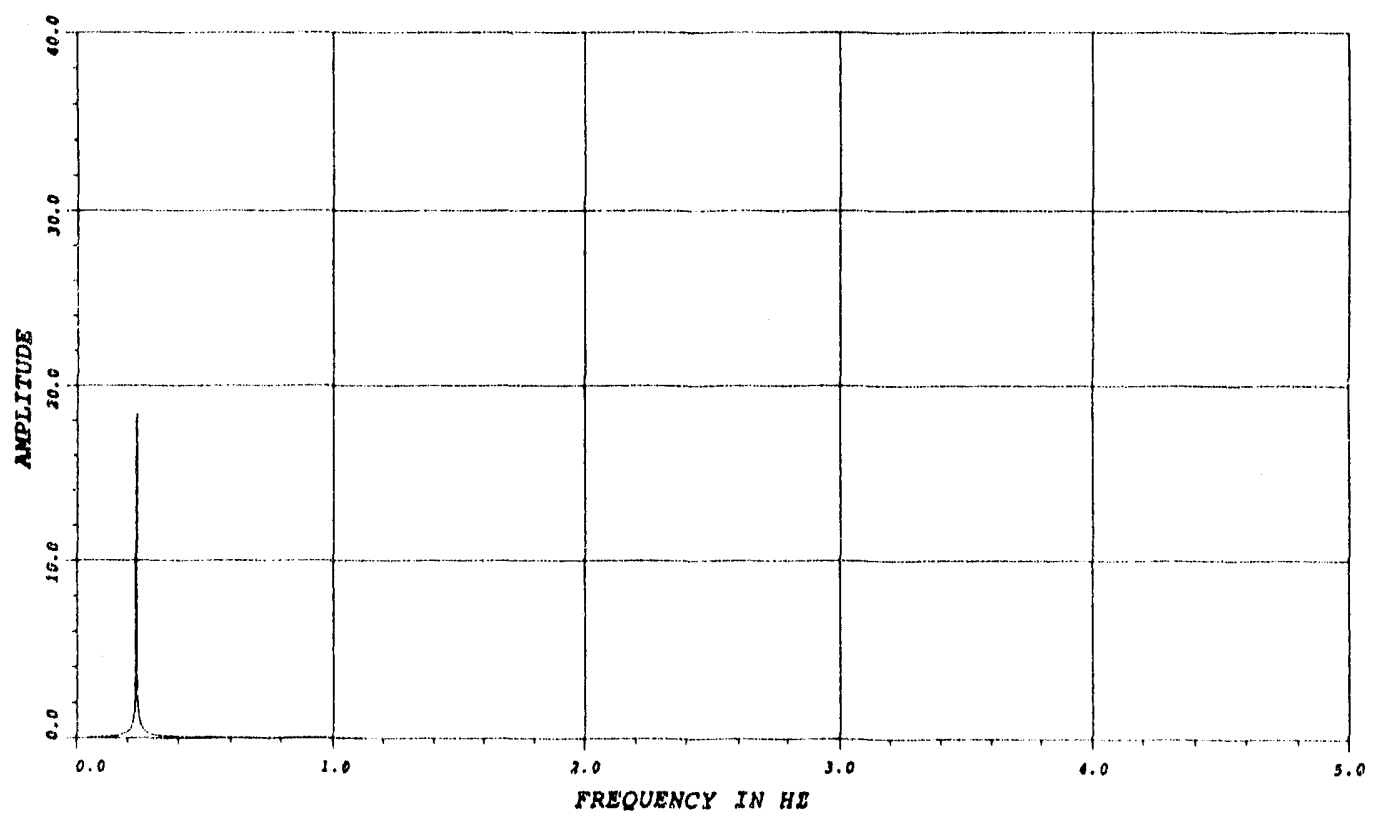

Ejg. 10. Sloshing Wave Height as a Function of Time at Node 131 of the Large Tank for the Case of $\mu=10,000 \mathrm{cP}$ Due to Resonant Harmonic Excitation with a Frequency of $0.233 \mathrm{~Hz}$ 
INPUTT ACCELERATION

TMAX,AMAX TMIN,AMIN $=3.70 \quad 92.6408 \quad 0.39 \quad-90.7787$

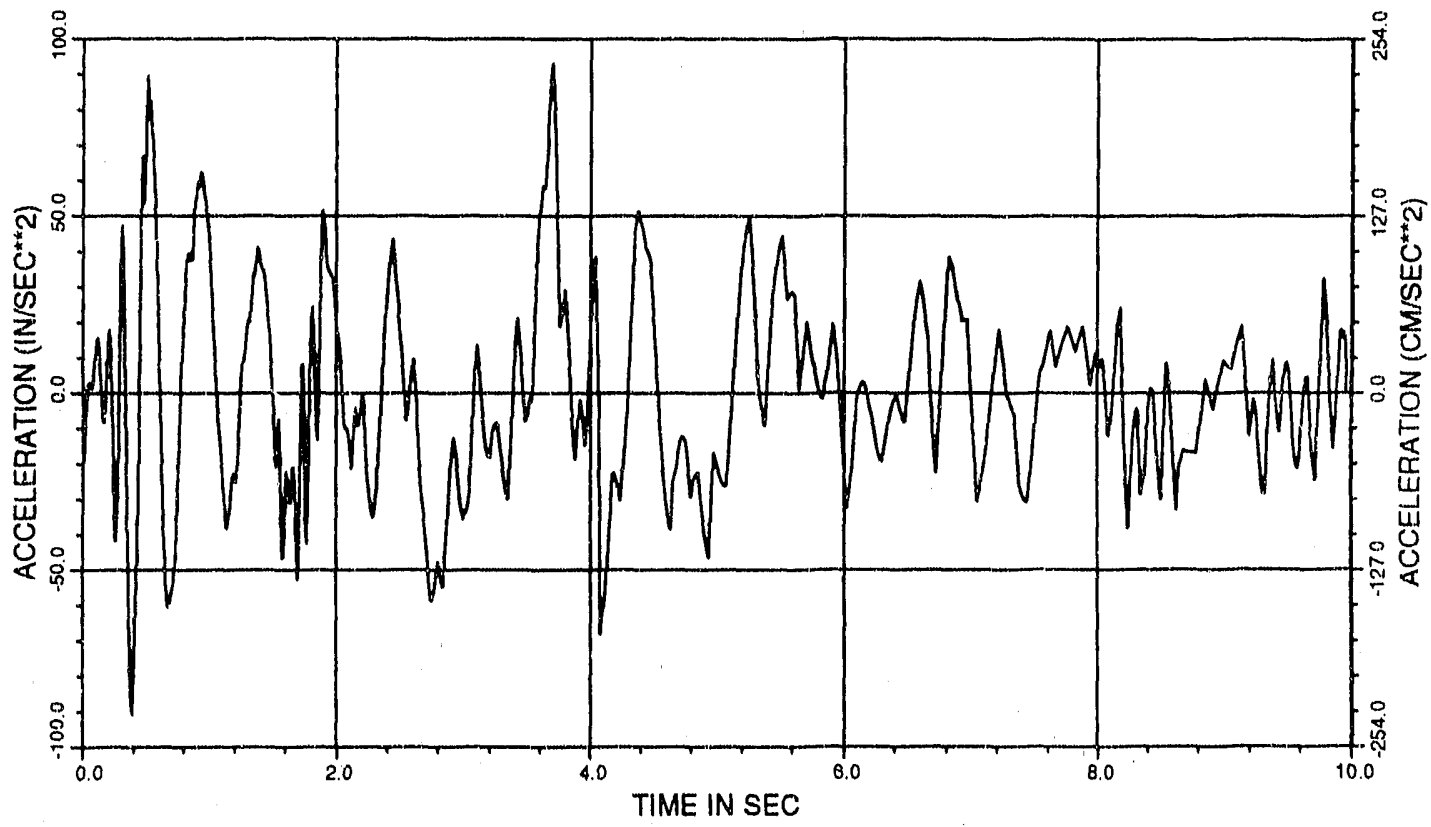

INPUT ACCELERATION

MAX, FREQUENCY,AMPLITUDE $=0,9020.8539$

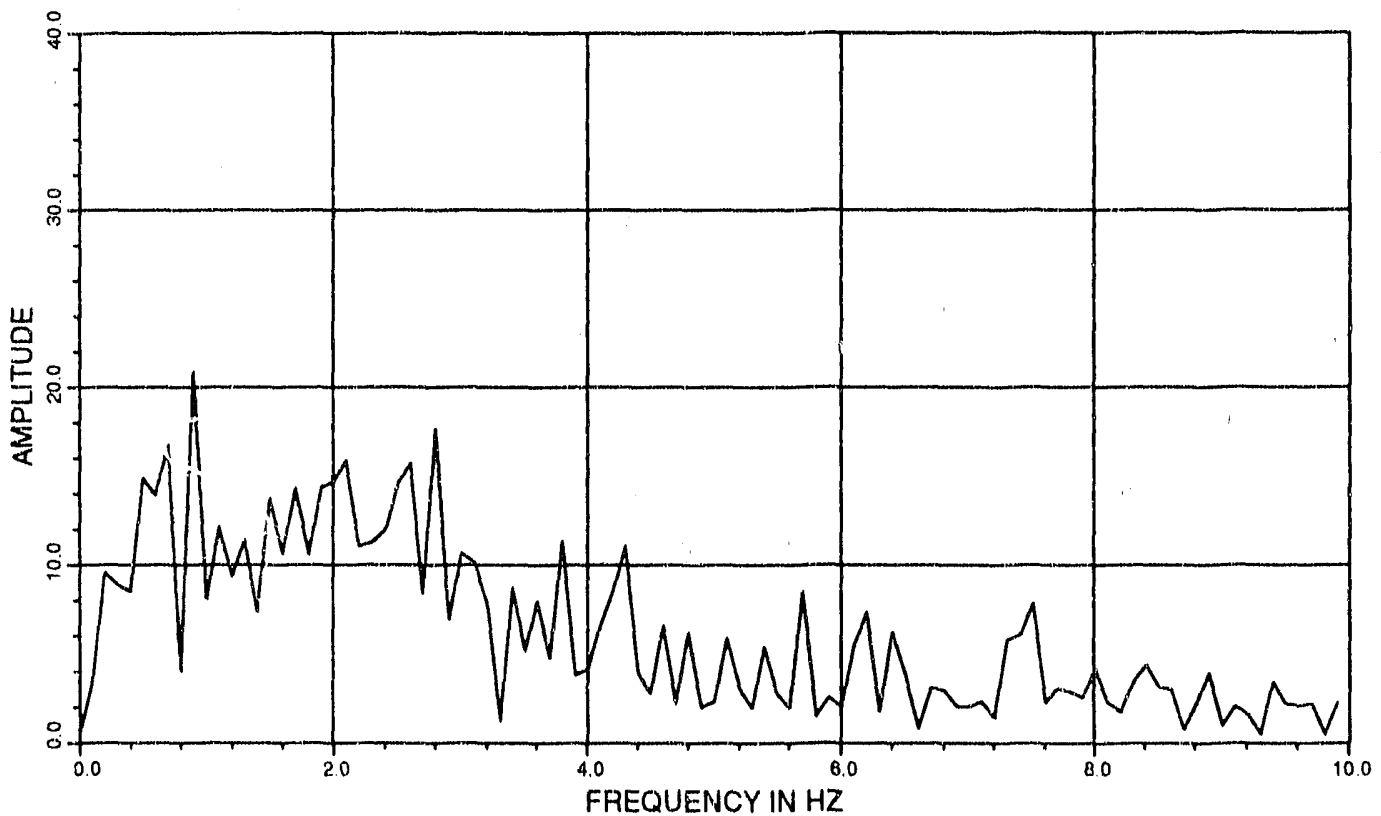

Fig. 11. Time History and FFT of Base Motion 1 


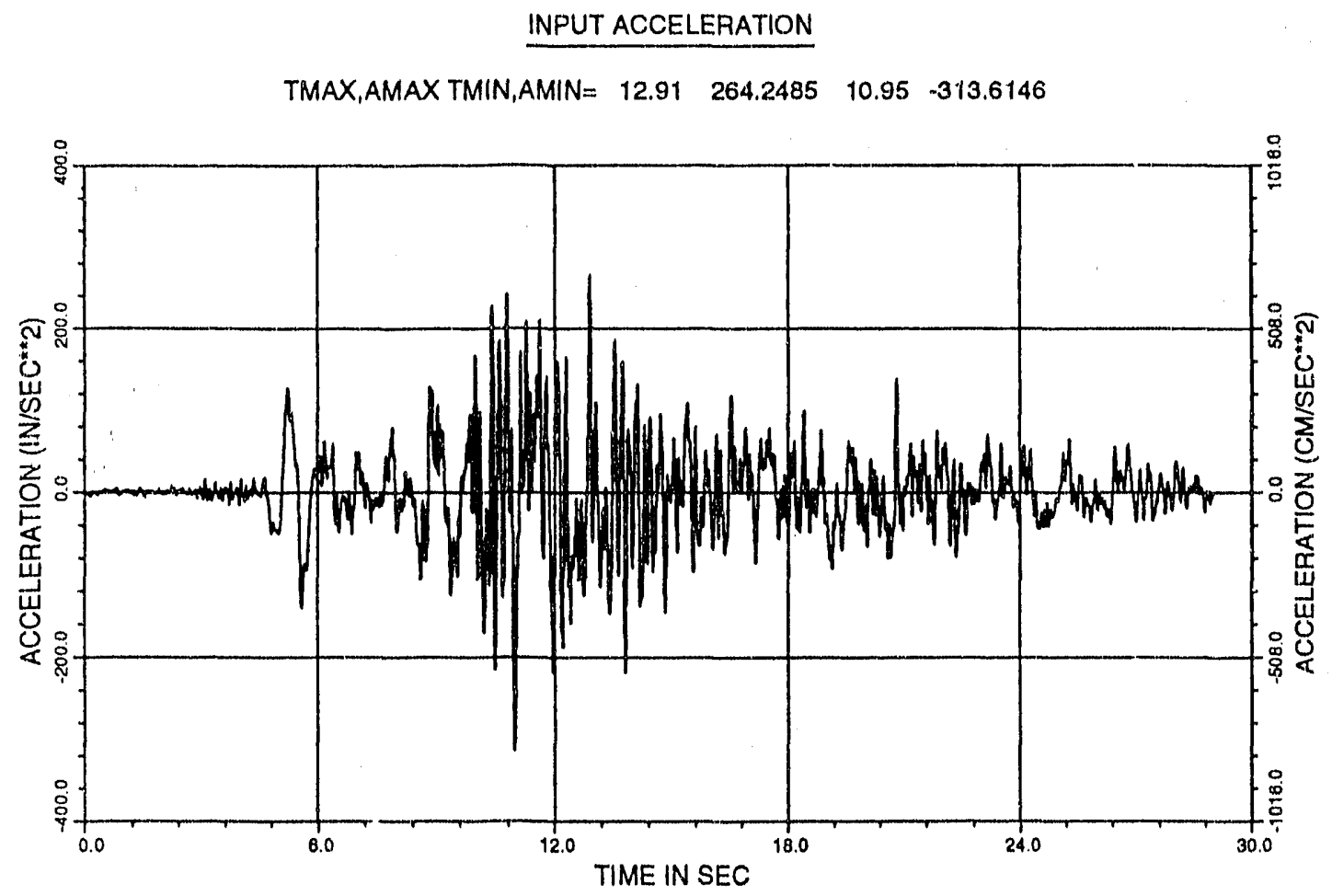

INPUT ACCELERATION

MAX. FREQUENCY,AMPLITUDE $=1.318 .7005$

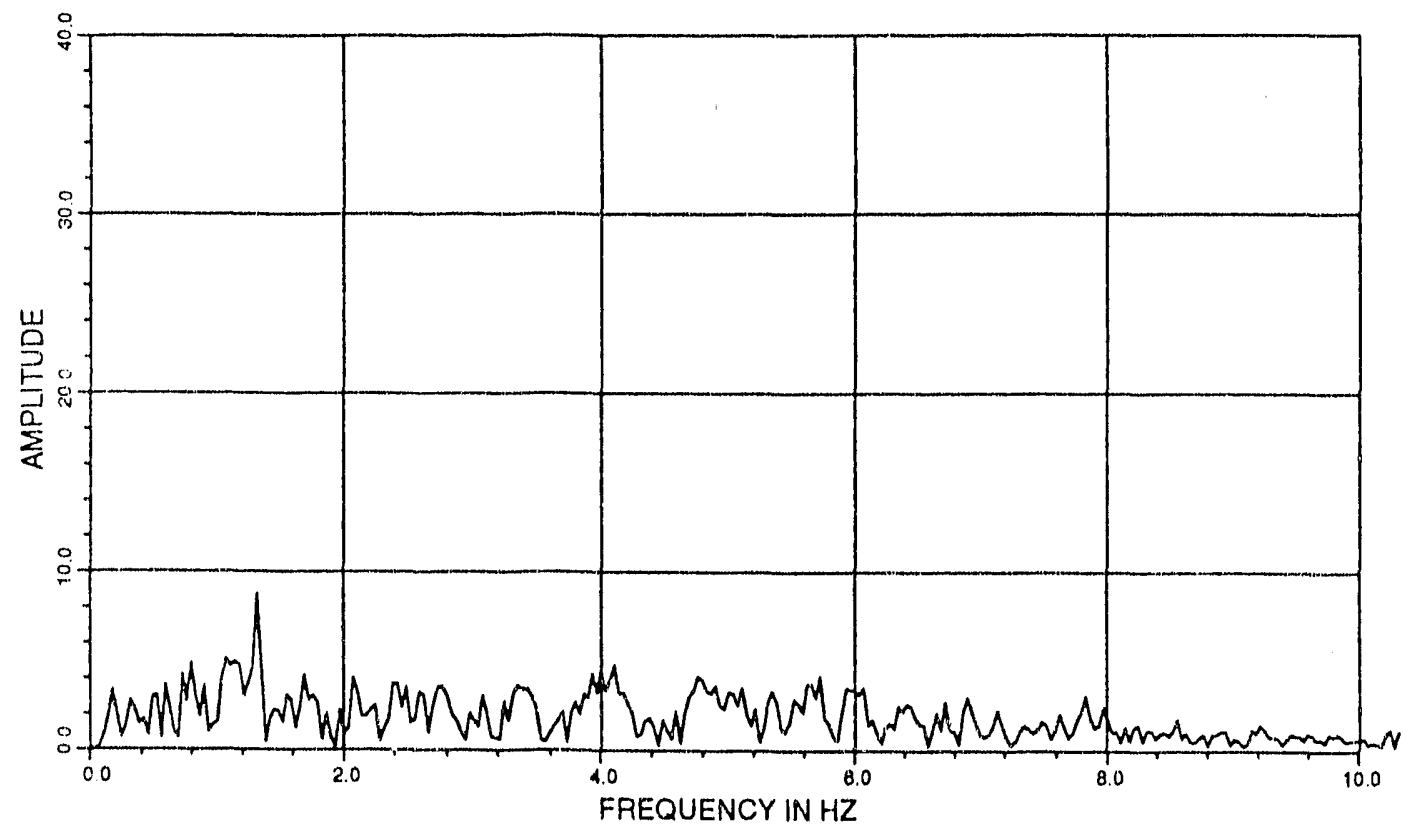

Fig. 12. Time History and FFT of Base Motion 2 
A-1

\section{APPENDIX A}

\section{Basic Equations and Solution Algorithm in FLUSTR Code}

\section{A.1 Governing Equations for p-V Formulation}

The behavior of a Newtonian, isothermal, compressible and viscid fluid is governed by the following set of equations:

Continuity Equation

$$
\frac{1}{\beta} p_{, t}+v_{k, k}=0 \quad \text { in } \Omega
$$

Momentum Equation

$$
\rho\left(v_{i, t}+v_{i, j} v_{j}\right)=-p_{, i}+\mu\left(v_{i, j}+v_{j, i}\right)_{, j}+b_{i} \quad \text { in } \Omega
$$

where $\beta=$ bulk modulus

$\rho=$ fluid mass density

$v=$ velocity

$\mathrm{p}=$ pressure

$\mu=$ dynamic viscosity

$b=$ body forces

Boundary conditions are:

$$
\begin{array}{ll}
v_{i}=g_{i} & \text { on } \Gamma^{g} \\
T_{i j} n_{j}=h_{i} & \text { on } \Gamma^{h}
\end{array}
$$

Initial condition is

$$
\mathrm{v}_{\mathrm{i}}=\mathrm{v}_{\mathrm{oi}} \quad \text { in } \Omega \text { at } \mathrm{t}=\mathrm{t}_{\mathrm{o}}
$$




\section{A-2}

$g_{i} ; h_{i} ; v_{o i}=$ given surface velocity, surface traction, initial condition

$\tau_{\mathrm{ij}} \quad=$ Cauchy stress tensor

$\Omega \quad$ = domain

$\Gamma \quad=$ surface (boundary)

In order to obtain the matrix governing equations, the weak forms of Eqs. (A-1) and (A-2) have to be established. Thus, Eq. (A-1) is multiplied by a pressure test function, $\delta p$, and integrated over the fluid domain to obtain the weak form of the continuity equation

$$
\int_{\Omega} \frac{1}{\beta} \delta p_{, t} d \Omega+\int_{\Omega} \delta p v_{k, k} d \Omega=0
$$

Similarly, the weak form of the momentum equation is established by multiplying Eq. (A-2) by a velocity test function, $\delta v_{i}$, and integrating over the domain

$$
\begin{aligned}
\int_{\Omega} \rho \delta v_{i}\left[v_{i, i}+v_{i, j} v_{j}\right] d \Omega= & -\int_{\Omega} \delta v_{i} p_{, i} d \Omega \\
& +\int_{\Omega} \mu \delta v_{i}\left[v_{i, j}+v_{j, i}\right]_{, j} d \Omega \\
& +\int_{\Omega} \delta v_{i} b_{i} d \Omega
\end{aligned}
$$

The divergence theorem is applied to Eq. (A-4) to cast the momentum equation into its proper form for a finite element analysis: 


\section{A-3}

$\int_{n} \rho \delta v_{i} v_{i, i} d \Omega+\int_{\Omega} \rho \delta v_{i} v_{i, j} v_{j} d \Omega=$

fluid mass term nonlinear convective term

$$
\begin{aligned}
& =\int_{\Omega} \delta v_{j, j} p d \Omega-\int_{\Omega} 2 \mu \delta v_{(i, j)} v_{(i, j)} d \Omega+\int_{\Omega} \delta v_{i} b_{i} d \Omega \\
& \text { pressure term } \quad \text { bodscosity term force term } \\
& +\int_{\Gamma^{b}} \delta v_{i} h_{i} d \Omega \\
& \text { surface traction term }
\end{aligned}
$$

\section{A.2 Finite Element Formulation}

A Lagrangian formulation is adopted in the development of the matrix governing equations. Three degrees-of-freedom per node are necessary to solve for fluid velocities whereas one value per element is adequate to represent the fluid pressure.

Velocity interpolation: 3 per node

$$
\begin{array}{lll}
v_{1}=\sum_{1=1}^{N E N} N_{1 i} v_{1} & N E N: & \text { number of nodes per element } \\
& N_{1:} & \text { interpolation functions } \\
& v_{1}: & \text { nodal velocity }
\end{array}
$$

Pressure interpolation: 1 per element

$\mathrm{p}$

After substituting the interpolation functions introduced above, the continuity equation becomes

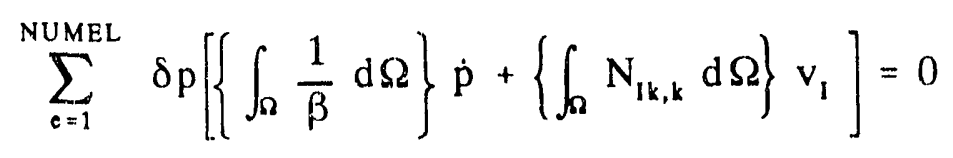


and the momentum equation takes the following form

$$
\begin{aligned}
& \sum_{e=1}^{N U M E L} \delta v_{1}\left[\left\{\int_{\Omega} \rho N_{11} N_{j 1} d \Omega\right\} \dot{v}_{J}-\left\{\int_{\Omega} N_{1 j, j} d \Omega\right\} p\right. \\
& +\left\{\int_{\Omega} 2 \mu N_{11, j} N_{j i, j} d \Omega\right\} v_{J}-\left\{\int_{\Omega} N_{11} b_{i} d \Omega\right\} \\
& \left.-\left\{\int_{p h} N_{11} h_{1} d \Gamma\right\}\right]=0
\end{aligned}
$$

where NUMEL is the total number of fluid elements in the mesh.

\section{A.3 Matrix Governing Equations}

After appropriate rearrangement of Eqs. (A-6) and (A-7), the matrix form of the continuity and momentum equations are obtained

$$
\begin{aligned}
& M^{p} \dot{p}+G^{T} \mathbf{v}=0 \\
& M^{\mathrm{F}} \dot{\mathbf{v}}+K_{\mu} \mathbf{v}-\mathbf{G} \mathbf{p}=\mathbf{f}
\end{aligned}
$$

where a superposed " $\mathrm{T}$ " denotes the transpose of a matrix, and

$$
\begin{aligned}
& \mathbf{M}^{\mathrm{p}}=\int_{\Omega} \frac{1}{\beta} \mathrm{d} \Omega \\
& \mathbf{G}^{\mathrm{T}}=\int_{\Omega} \mathbf{N}_{\mathbf{k}, \mathbf{k}} \mathrm{d} \Omega \\
& \mathbf{M}^{\mathbf{F}}=\int_{\Omega} \rho \mathbf{N}^{\mathrm{T}} \mathbf{N} \mathrm{d} \Omega \\
& \mathbf{K}_{\mathbf{m}}=\int_{\Omega} 2 \mu \mathbf{N}_{, j}^{\mathrm{T}} \mathbf{N}_{, J} \mathrm{~d} \Omega \\
& \mathbf{f}=+\int_{\Omega} \mathbf{N}^{\mathrm{T}} \mathbf{b} \mathrm{d} \Omega+\int_{\mathrm{r}^{\mathrm{T}}} \mathbf{N}^{\mathrm{T}} \mathbf{h} \mathrm{d} \Gamma
\end{aligned}
$$

Note the viscosity term $\mathbf{K}_{\mu} \mathbf{v}$ is explicitly integrated in the computer code. 
The fluid equations, Eqs. (A-8) and (A-9), are combined with the structural governing equation to complete the set of fluid-structure governing equations

$$
\begin{aligned}
& M^{p} \dot{p}+G^{T} v=0 \\
& M^{p} \dot{v}-G p=f-K_{\mu} v \\
& M^{s} a+C^{s} v+K^{s} d=f^{s}
\end{aligned}
$$

where the superposed "s" denotes structural quantities.

\section{A.4 Solution Algorithm}

The standard Newmark time integration scheme is employed in the solution procedure. This predictor-corrector algorithm consists of two sets of equations

$$
\begin{aligned}
& \text { predictor: } \quad \tilde{d}_{n+1}=d_{n}+\Delta t \mathbf{v}_{n}+\left(\frac{1}{2}-\beta\right) \Delta t^{2} a_{n} \\
& \tilde{\mathbf{v}}_{\mathrm{n}+}=\mathbf{v}_{\mathrm{n}}+(1-\gamma) \Delta \mathrm{t} \mathbf{a}_{\mathrm{n}} \\
& \tilde{\mathbf{p}}_{\mathrm{n}+1}=\mathbf{p}_{\mathrm{n}}+(1-\alpha) \Delta t \dot{\mathrm{p}}_{\mathrm{n}} \\
& \text { corrector: } \quad d_{n+1}=\tilde{d}_{n+1}+\beta \Delta t^{2} a_{n+1} \\
& v_{n+1}=\tilde{v}_{n+1}=\gamma \Delta t a_{n+1} \\
& p_{n+1}=\tilde{p}_{n+1}+\alpha \Delta t \dot{p}_{n+1}
\end{aligned}
$$

where $\alpha, \beta$ and $\gamma$ are time integration parameters; $\Delta t$ is the time step; $d_{n}, v_{n}, a_{n}$ and $p_{n}$ are the approximations at $d\left(t_{n}\right), \dot{d}\left(t_{n}\right), \ddot{d}\left(t_{n}\right)$ and $p\left(t_{n}\right)$, respectively; $t_{n}$ denotes the current time.

The corrector formulas are substituted into Eqs. (A-10) and rearranged to yield

$$
\begin{aligned}
& M^{p} \dot{\mathbf{p}}_{n+1}+\gamma \Delta t \mathbf{G}^{\mathrm{T}} \mathbf{a}_{\mathrm{n}+1}=-\mathbf{G}^{\mathrm{T}} \tilde{\mathbf{v}}_{\mathrm{n}+1} \\
& \mathbf{M}^{\mathbf{F}} \mathbf{a}_{n+1}=\alpha \Delta t \mathbf{G} \dot{\mathbf{p}}_{n+1}+\mathbf{G} \tilde{\mathbf{p}}_{\mathrm{n}+1}+\mathbf{f}_{\mathrm{n}+1}^{\mathbf{F}} \\
& \left(\mathbf{M}^{s}+\gamma \Delta t \mathbf{C}^{s}+\beta \Delta t^{2} \mathbf{K}^{s}\right) \mathbf{a}_{n+1}=\mathbf{f}_{n+1}^{s}-\mathbf{C}^{s} \tilde{\mathbf{v}}_{n+1}-\mathbf{K}^{s} \tilde{\mathbf{d}}_{n+1}
\end{aligned}
$$


All fluid and structural degrees-of-freedom can be assembled into a single equation (Eqs. (A-12) and (A-13))

$$
B a_{a+1}=f_{a+1}^{*}+\alpha \Delta t G \dot{p}_{a+1}
$$

where the generalized mass matrix and the generalized force vector are defined is

$$
\begin{aligned}
& \mathbf{E}=\left(\mathbf{M}^{\mathbf{\prime}}+\gamma \Delta \mathbf{t}^{\mathbf{\prime}}+\beta \Delta \mathbf{t}^{2} \mathbf{K}^{\prime}\right)+\mathbf{M}^{\mathbf{F}} \\
& f_{n+1}^{*}=f_{n+1}^{f}+f_{n+1}^{z}+G \tilde{p}_{n+1}-C^{\prime} \tilde{v}_{n+1}-K^{\prime} \tilde{d}_{n+1}
\end{aligned}
$$

After $\mathbf{a}_{n+1}$ is solved in Eq. (14), it is substituted into Eq. (11) to solve for $\dot{\mathbf{p}}_{\mathbf{n}+1}$, i.e.

$$
\left(M^{p}+\alpha \gamma \Delta t^{2} G^{T} B^{-1} G\right) \dot{p}_{n+1}=-\gamma \Delta t G^{T} a_{a+1}^{*}-G^{T} \tilde{\mathbf{v}}_{\mathbf{z}+1}
$$

where

$$
a_{n+1}^{*}=B^{-1} f_{n+1}^{*}
$$

In Eq. (A-16) $\mathbf{M}^{p}$ is generally diagonal (lumped mass), however, $\mathbf{G}^{\top} \mathbf{B}^{-1} \mathbf{G}$ is a full matrix. Consequently, solving for $\dot{\boldsymbol{p}}_{\mathrm{a}, 1}$ in this furm becomes too costly and requires huge storage. Therefore, an approximation for $\mathbf{B}^{-1}$ can be introduced

$$
\mathbf{B}^{-1} \sim \mathbf{M}^{-1}+\text { (higher order terms) }
$$

Remarks: (i) This algorithm is $\Delta \mathrm{t}^{3}$ - accurate.

(ii) The approximation in Eq. (A-18) is used only in evaluating element pressures. The nodal accelerations are solved from Eq. (A-14) by using the original B matrix. 
B-1

\section{APPENDIX B \\ Comparison of FLUSTR Code Predictions with Experimental Data}

\section{B.1 Code Validation}

The FLUSTR-ANL computer code has been extensively validated by using the experimental data obtained from sloshing tests [5] conducted in 1984-87 by EPRI and CRIEPI. The objectives of the sloshing tests are: (1) to gain an improved understanding of the basic sloshing phenomena in a pool-type LMR which has many deck-mounted components that are submerged in a large pool of sodium, and (2) to validate the ANL-developed computer code, FLUSTR-ANL, by comparing the code predictions with experimental results.

The test model, $7.3 \mathrm{ft} .(2230 \mathrm{~mm})$ in diameter, is a $1 / 10$-scale model designed to simulate the hot plenum section of a pool-type LMFBR reactor. The bottom half of the reactor (i.e. the portions below the horizontal redan) was excluded from the design of the model, on the basis of the understanding that the cold pool has little effect on the sloshing phenomena of the hot sodium pool. The test model has all the major deck-mounted components contained in the reference pool reactor vessel, four IHXs, four primary pumps, the UIS and a thermal baffle. To quantitatively evaluate the effects of the deck-mounted components and thermal baffle on sloshing behaviors, the following five model configurations were mainly considered as geometrical parameter:

- Configuration 1: reactor tank without components and thermal baffle

- Configuration 2; reactor tank with components but without thermal baffle

- Configuration 3: reactor tank with thermal baffle but without components

- Configuration 4: reactor tank with components and thermal baffle

- Configuration 5: configuration 4 with water included in the annulus between the vessel and thermal baffle

Vibrational tests (sine sweeps, resonant sinusoidal waves, superimposed sine waves) and El Centro ground excitations were performed to determine the dynamic characteristics of the sloshing motion in the LMR tank under earthquake-simulated loadings. Wave heights, pressure, strain, displacement and acceleration were measured. 


\section{B-2}

Numerical simulations were performed by using ANL-developed computer code, FLUSTR-ANL. The numerical simulations were divided into two items: the pre-test predictions and the post-test analysis. The pre-test calculations were conducted to: (1) provide guidance in design of the test articles, and (2) to attempt to analytically predict the expected sloshing behavior. The post-test simulation was performed to validate the FLUSTR-ANL computer code. Detailed results of the post-test analyses are given in Ref. [5].

The following material is taken directly from Ref. 5 . 
Test model structure

(Vertical section of the test model)

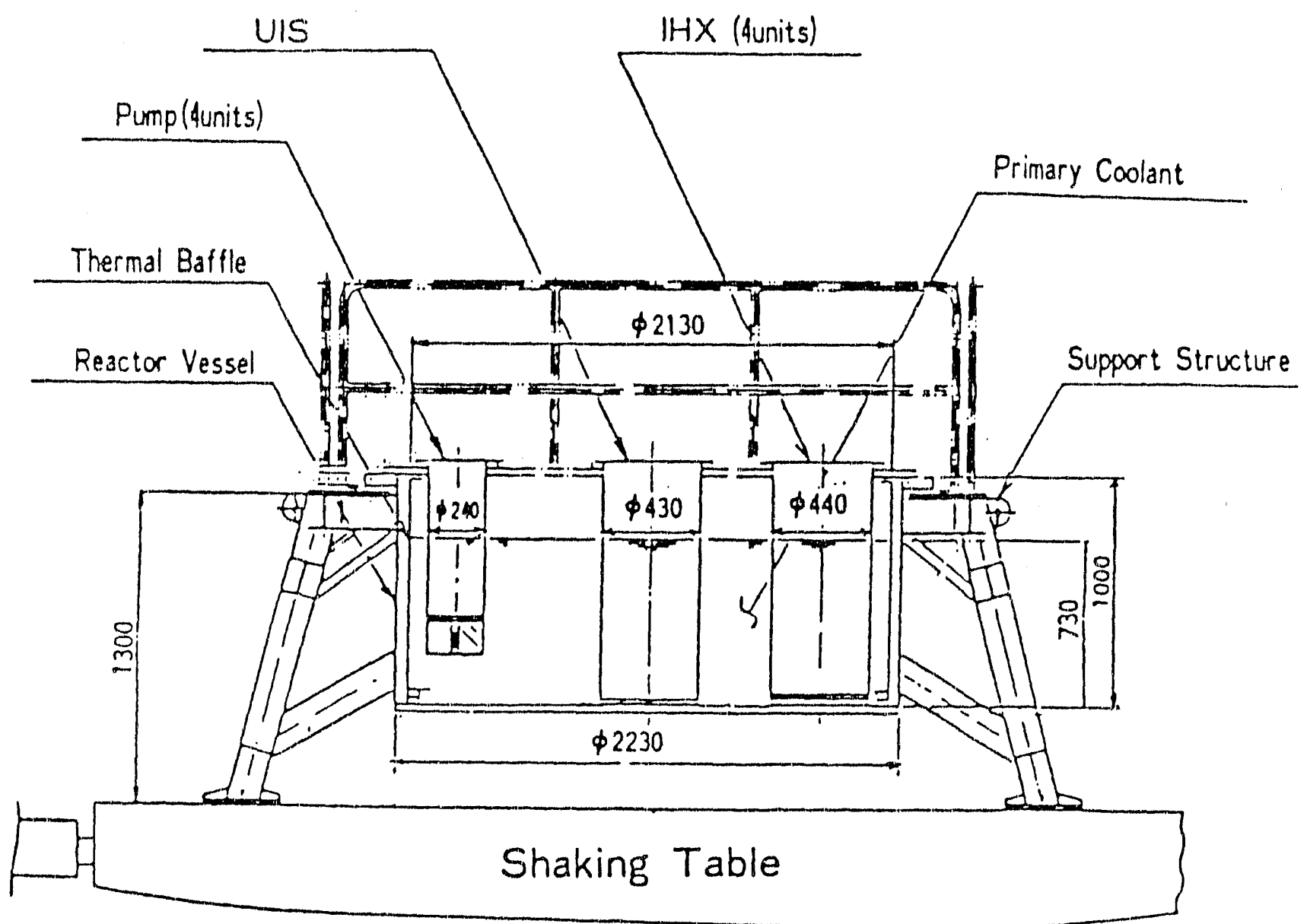

DIMENSIONS : $2.2 \mathrm{~m}$ (Diameter) $\times 1.0 \mathrm{~m}$ (Height)

SCALE $: 1 / 10$ scale of reference reactor structure

WEIGHT : 8 Ton (Including water: 2Ton) 


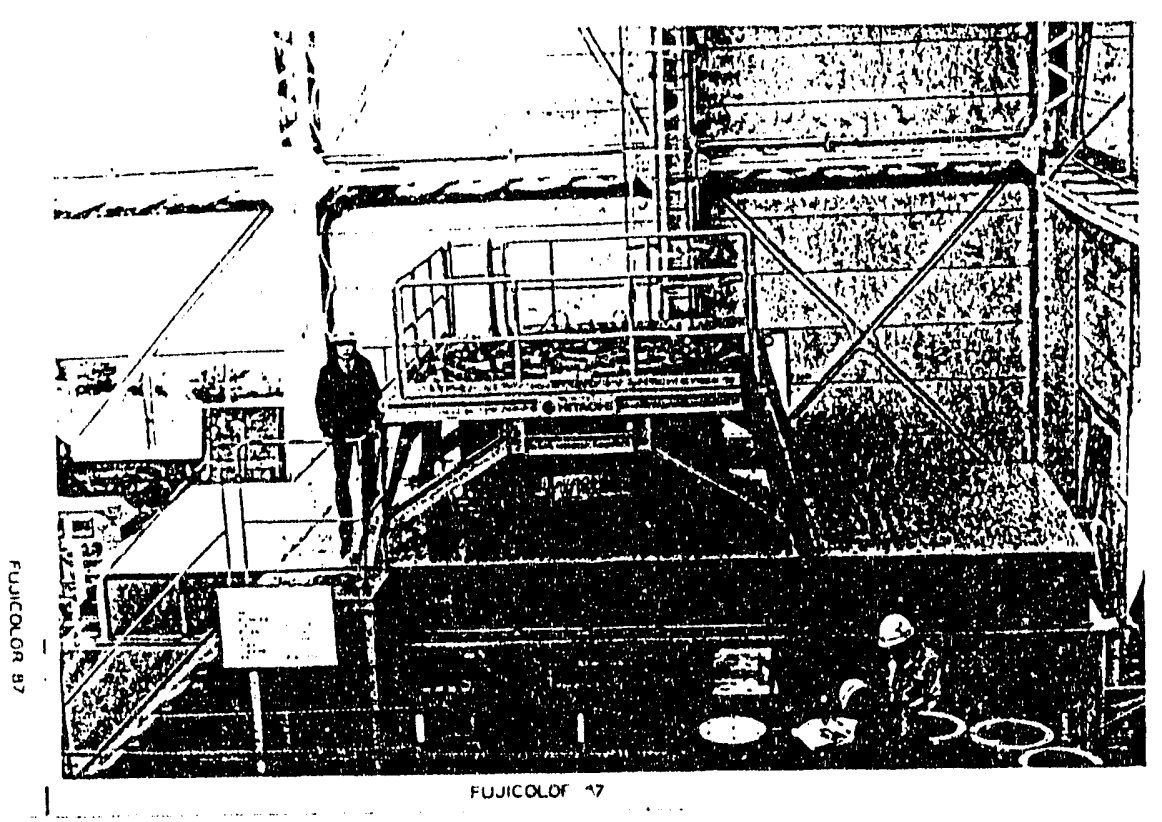

The photograph shows the sloshing test model and one dimensional long period shaking table.

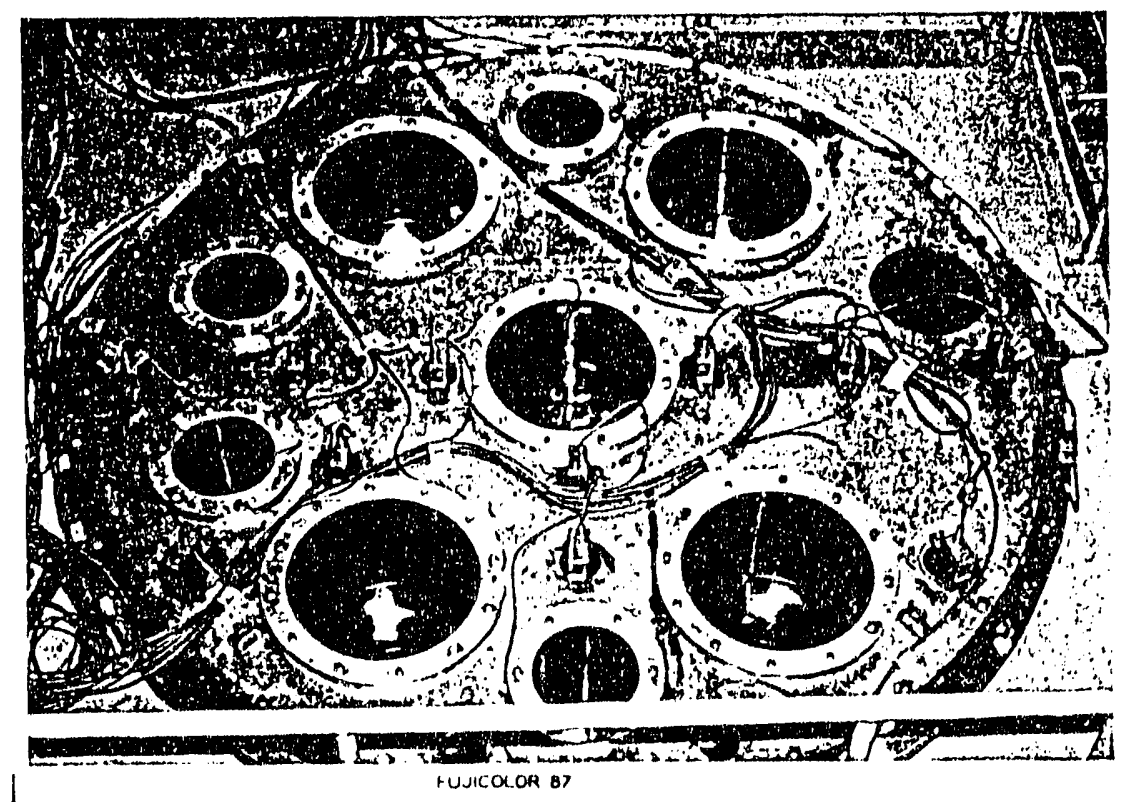

The photograph shows the plan view of test model (test configuration 4 , Direction A)

Configuration 4 is a flexible thermal baffle with internals (IHXs, Pumps and UIS) and water. 
Test Model Configuration

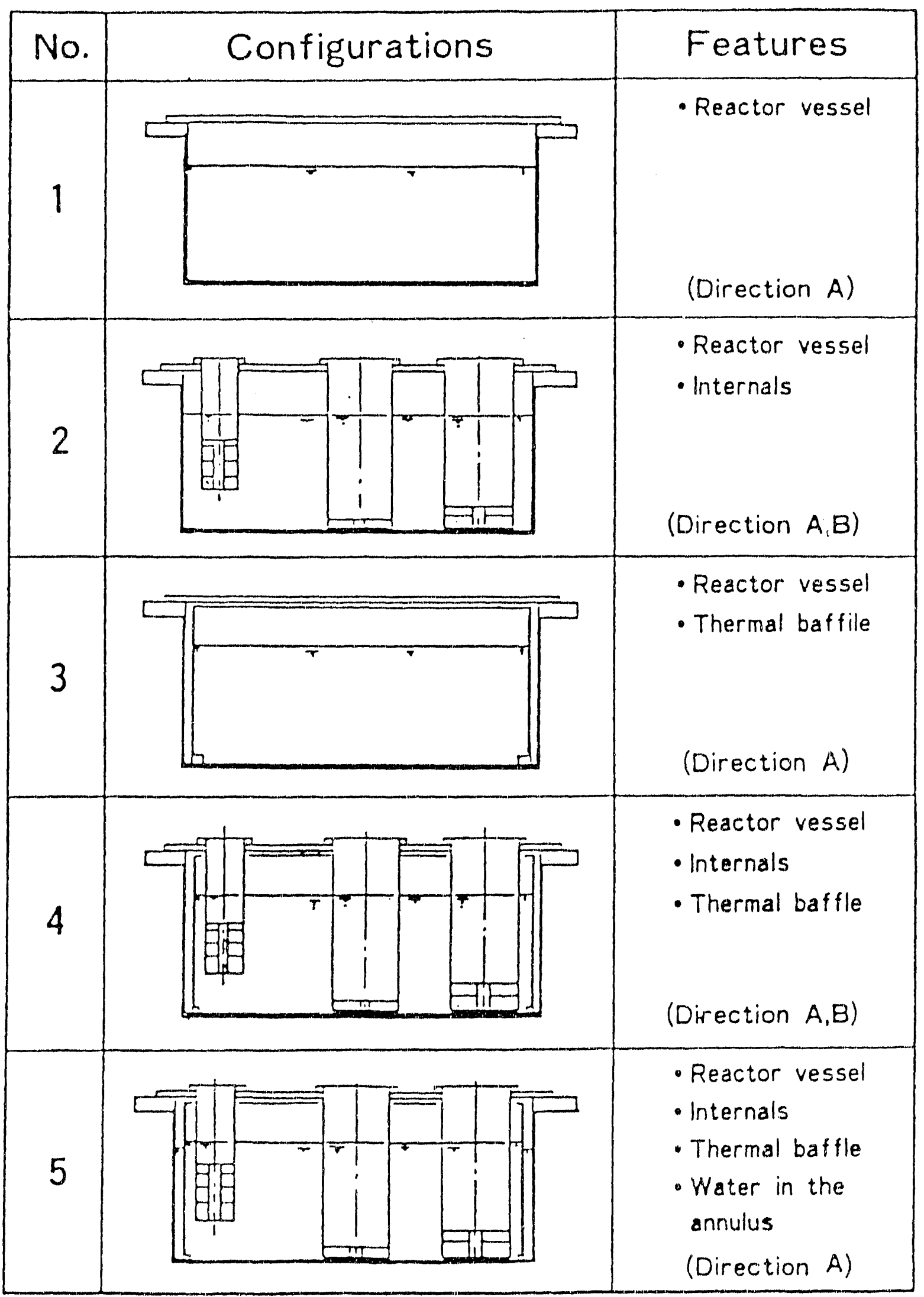




\section{EL-CENTRO 100 GAL FROM COMO R2401.ACC9X TIME HISTORY}

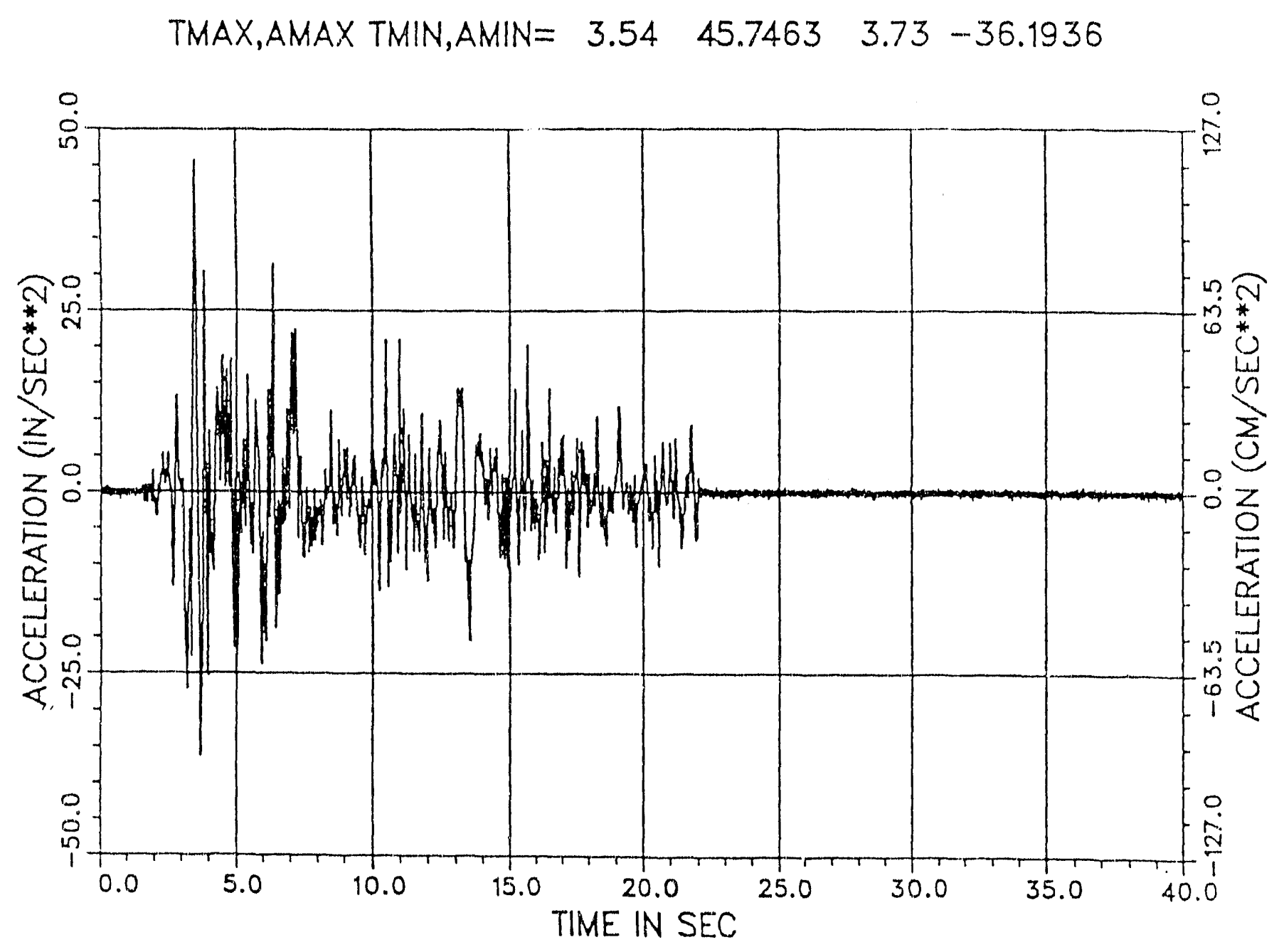

Fig. B-4. Input Acceleration Time History of Mathematical Model of Configuration 1 


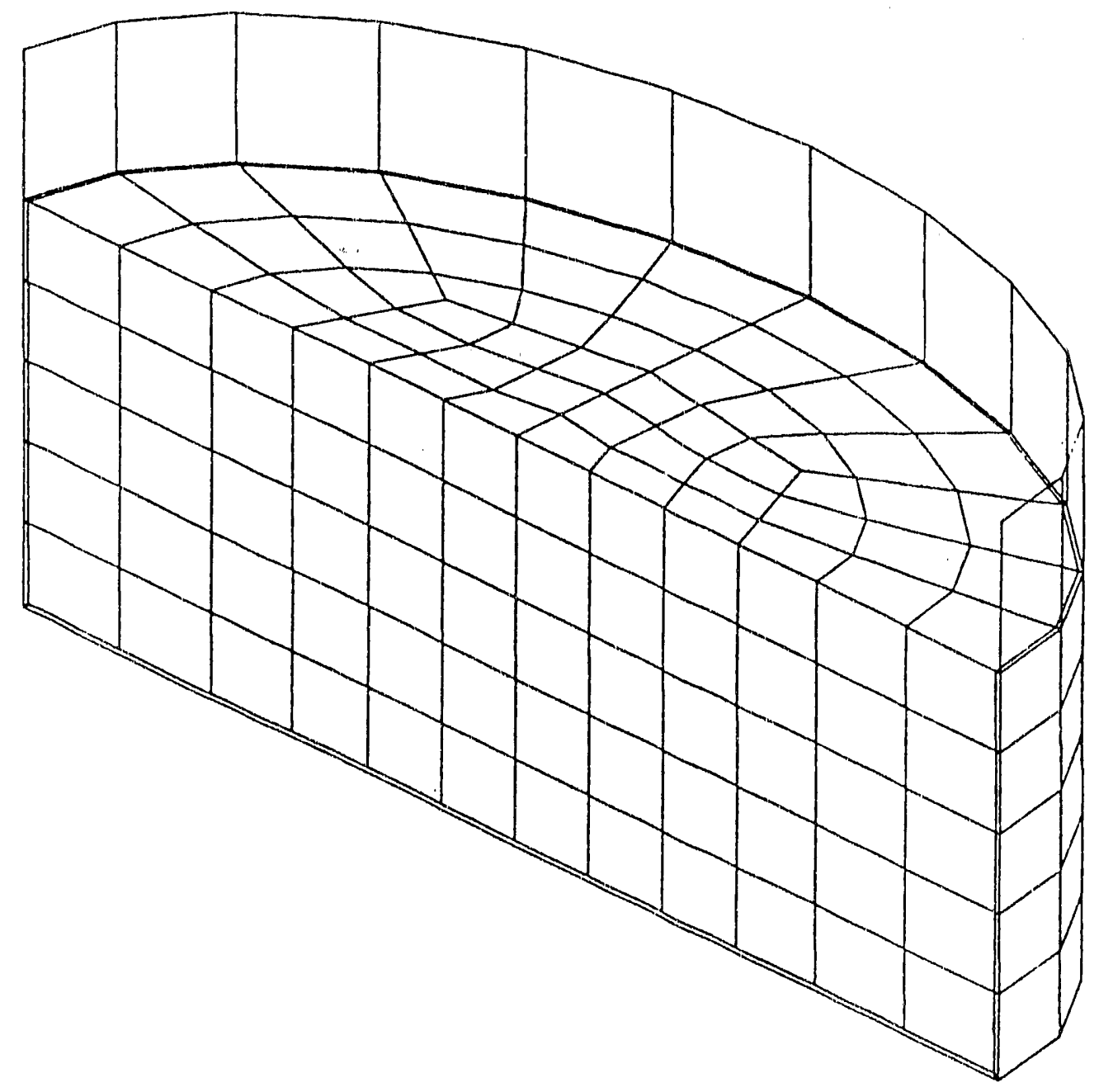

Fig. B-5. Mathematical Model of Configuration 1 


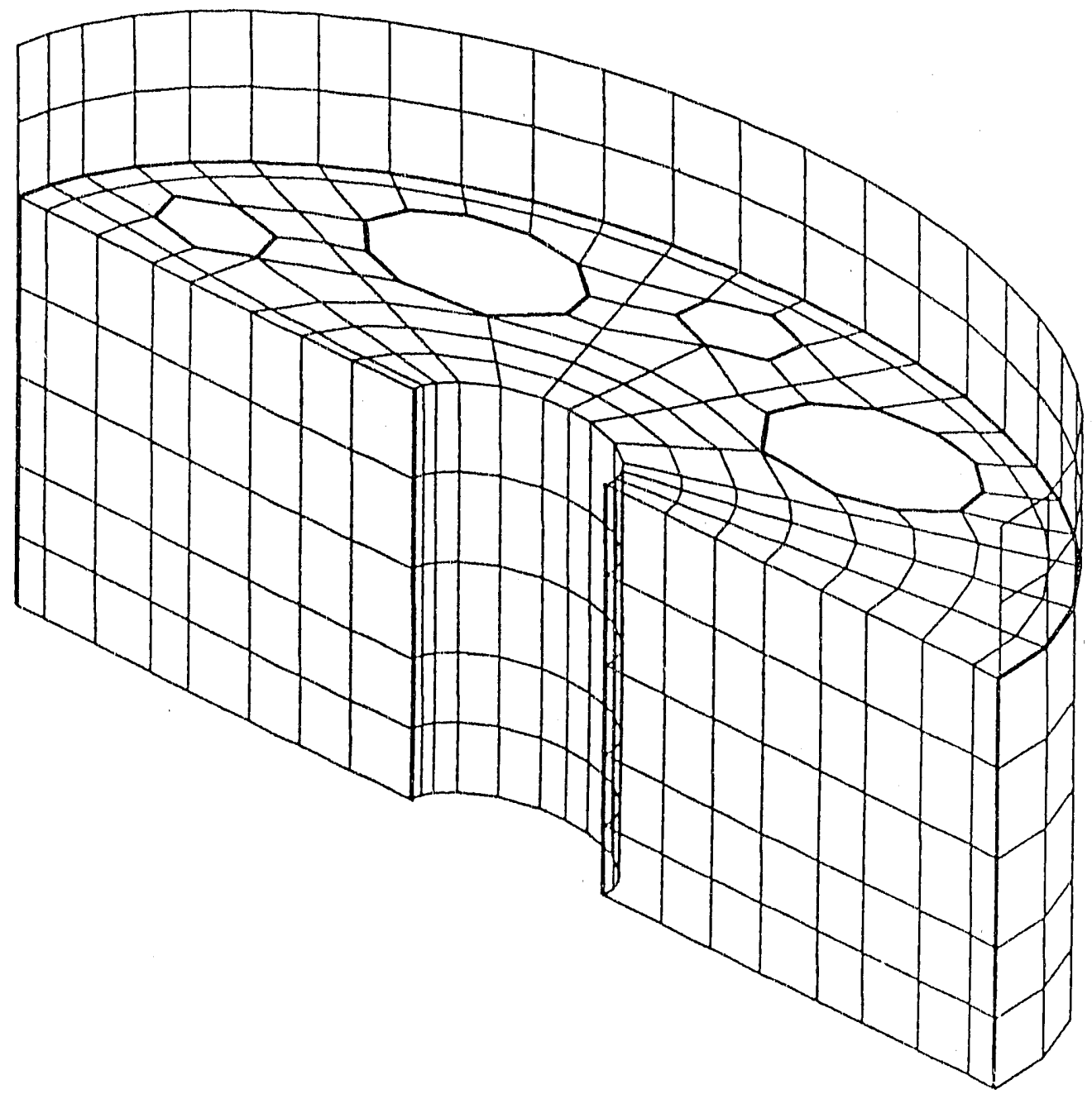

Fig. B-6. Mathematical Model of Configuration 2 


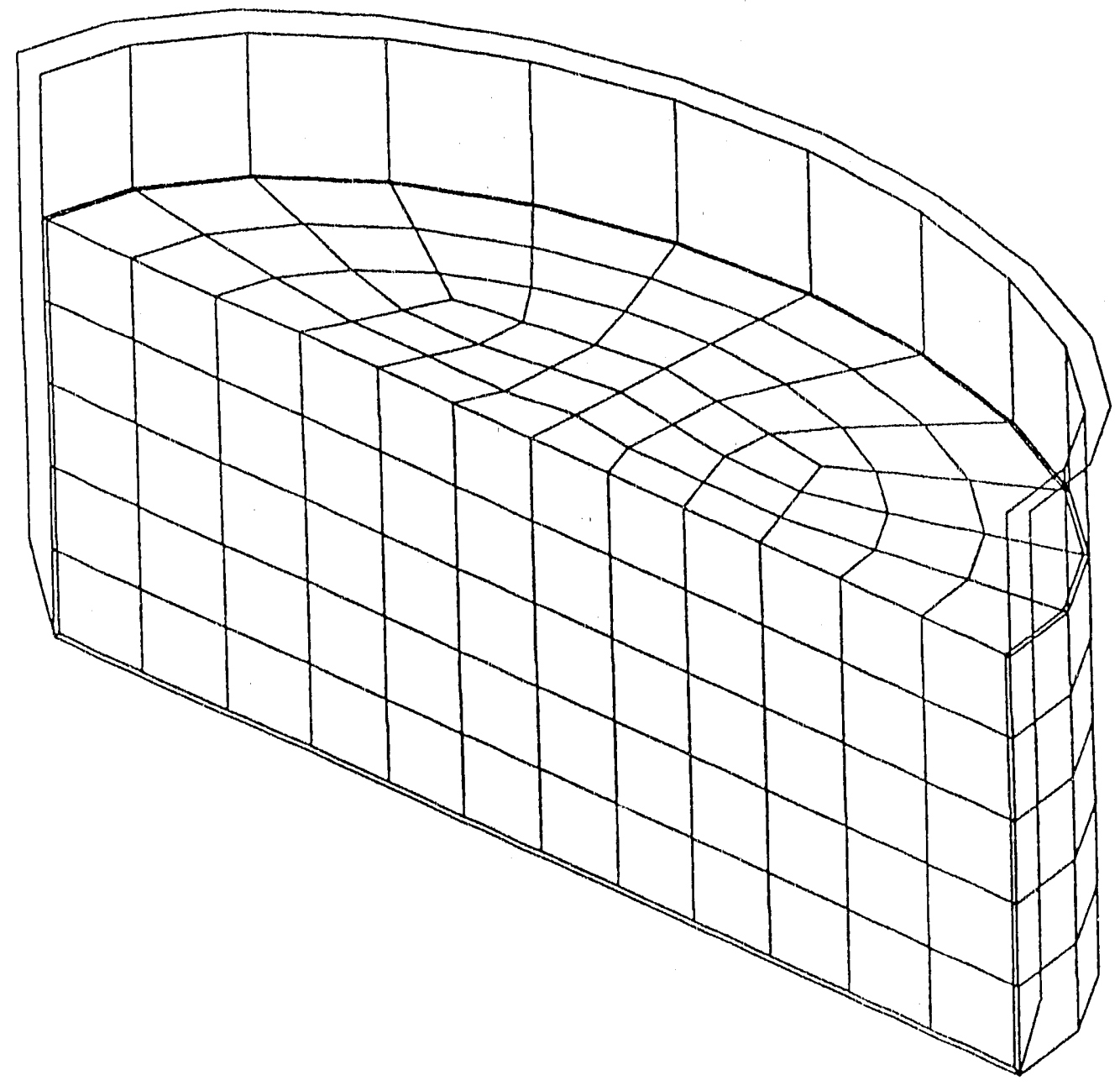

Fig. B-7. Mathematical Model of Configuration 3 


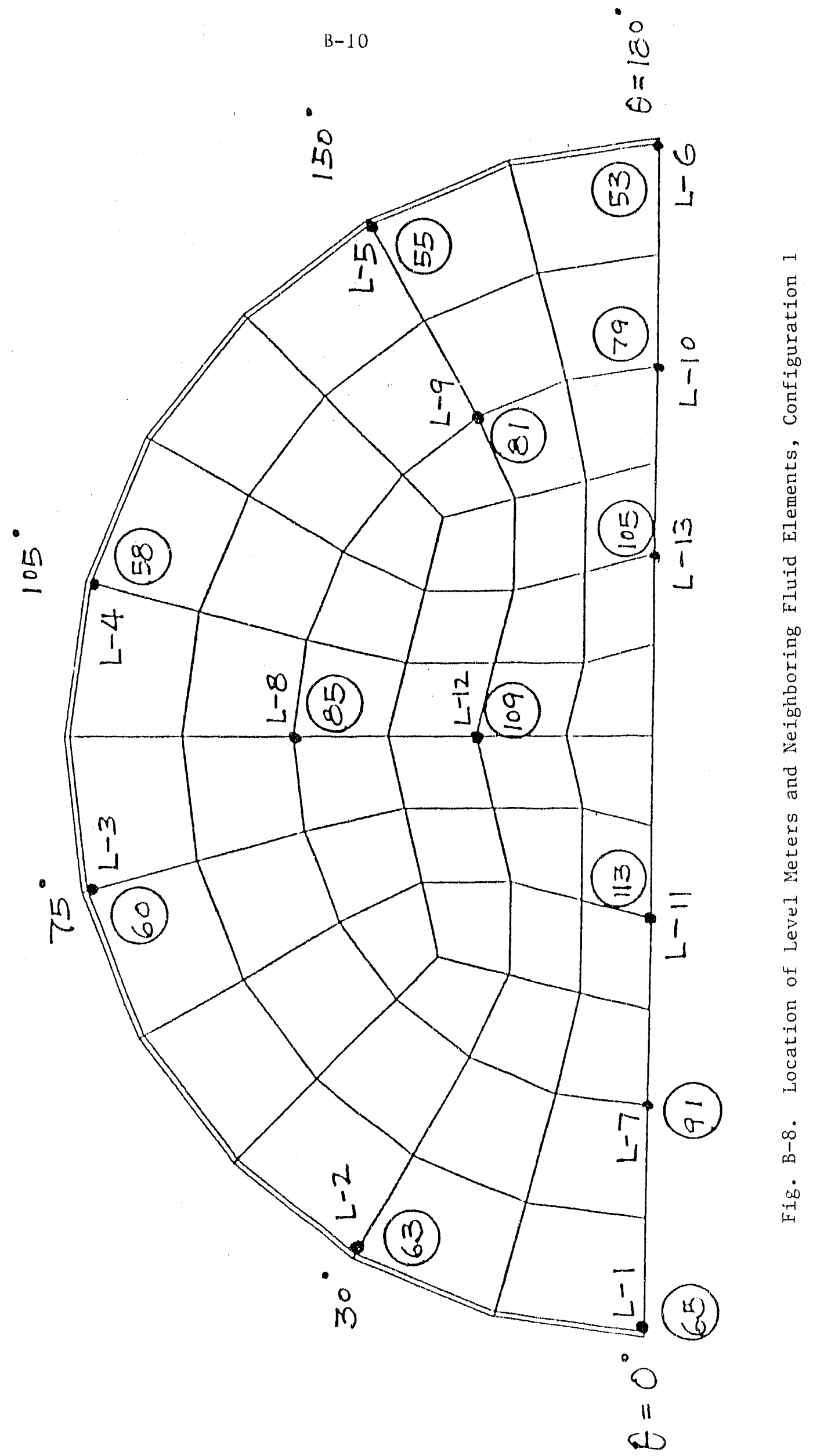


R2401 (100 GAL ELCENTRO), L-1 ( O DEGREE BY TANK WALL)

TMAX, AMAX TMIN,AMIN $=27.36 \quad 4.8332 \quad 21.37-3.9929$

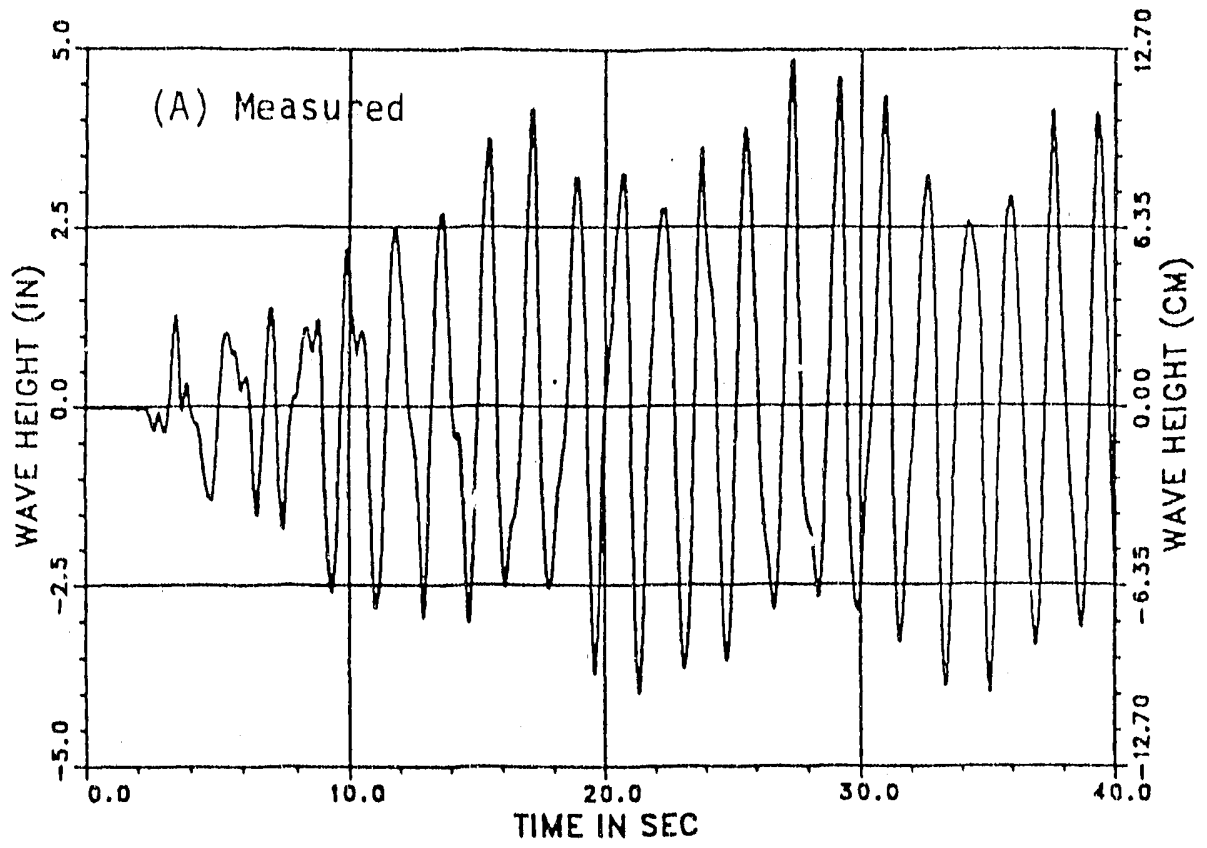

FL-37,2401 (100 GAL EL-CENTRO),NODE 65-LI ( O DEG.)

TMAX, AMAX TMIN,AMIN $=23.92 \quad 3.9416 \quad 21.38-4.2252$

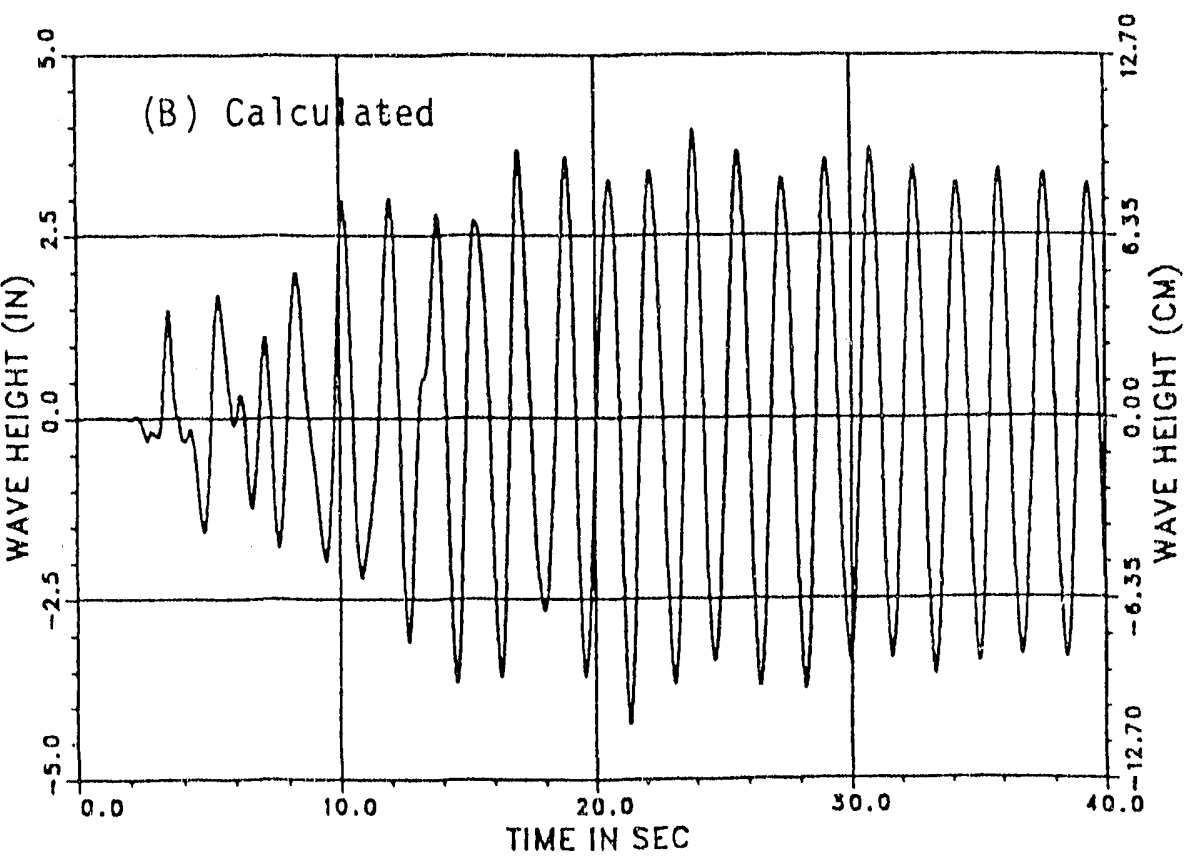

Fig. B-9. Comparison of Measured and Computed Wavi Height Time History at $L-1$ of Configuration 1 
R2401 (100 GAL ELCENTRO) , L-1 ( O DEGREE BY TANK WALL)

MAX. FREQUENCY,AMPLITUDE $=0.58 \quad 1.0446$

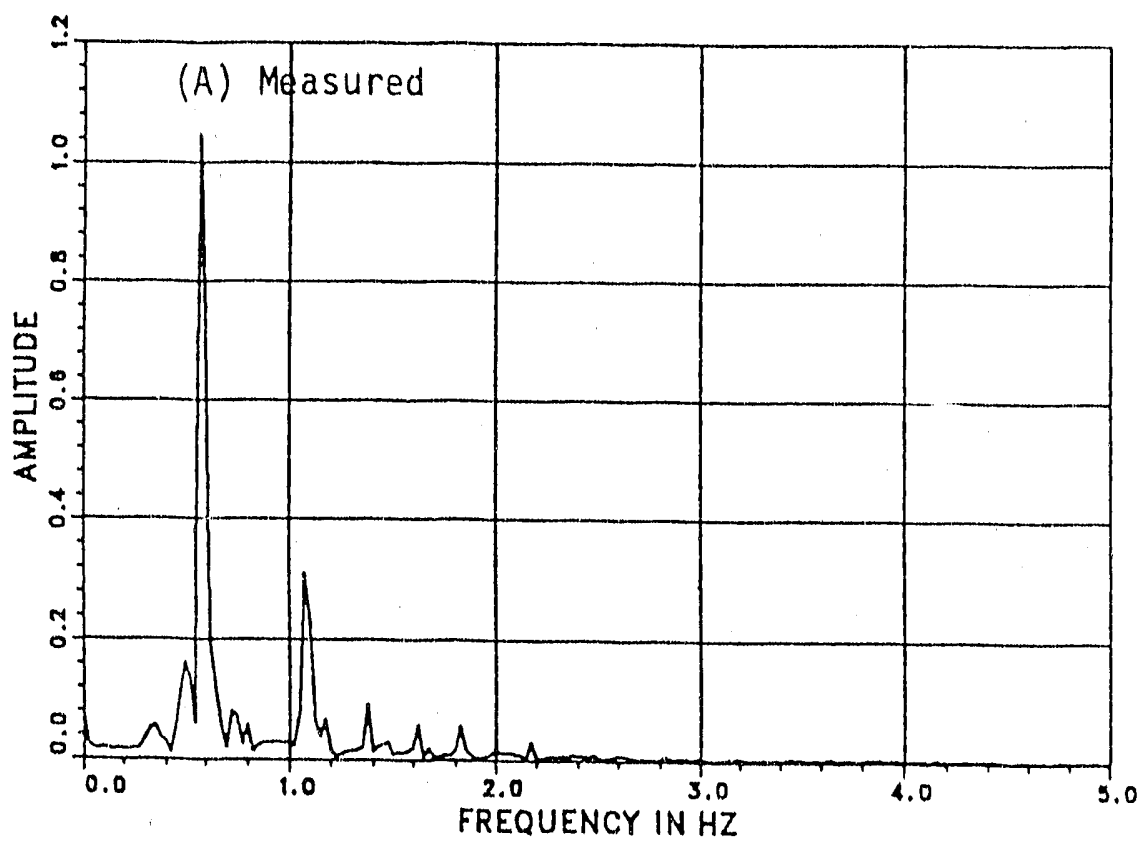

FL-37.2401 (100 GAL EL-CENTRO),NODE 65-L1 ( O DEG.) MAX. FREQUENCY,AMPLITUDE $=0.58 \quad 1.1084$

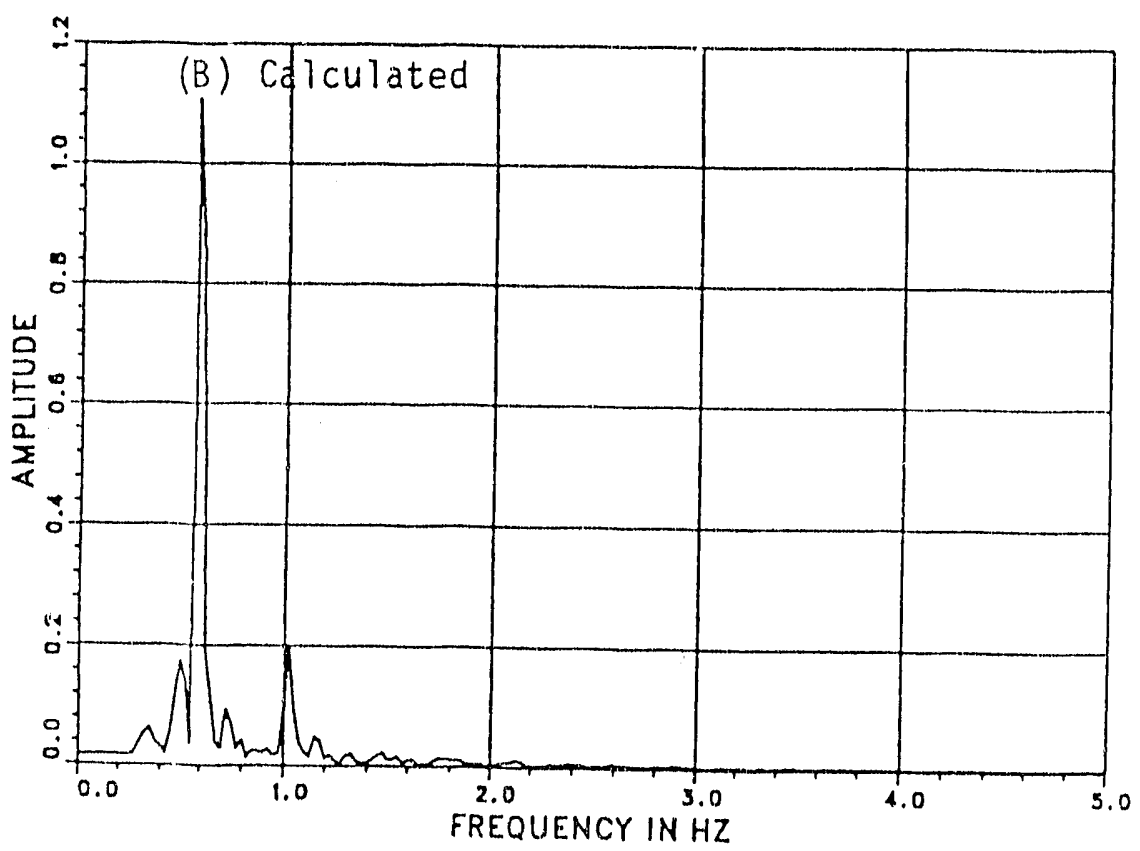

Fig. B-10. Comparison of Measured and Computed FFT of Wave Height at L-1 of Configuration 1 

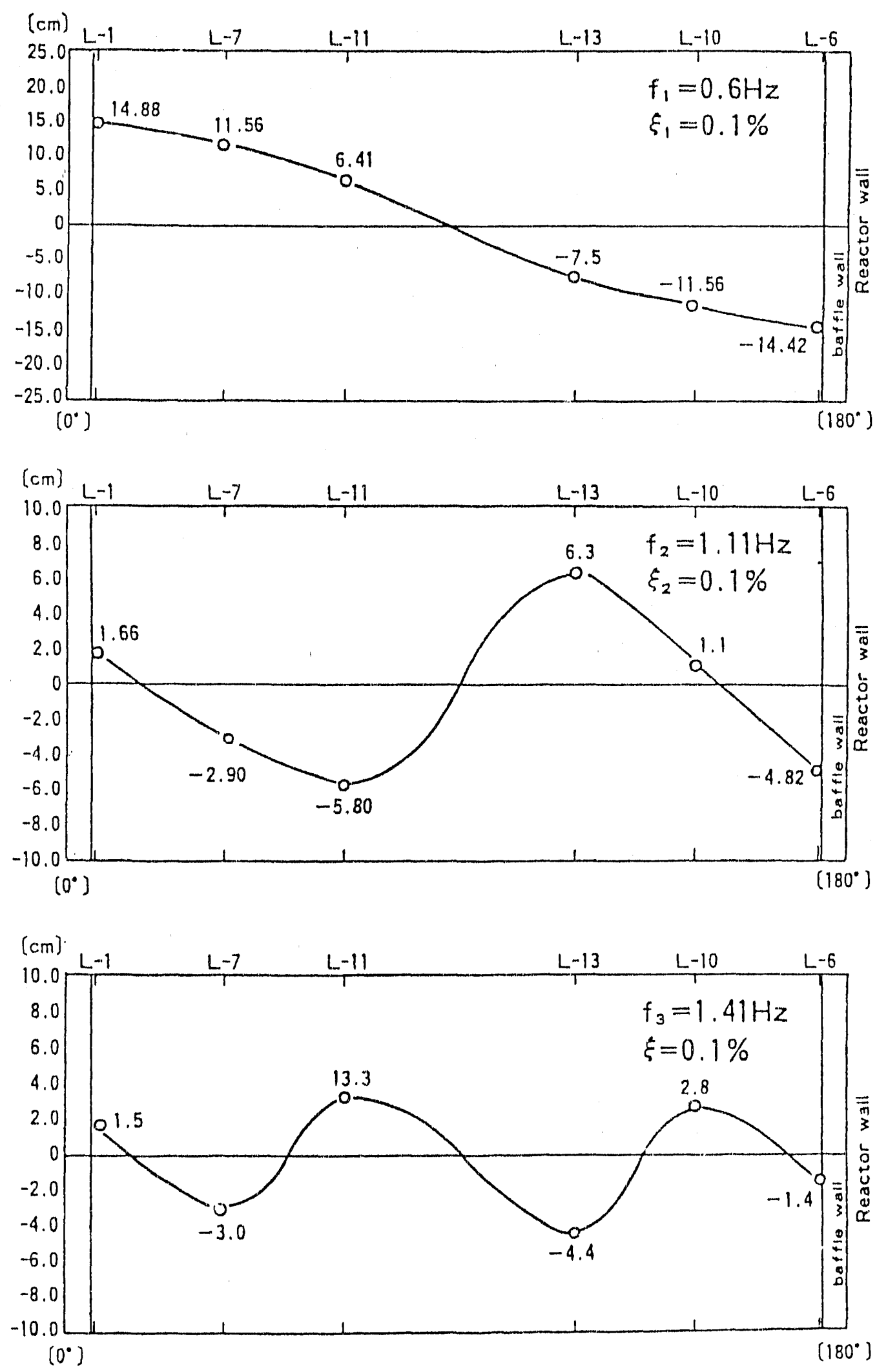

Fig. B-11. Three Lowest Sloshing Modes of Configuration 1 


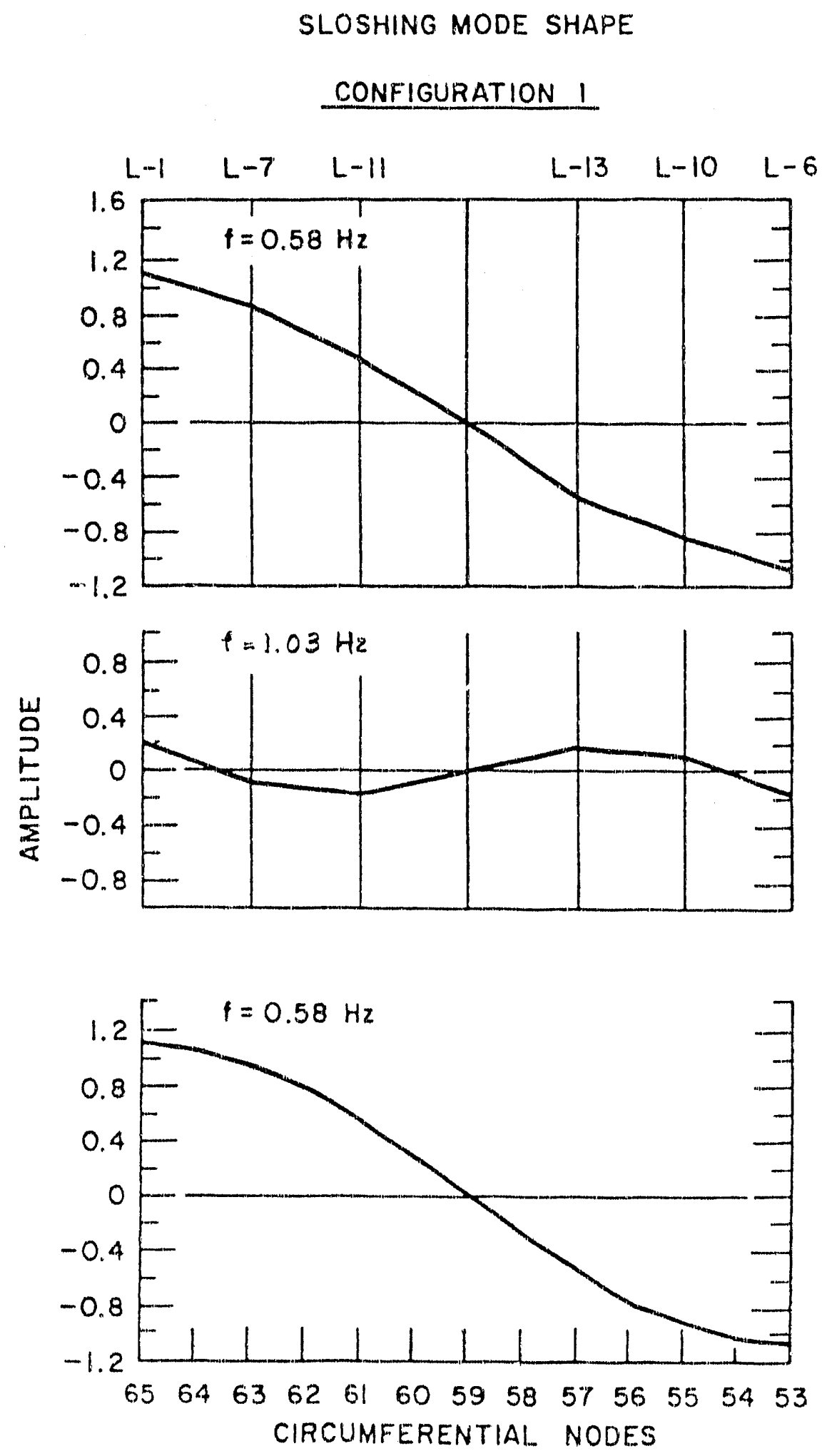

Fig. B-12. Shape of Sloshing Modes, Configuration 1 


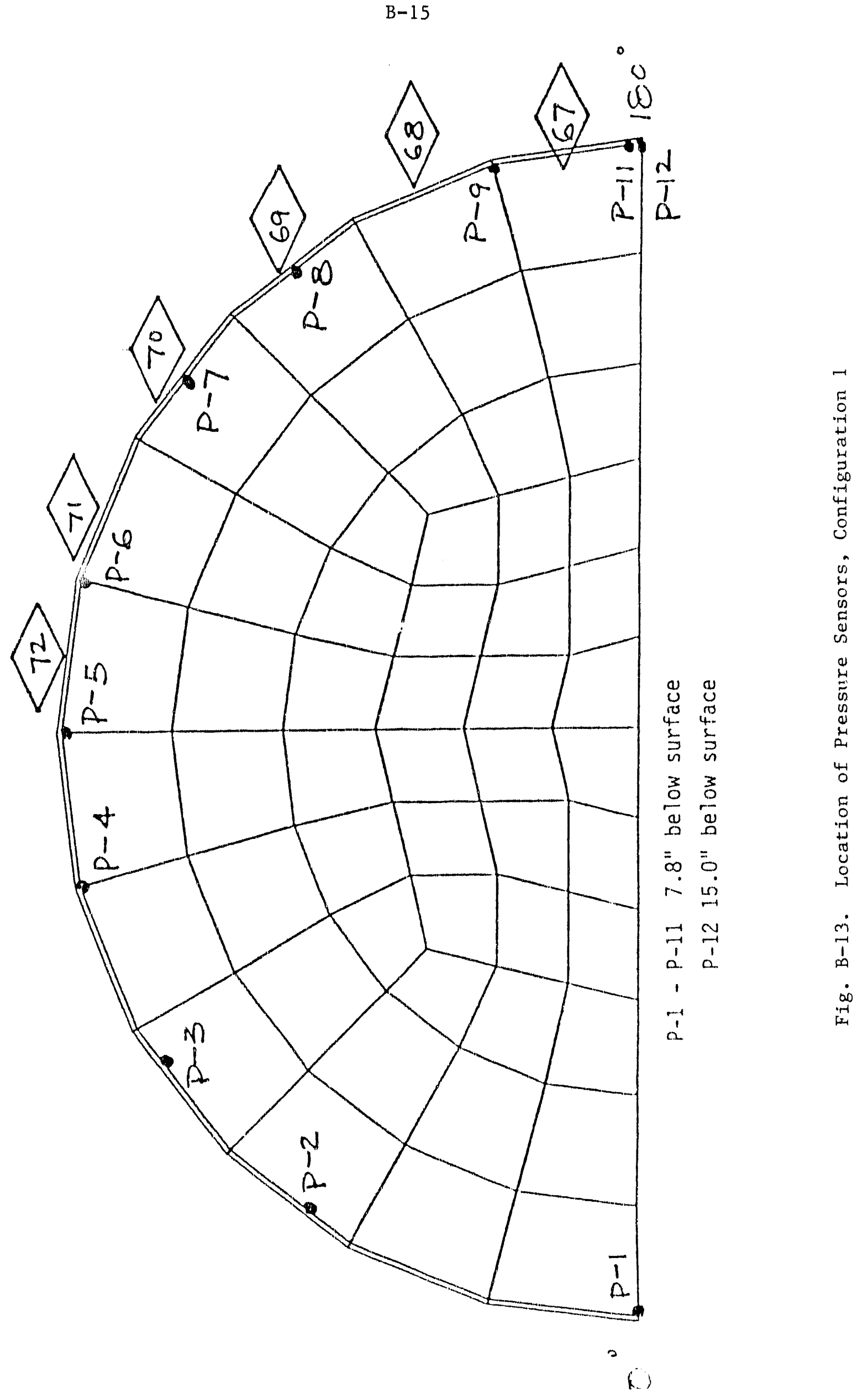


R2401(100GAL ELCENTRO) P11(180 DEGREE,7.8" BELOW SURFACE)

TMAX, AMAX TMIN, AMIN $=23.11 \quad 0.0978 \quad 27.35-0.0979$

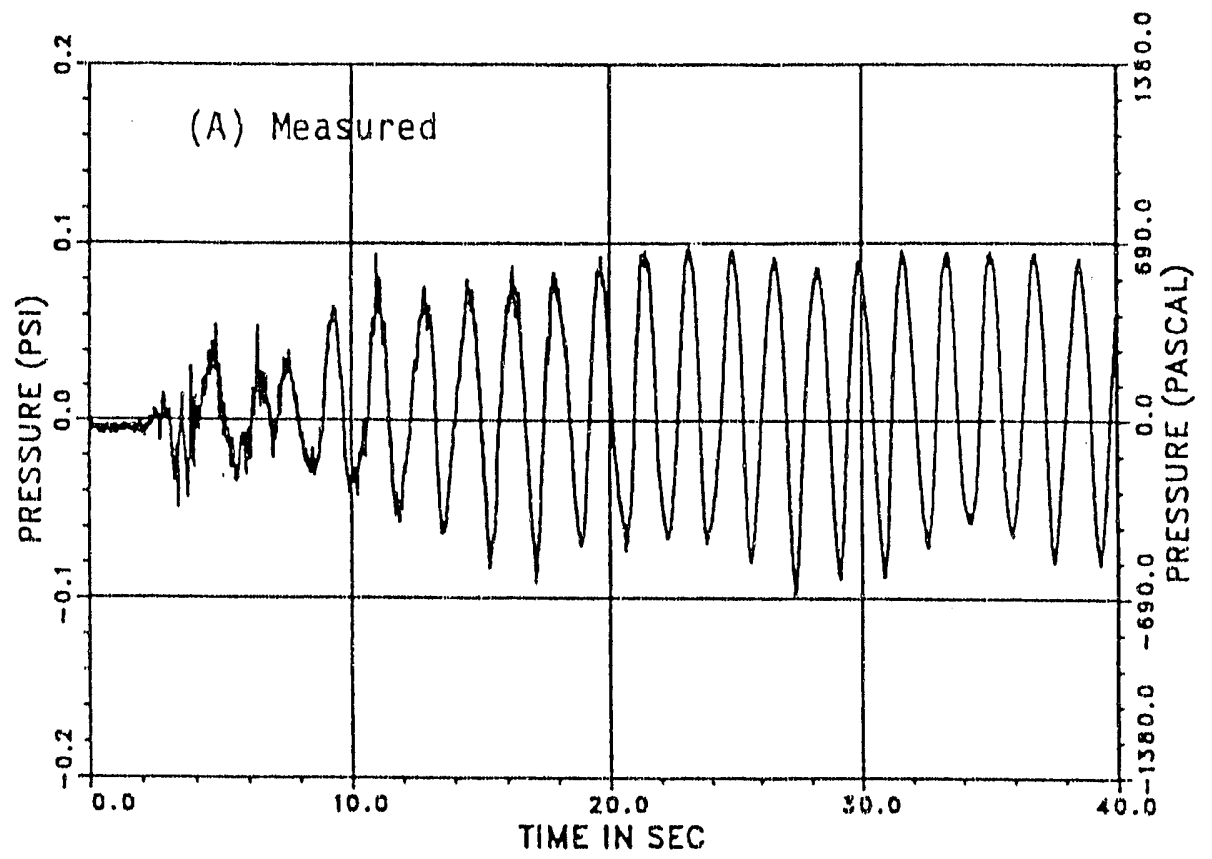

FL-37,2401 (100 GAL EL-CENTRO), ELEMENT F7 (172.5 DEG. LAYER 2)

TMAX, AMAX THIN, AMIN $=16.24 \quad 0.0931 \quad 20.62-0.0956$

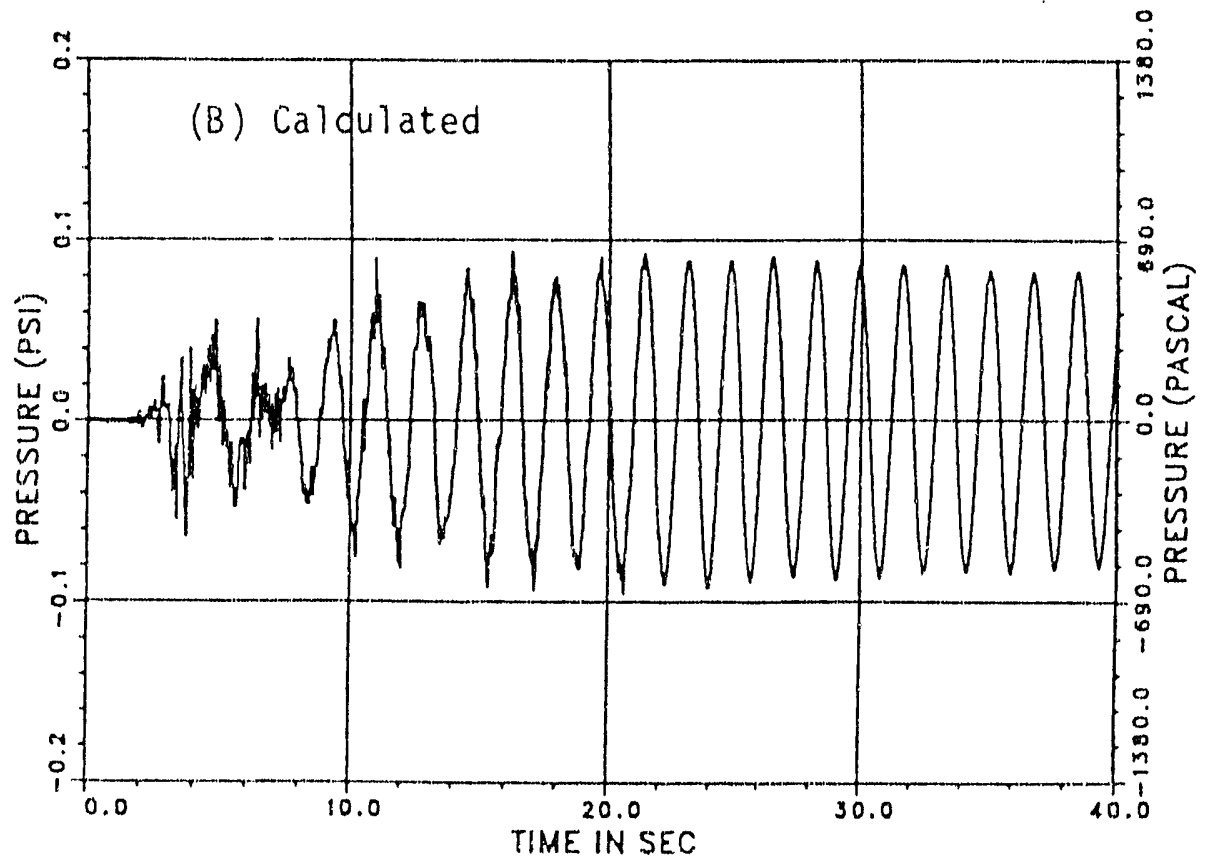

Fig. B-14. Comparison of Measured and Computed Fluid Pressure at Sensor P-11 of Configuration 1 


\section{B-17}

Table B-1. Comparison of Fluid Pressure (psi) of Configuration 1 Between Measured and Predicted Values

\begin{tabular}{||c|c|c|c|c|c||}
\hline \multicolumn{2}{||c|}{ Measured Fluid Pressure (psi) } & \multicolumn{3}{c|}{ Calculated Fluid Pressure (psi) } \\
\hline $\begin{array}{c}\text { Pressure } \\
\text { Meter }\end{array}$ & $\begin{array}{c}\text { Maximum } \\
\text { Pressure }\end{array}$ & $\begin{array}{c}\text { Minimum } \\
\text { Pressure }\end{array}$ & $\begin{array}{c}\text { Fluid } \\
\text { Element }\end{array}$ & $\begin{array}{c}\text { Maximum } \\
\text { Pressure }\end{array}$ & $\begin{array}{c}\text { Minimum } \\
\text { Pressure }\end{array}$ \\
\hline P-11 & 0.098 & -0.098 & 67 & 0.093 & -0.095 \\
F-9 & 0.085 & -0.10 & 68 & 0.087 & -0.089 \\
P-8 & 0.078 & -0.088 & 69 & 0.076 & -0.076 \\
P-7 & 0.057 & -0.061 & 70 & 0.057 & -0.059 \\
P-6 & 0.025 & -0.028 & 71 & 0.035 & -0.036 \\
P-5 & 0.009 & -0.01 & 72 & 0.012 & -0.012 \\
P-12 & 0.078 & -0.084 & 133 & 0.090 & -0.089 \\
\hline
\end{tabular}



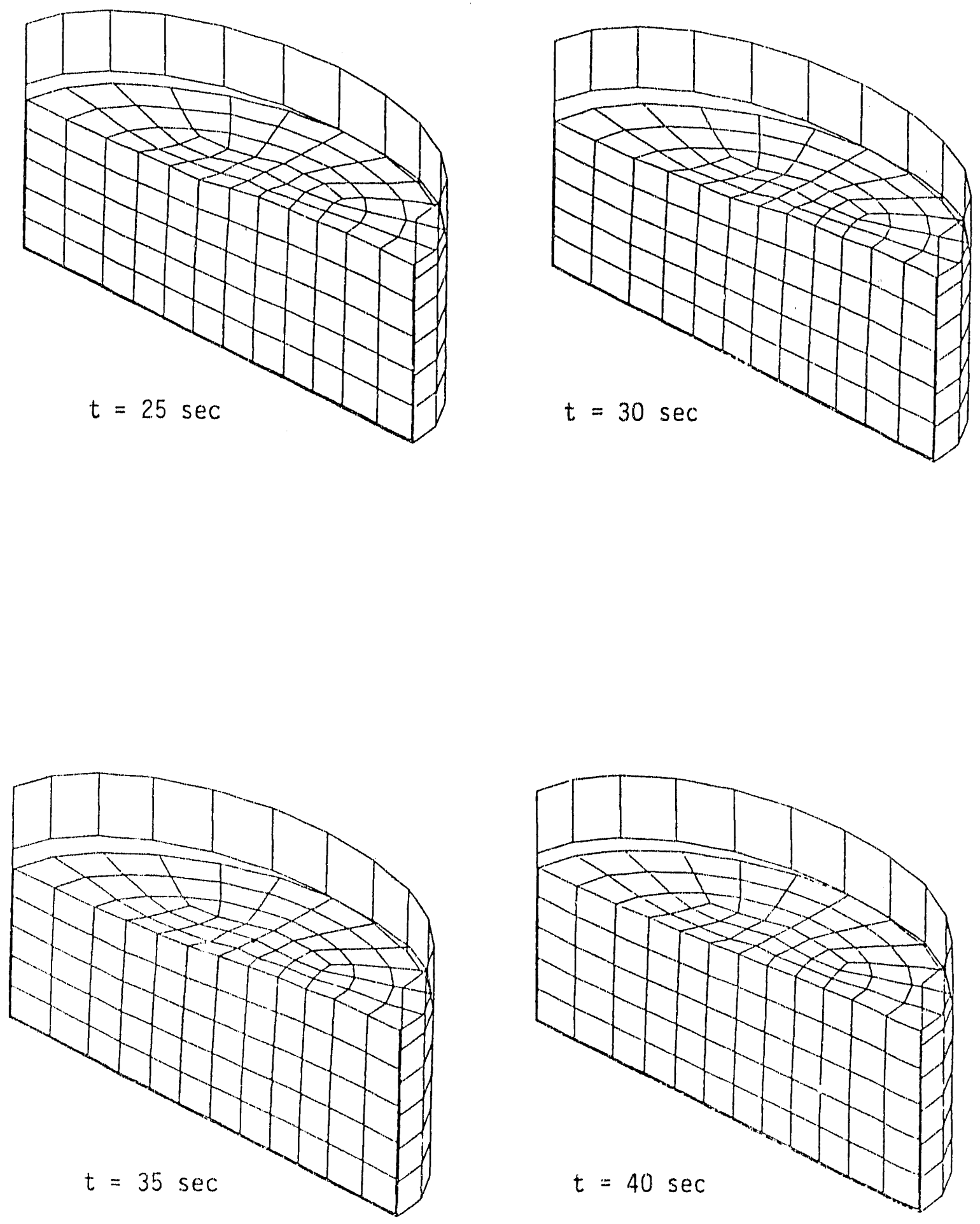

Fig. B-15. Mesh Configuration of Configuration 1 at Time Instant $t=25$, 30,35 , and $40 \mathrm{~s}$ 


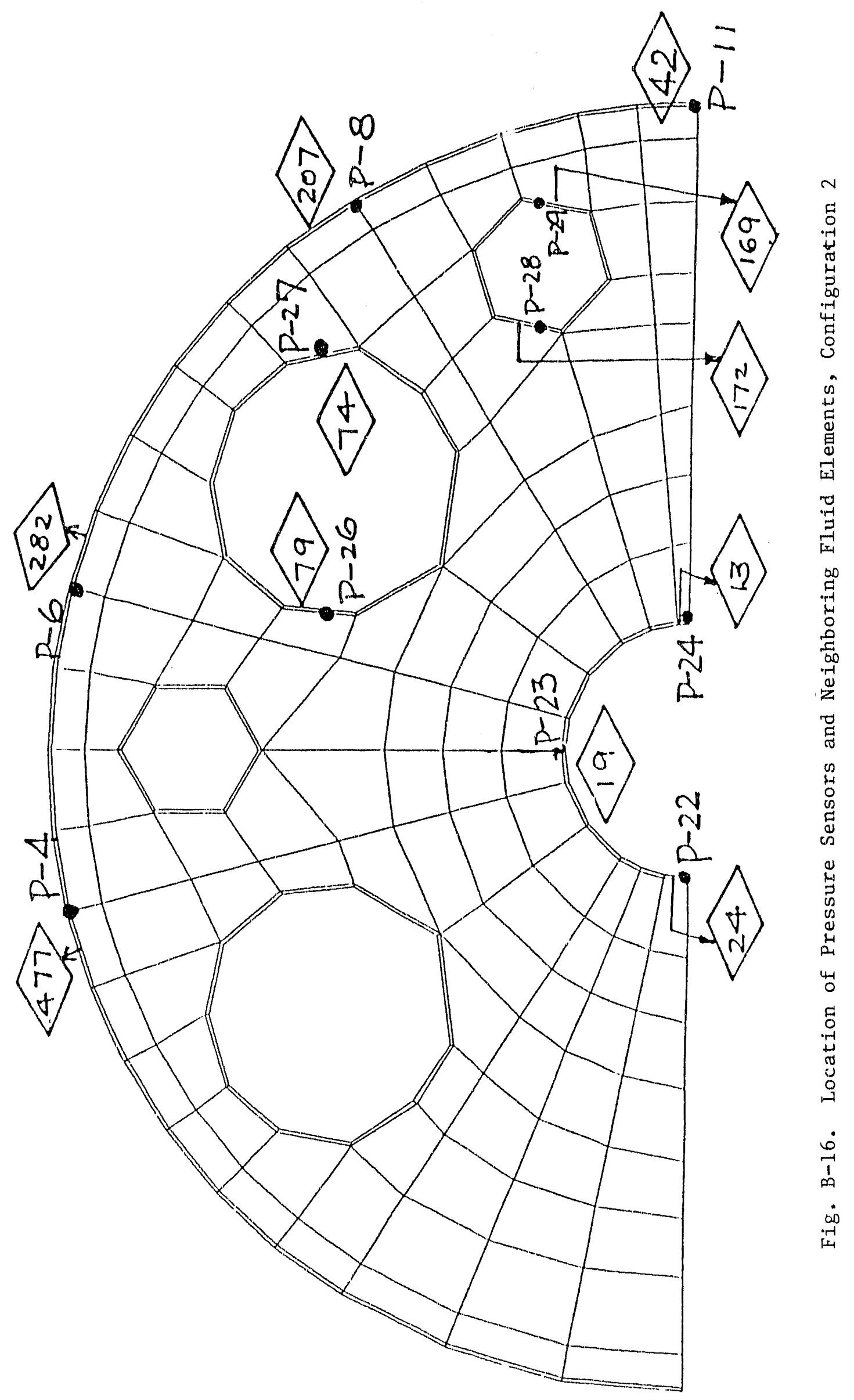


R2802 (100 GAL EL-CENTRO) P27 (180 DEG. IHX-2)

TMAX,AMAX TMIN,AMIN $=14.64 \quad 0.0707 \quad 13.58-0.0630$

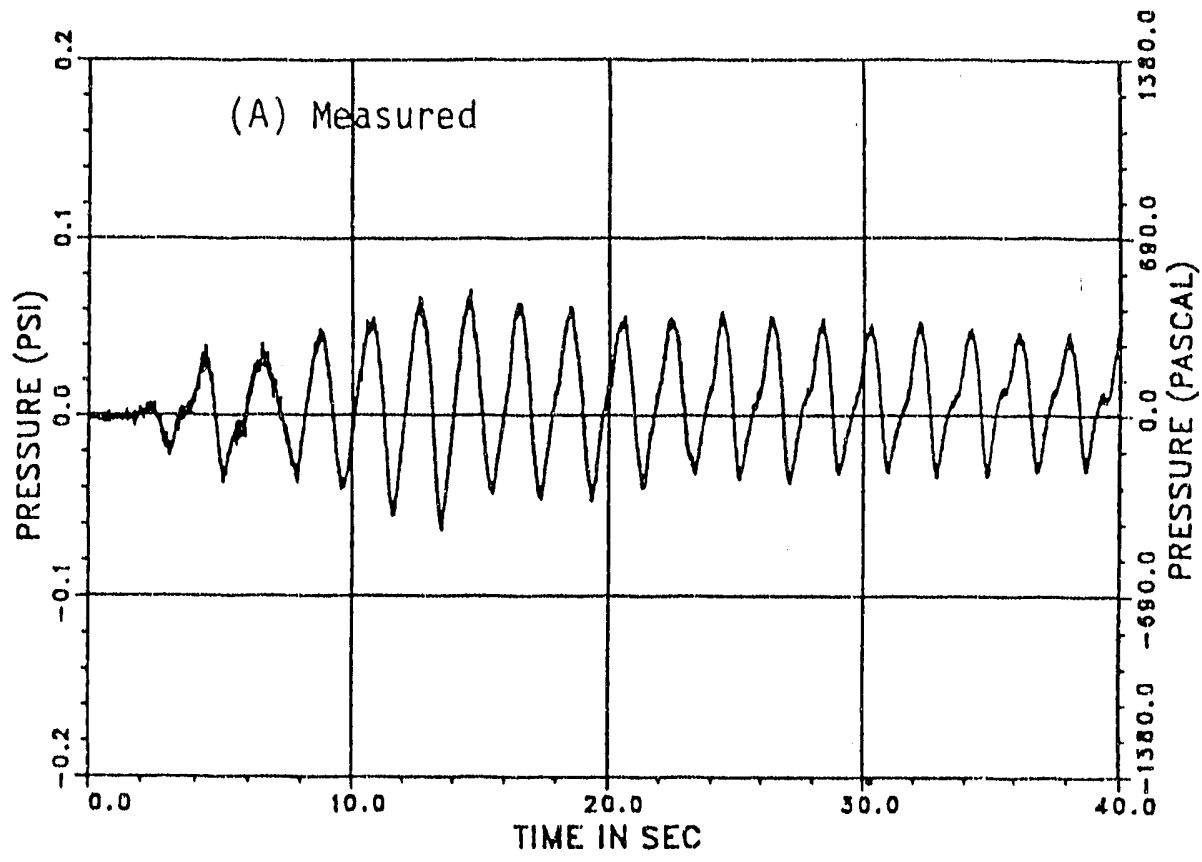

F2802(100 GAL EL-CENTRO,.001\% V),ELEM. 74-P27(180 DEG IHX-2)

TMAX, AMAX TMIN,AMIN $=12.88 \quad 0.0885 \quad 11.82 \quad-0.0741$

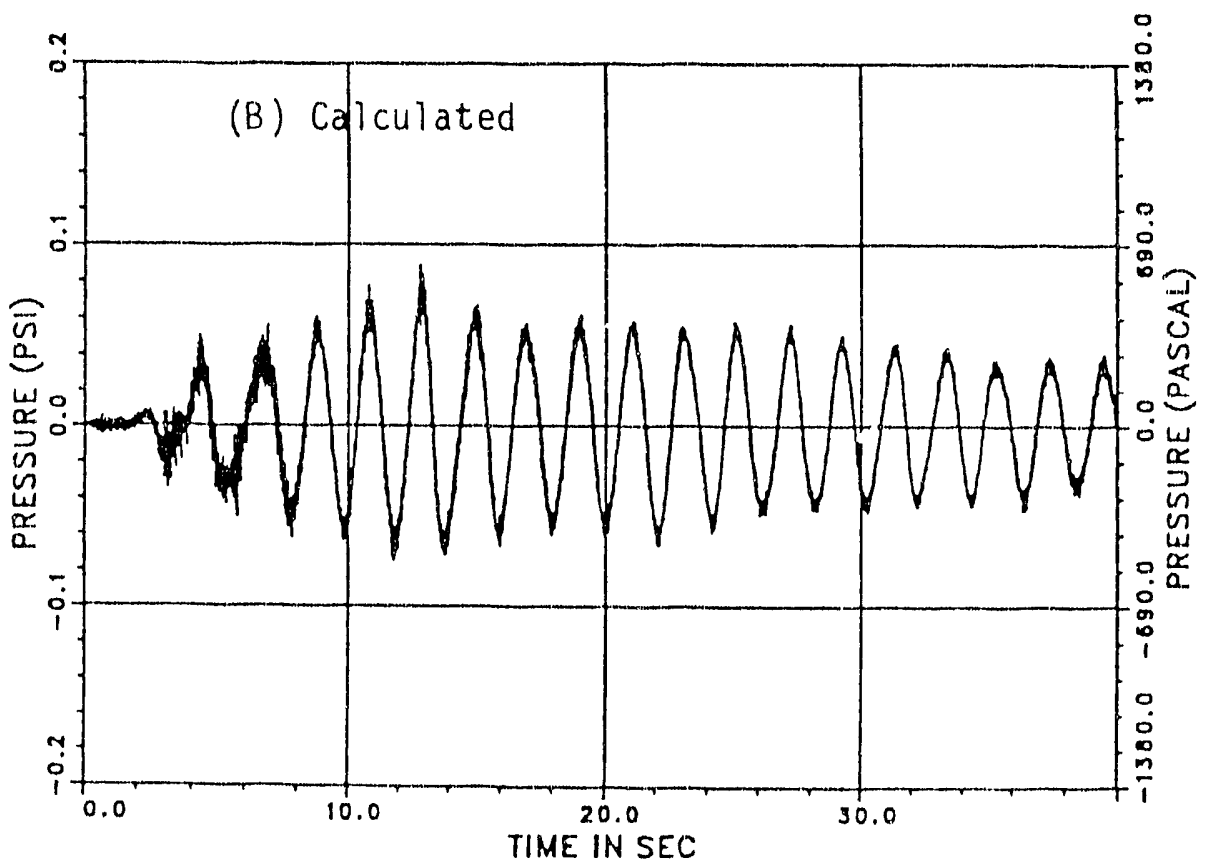

Fig. B-17. Comparison of Measured and Computed Fluid Pressure at Sensor P-27 of Configuration 2 


\section{B-21}

Table B-2. Comparison of Fluid Pressure (psi) of Configuration 2 Between Measured and Predicted Values

\begin{tabular}{||c|c|c|c|c|c||}
\hline \multicolumn{2}{||c|}{ Measured Fluid Pressure (psi) } & \multicolumn{3}{c|}{ Calculated Fluid Pressure (psi) } \\
\hline $\begin{array}{c}\text { Pressure } \\
\text { Meter }\end{array}$ & $\begin{array}{c}\text { Maximum } \\
\text { Pressure }\end{array}$ & $\begin{array}{c}\text { Minimum } \\
\text { Pressure }\end{array}$ & $\begin{array}{c}\text { Fluid } \\
\text { Element }\end{array}$ & $\begin{array}{c}\text { Maximum } \\
\text { Pressure }\end{array}$ & $\begin{array}{c}\text { Minimum } \\
\text { Pressure }\end{array}$ \\
\hline P-4 & 0.020 & -0.027 & 477 & 0.029 & -0.029 \\
P-6 & 0.027 & -0.030 & 282 & 0.032 & -0.030 \\
P-8 & 0.082 & -0.078 & 207 & 0.081 & -0.077 \\
P-11 & 0.095 & -0.071 & 42 & 0.087 & -0.095 \\
P-22 & 0.034 & -0.057 & 24 & 0.057 & -0.053 \\
P-23 & 0.012 & -0.015 & 19 & 0.019 & -0.010 \\
P-24 & 0.040 & -0.052 & 13 & 0.055 & -0.054 \\
P-26 & 0.017 & -0.022 & 79 & 0.039 & -0.035 \\
P-27 & 0.070 & -0.063 & 74 & 0.088 & -0.074 \\
P-28 & 0.066 & -0.062 & 122 & 0.072 & -0.068 \\
P-29 & 0.078 & -0.071 & 169 & 0.091 & -0.091 \\
\hline
\end{tabular}



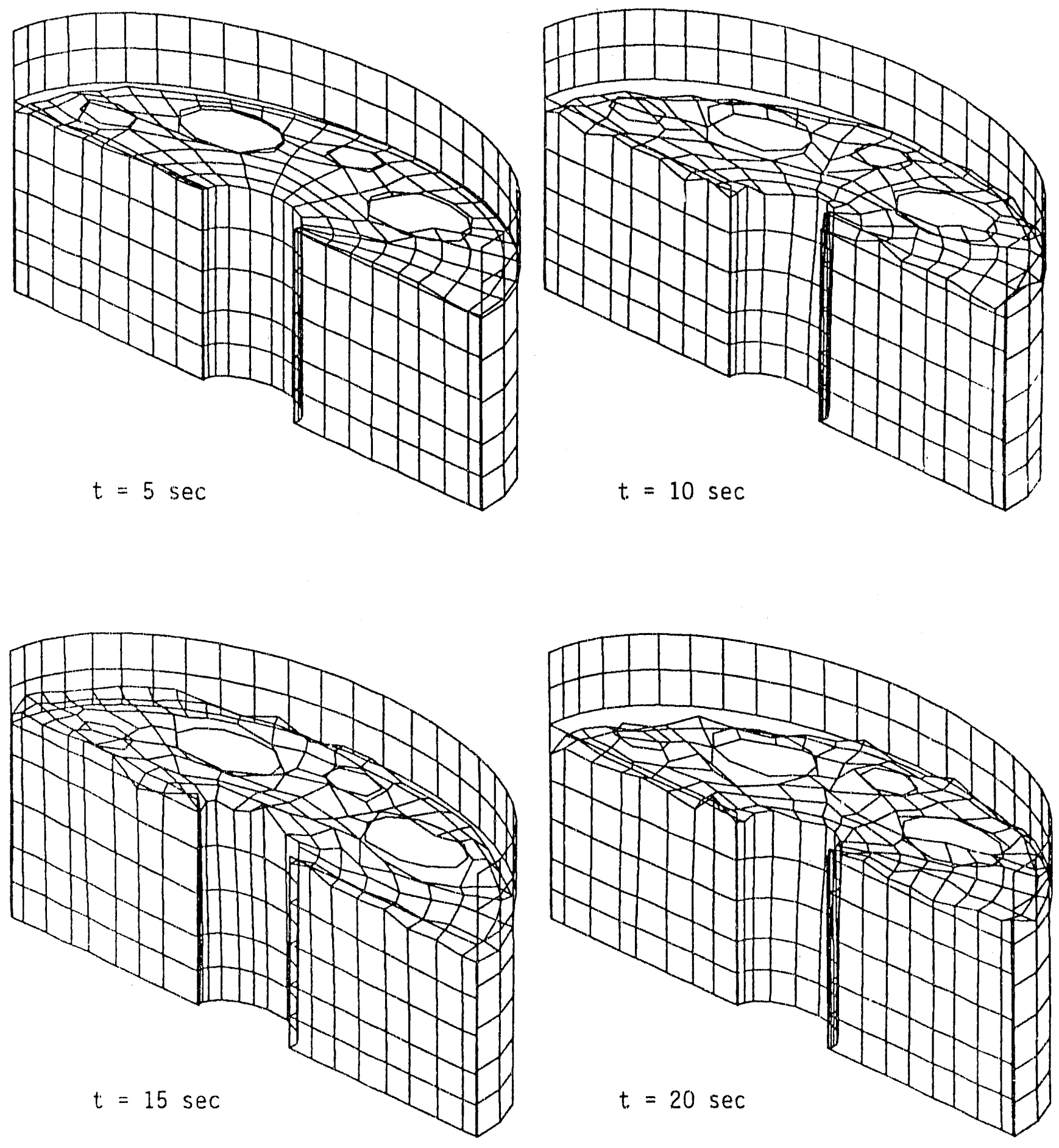

F1g. B-18. Mesh Configuration of Configuration 2 


\section{APPENDIX C}

Time History Plots of the Sloshing Wave Height and Hydrodynamic Pressures for the Case of $\mu=60 \mathrm{cP}$ for Base Motion 1 


$$
\text { C-1 }
$$

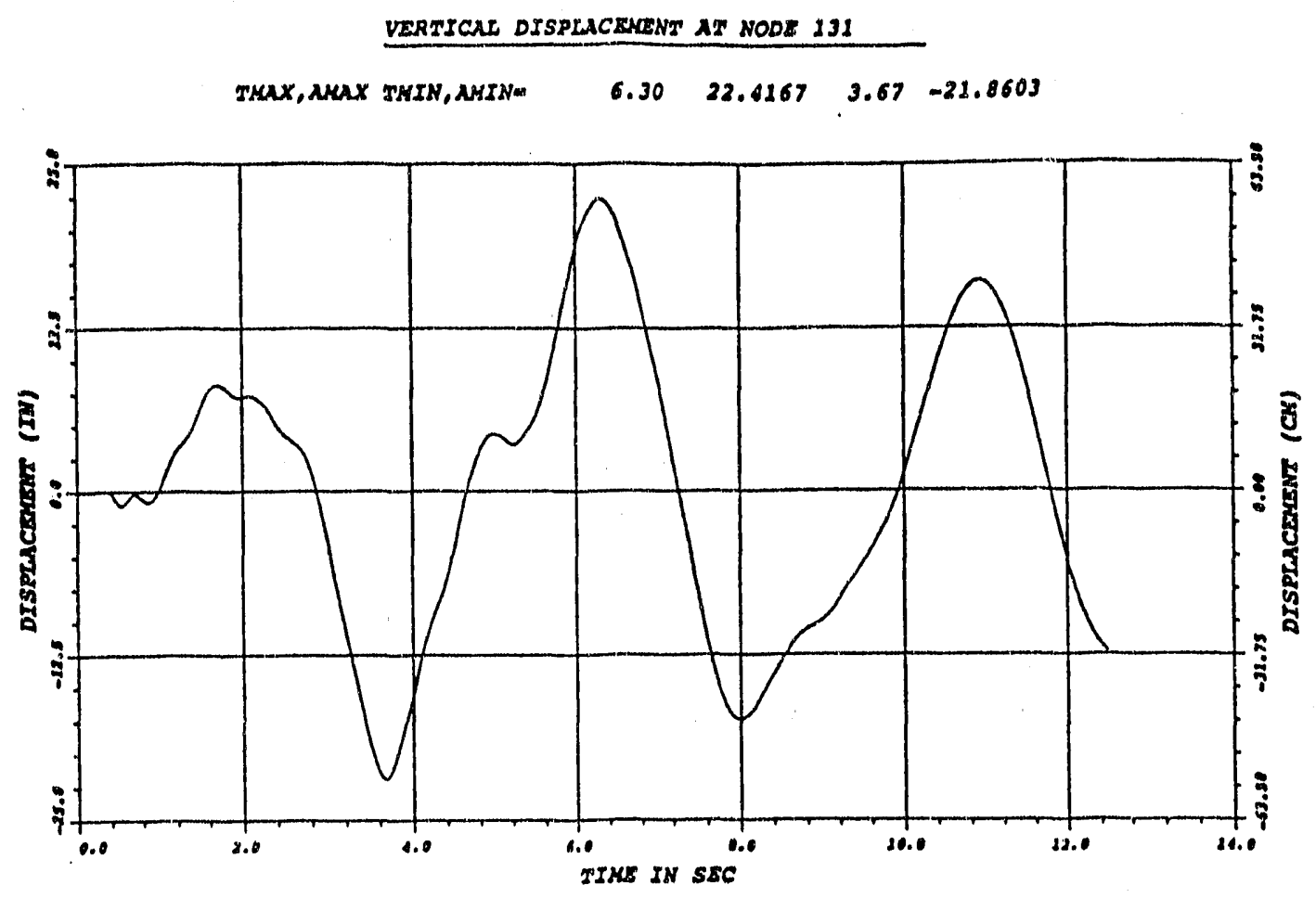

VERTYCAL DISPLACBMENT AT NODE 131

HAX. FREQUENCY, ANPLITUDE. $\quad 0.216 .2072$

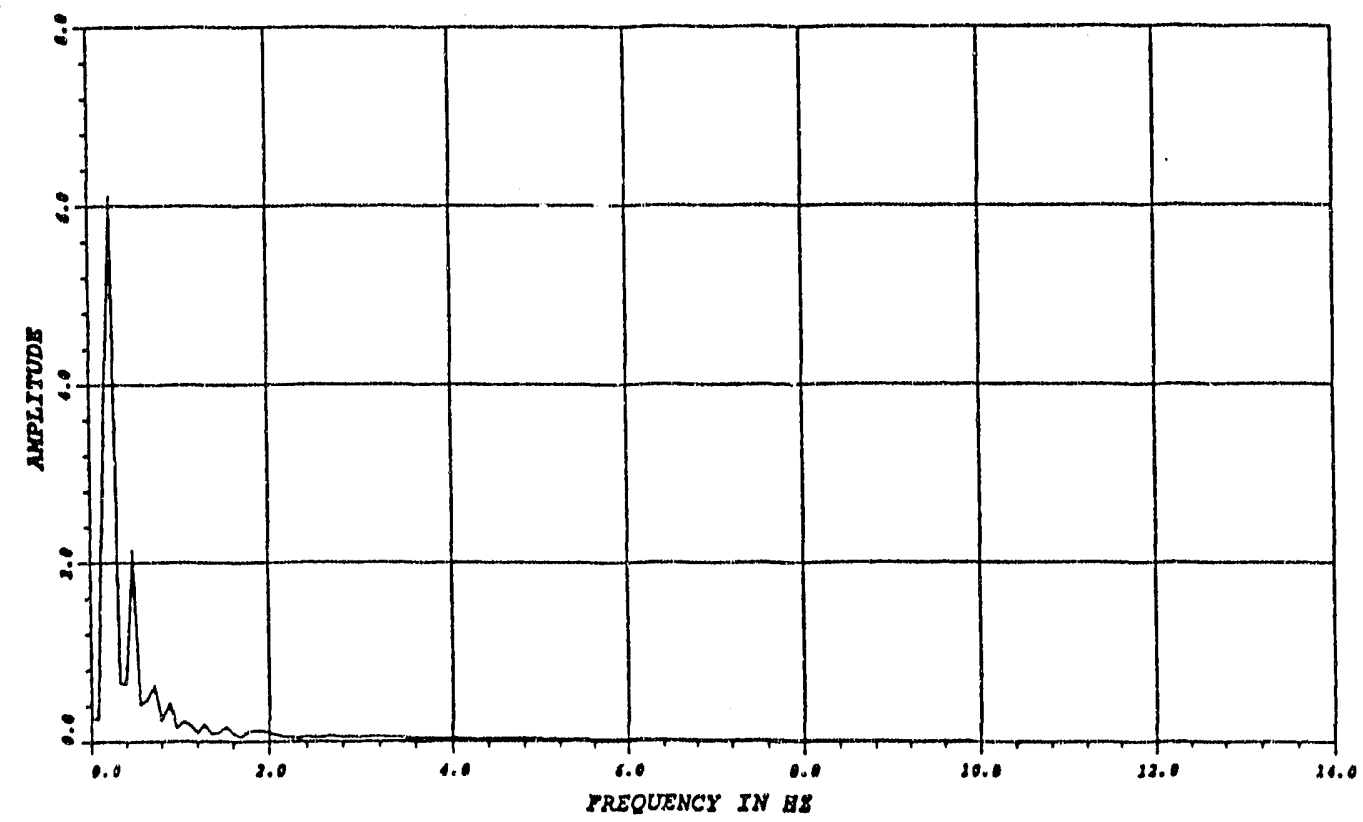

Fig. C-1. Time History of Sloshing Wave Height at Node 131 and its FFT for the Case of $\mu=60 \mathrm{cP}$ 
IMPULSIVE PRESSURE AT ELEMENT 1

TMAX,AMAX TMIN,AMIN $=3.70 \quad 0.8476 \quad 4.08 \quad-0.6245$

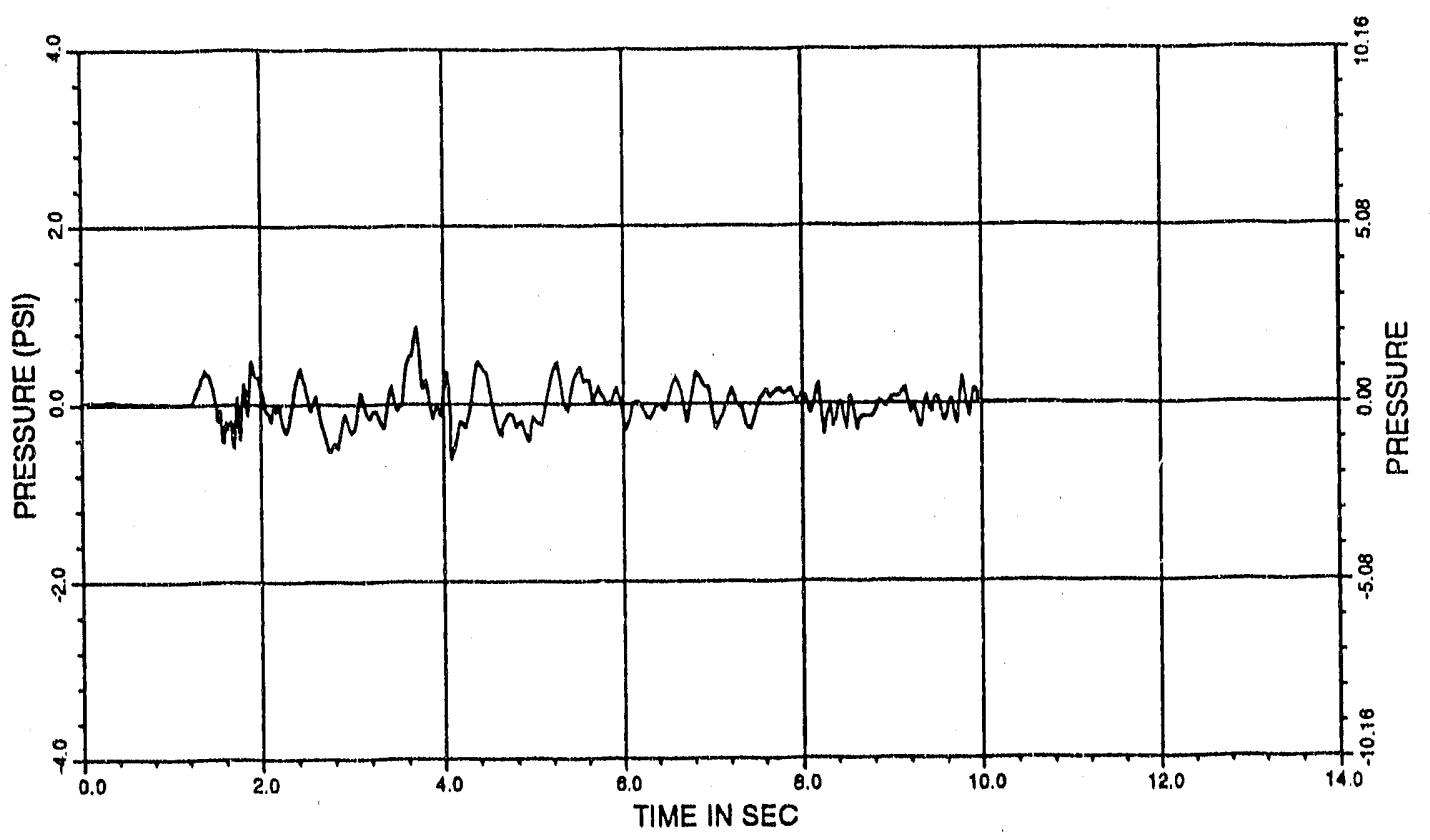

IMPULSIVE PRESSURE AT ELEMENT 1

MAX, FREQUENCY,AMPLITUDE $=0.88 \quad 0.0362$

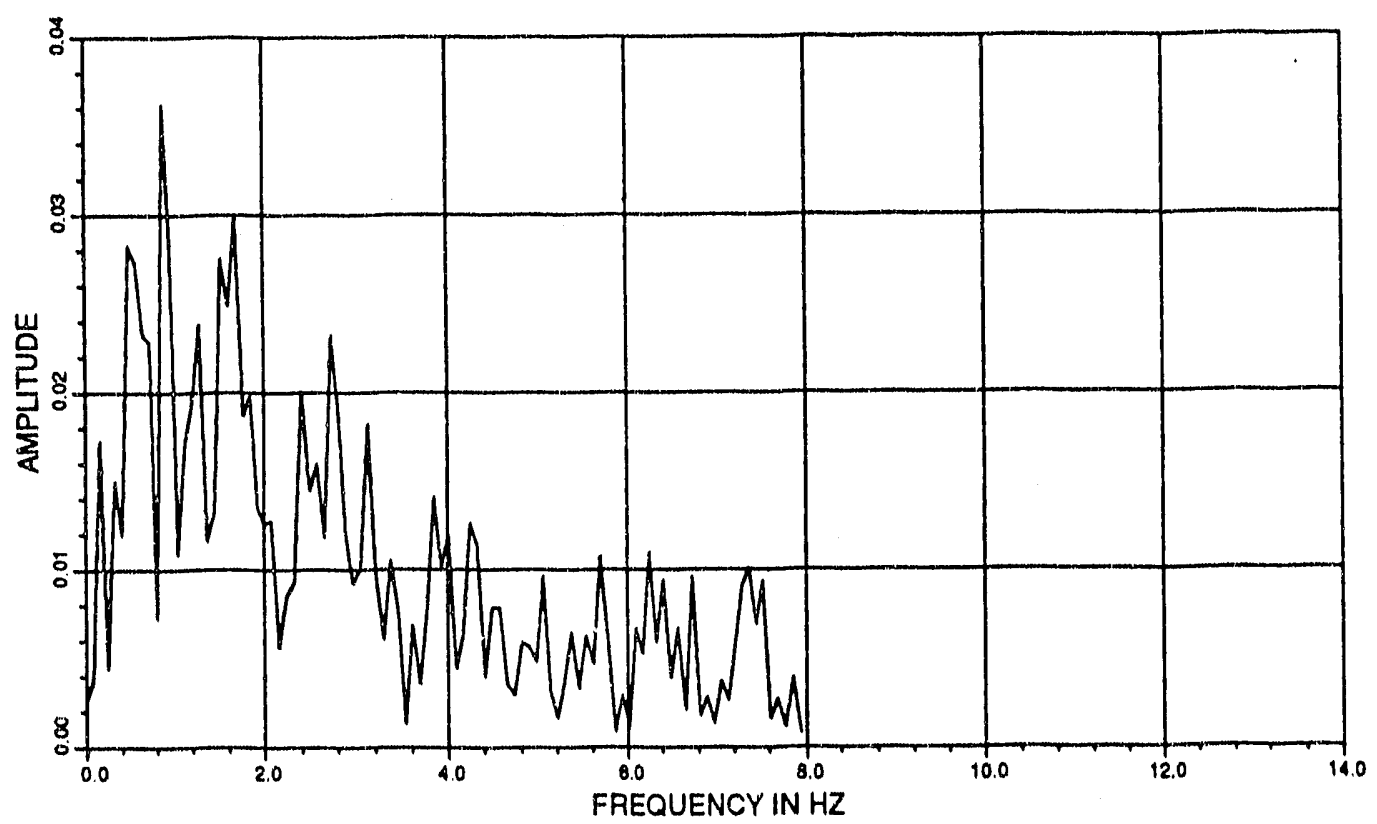

Fig. C-2, Time History of the Impulsive Pressure at Element 1 and its FFT for the Case of $\mu=60 \mathrm{cP}$ 

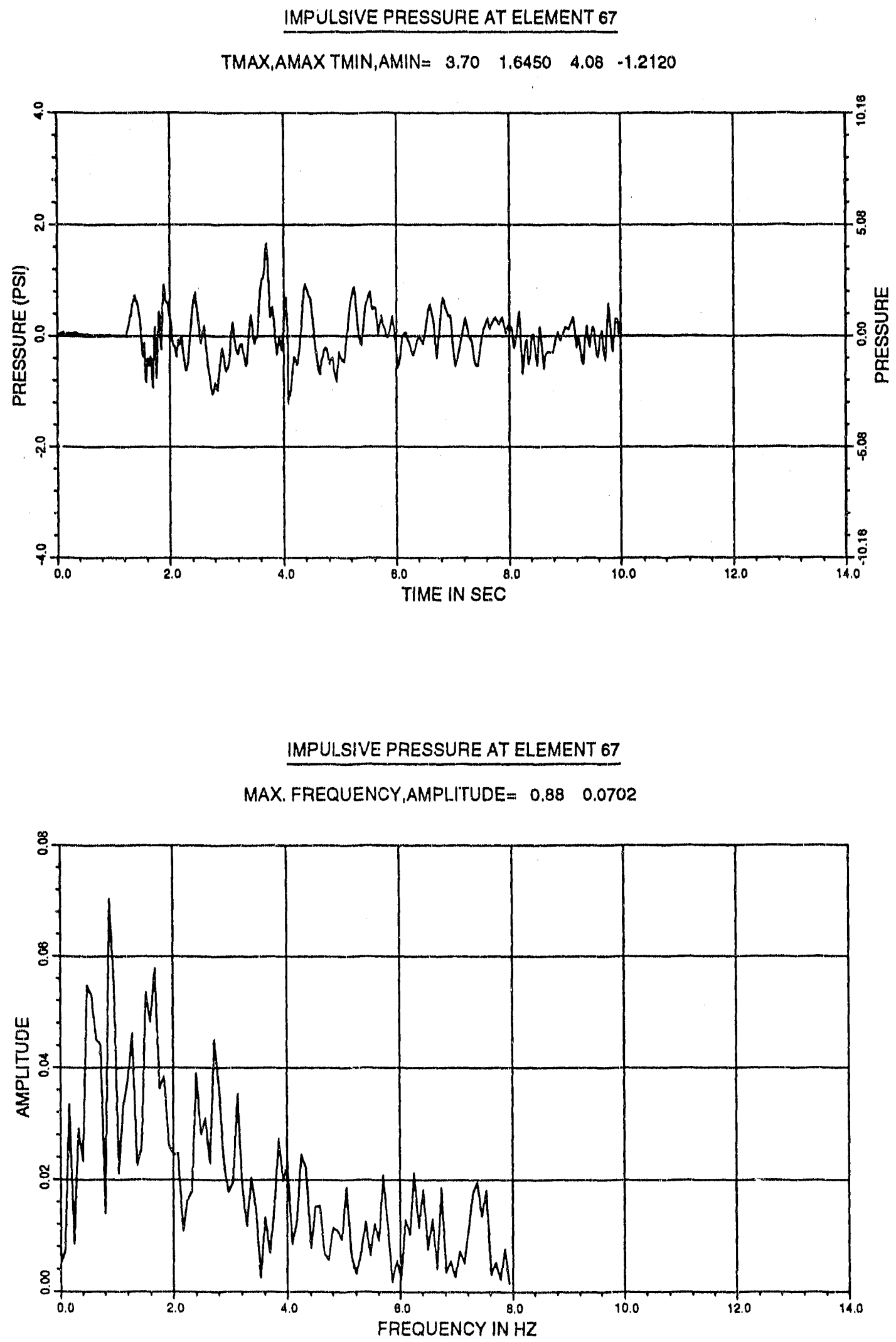

Fig. C-3. Time History of the Impulsive Pressure at Element 67 and its FFT for the Case of $\mu=67 \mathrm{cP}$ 


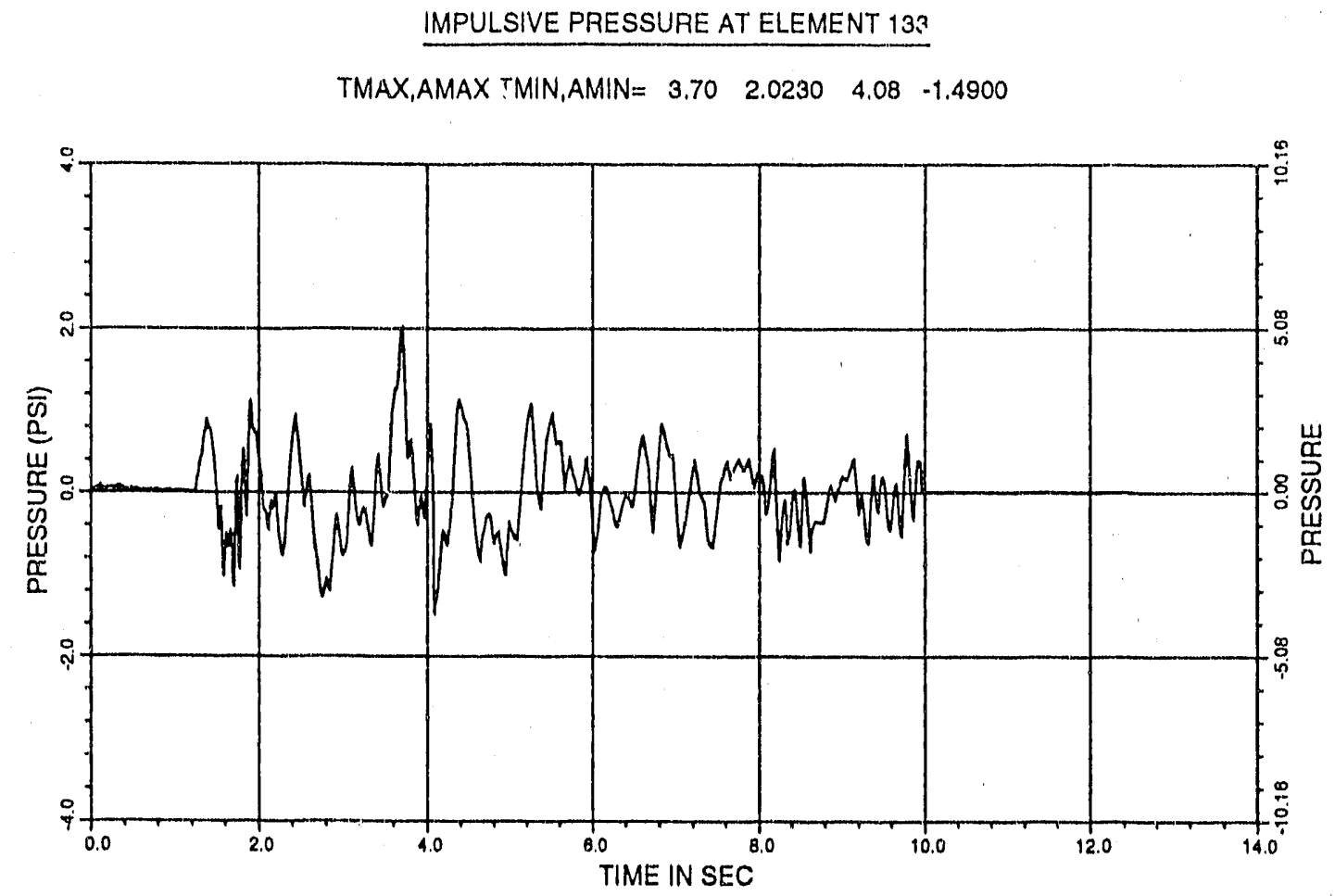

IMPULSIVE PRESSURE AT ELEMENT 133

MAX. FREQUEINCY,AMPLITUDE $=0,88 \quad 0,0864$

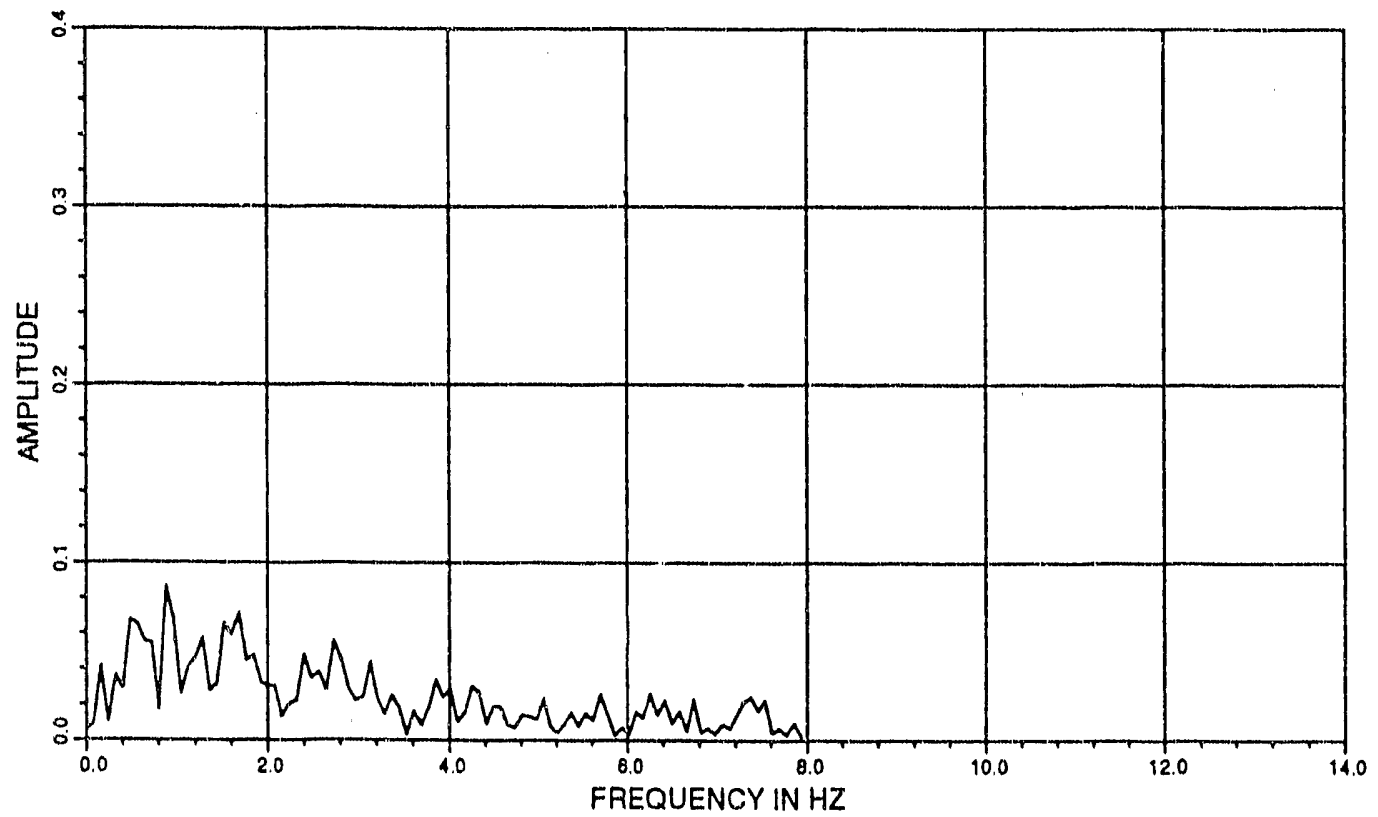

Fig. C-4. Time History of the Impulstve Pressure at Element 133 and i.ts FFT for the Case of $\mu=60 \mathrm{cP}$ 


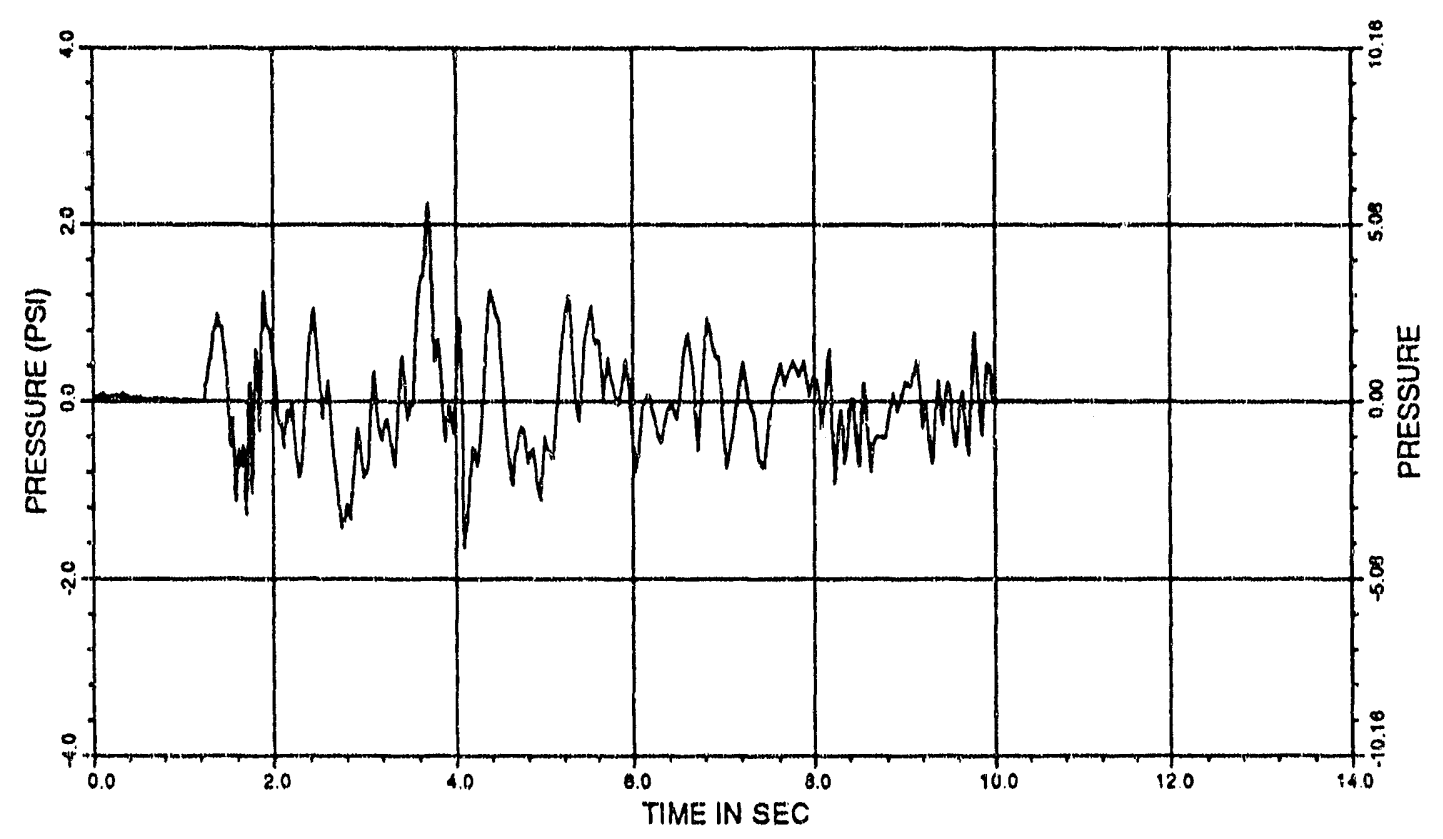

IMPULSIVE PRESSURE AT ELEMENT 199

MAX. FREOUENCY,AMPLITUDE $=0.88 \quad 0.0955$

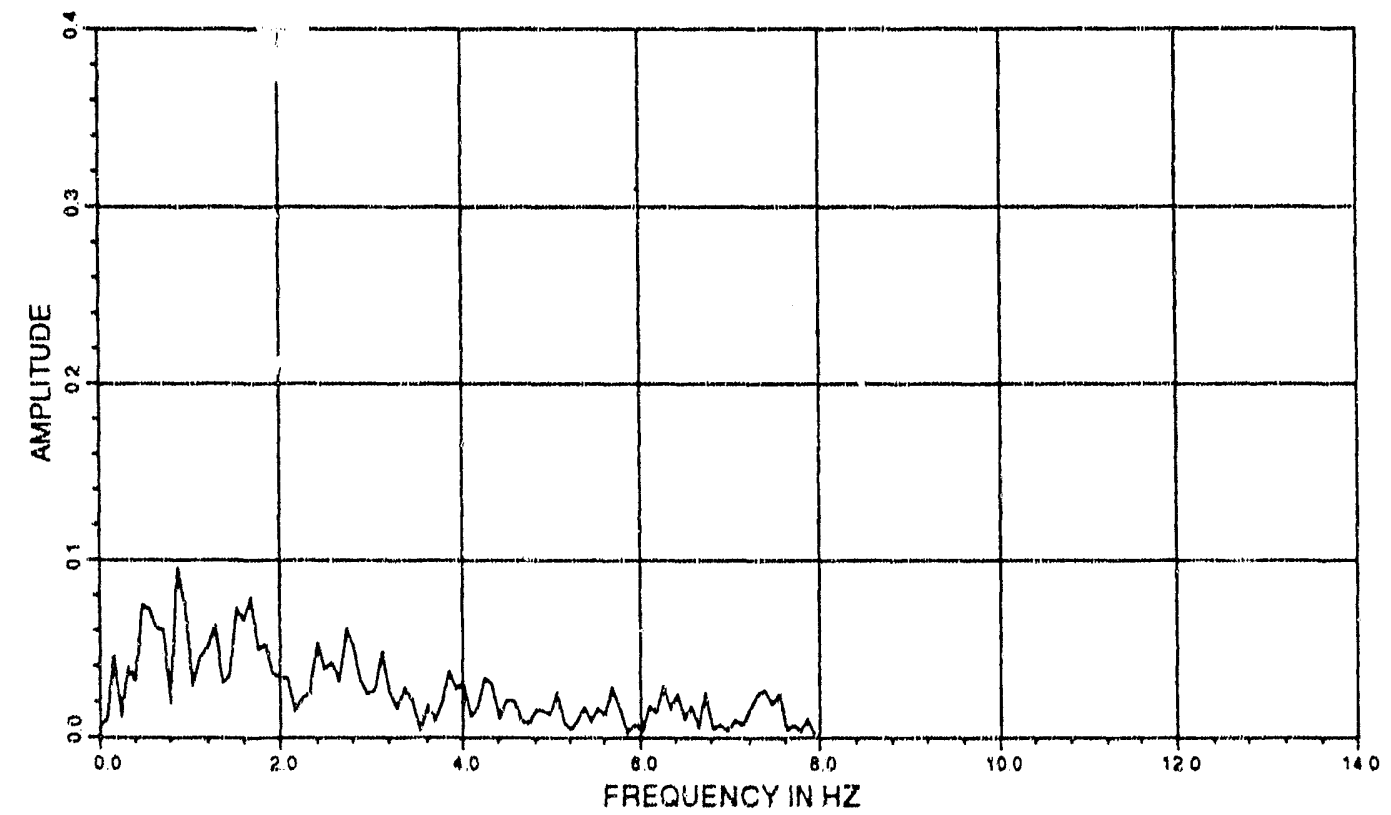

Fig. C-5. Time History of the Impulsive Pressure at Element 199 and its FFT for the Case of $\mu=60 \mathrm{cP}$ 
IMPULSIVE PRESSURE AT ELEMENT 265

TMAX,AMAX TMIN,AMIN $=3.70 \quad 2.3600 \quad 4.08 \cdot 1.7380$

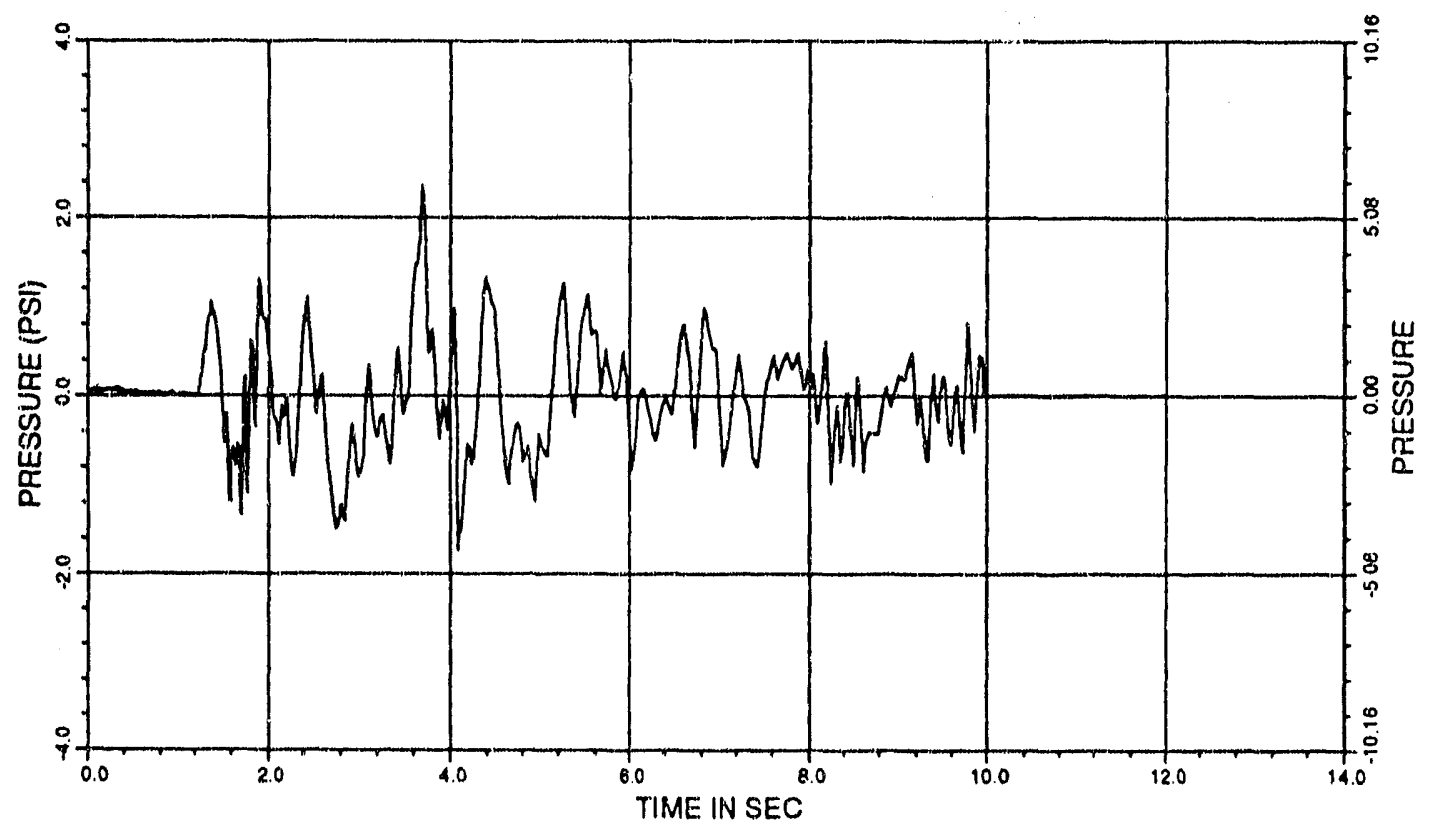

IMPULSIVE PRESSURE AT ELEMENT 265

MAX. FREQUENCY,AMPLITUDE $=0.88 \quad 0.1008$

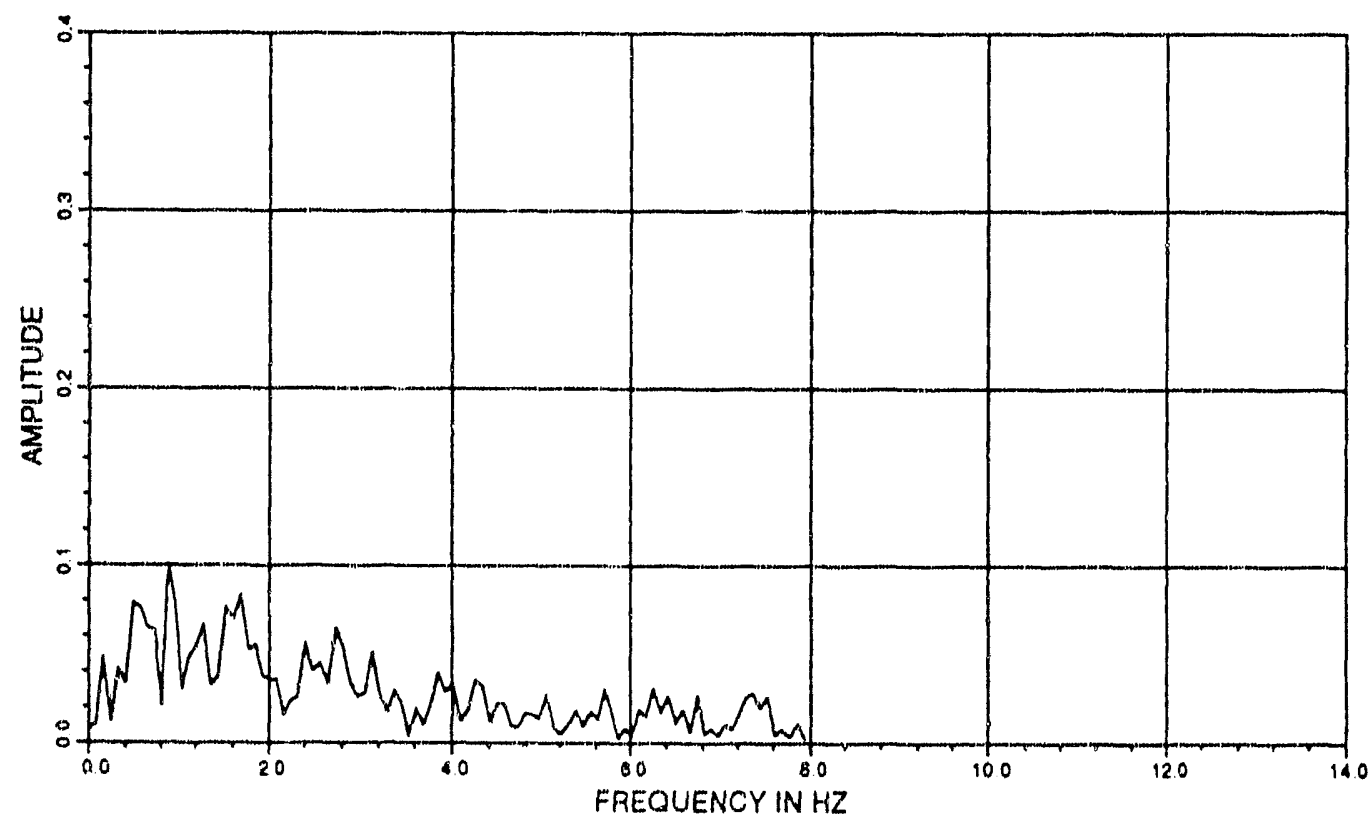

Fig. C-6. Time History of the Impulsive Pressure at Flement 265 and 1is FF' for the Case of $\mu=60 \mathrm{cP}$ 
IMPULSIVE PAESSURE AT ELEMENT 331

TMAX,AMAX TMIN,AMIN $=3.70 \quad 2.4310 \quad 4.08 \quad-1.7800$

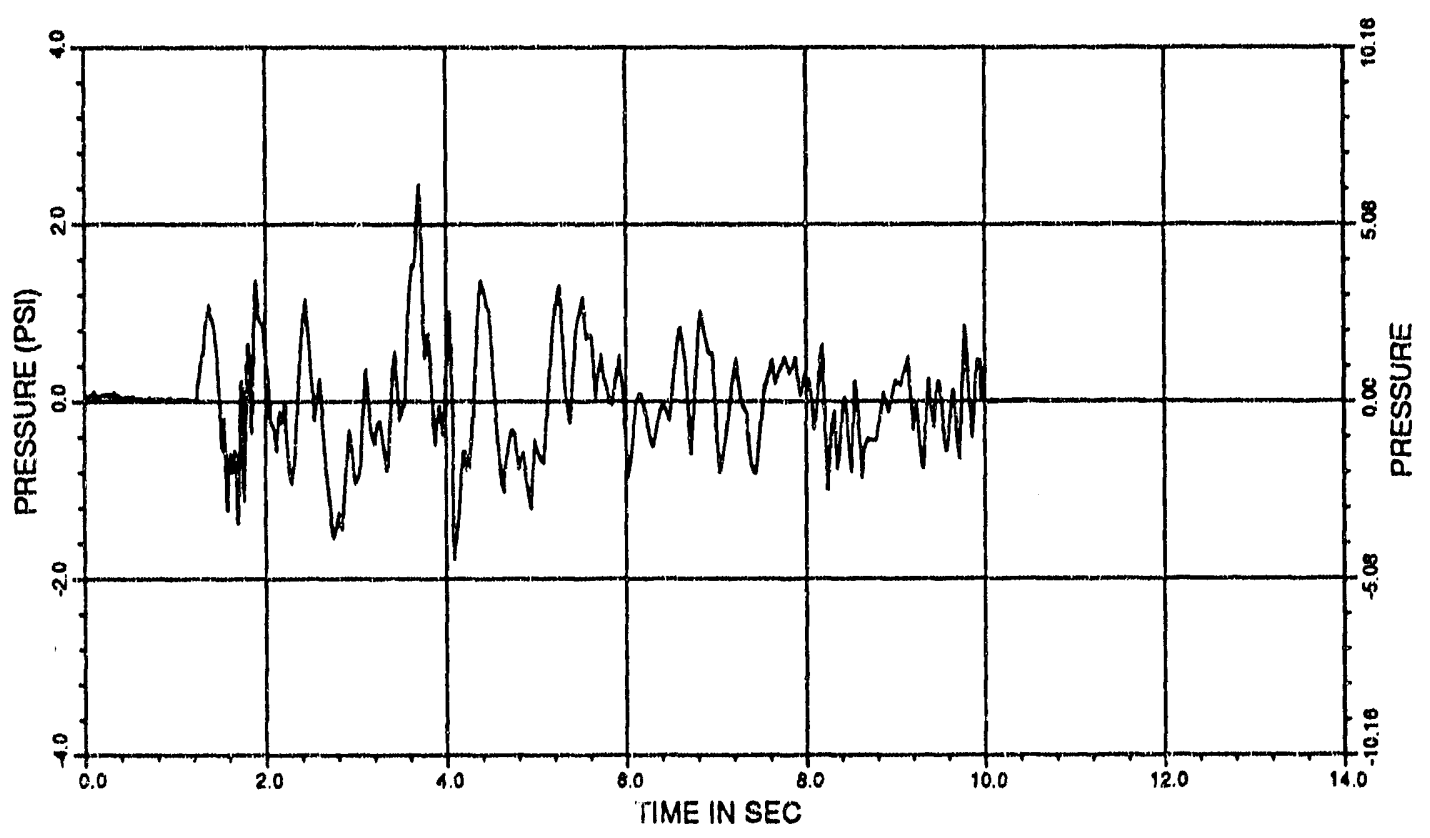

IMPULSIVE PRESSURE AT ELEMENT 331

MAX. FREQUENCY,AMPLITUDE $=0.880 .1038$

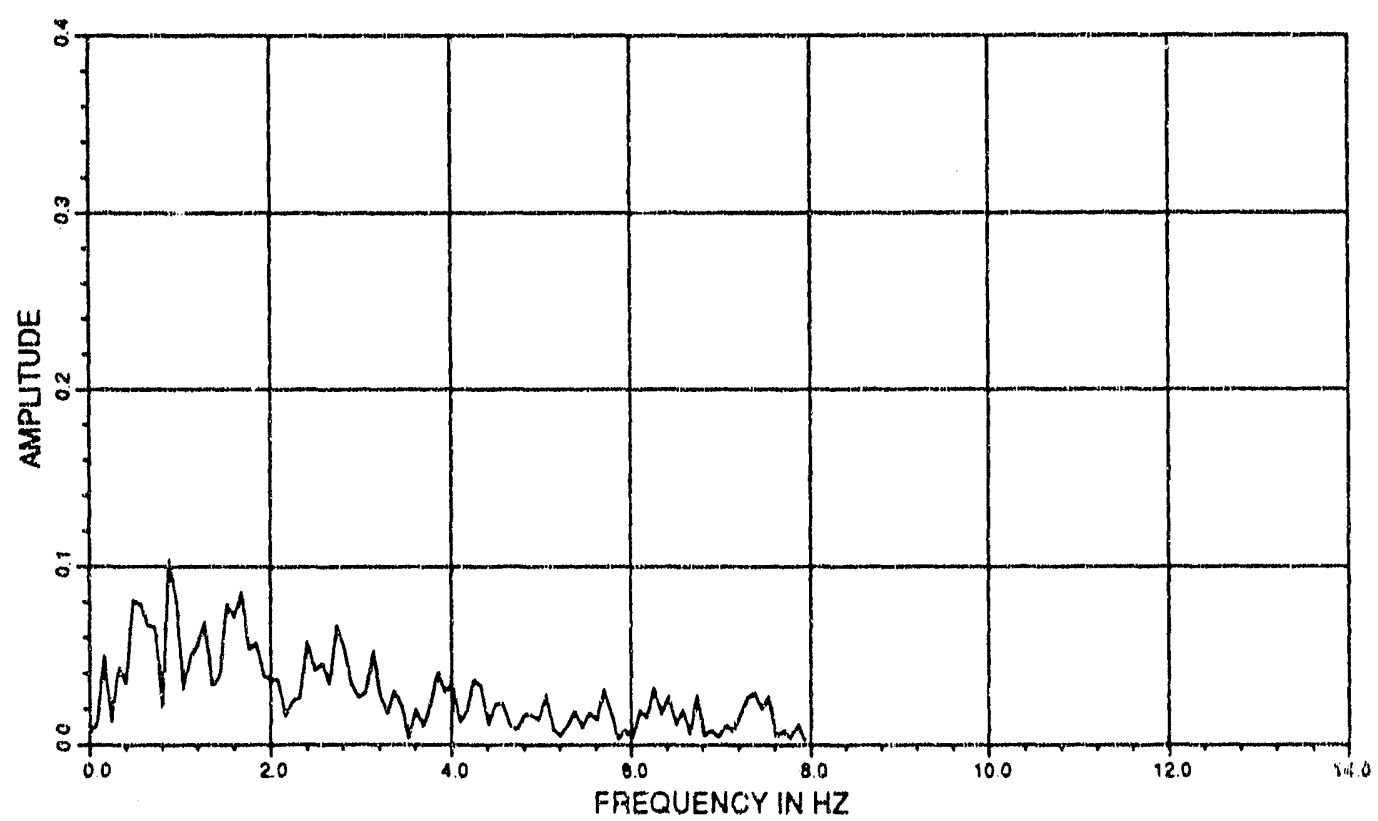

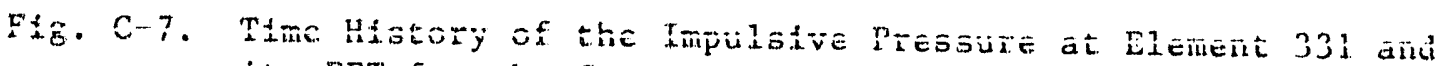
its FFT for the Case of $\mu=60 \mathrm{cP}$ 

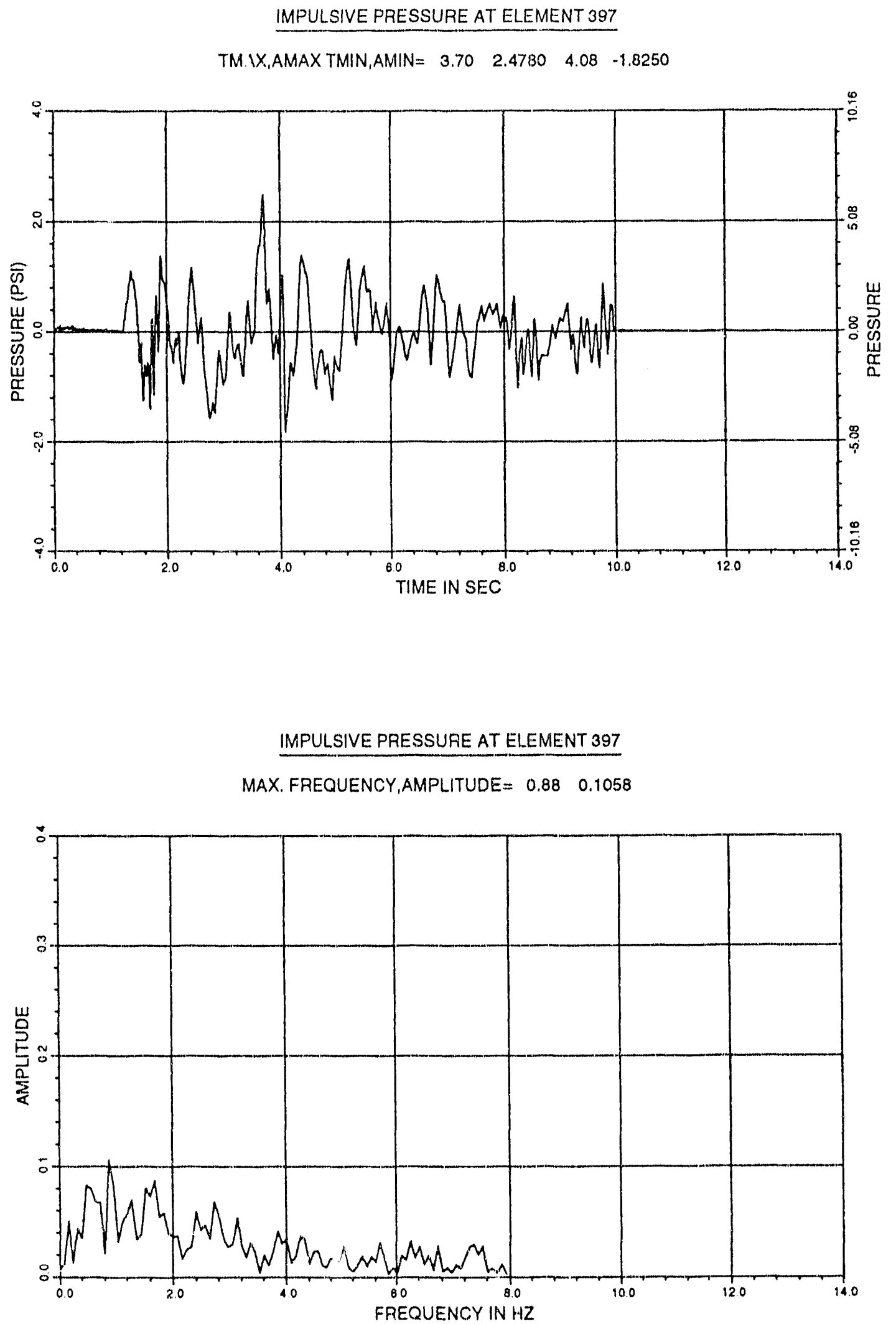

Fig. C-8. Time History of the Impulsive Pressure at Element 397 and iis Fríf for the Case ố $\mu=\overline{b u} \mathrm{cP}$ 

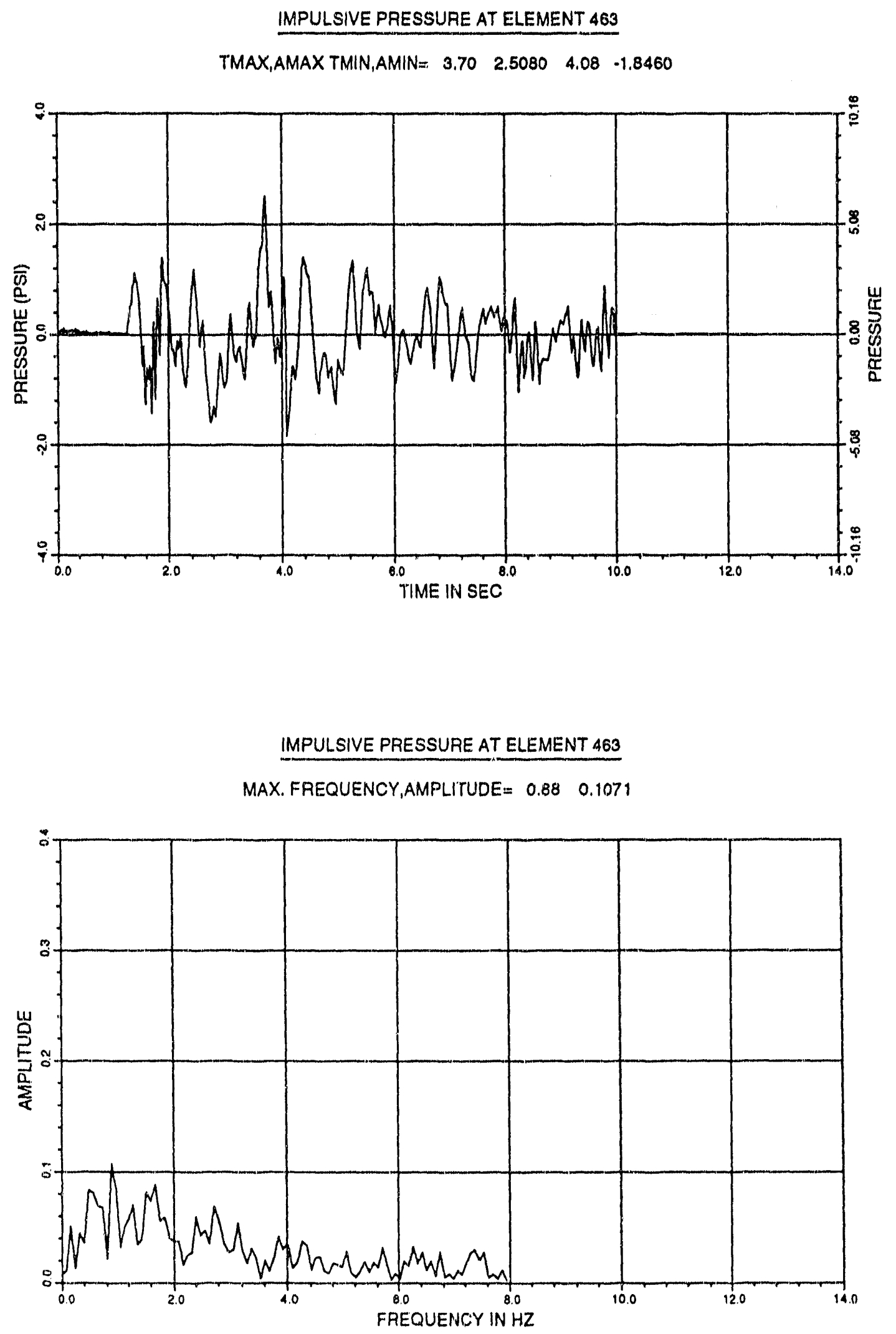

Fig. C-9. Time History of the Impulsive Pressure at Element 463 and its FFT for the Case of $\mu=60 \mathrm{cP}$ 

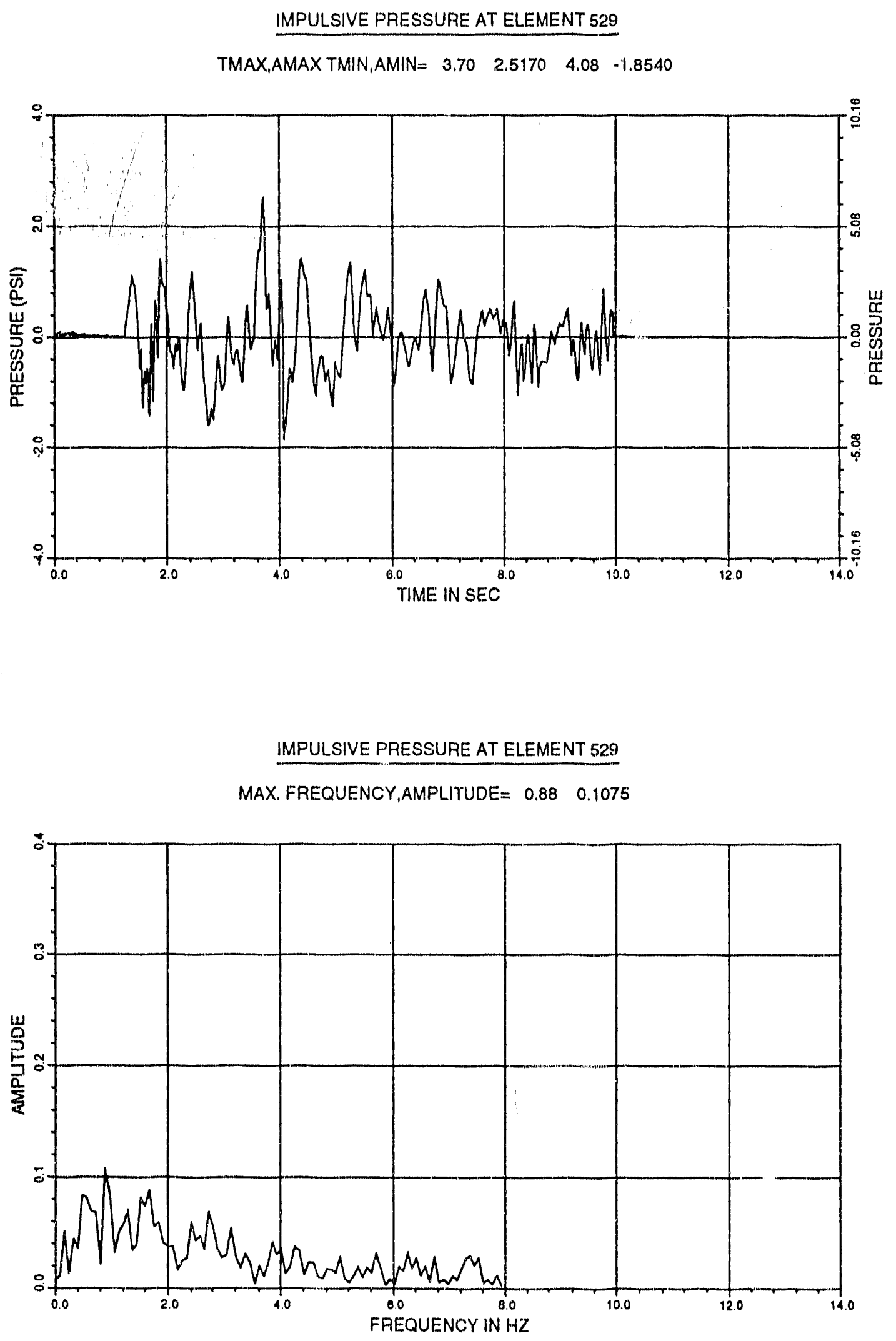

Ffg. C-10. Time History of the Impulsive Pressure at Element 529 and its FFT for the Case of $\mu=60 \mathrm{cP}$ 
IMPULSIVE PRESSURE AT ELEMENT 595

TMAX,AMAX TMIN,AMIN $=3.70 \quad 2.5180 \quad 4.08 \quad-1.8540$

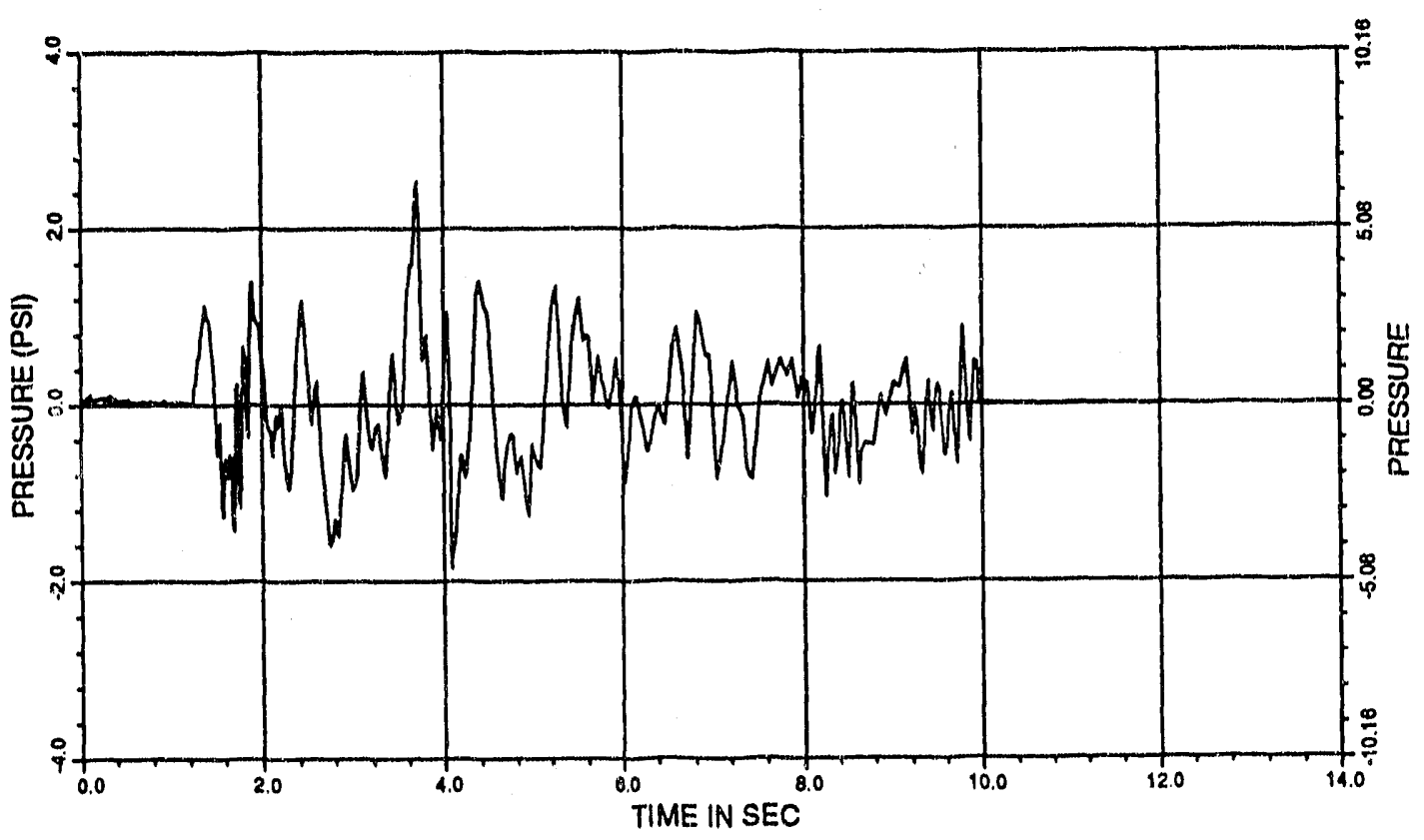

IMPULSIVE PRESSURE AT ELEMENT 595

MAX. FREQUENCY,AMPLITUDE $=0.88 \quad 0.1075$

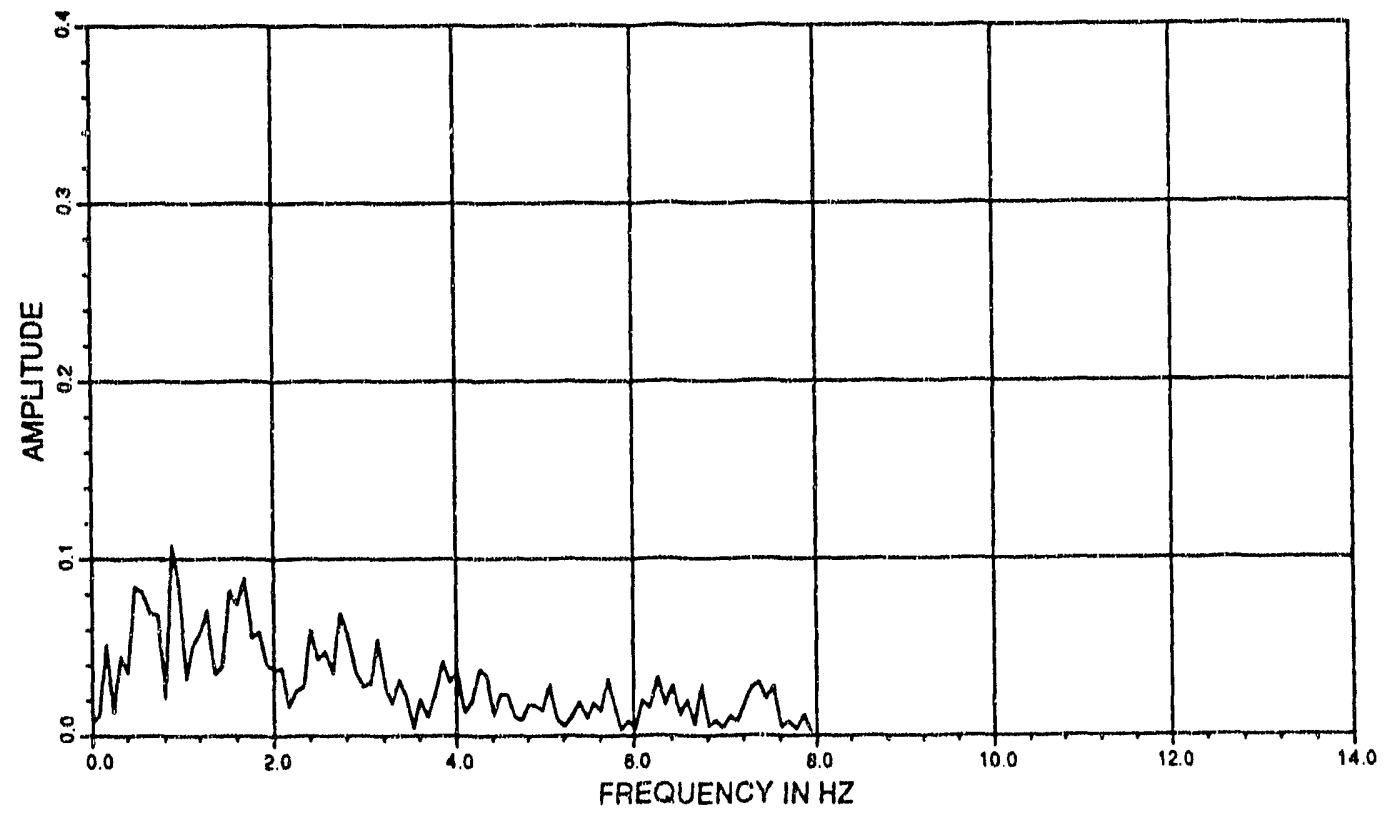

Fig. C-11. Time History of the Impulsive Pressure at Element 529 and its FFT for the Case of $\mu=60 \mathrm{cP}$ 


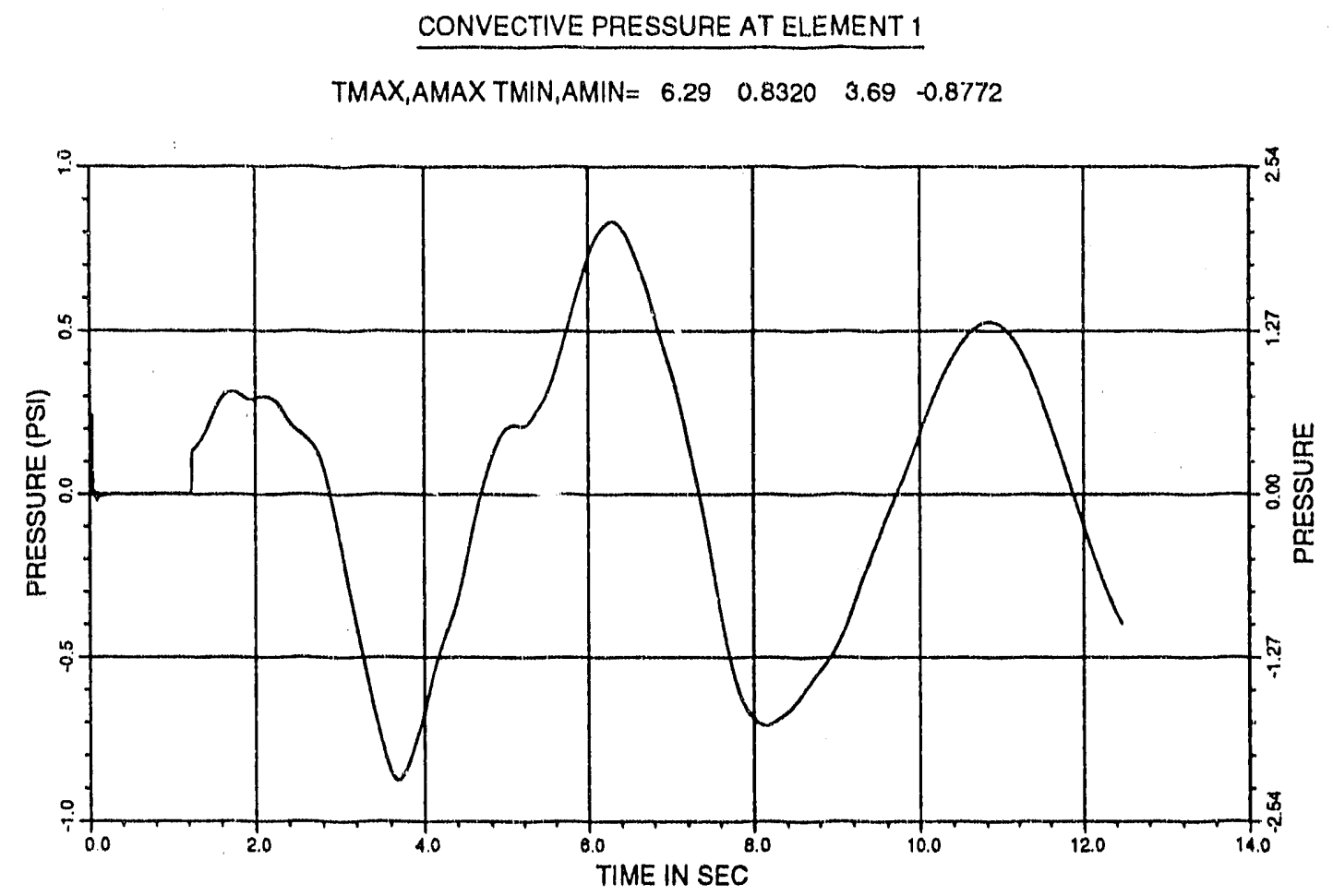

CONVECTIVE PRESSURE AT ELEMENT 1

MAX. FREQUENCY,AMPLITUDE $=0.24 \quad 0.2440$

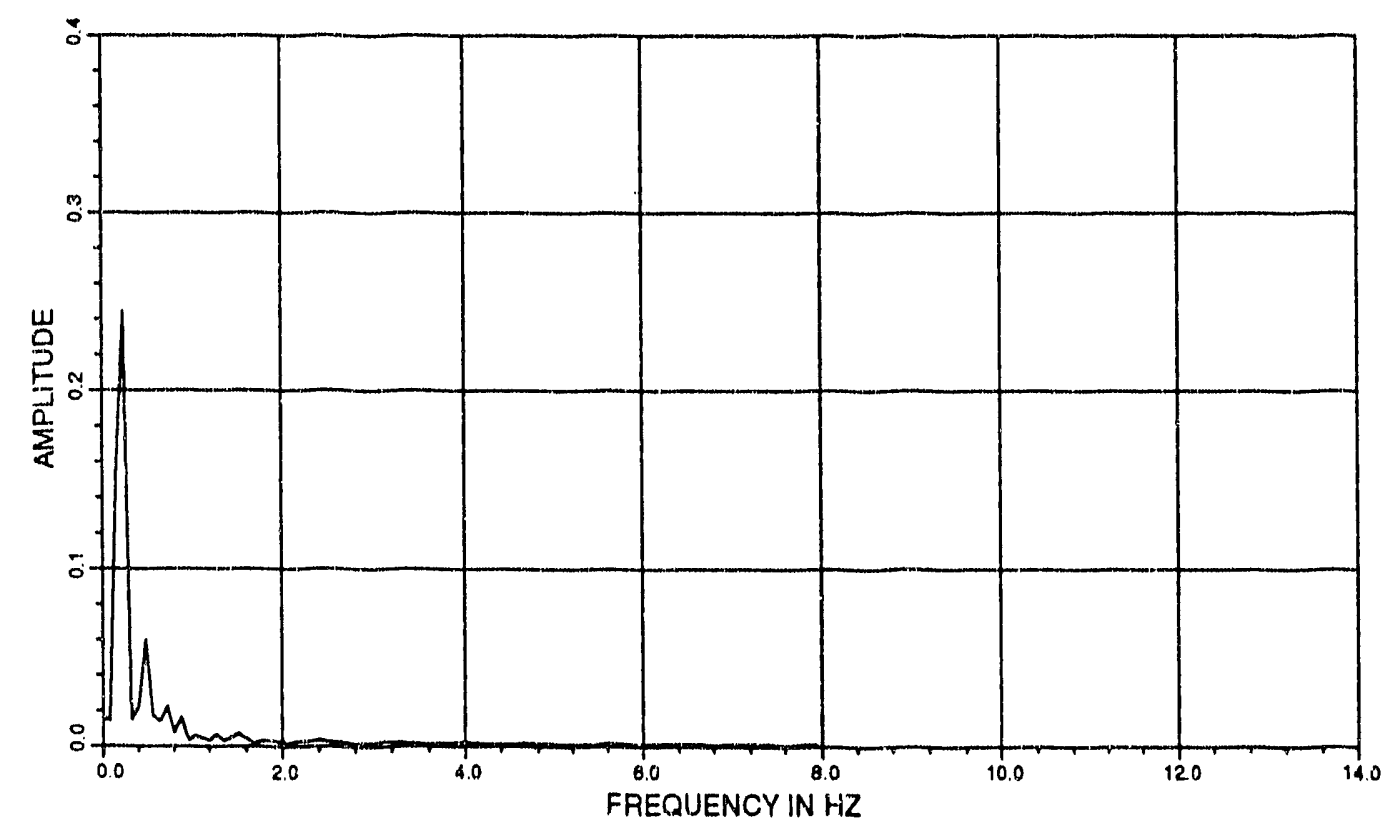

Fig. C-12. Time History of the Convective Pressure at Element 1 and its FFT for the Case of $\mu=60 \mathrm{cP}$ 
CONVECTIVE PRESSURE AT ELEMENT 67

TMAX,AMAX TMIN,AMIN $=6.22 \quad 0.6010 \quad 3.72 \quad-0.6475$

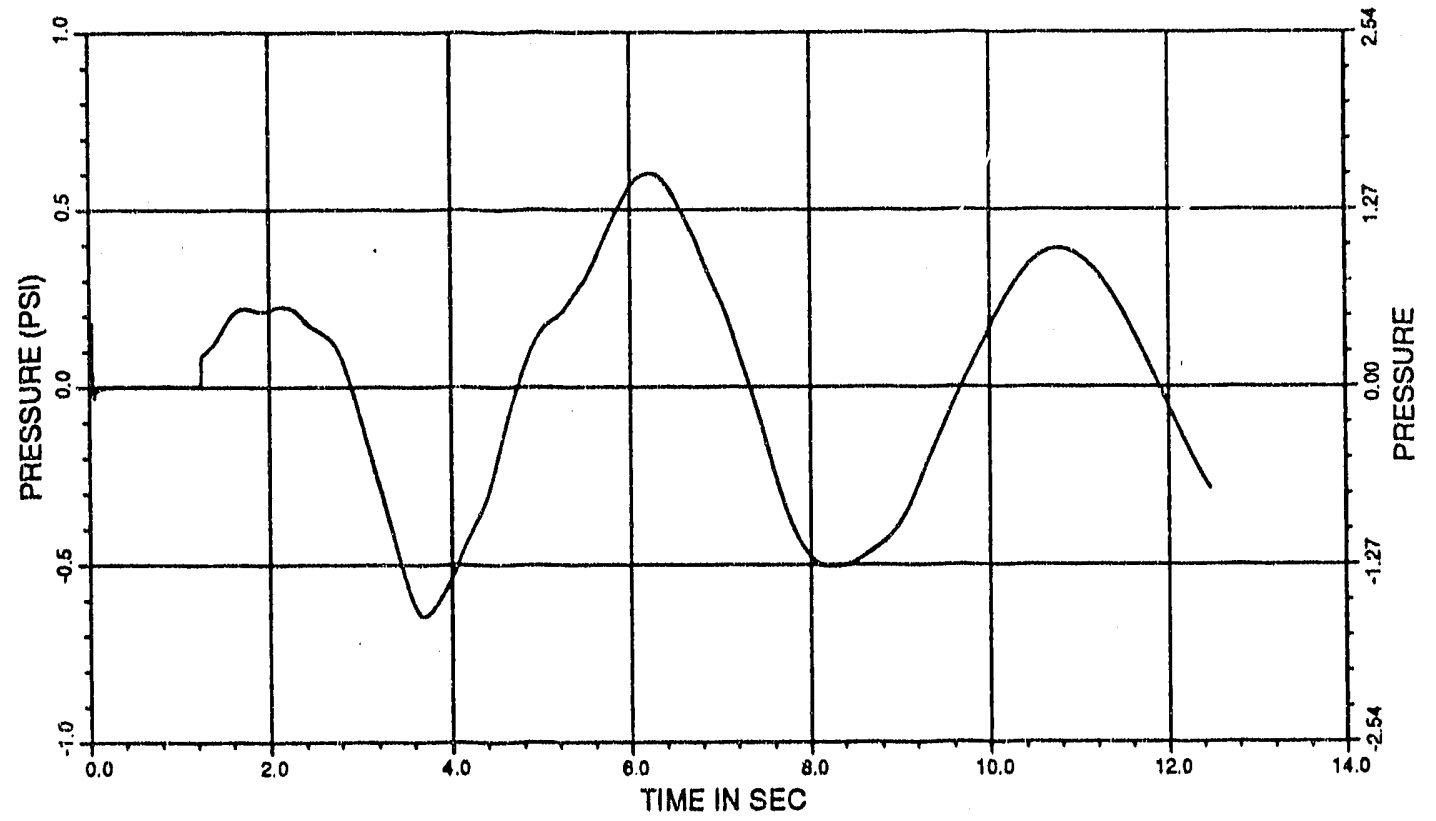

CONVECTIVE PRESSURE AT ELEMENT 67

AMAX. FREQUENCY,AMPLITUDE $=0.24 \quad 0.1854$

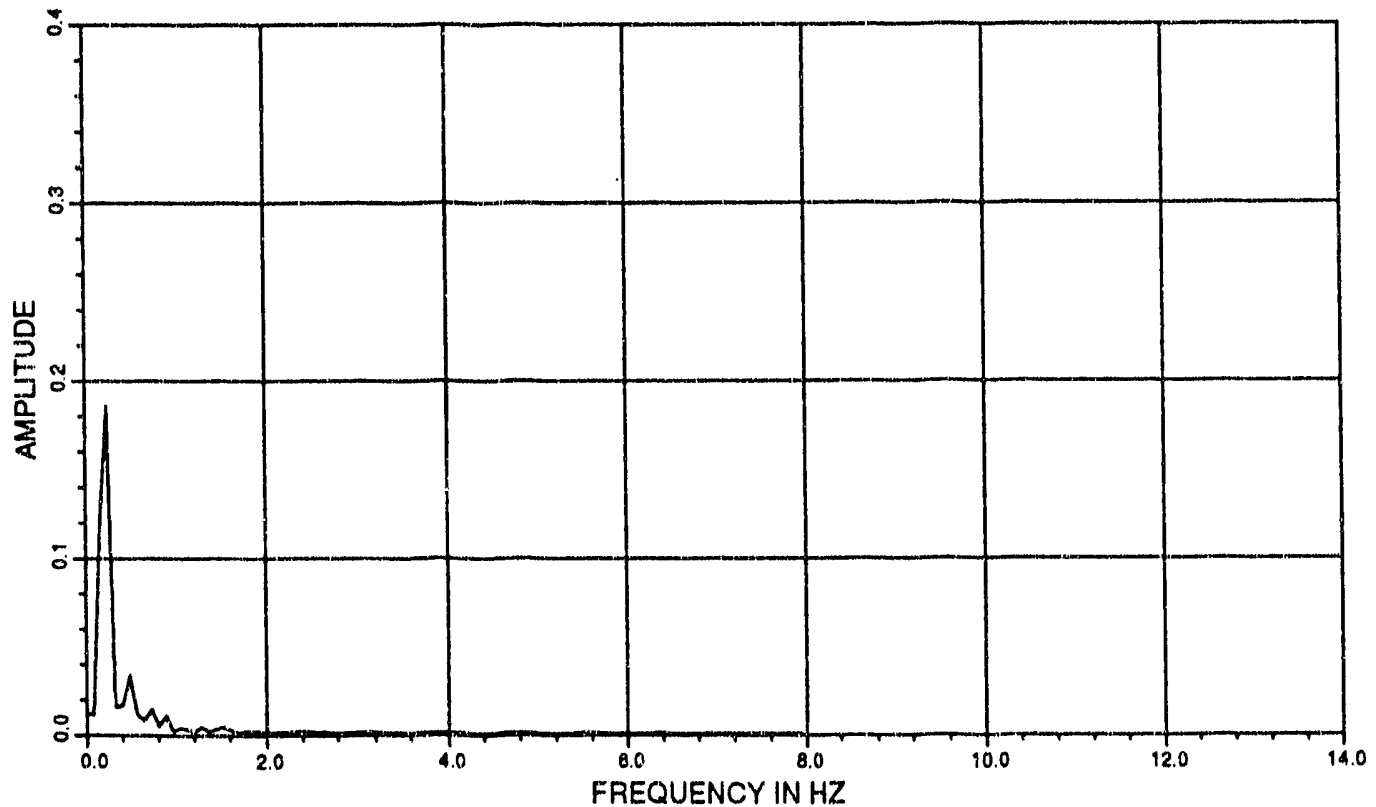

Fig. C-13. Time History of the Convective Pressure at Element 67 and its FFT for the Case of $\mu=60 \mathrm{cP}$ 


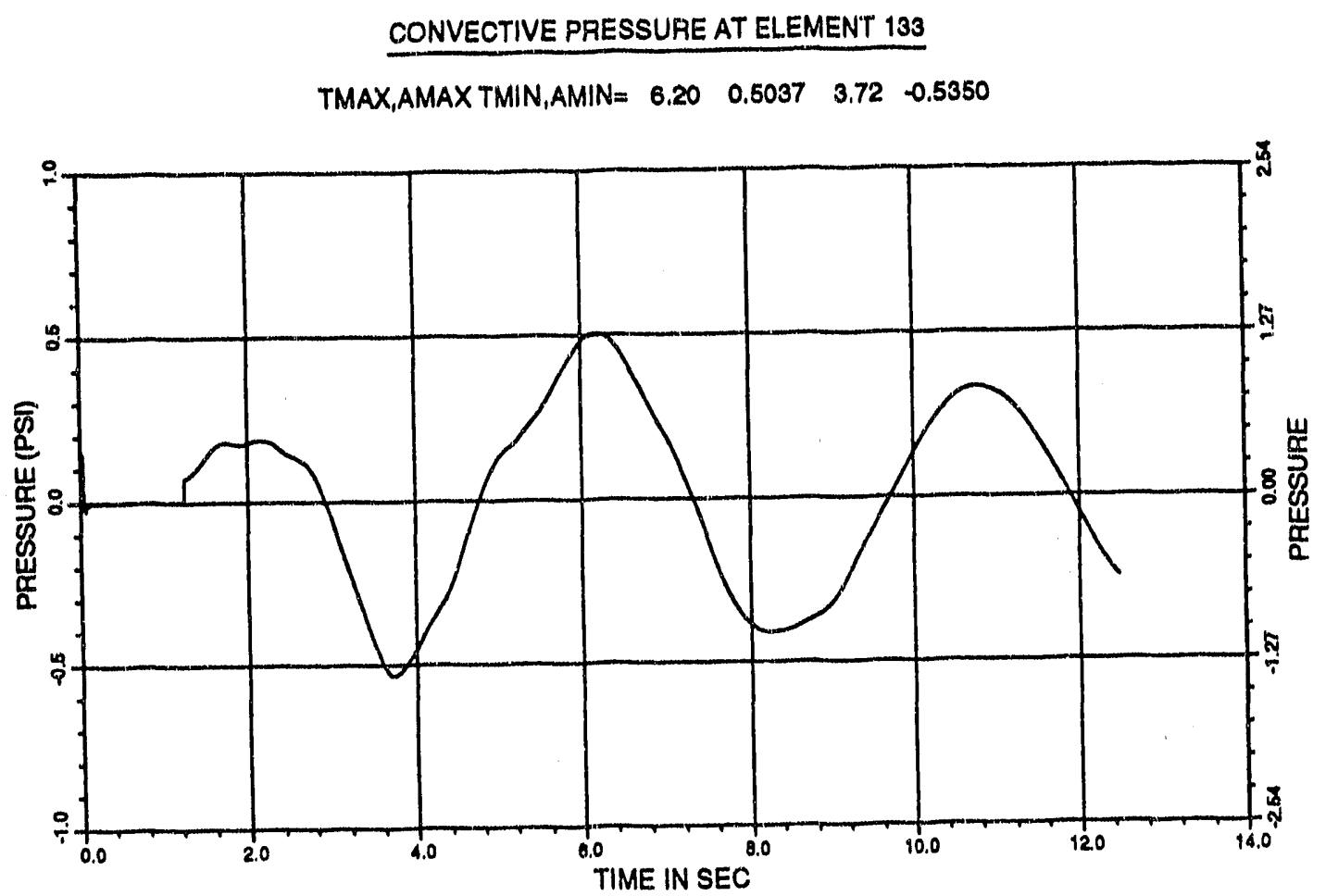

CONVECTIVE PRESSURE AT ELEMENT 133

MAX. FREQUENCY,AMPLITUDE $=0.240 .1549$

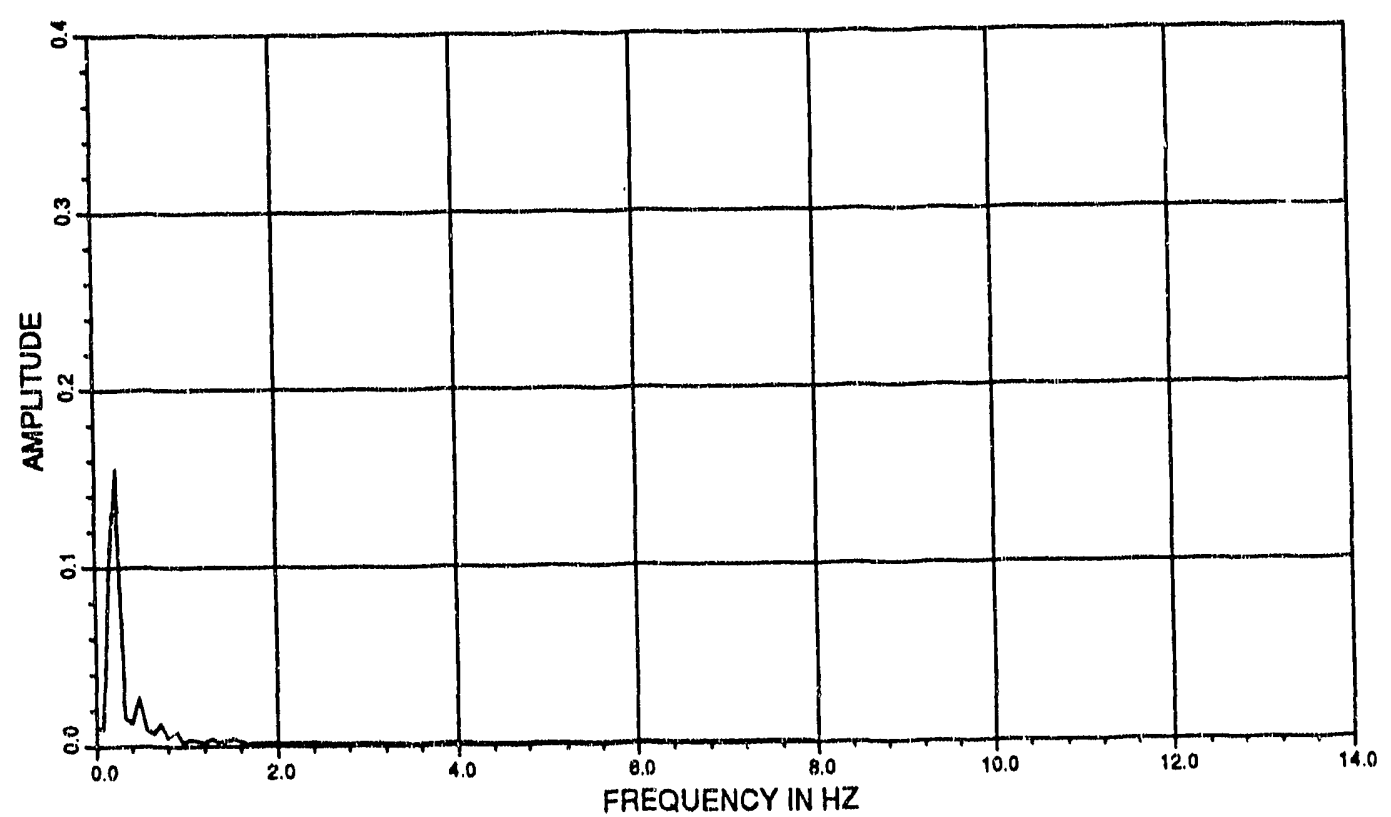

Fig. C-14. Time History of the Convective Pressure at Element 133 and 1.ts FFT for the Case of $\mu=60 \mathrm{cP}$ 
CONVECTIVE PRESSURE AT ELEMENT 199

TMAX,AMAX TMIN,AMIN $=6.18 \quad 0.4459 \quad 3.73 \quad-0.4700$

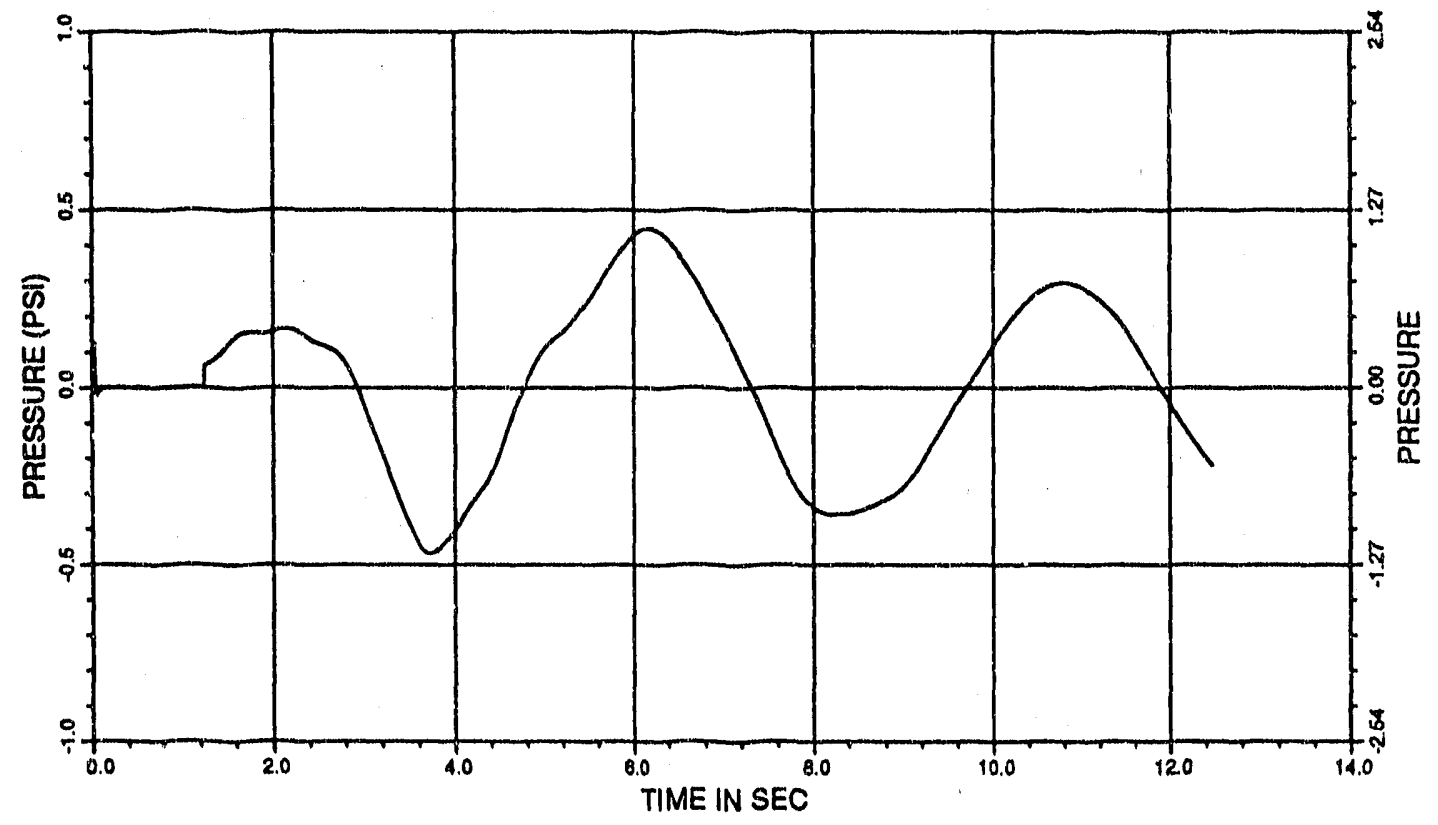

CONVECTIVE PRESSURE AT ELEMENY 199

MAX. FREQUENCY,AMPLITUDE $=0.24 \quad 0.1369$

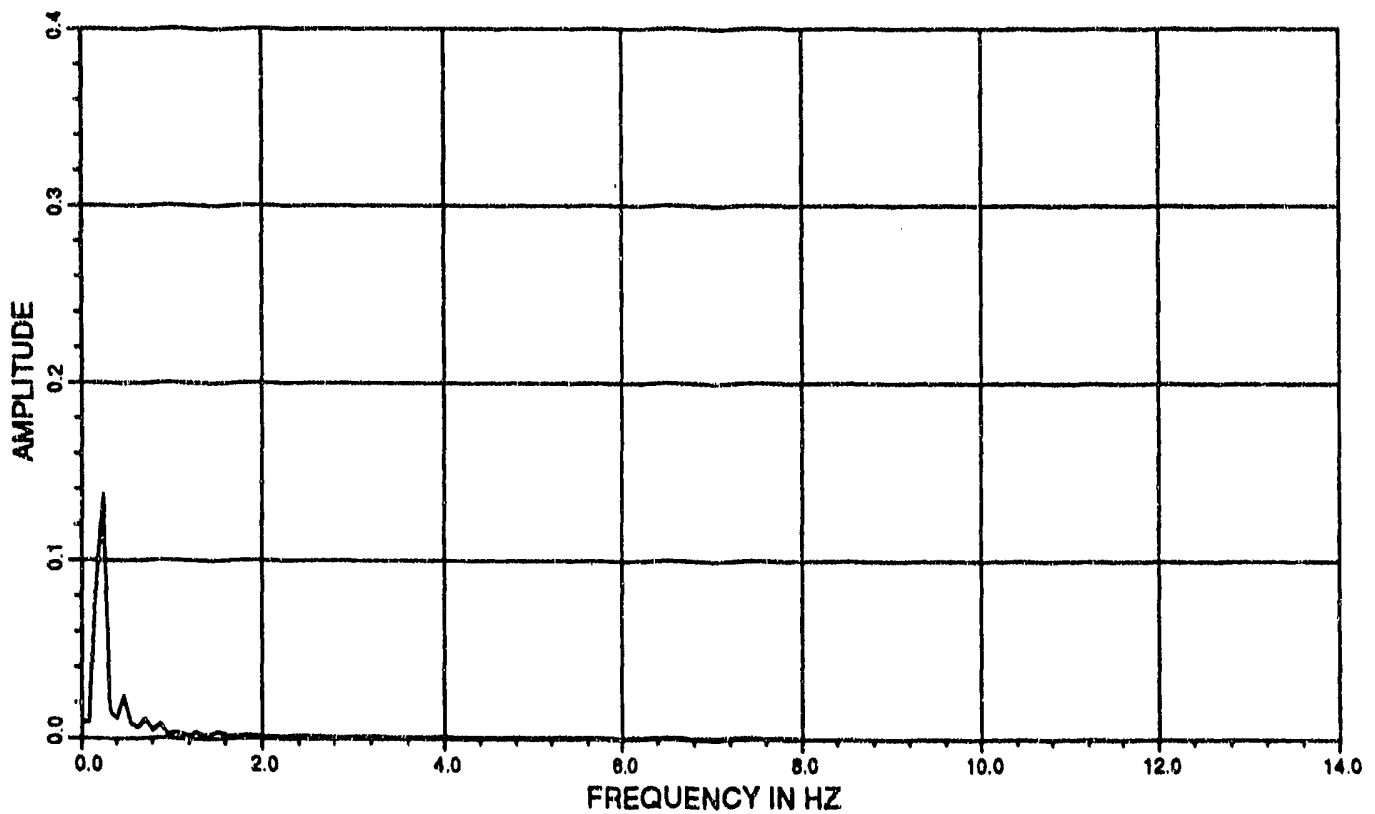

Fig. C-15. Time History of the Convective Pressure at Element 199 and its FFT for the Case of $\mu=60 \mathrm{cP}$ 
CONVECTIVE PRESSURE AT ELEMENT 265

TMAX,AMAX TMIN,AMIN $=6.17 \quad 0.4124 \quad 3.73 \quad-0.4330$

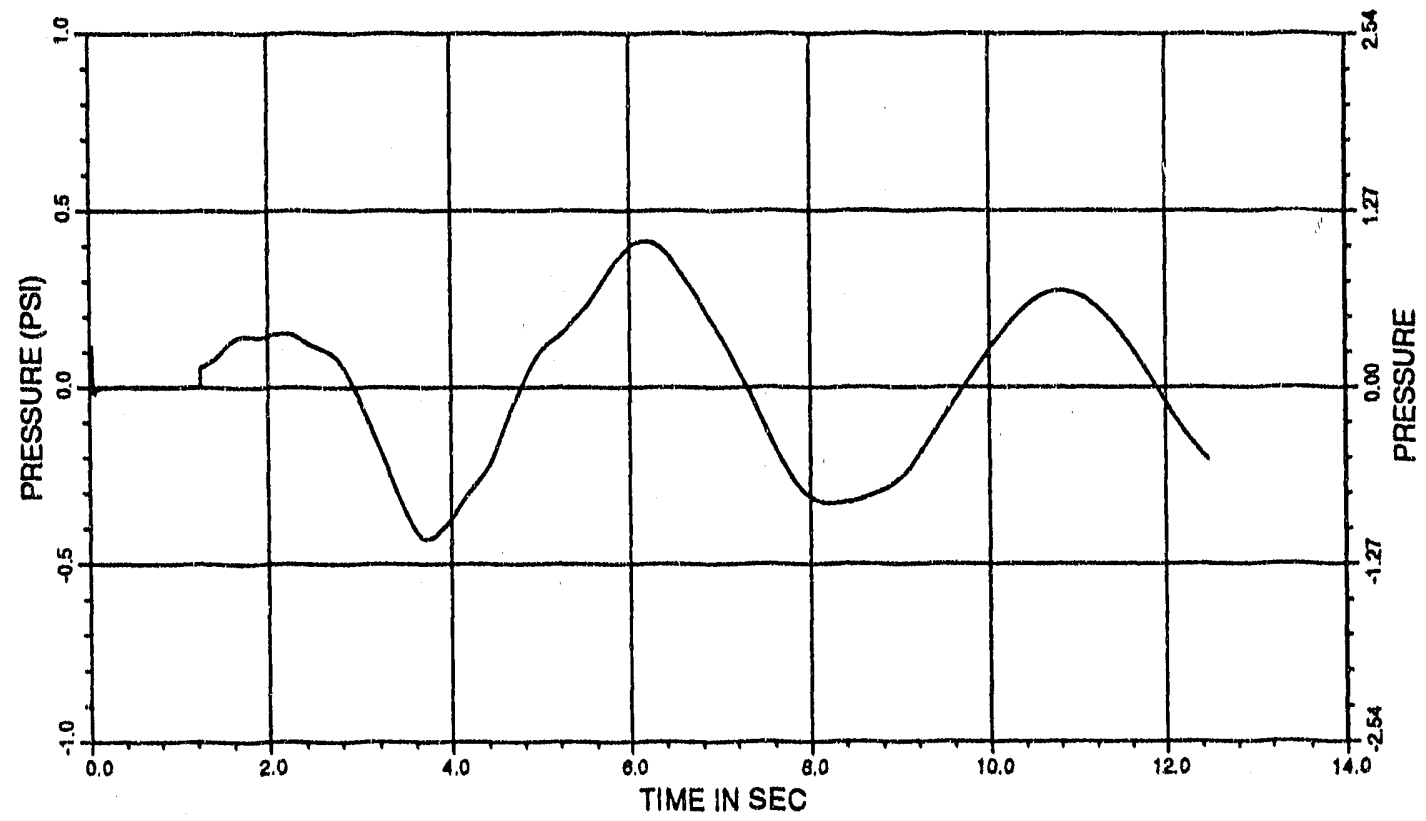

CONVECTIVE PRESSURE AT ELEMENT 265

MAX. FREQUENCY,AMPLITUDE $=0.24 \quad 0.1265$

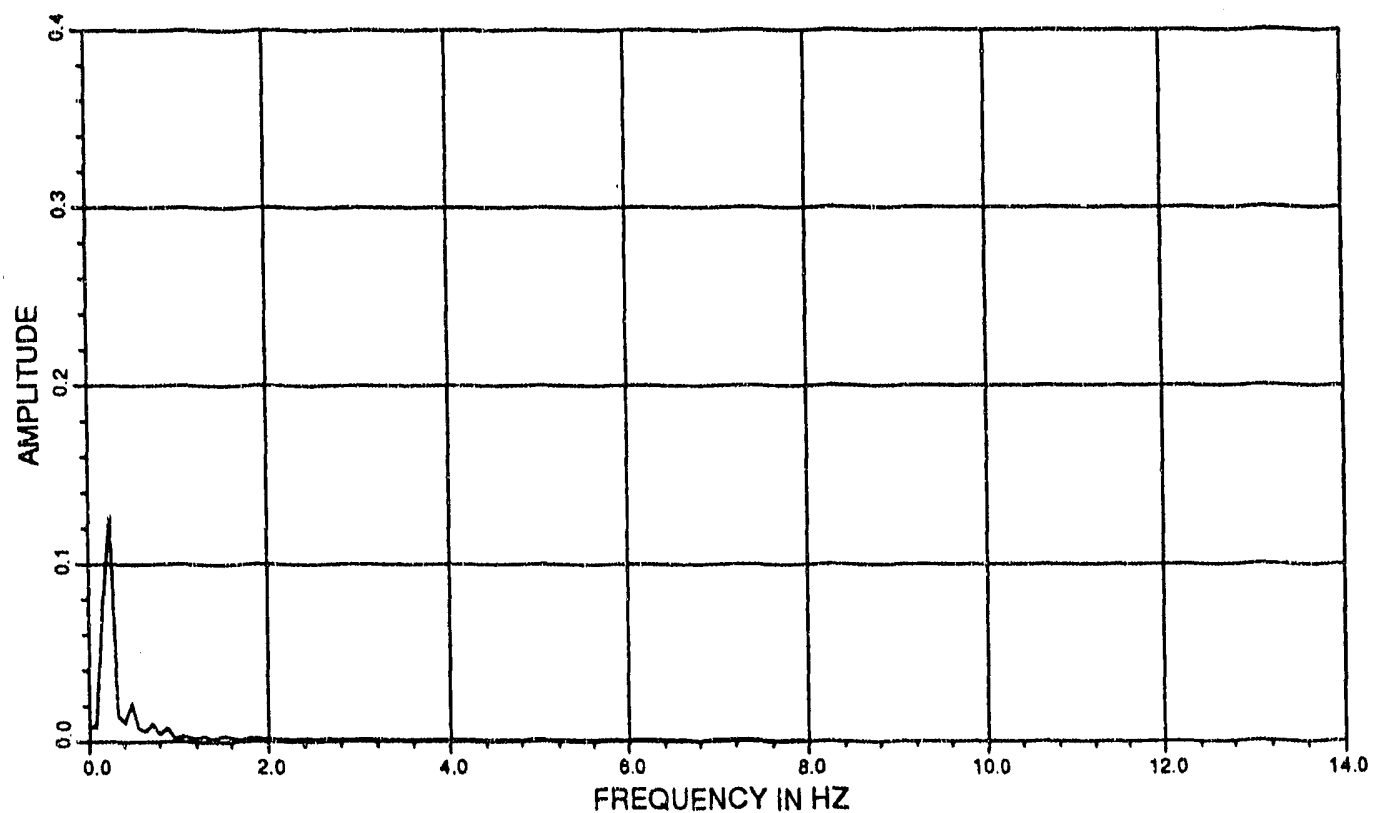

Fig. C-16. Time History of the Convective Pressure at Element 265 and its FFT for the Case of $\mu=60 \mathrm{cP}$ 


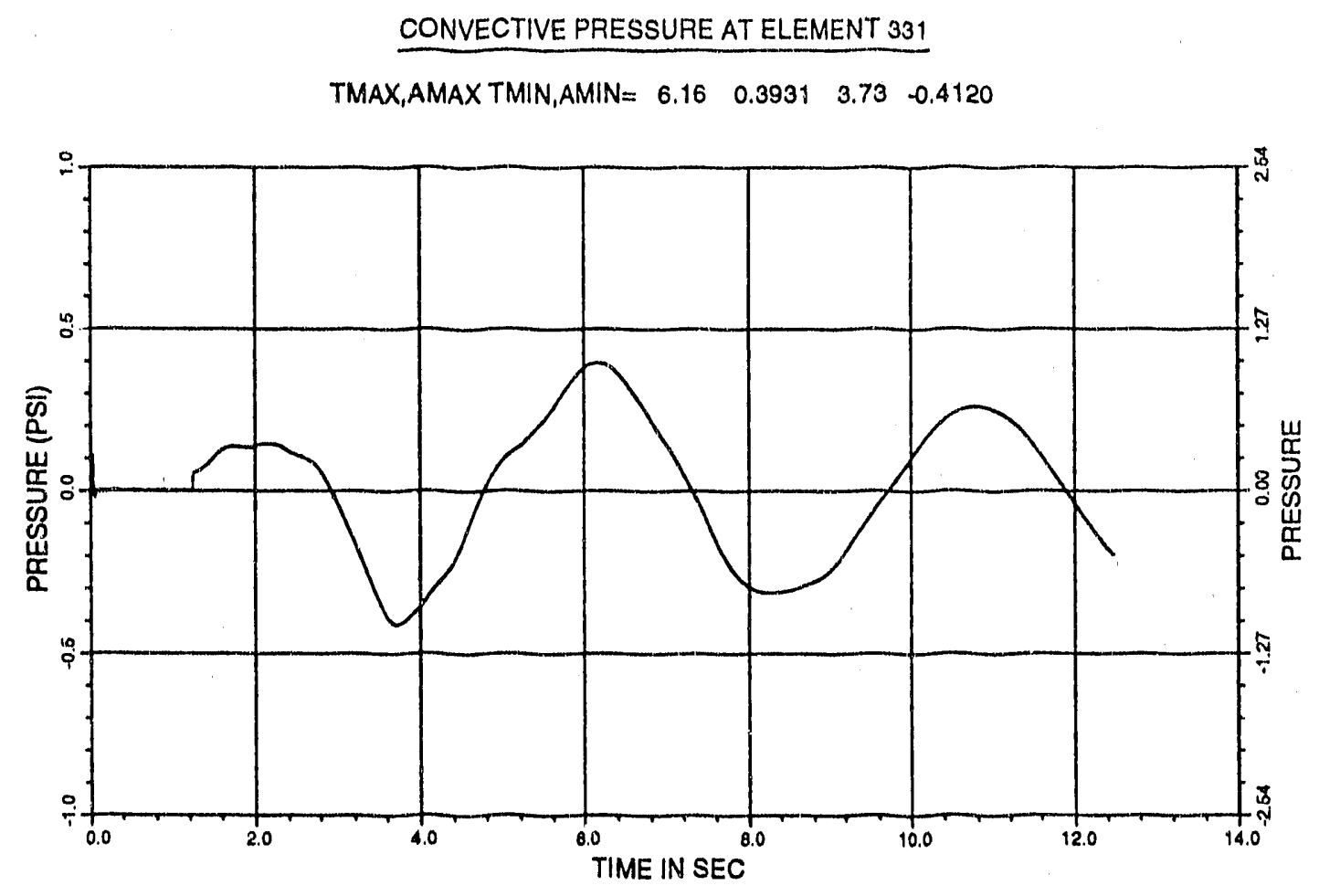

CONVECTIVE PRESSURE AT ELEMENT 331

MAX. FREQUENCY,AMPLITUDE $=0.24 \quad 0.1204$

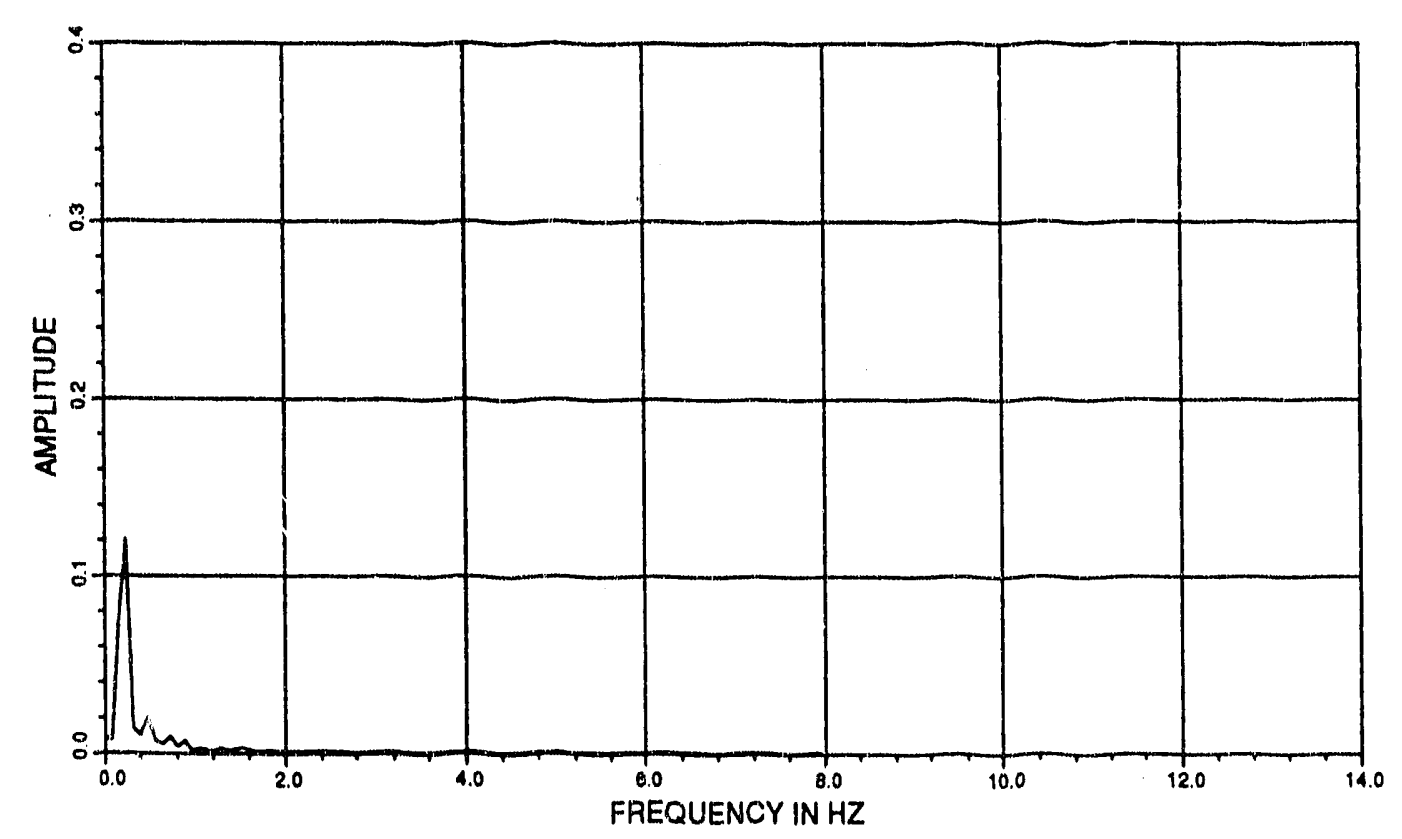

Fig. C-17. Time History of the Convective Pressure at Element 331 and its FFT for the Case of $\mu=60 \mathrm{cP}$ 


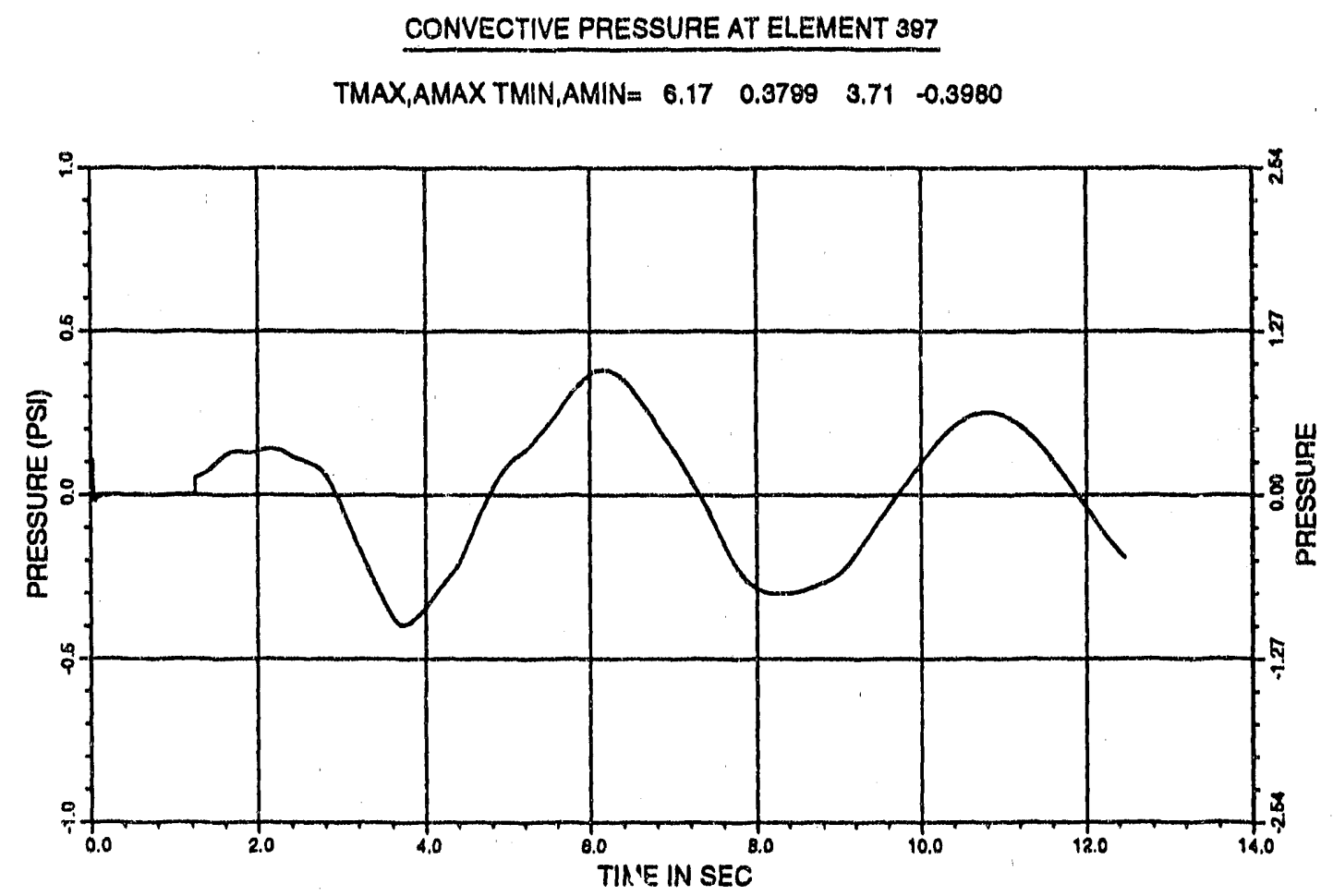

CONVECTIVE PRESSURE AT ELEMENT 397

MAX. FREQUENCY,AMPLITUDE $=0.24 \quad 0.1164$

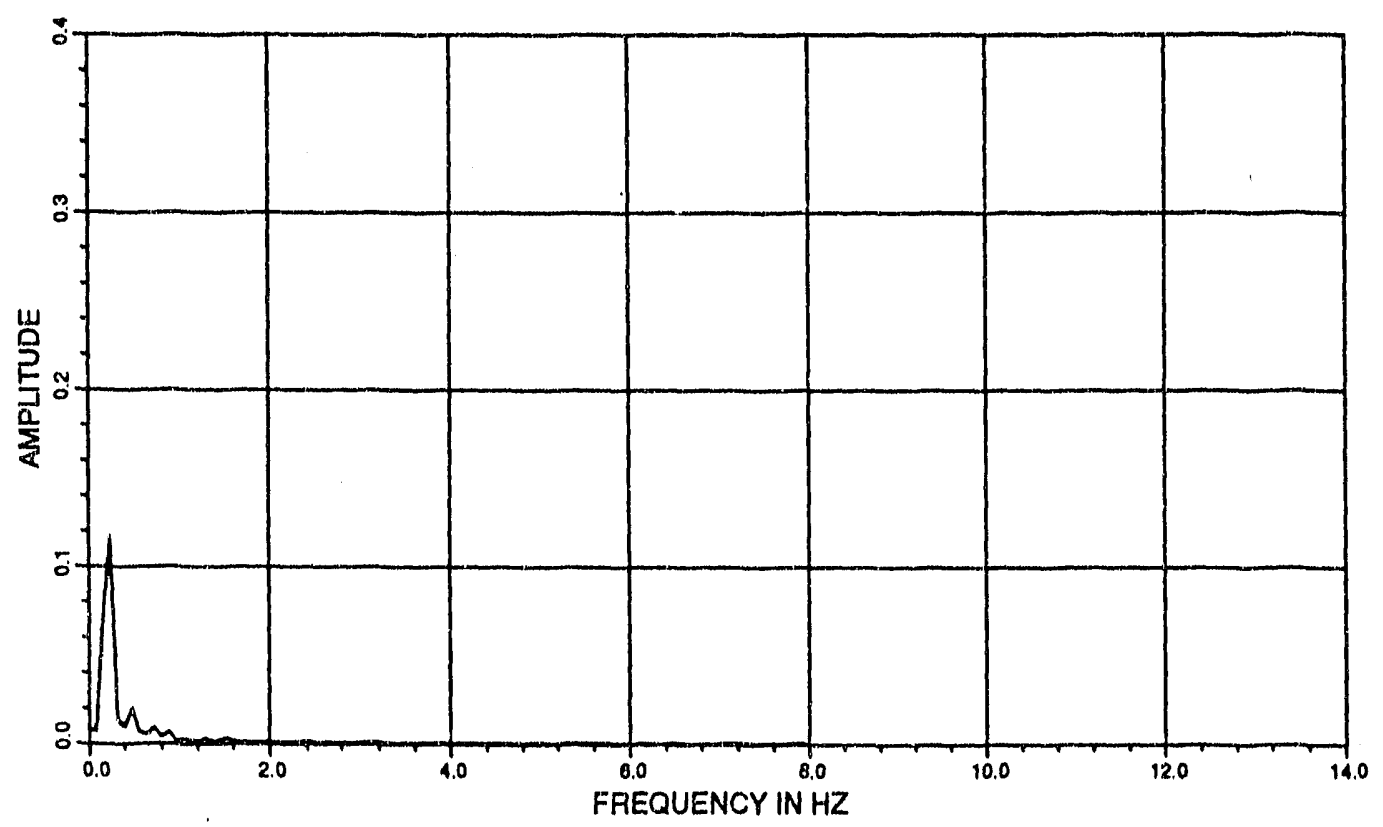

Fig. C-18. Time History of the Convective Pressure at Element 397 and its FFT for the Case of $\mu=60 \mathrm{cP}$ 
CONVECTIVE PRESSURE AT ELEMENT 463

TMAX,AMAX TMIN,AMIN= $=\begin{array}{lllll}6.16 & 0.3718 & 0.73 & 0.3890\end{array}$

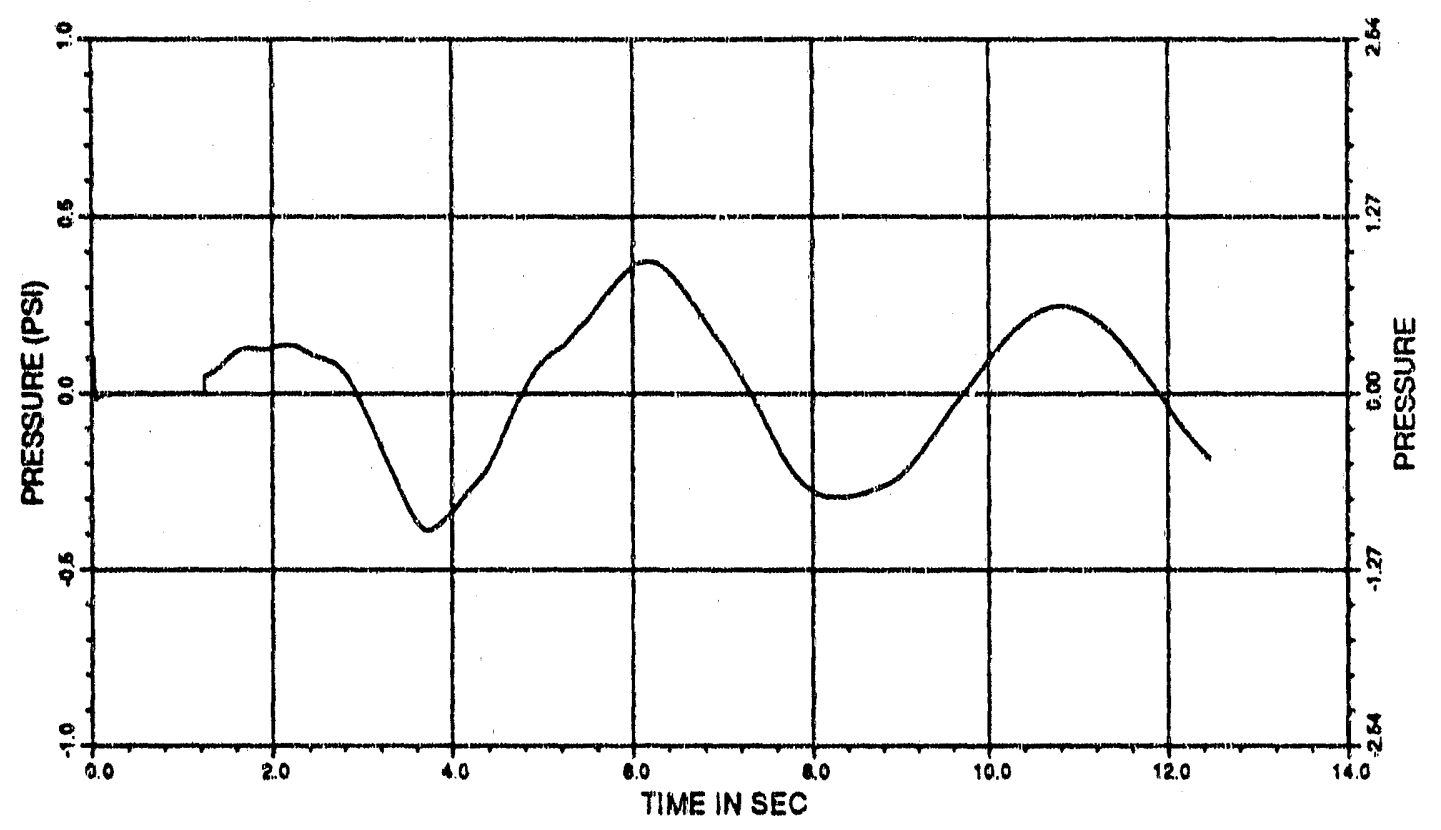

CONVECTIVE PRESSURE AT ELEMENT 463

MAX. FREQUENCY,AMPLITUDE: $0.24 \quad 0.1138$

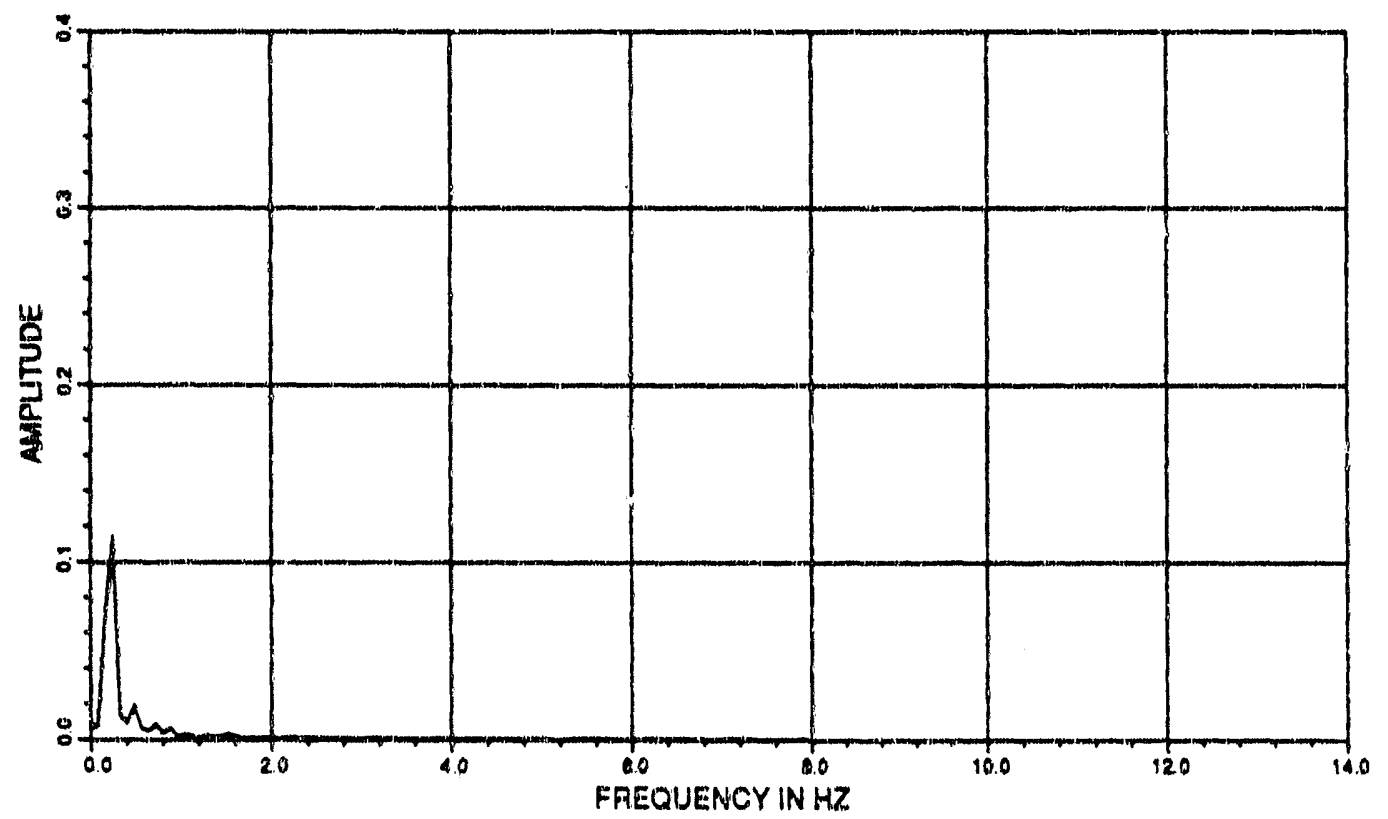

F1g. C-19. Time History of the Convective Pressure at Element 463 and 1ts FFT for the Case of $\mu=60 \mathrm{cP}$ 

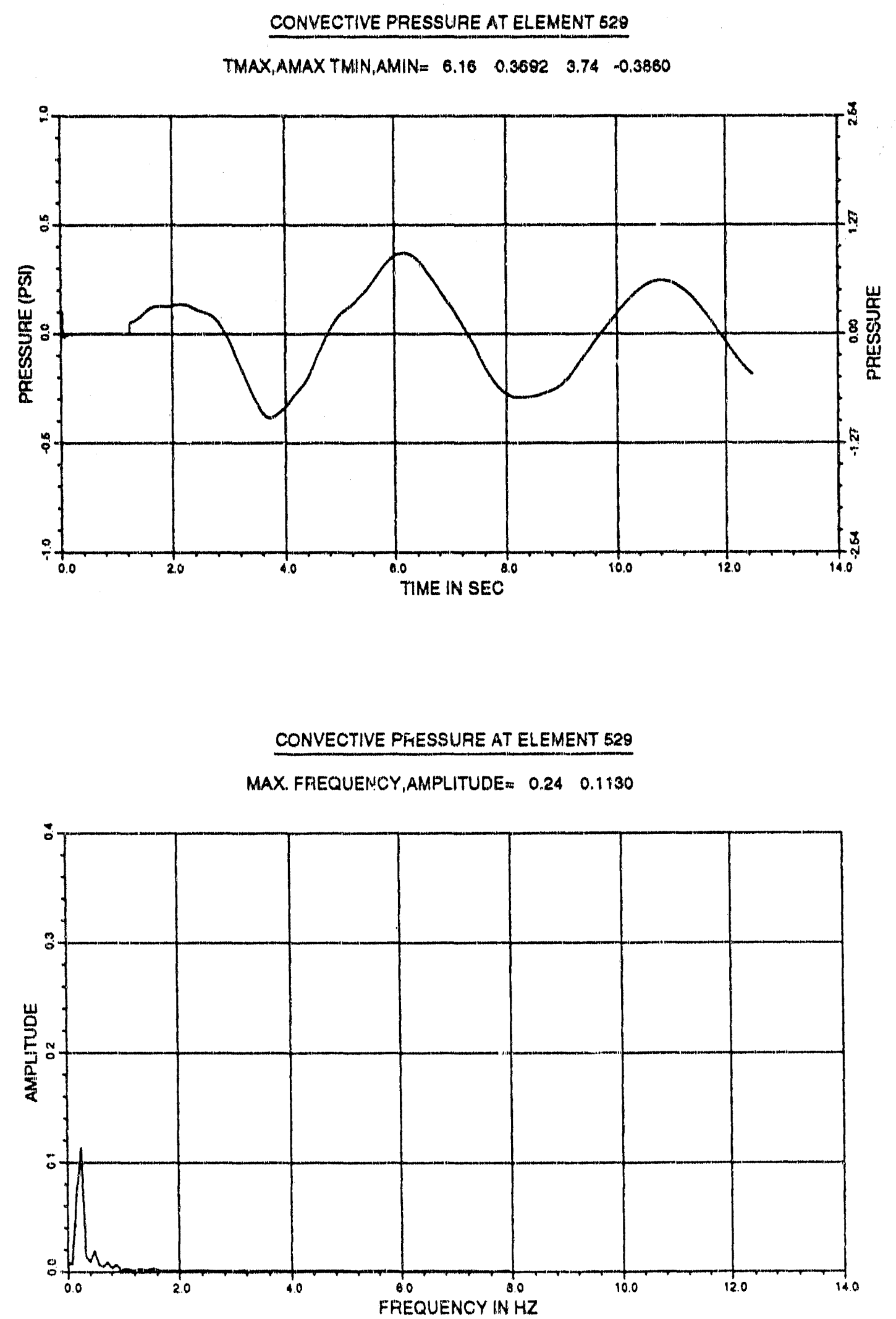

Fig. C-20. Time History of the Convective Pressure at Element 529 and its $\mathrm{FFT}$ for the Case of $\mu=60 \mathrm{cP}$ 
CONVECTIVE PRESSURE AT ELEMENT 595

TMAX,AMAX TMIN,AMIN:= $6.16 \quad 0.3690 \quad 3.73 \quad-0.3860$

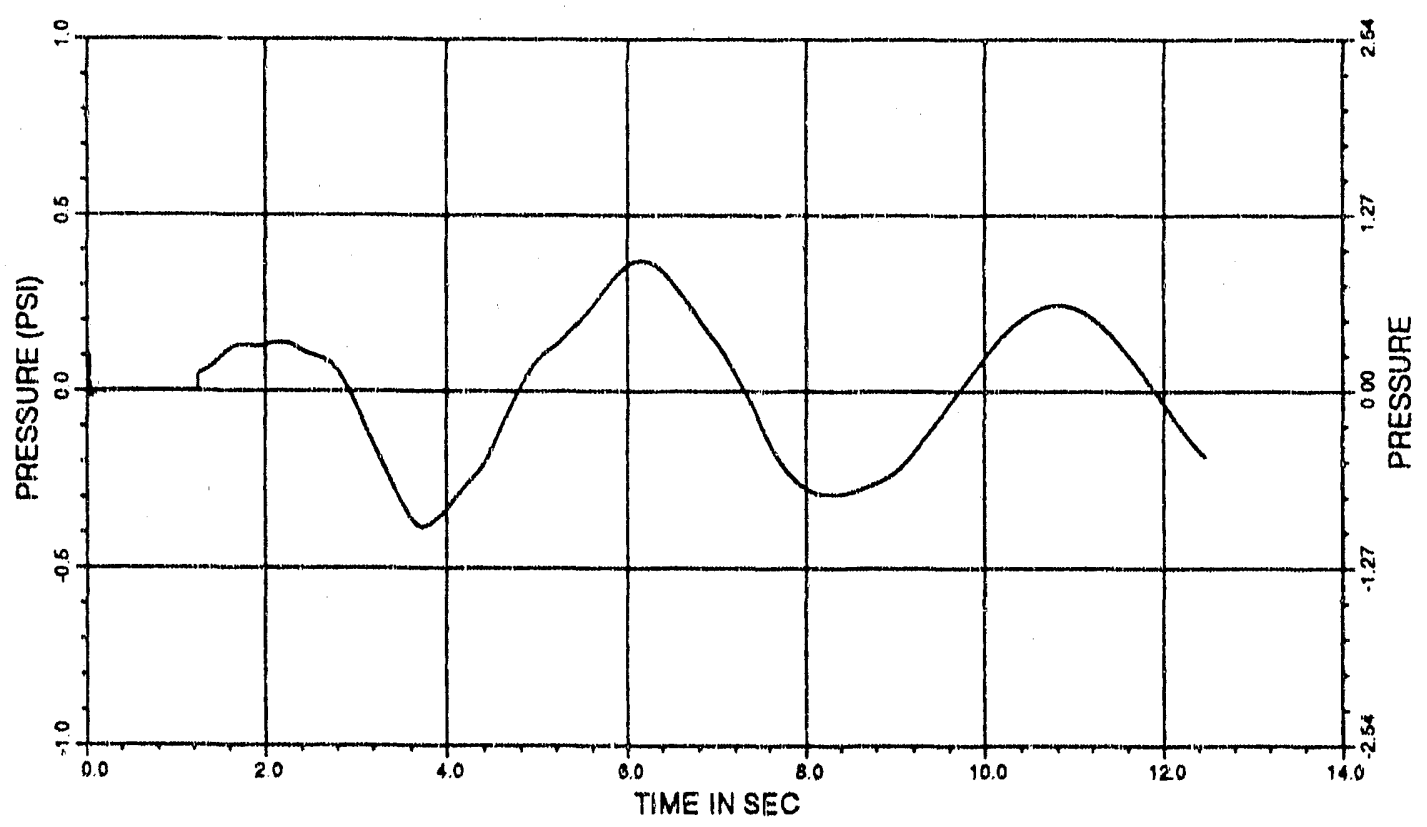

CONVECTIVE PRESSURE AT ELEMENT 595

MAX, FREQUENCY,AMPLITUDE $=0.24 \quad 0.1130$

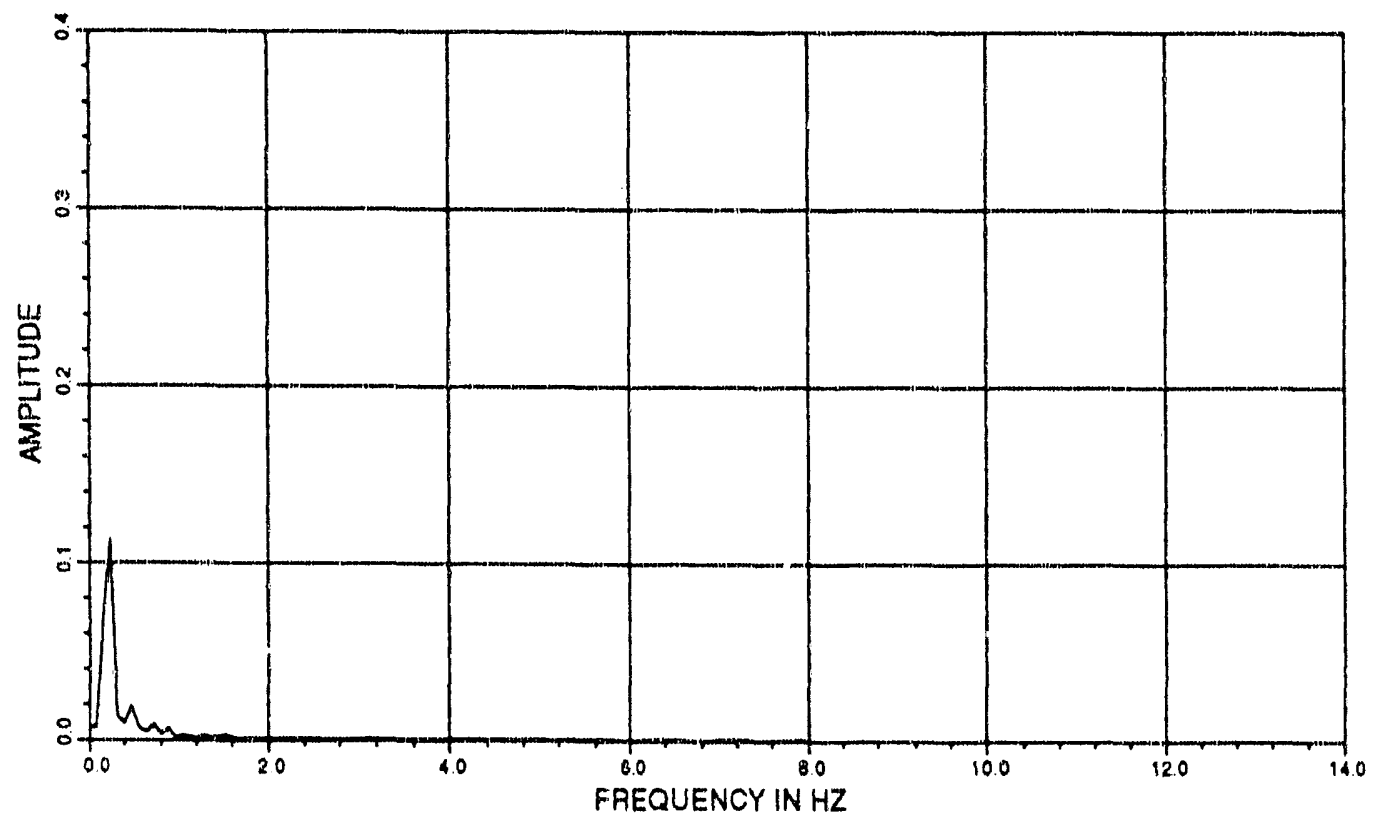

Fig. C-21. Time History of the Convective Pressure at Element 595 and its FFT for the Case of $\mu=60 \mathrm{cP}$ 


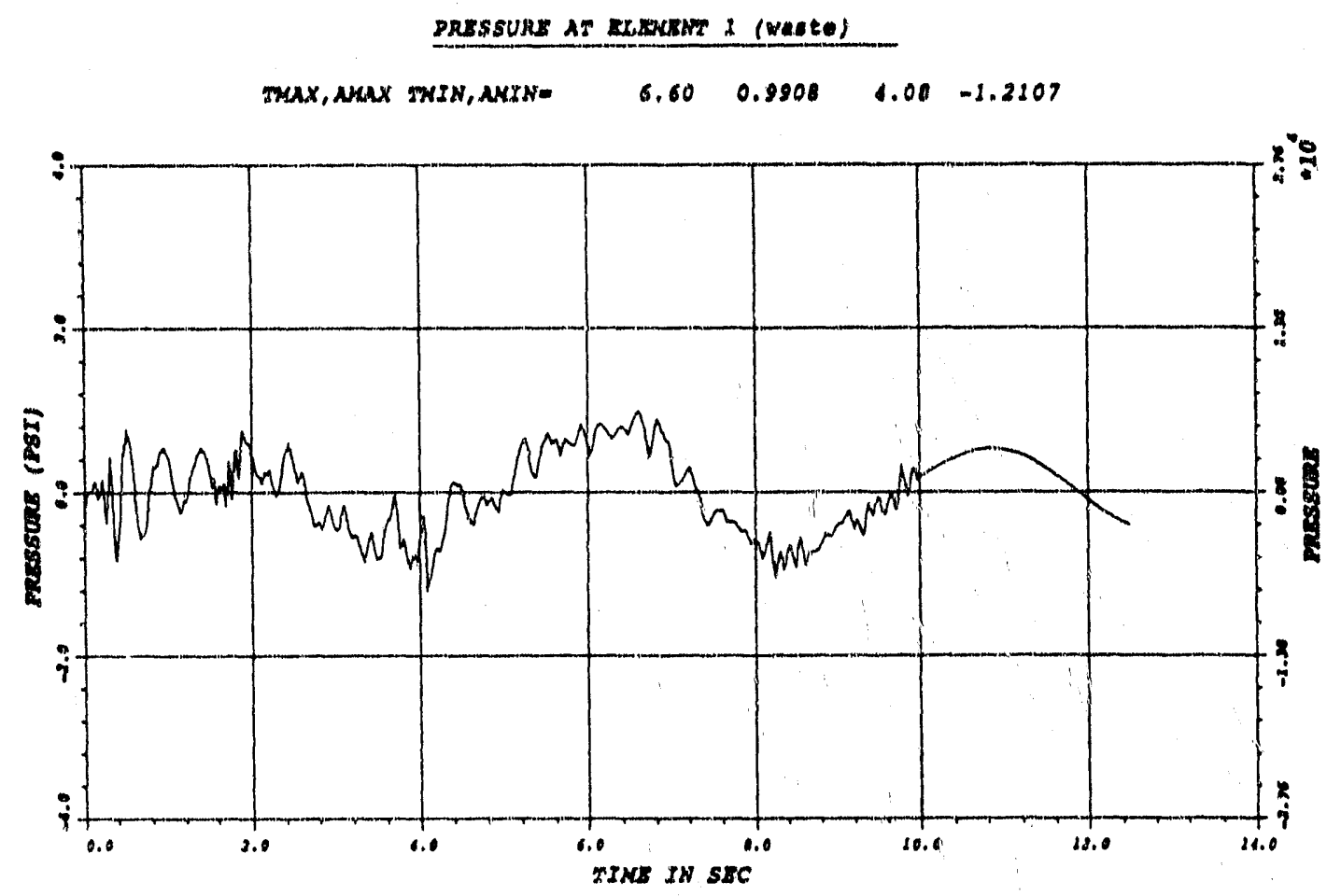

PRSSisurer AT ELENGNT 1 (waste)

NAX, FREQUENCY, AMELITUDZE 0.240 .2183

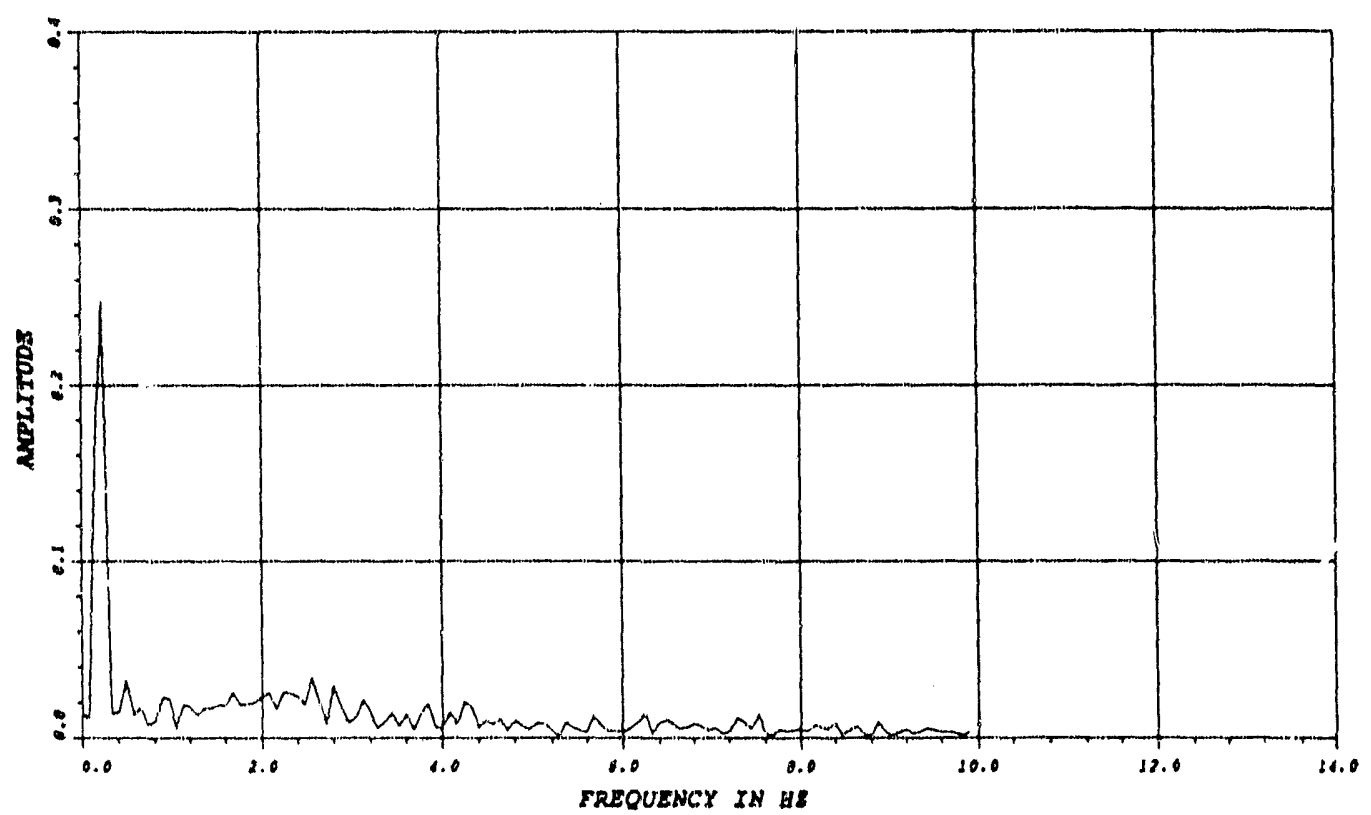

Fig. C-22. Time History of the Total Pressure at Element 1 and its FFT for the Case of $\mu=60 \mathrm{cP}$ 


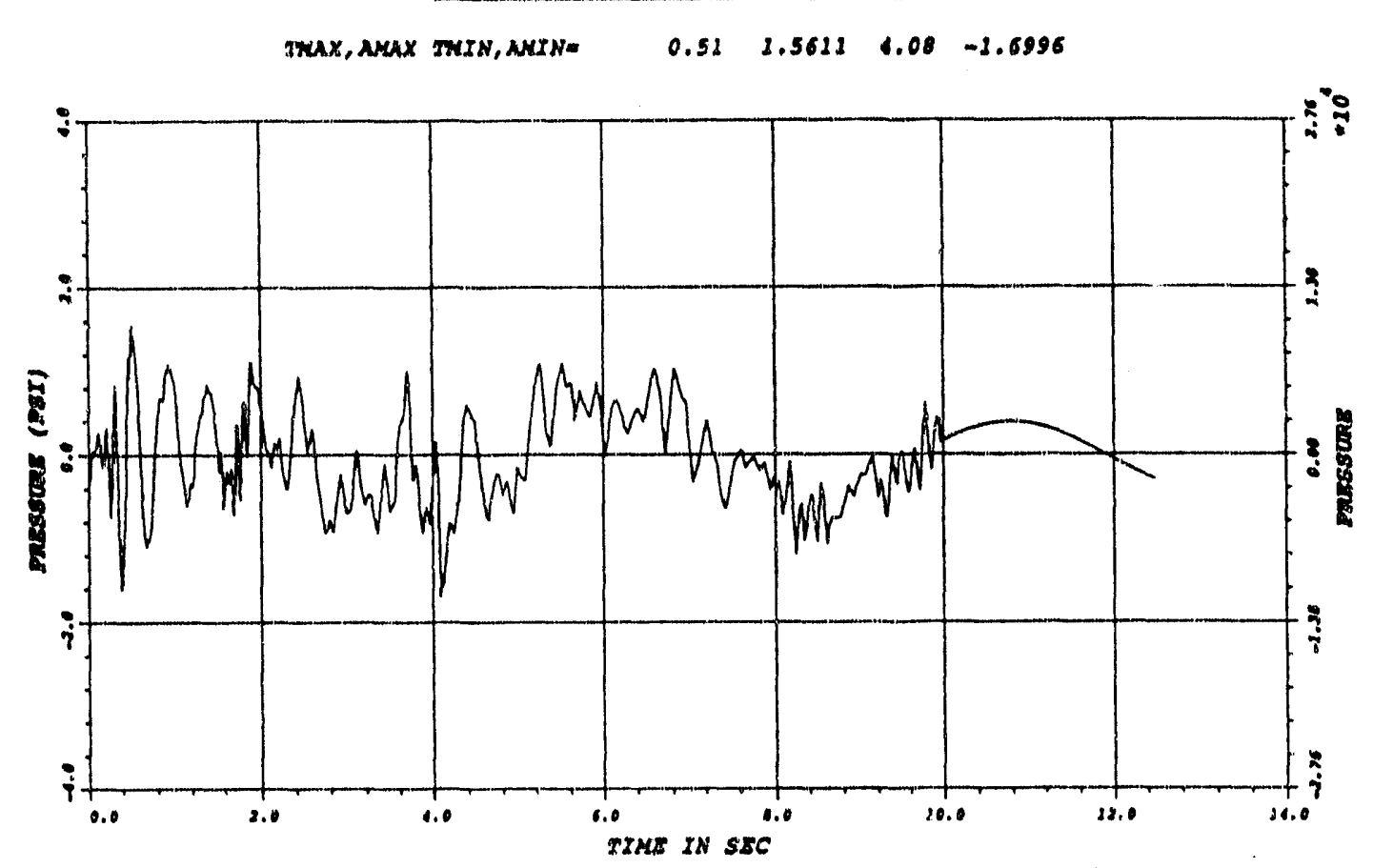

PRESSURS AT ELWERT G7 (WAEte)

MAX, PRSQUENCY, NOPLITUDE= 0.210 .1905

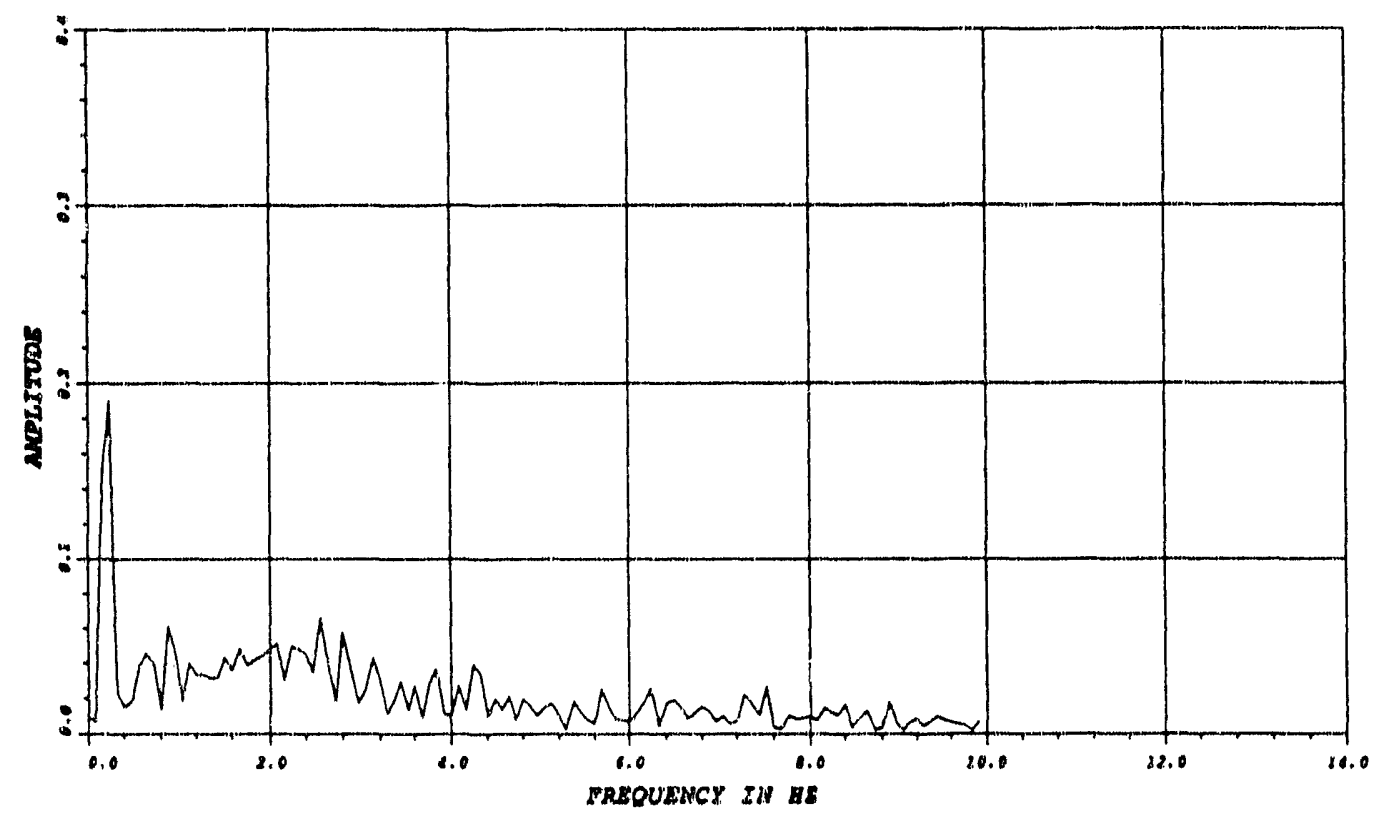

Fig. C-23. Time History of the Total Pressure at Element 67 and its FFT for the Case of $\mu=60 \mathrm{cP}$ 
PRASSURA AT RLERENT 133 (westo)

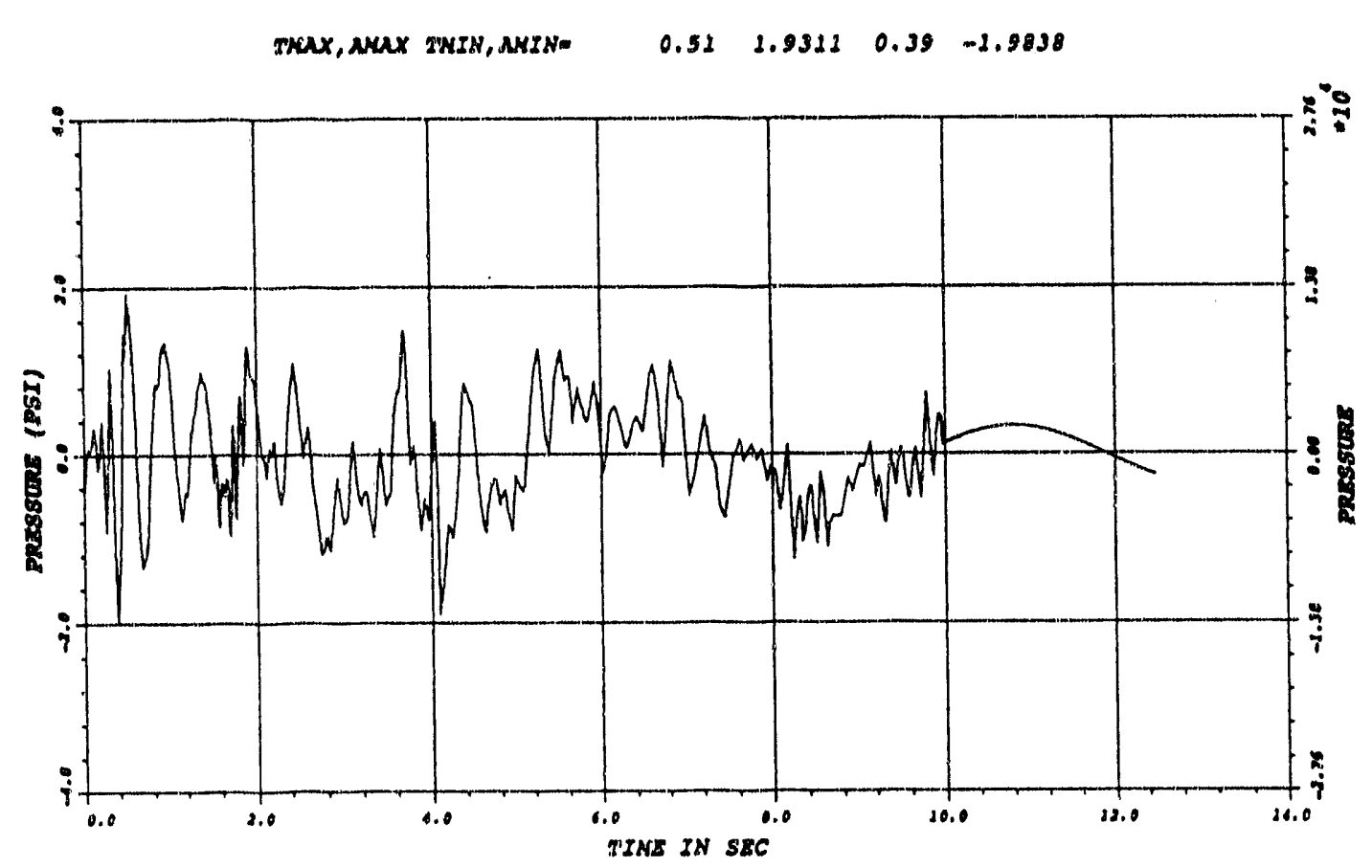

PRESSURE AT ELAKENT 133 (wAETe)

MAX, FRSQUENCY, MAPEITUDS- $\quad 0.210 .1605$

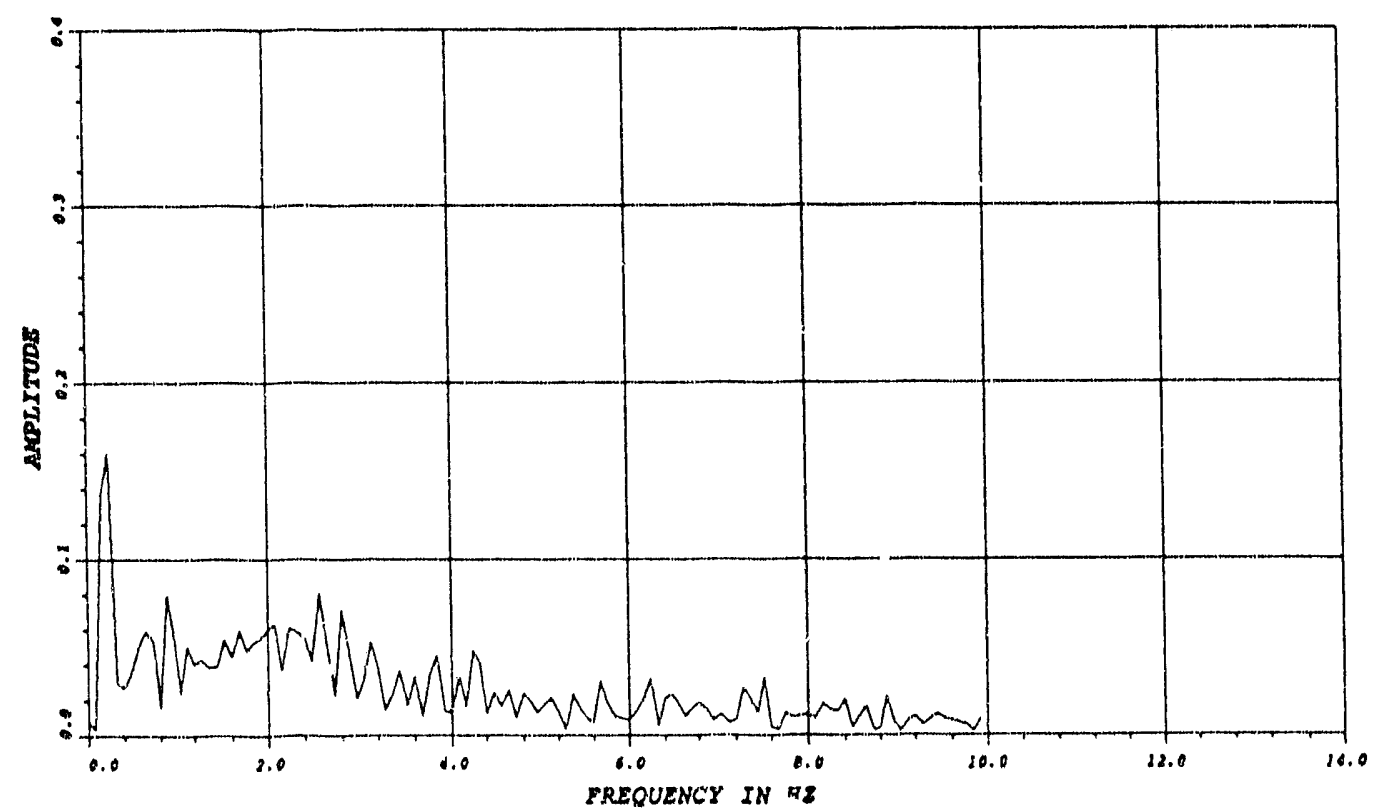

Fig. C-24. Time History of the Total Pressure at Element 133 and its FFT for the Case of $\mu=60 \mathrm{cP}$ 


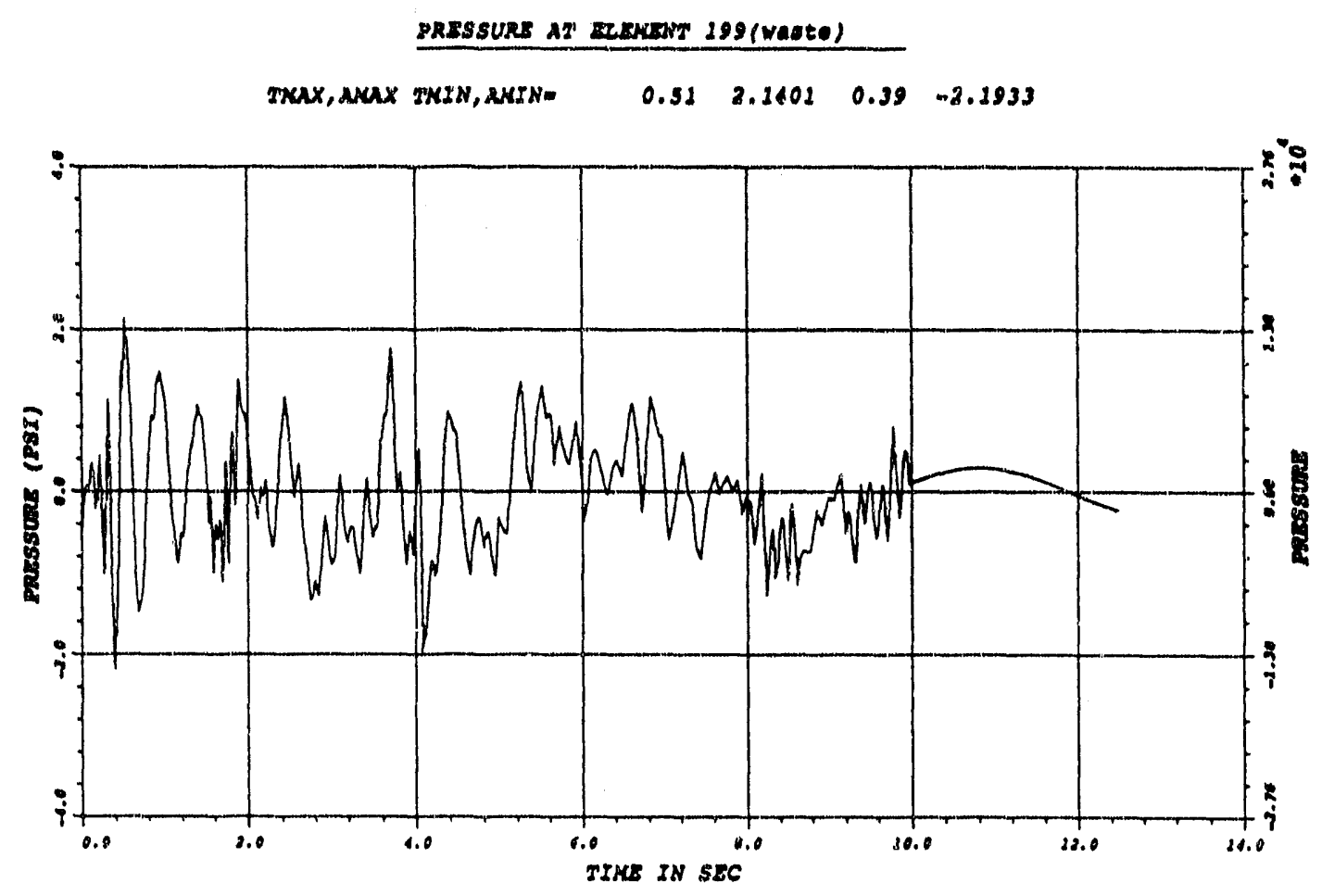

PRESSURS AT ELENENT 299 (Waote)

MAX. MREQUENCY, ANOPITUDEEW 0.240 .2129

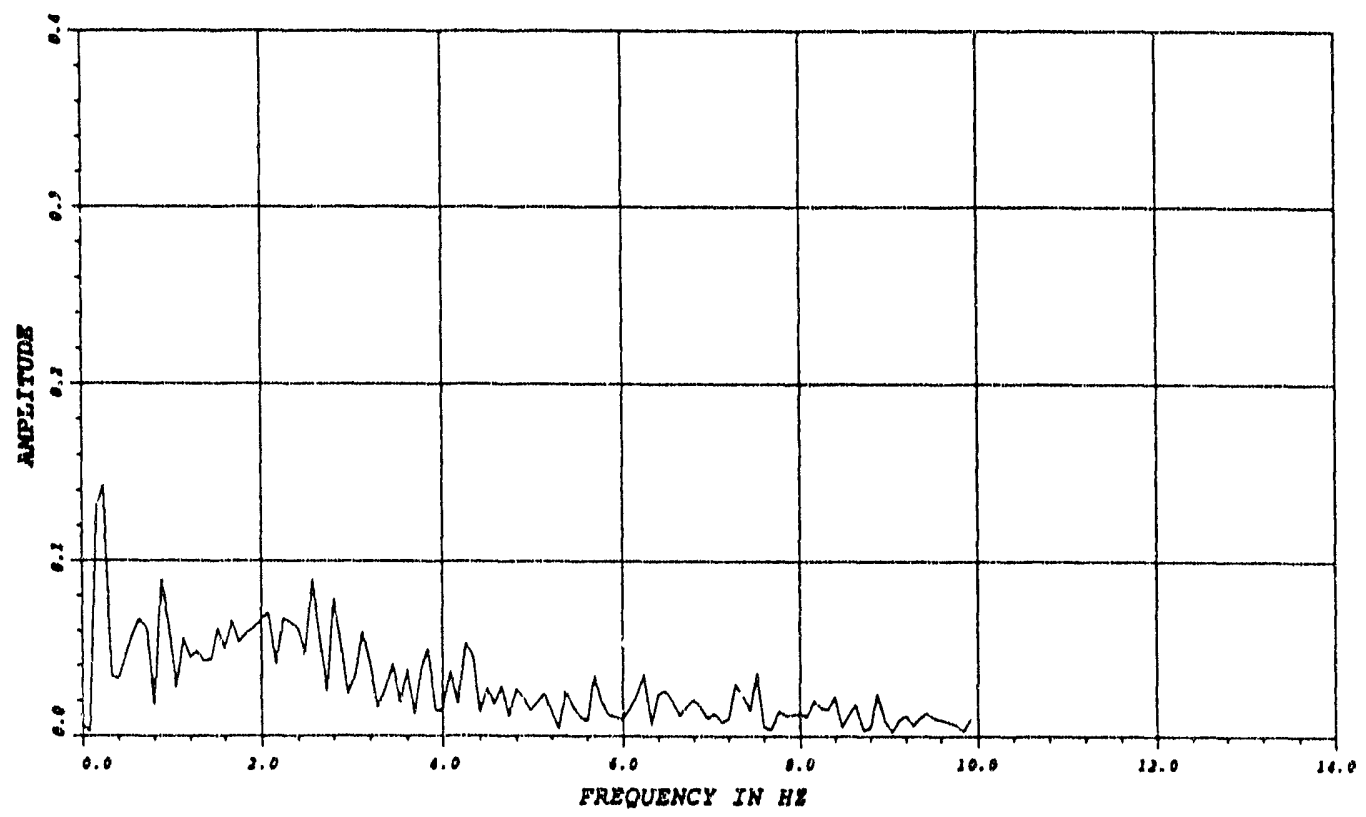

Fig. C-25. Time History of the Total Pressure at Element 199 and i.ts FFT for the Case of $\mu=60 \mathrm{cP}$ 

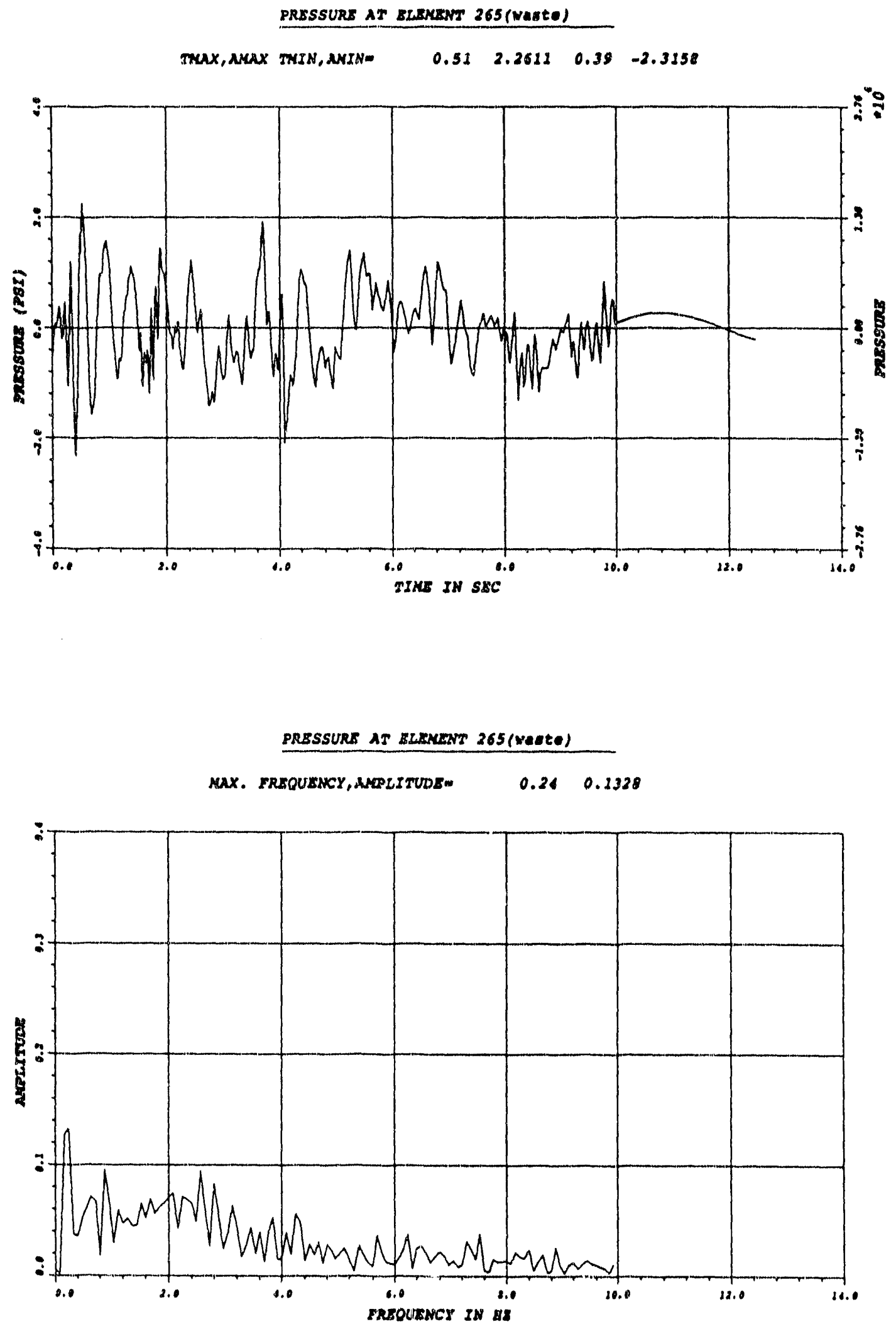

Fig. C-26. Time History of the Total Pressure at Element 265 and its FFT for the Case of $\mu=60 \mathrm{cP}$ 


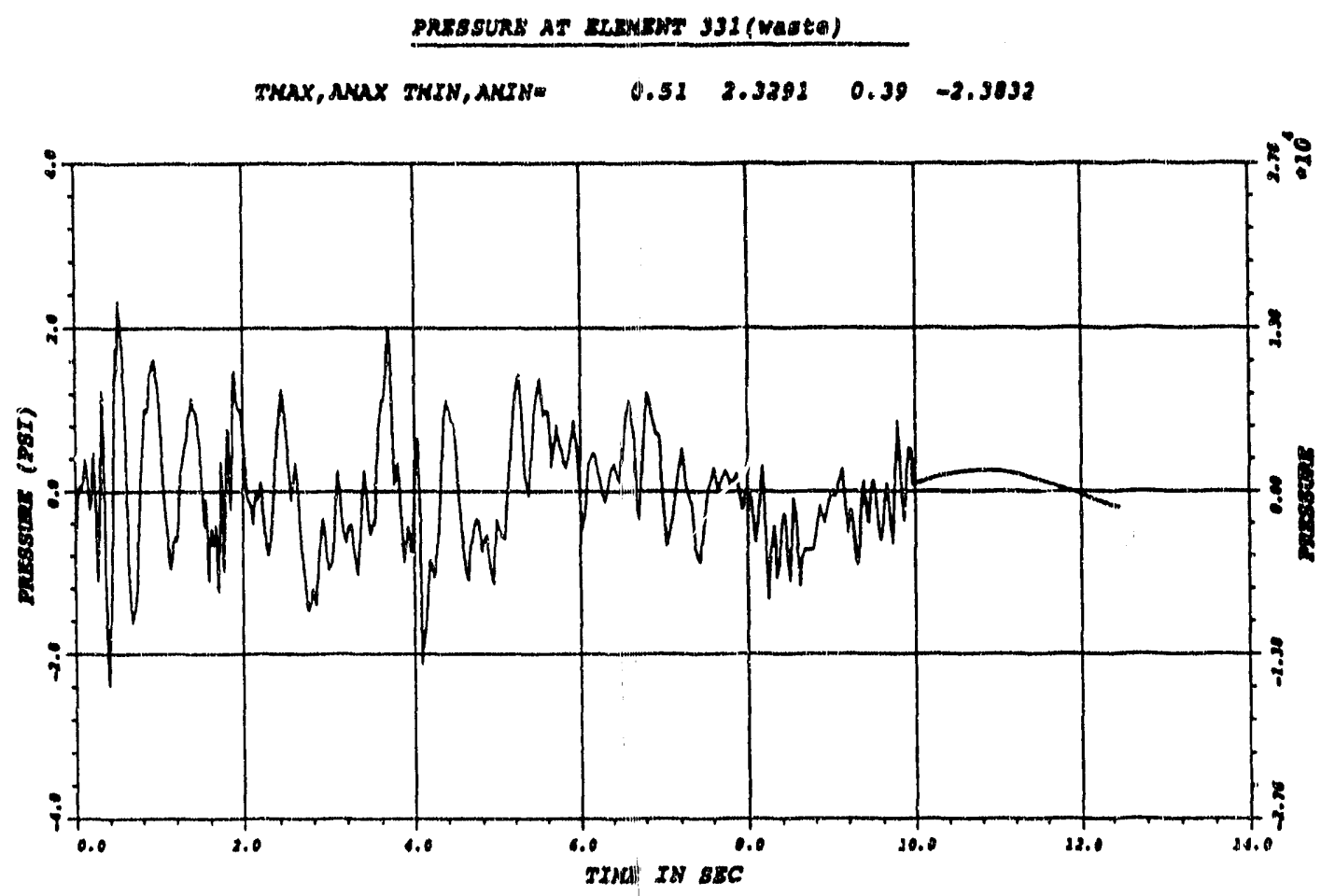

BRESSURE AT ERATHANY 331(wante)

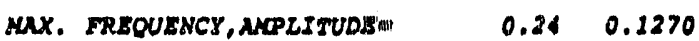

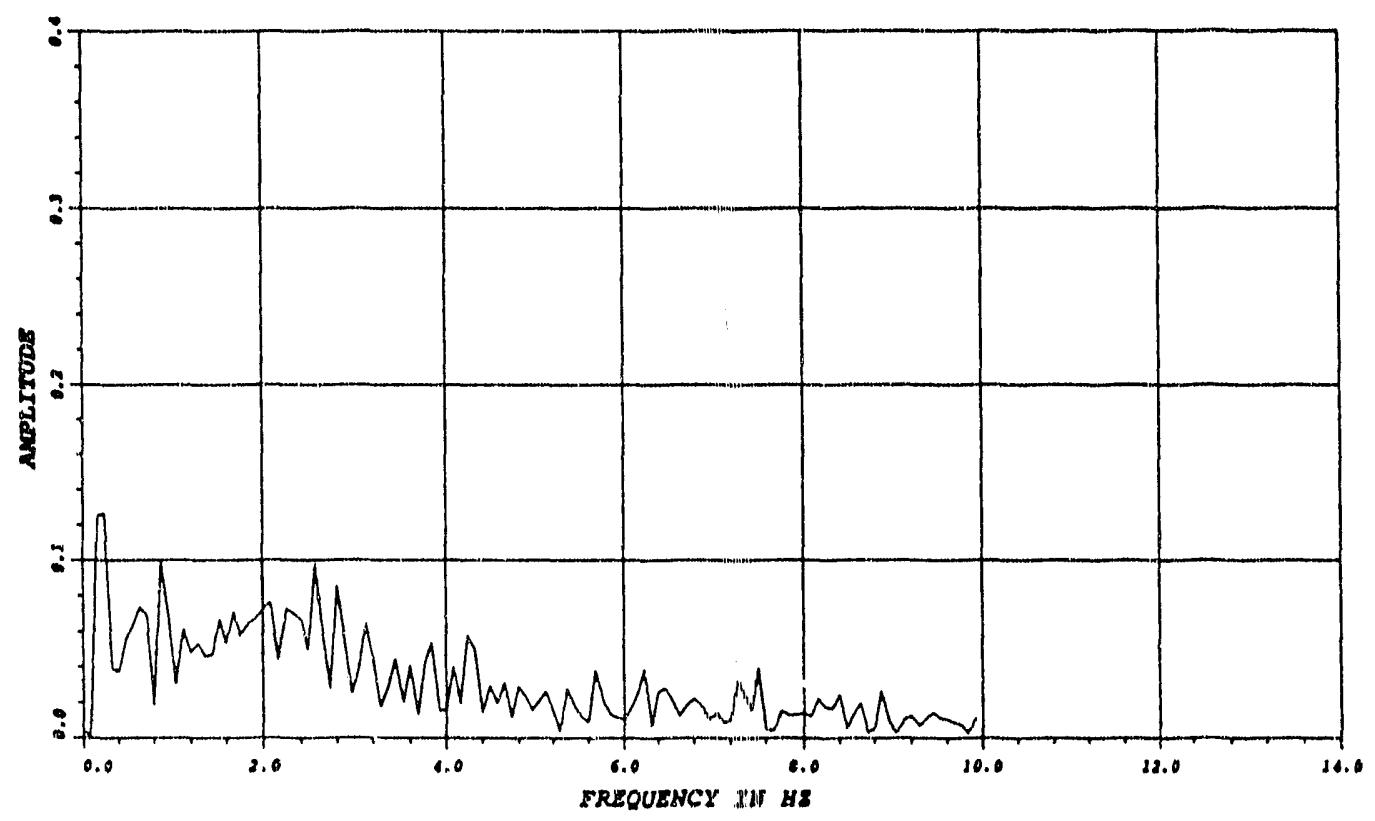

Fig. C-27. Time History of the Total Pressure at Element 331 and its FET for the Case of $\mu=60 \mathrm{cP}$ 


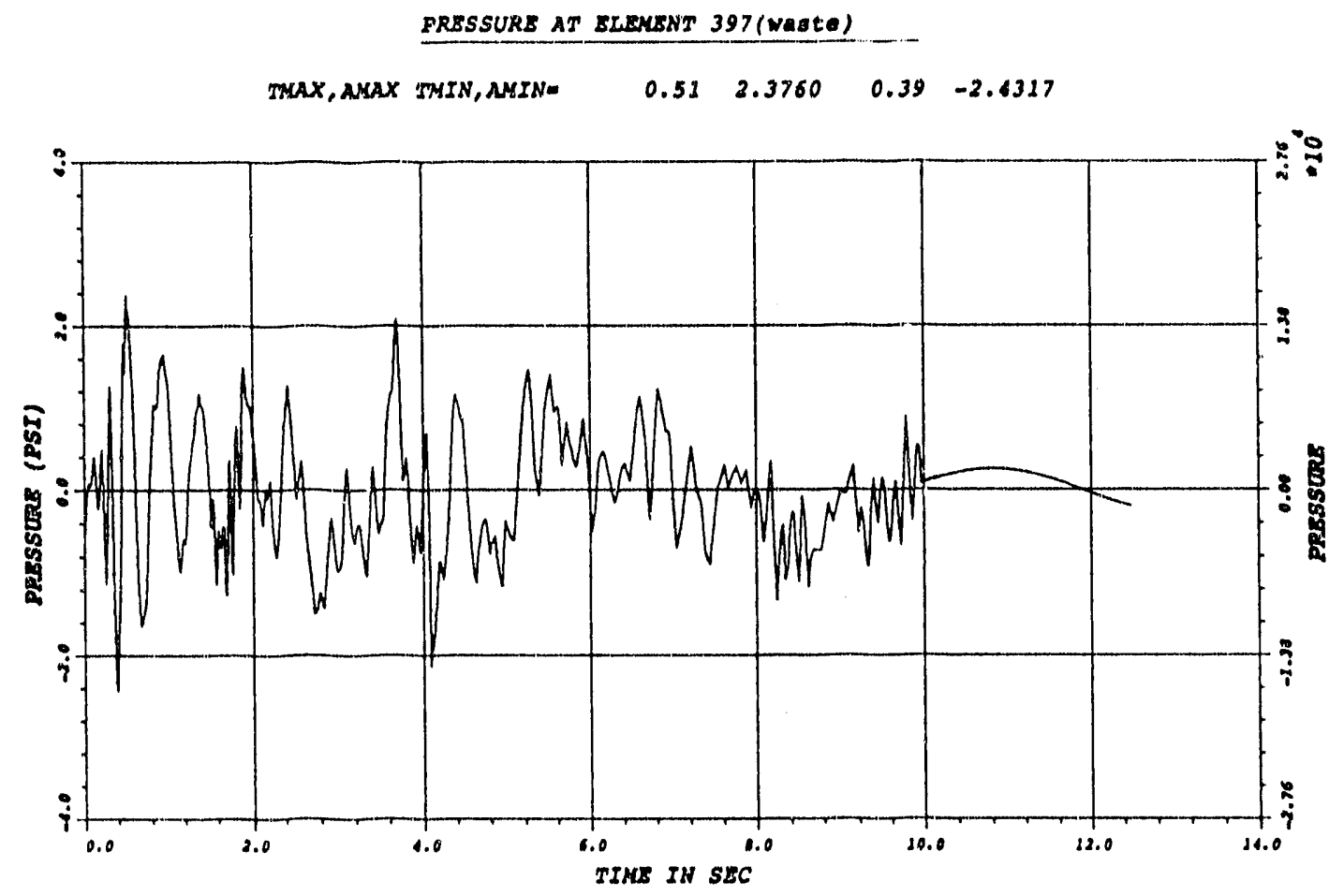

PRESSURE AT ELAKENT 397(WARte)

MAX. FREQUENGY, ANPLITUDE

$0.16 \quad 0.1234$

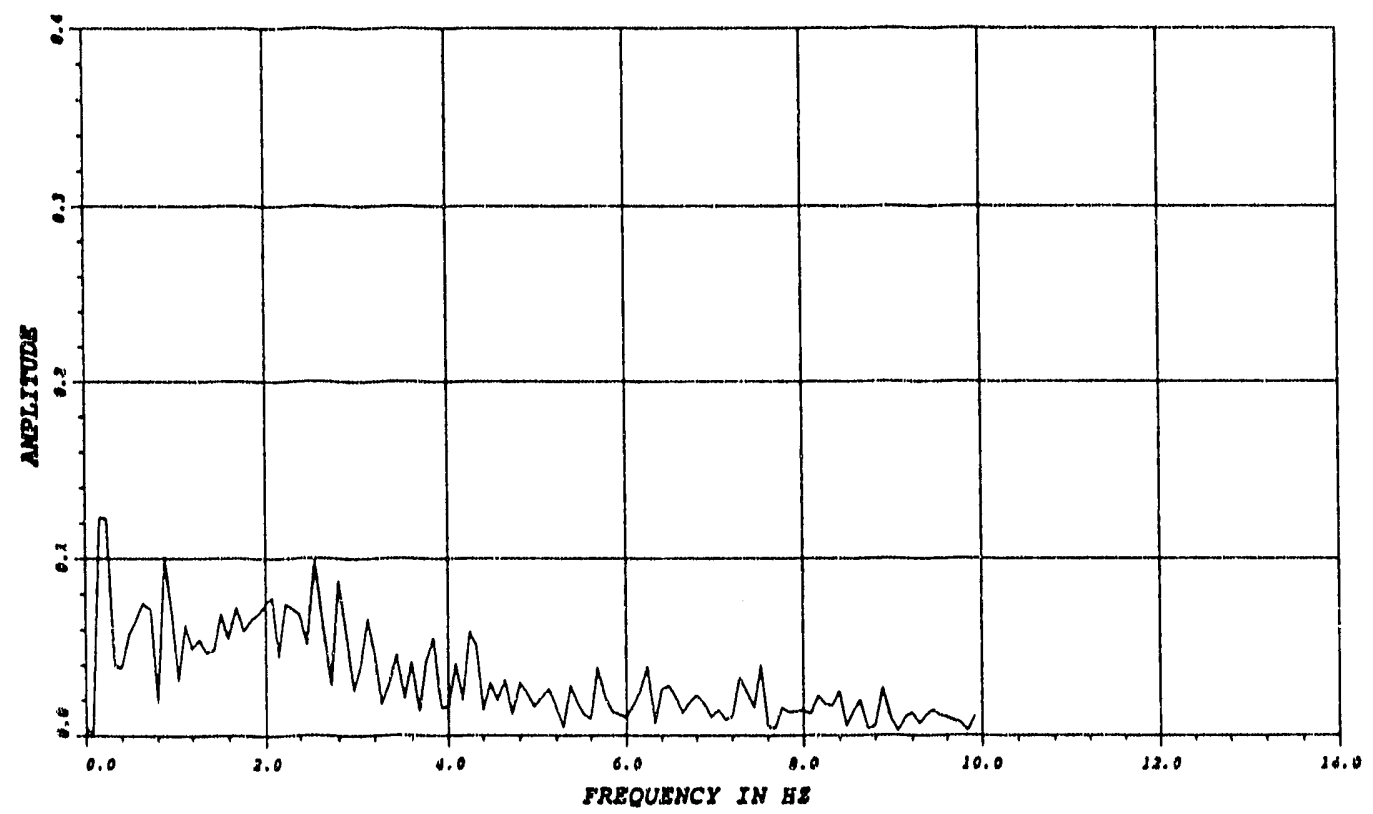

Fig. C-28. Time History of the Total Pressure at Element 397 and its FFT for the Case of $\mu=60 \mathrm{cP}$ 
PRASSURS AT SLENEST 163(wAste)

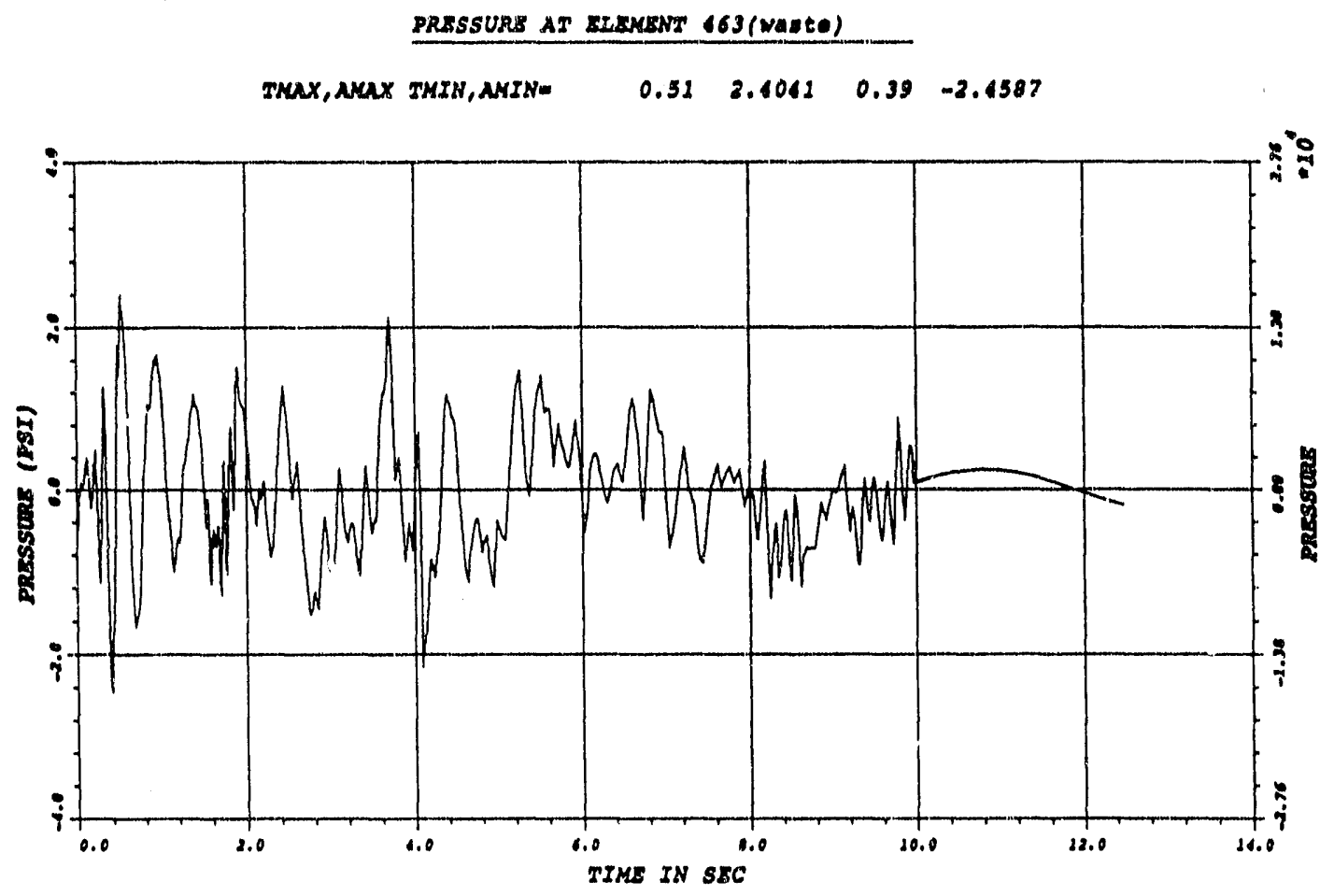

PRESSURE AT ELEHENT 163 (WAOTO)

MAX. TRSOUENCY, AMPLITUDS-

$0.16 \quad 0.1224$

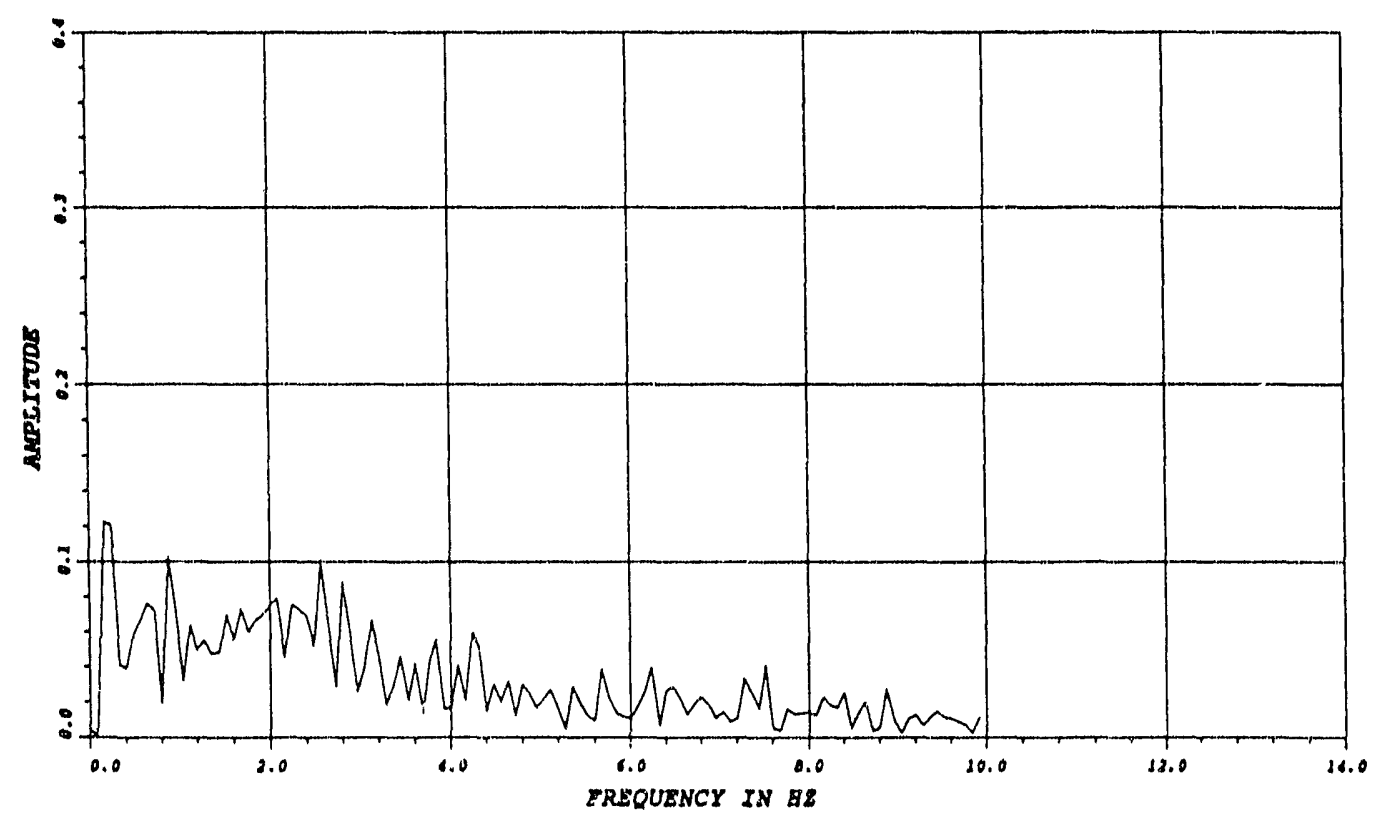

Fig. C-29. Time History of the Total Pressure at Element 463 and its FFT for the Case of $\mu=60 \mathrm{cP}$ 


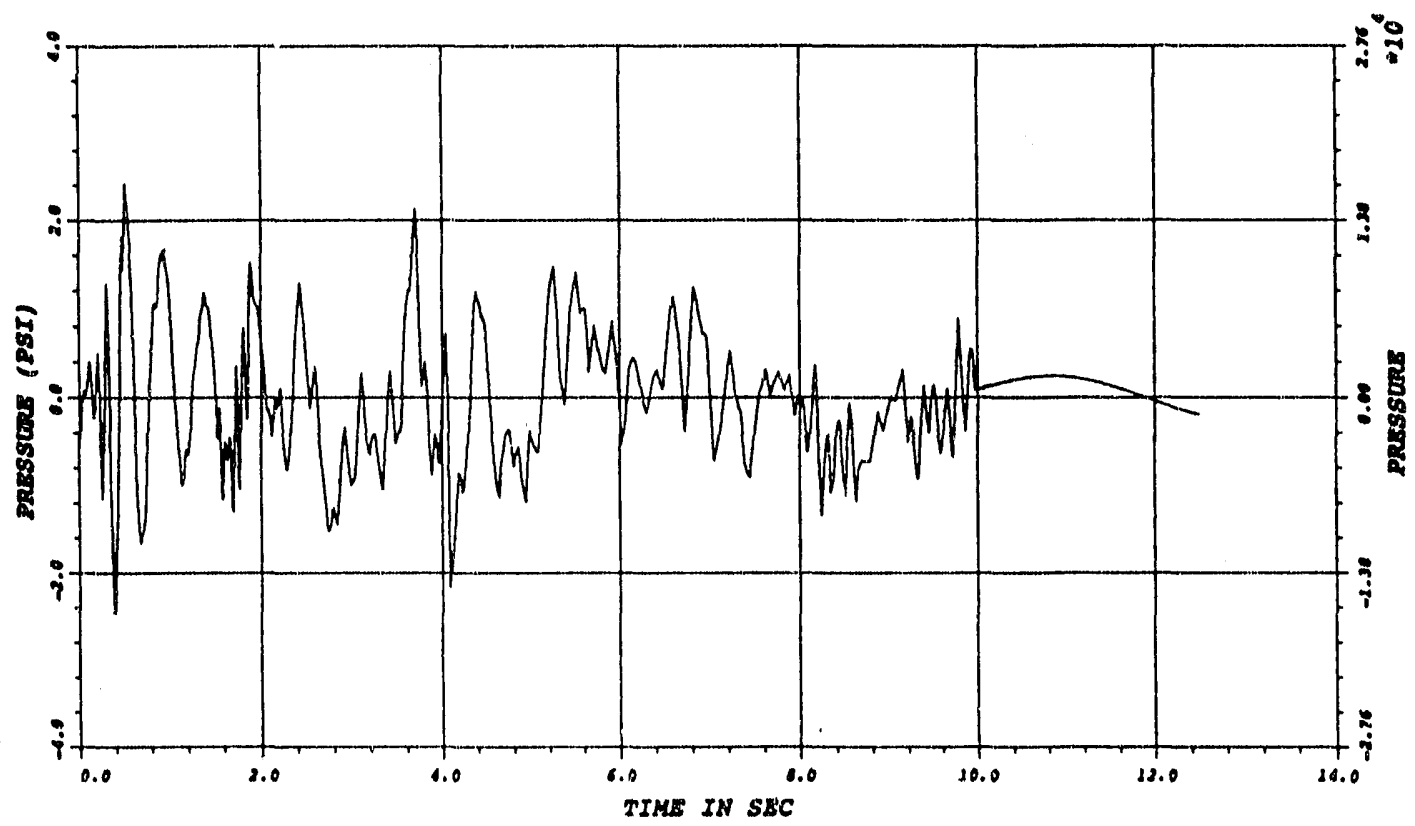

PRESSURE AT ELERENT 529 (wanta)

MAX. FREQUENCY, MMPLITUDE"

$0.16 \quad 0.2221$

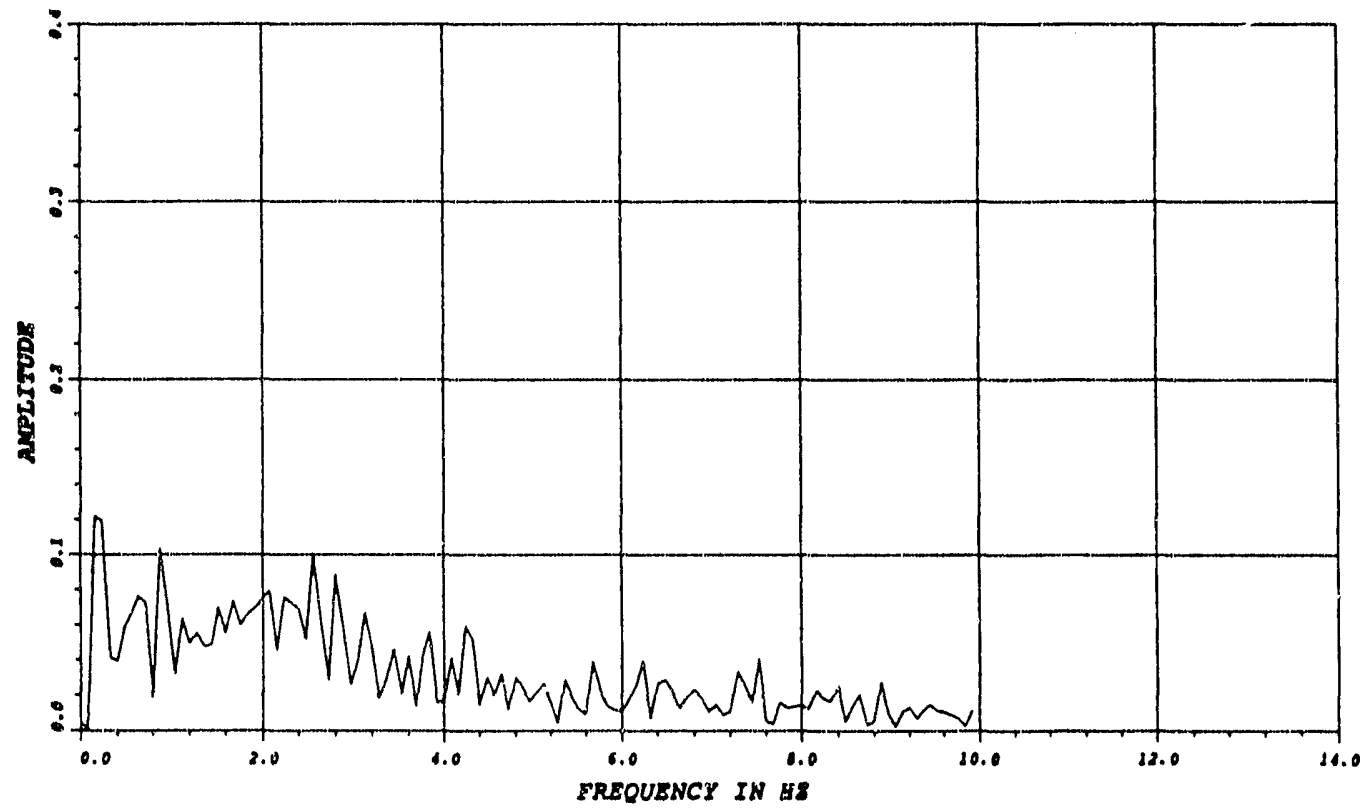

Fig. C-30. Time History of the Total Pressure at Element 529 and its FFT for the Case of $\mu=60 \mathrm{cP}$ 


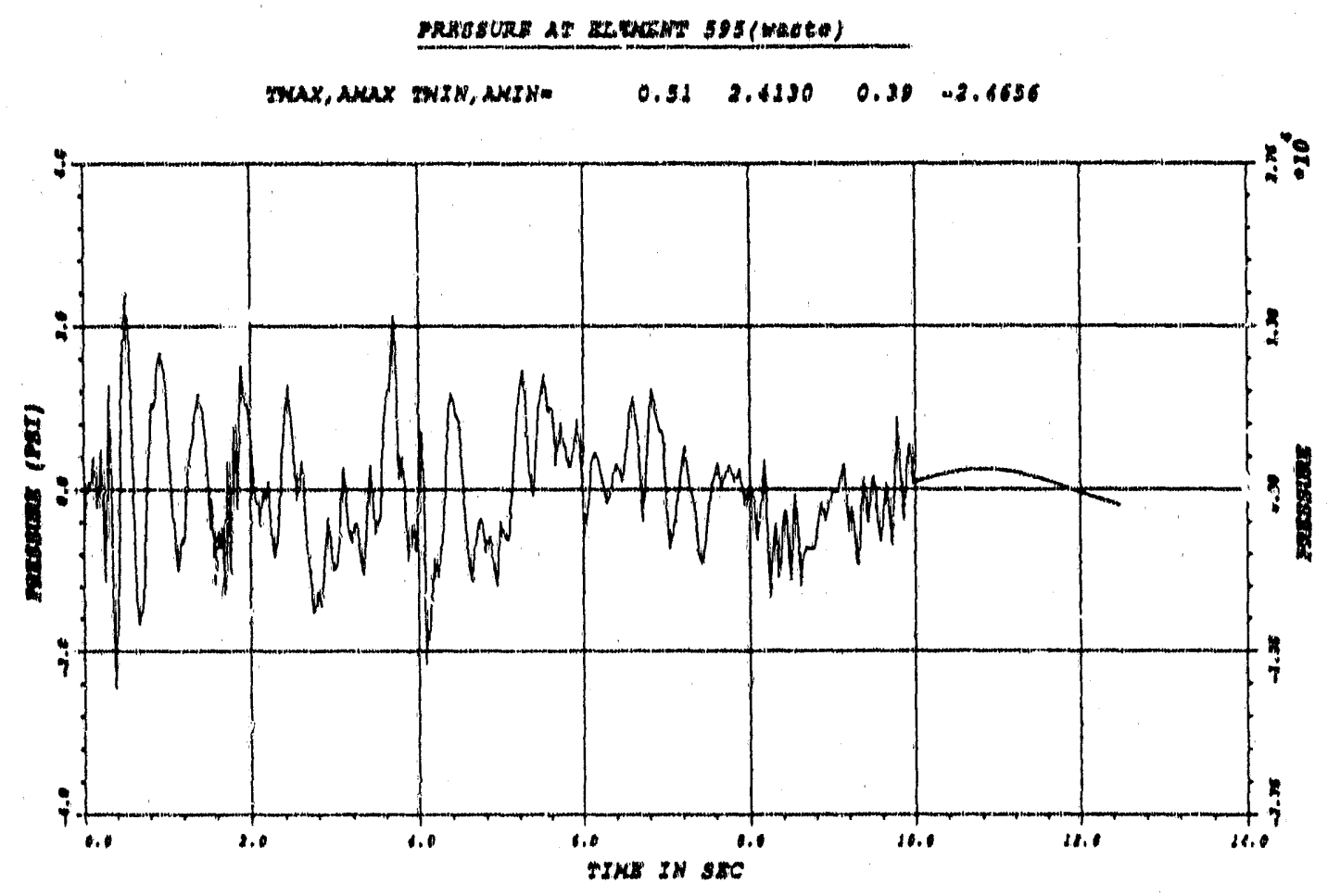

PRRSSURE AT MLEHCWN S9g (waste)

MAX. FREQUEMCY, AMPLITUDE: $\quad 0.26 \quad 0.1221$

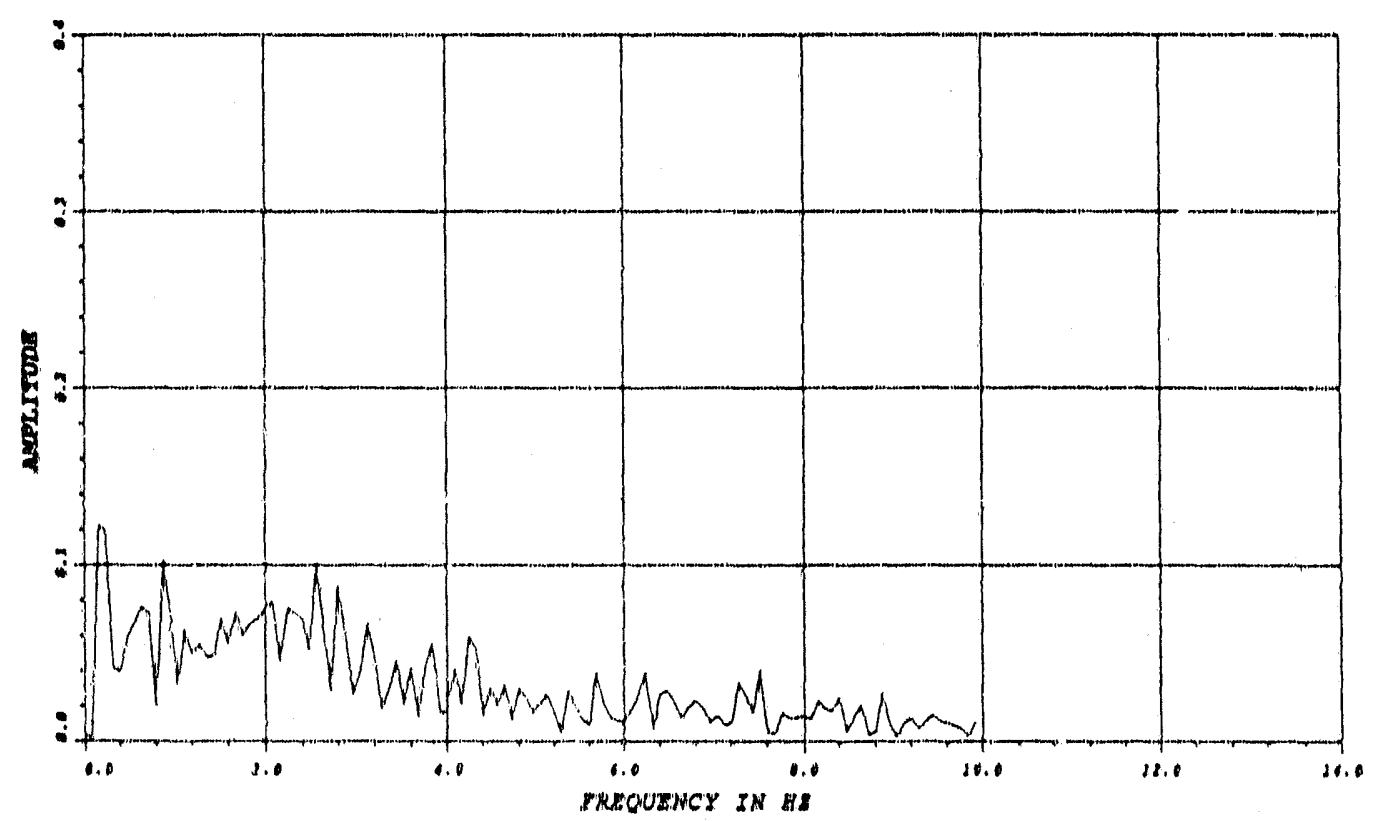

F1g. C-31. Time History of the Total Pressure at Element 595 and its FFT for the Case of $\mathrm{H} \approx 60 \mathrm{cP}$ 


\section{APPENDIX D}

Time History Plots of the Sloshing Wave Height and Hydrodynamic Pressures for the Case of $\mu=200 \mathrm{cP}$ for Base Motion 1 
VERTICAL. DISPLACEMENT AT NODE 131/wasto, 200cp)

TMAX,AMAX TMIN,ANIIN $=6.30 \quad 22.4138 \quad 3.67 \cdot 21.8488$

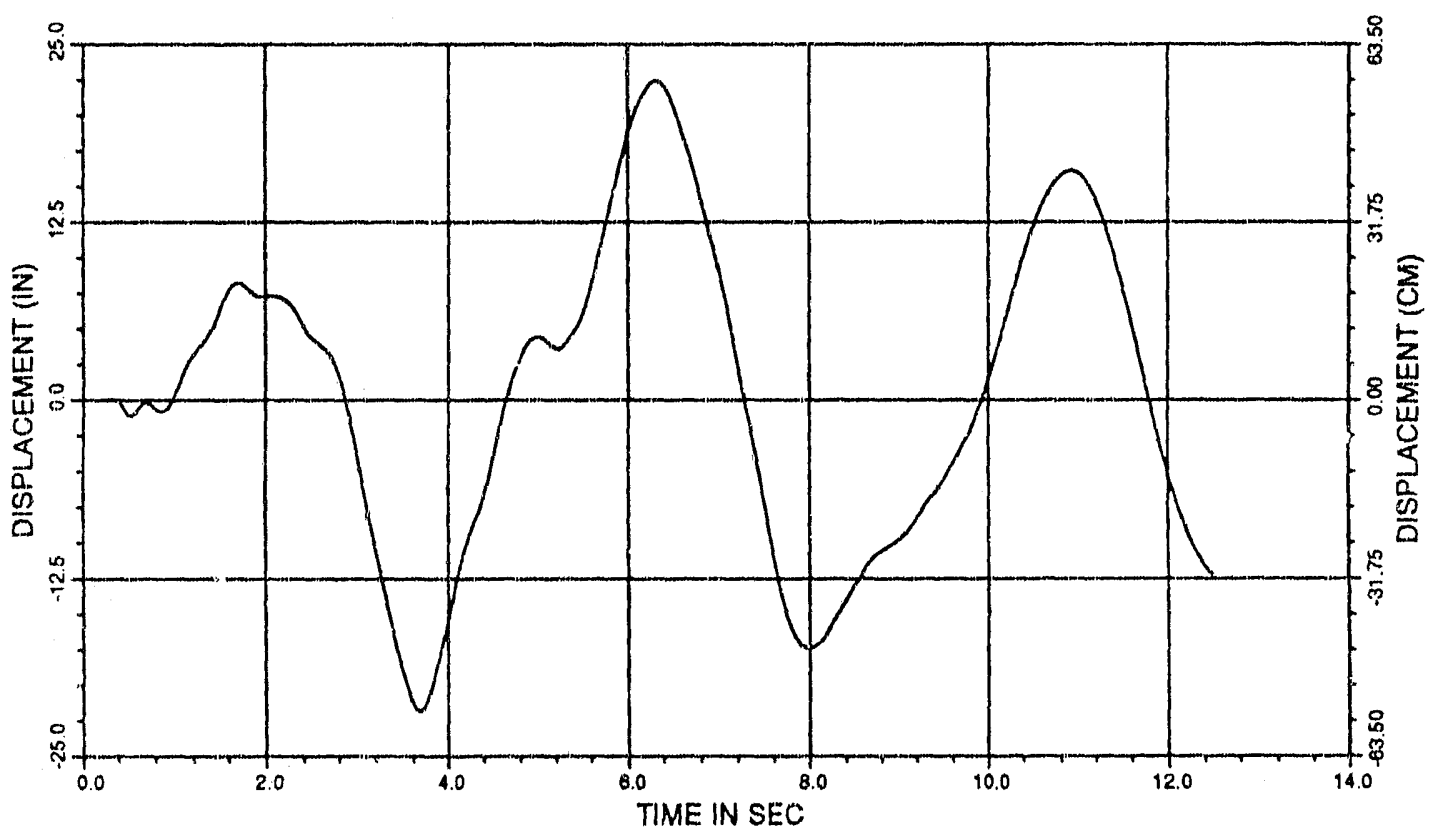

VERTICAL DISPLACEMENT AT NODE 131 (wasto, 200cp)

MAX. FAEQUENCY,AMPLITUDE $=0.24 \quad 6.1032$

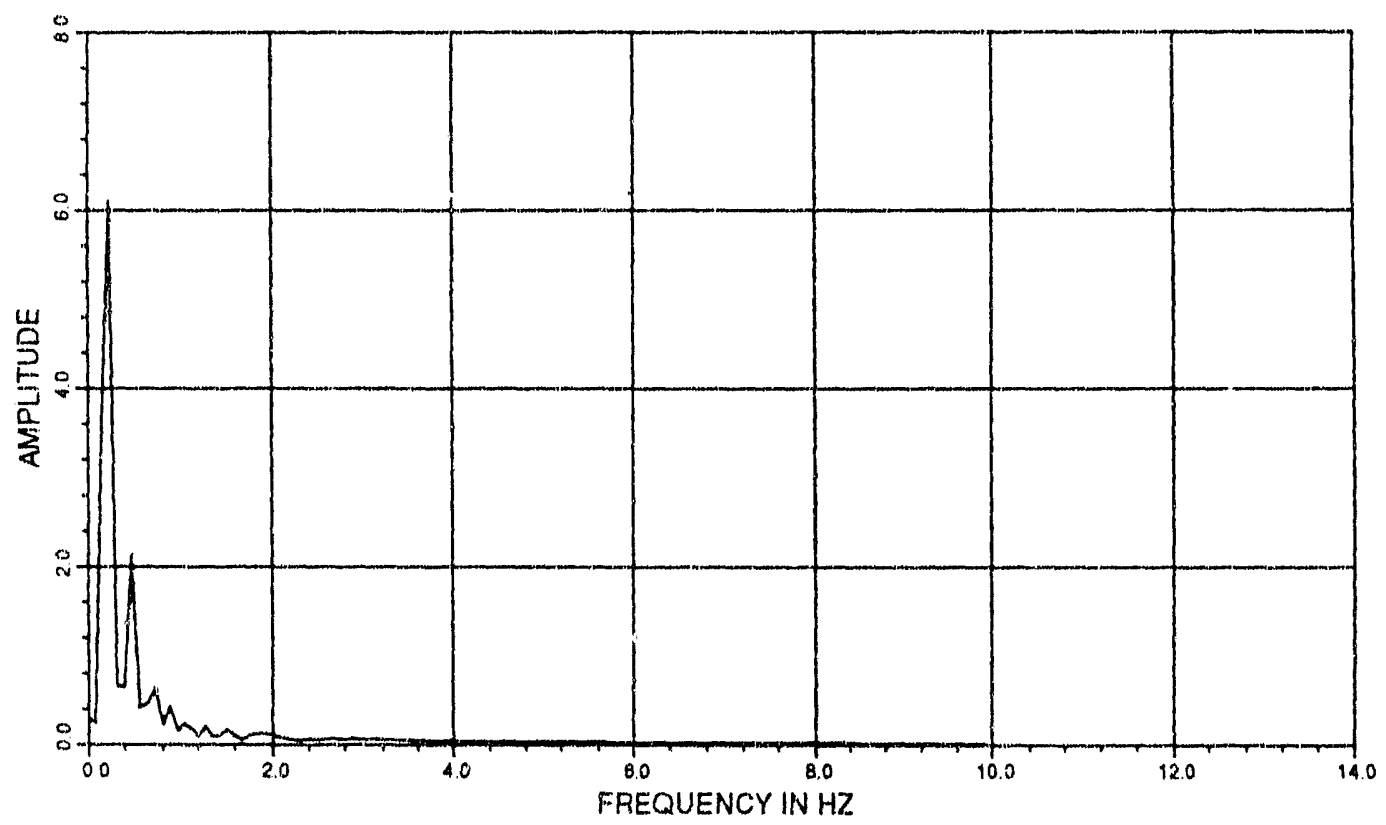

Fig. D-1. Time History of Slosling Wave Height at Node 131 and its FFT for the Case of $\mu=200 \mathrm{cP}$ 


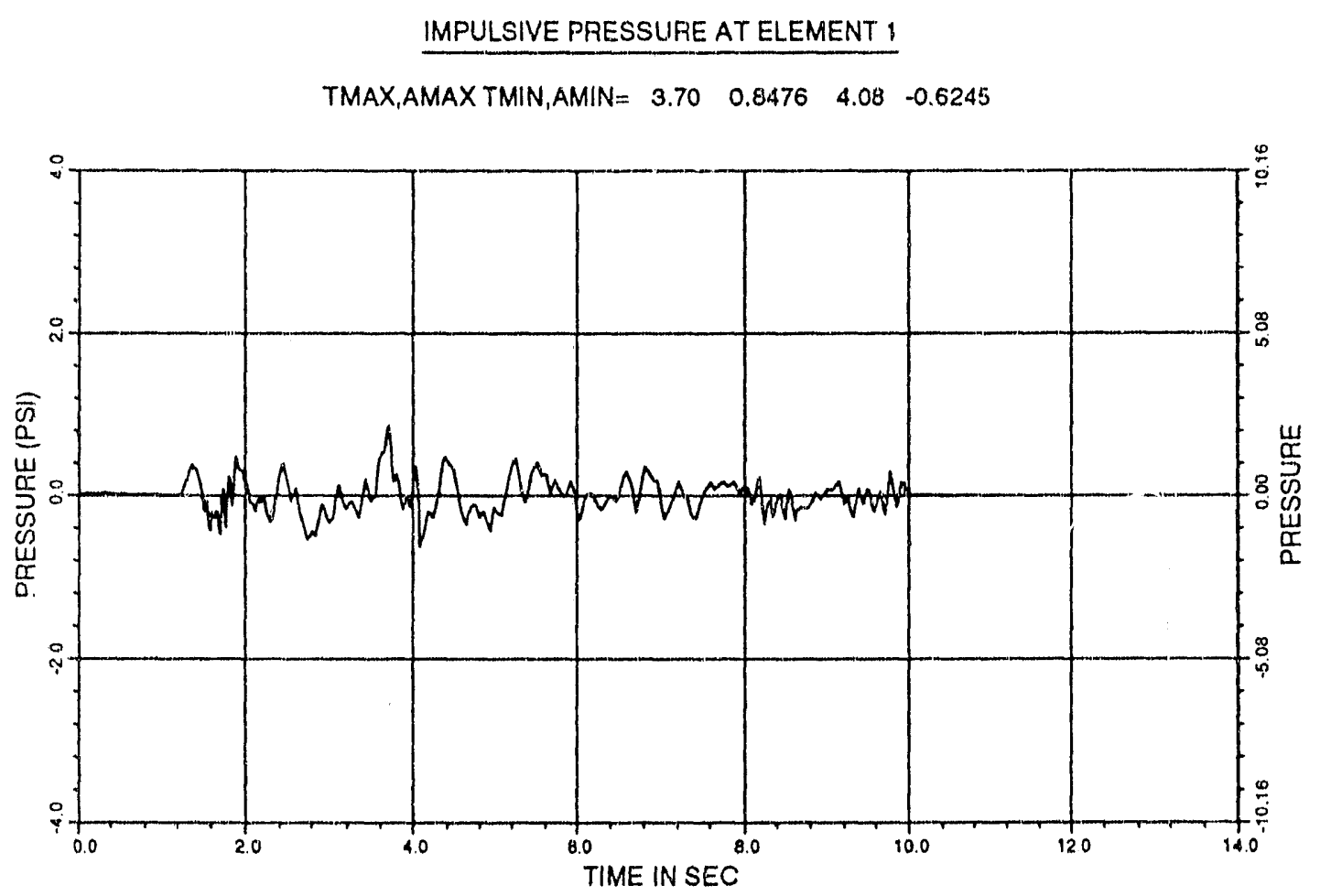

IMPULSIVE PRESSURE AT ELEMENT 1

MAX. FAEQUENCY,AMPLITUDE $=0.88 \quad 0.0362$

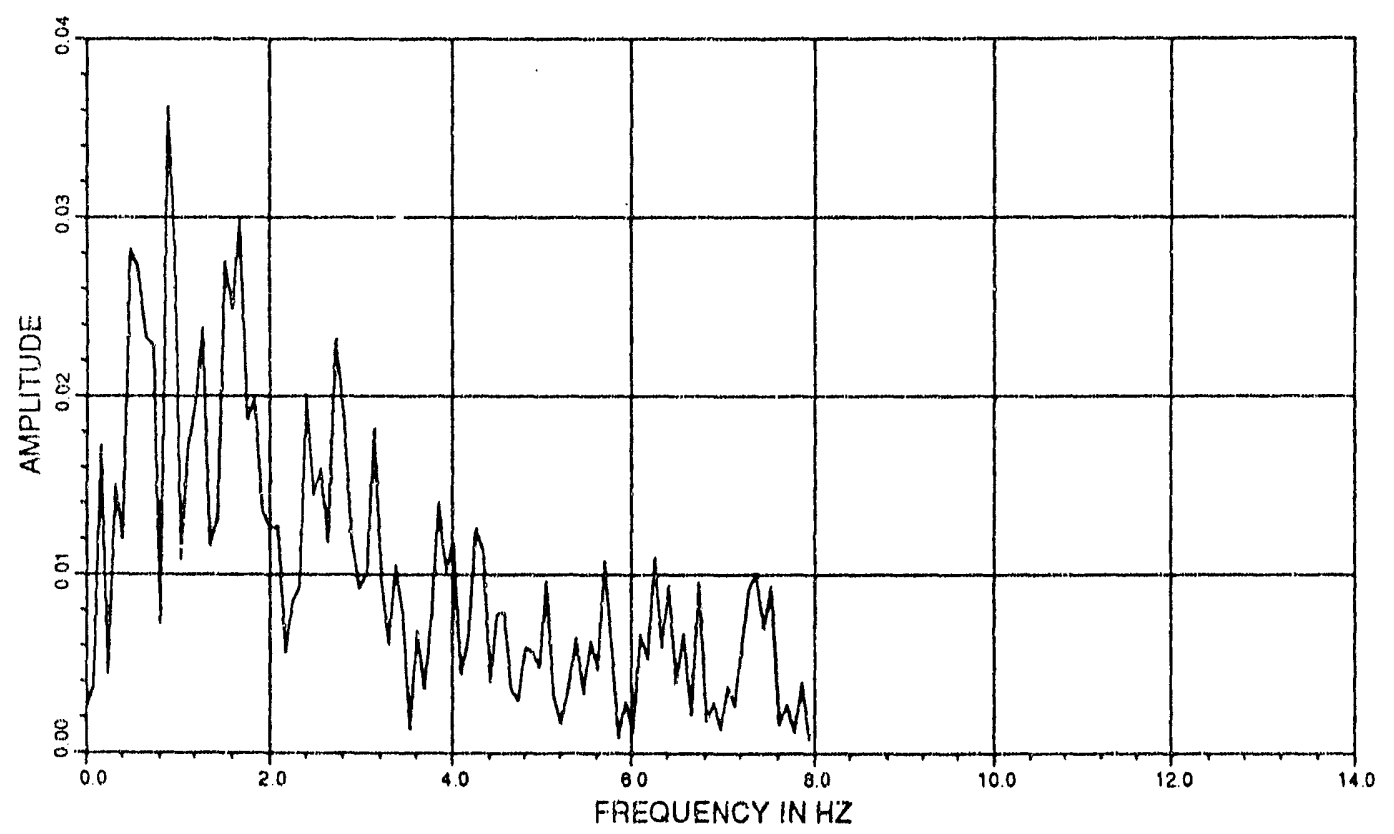

Fig. D-2. Time History of the Impulsive Pressure at Element 1 and its FFT for the Case of $\mu=200 \mathrm{cP}$ 
IMPULSIVE PRESSURE AT ELEMENT 67

TMAX,AMAX TMIN,AMIN $=3.70 \quad 1.6450 \quad 4.08 \quad \cdot 1.2120$

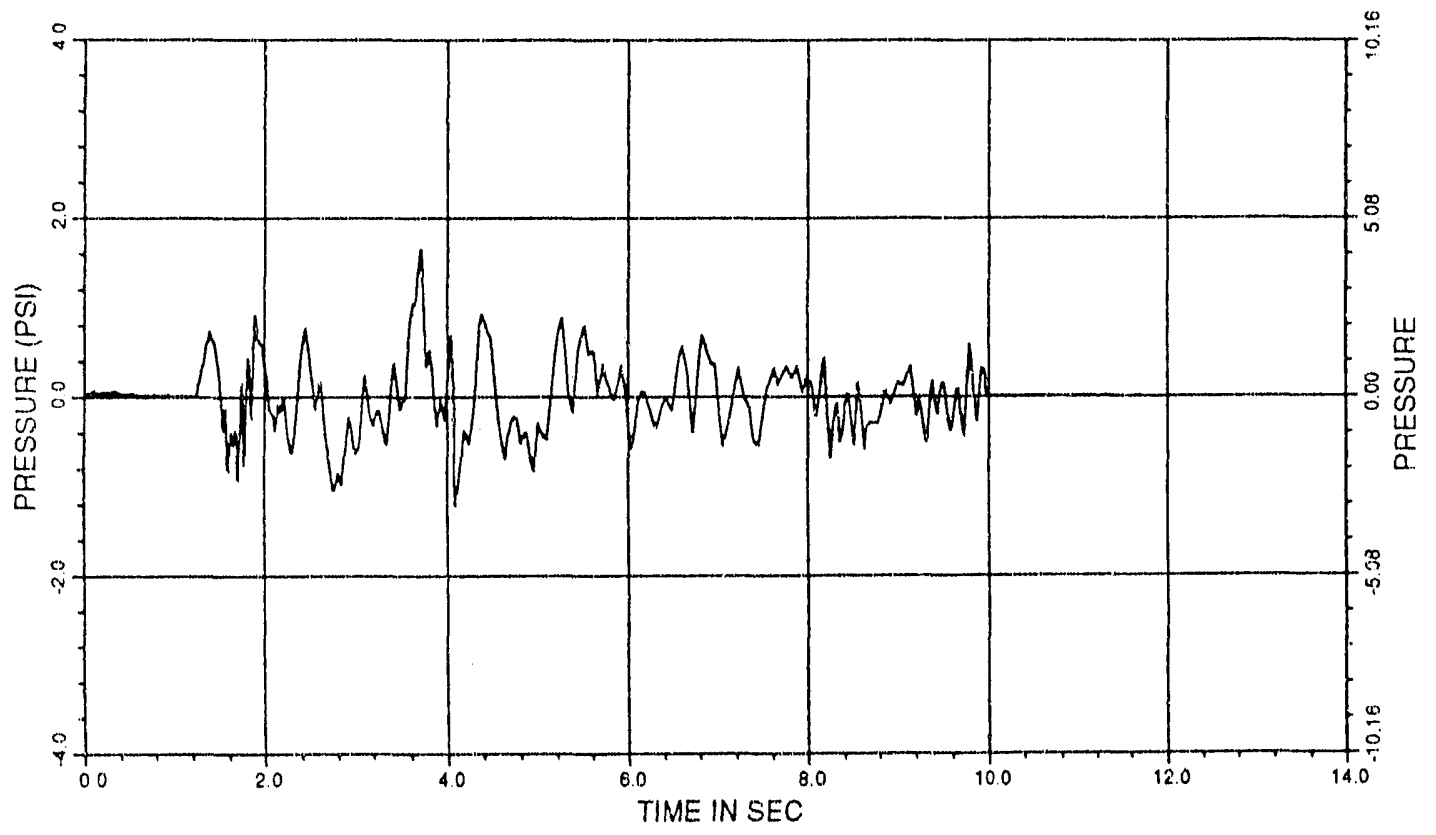

IMPULISIVE PRESSURE AT ELEMENT' 67

MAX. FREQUENCY,AMPL.ITUDE $=0.88 \quad 0.0702$

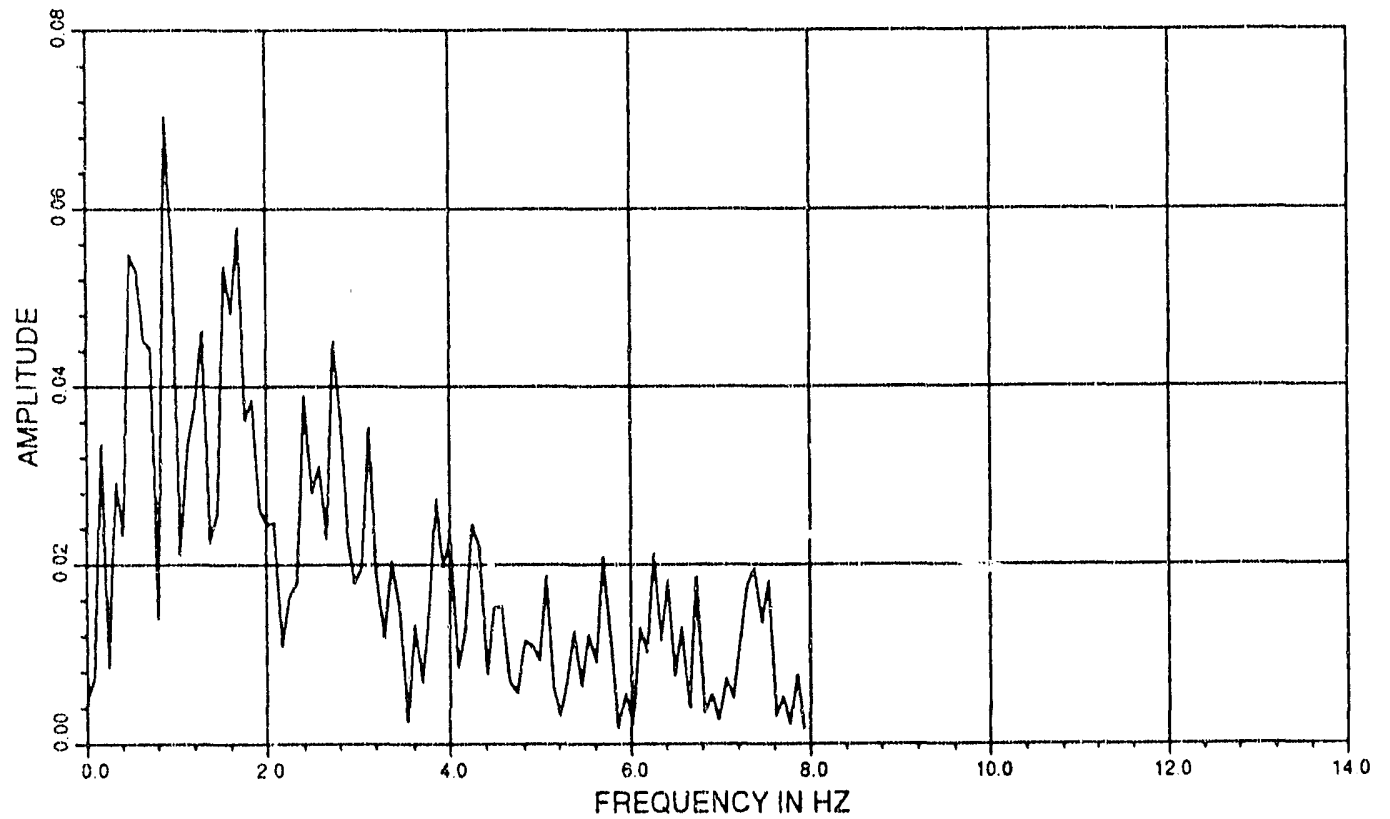

Fig. D-3. Time History of the Impulsive Pressure at Element 67 and its FFT for the Case of $\mu=200 \mathrm{cP}$ 
IMPULSIVE PRESSURE AT ELEMENT 133

TMAX,AMAX TMIN,AMIN $=\begin{array}{lllll}3.70 & 2.0230 & 4.08 & -1.4900\end{array}$

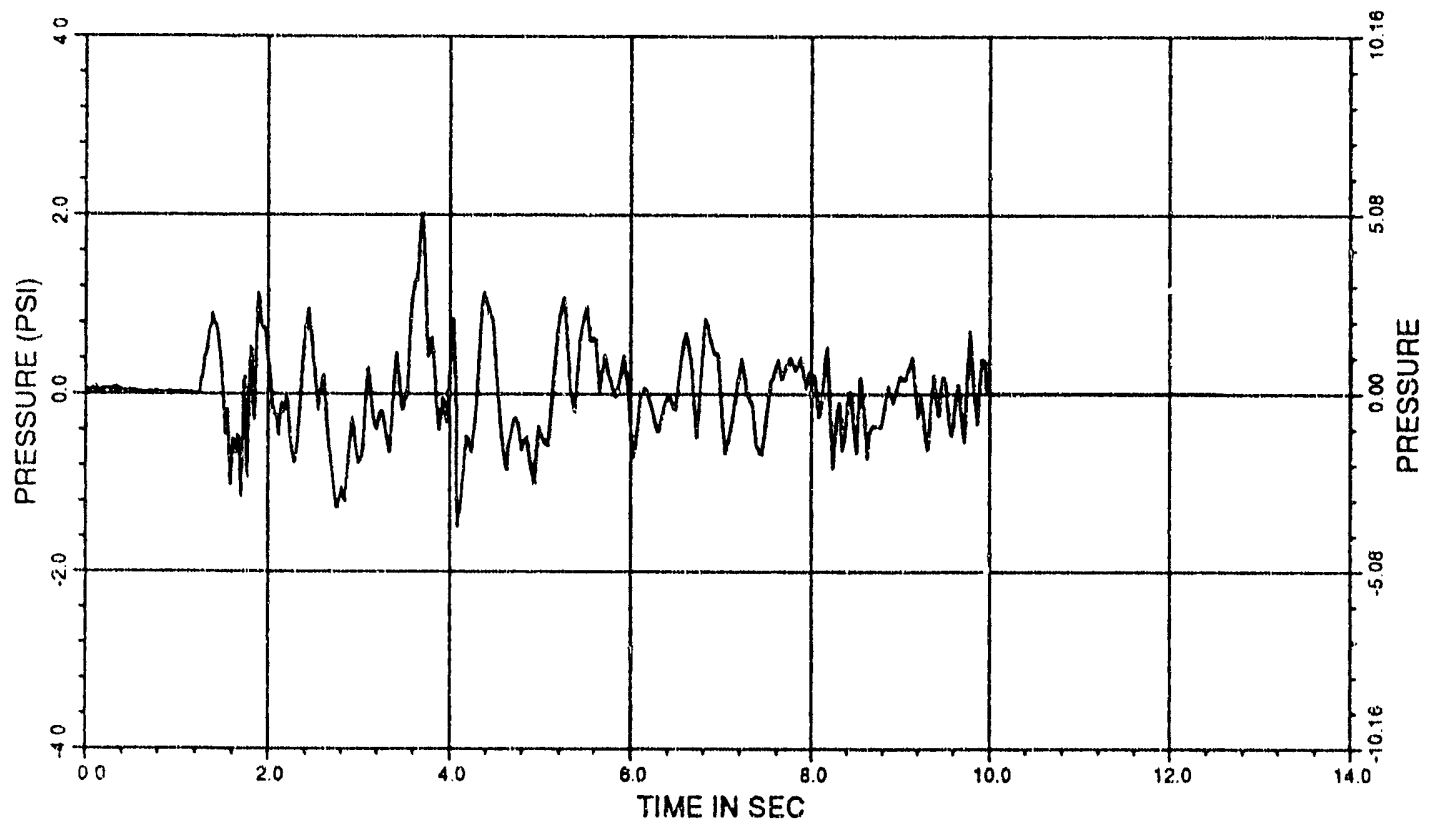

IMPULSIVE PRESSURE AT ELEMENT 133

MAX. FREQUENCY,AMPLITUDE $=0.88 \quad 0.0864$

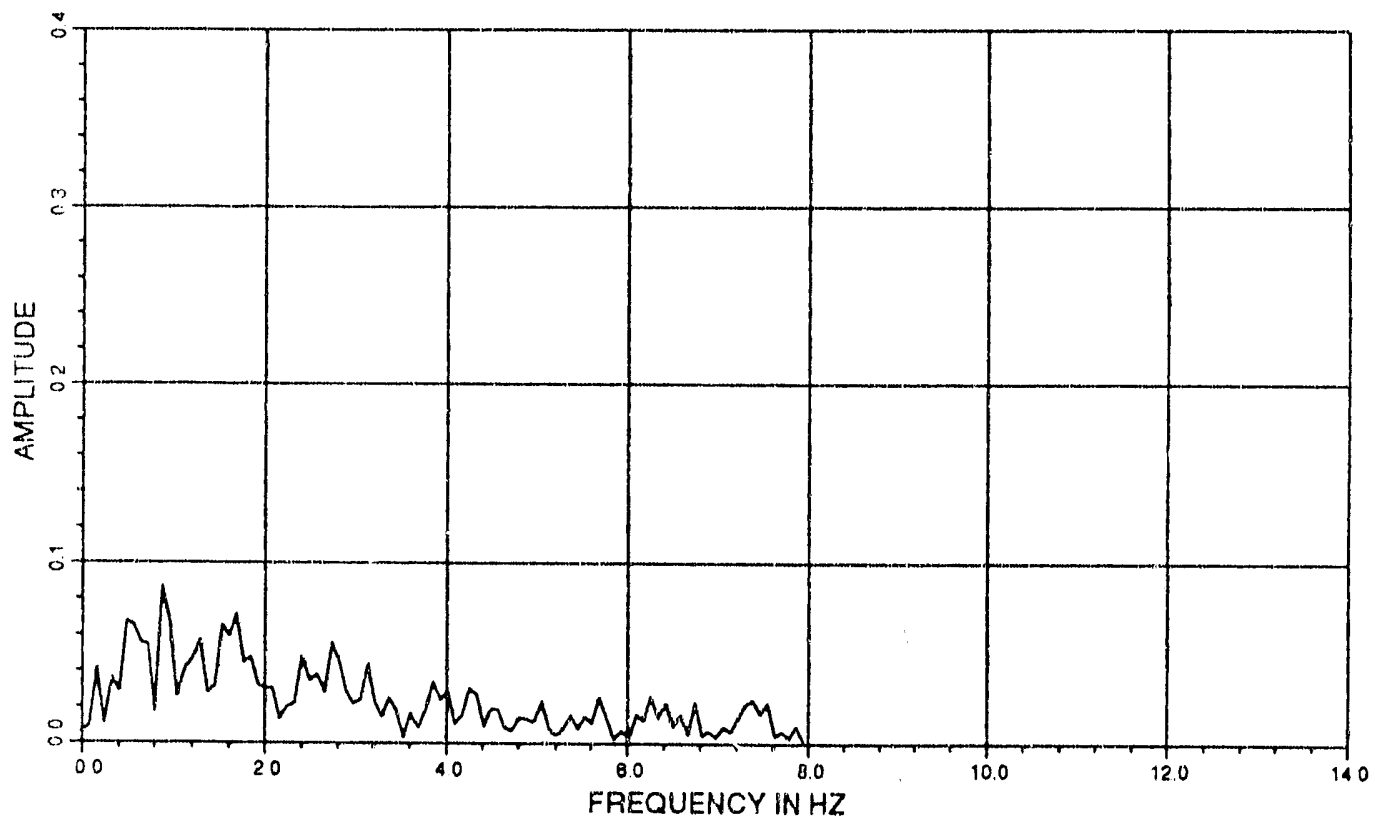

Fig. D-4. Time History of the Impulsive Pressure at Element 133 and its FFT for the Case of $\mu=200 \mathrm{cP}$ 
IMPULSIVE PRESSURE AT ELEMENT 199

TMAX,AMAX TMIN,AMIN $=3.70 \quad 2.2370 \quad 4.08 \quad-1.6470$

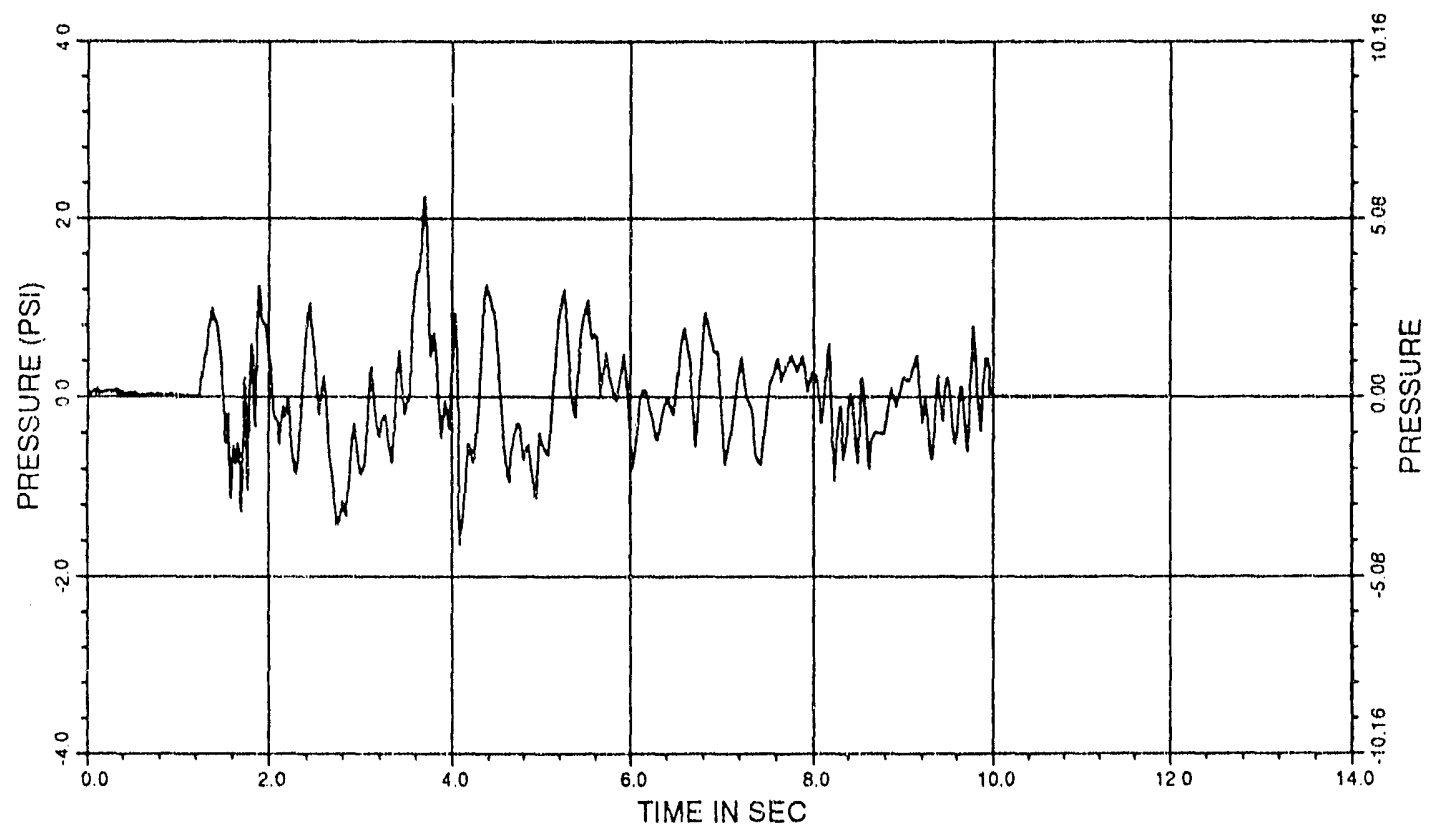

IMPULSIVE PRESSURE AT ELEMENT 199

MAX. FREQUENCY,AMPLITUDE $=0.88 \quad 0.0955$

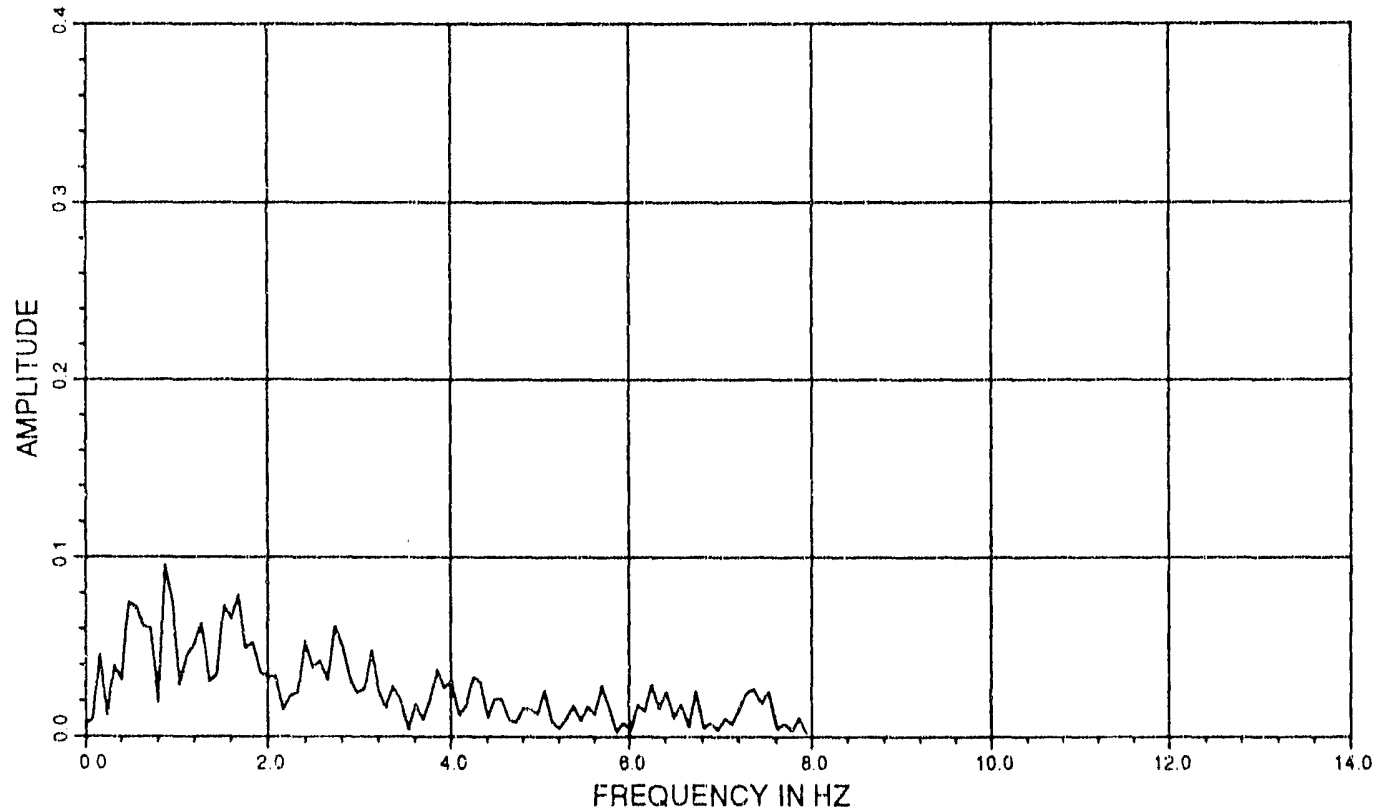

Fig. D-5. Time History of the Impulsive Pressure at Element 199 and its FFT for the Case of $\mu=200 \mathrm{cP}$ 


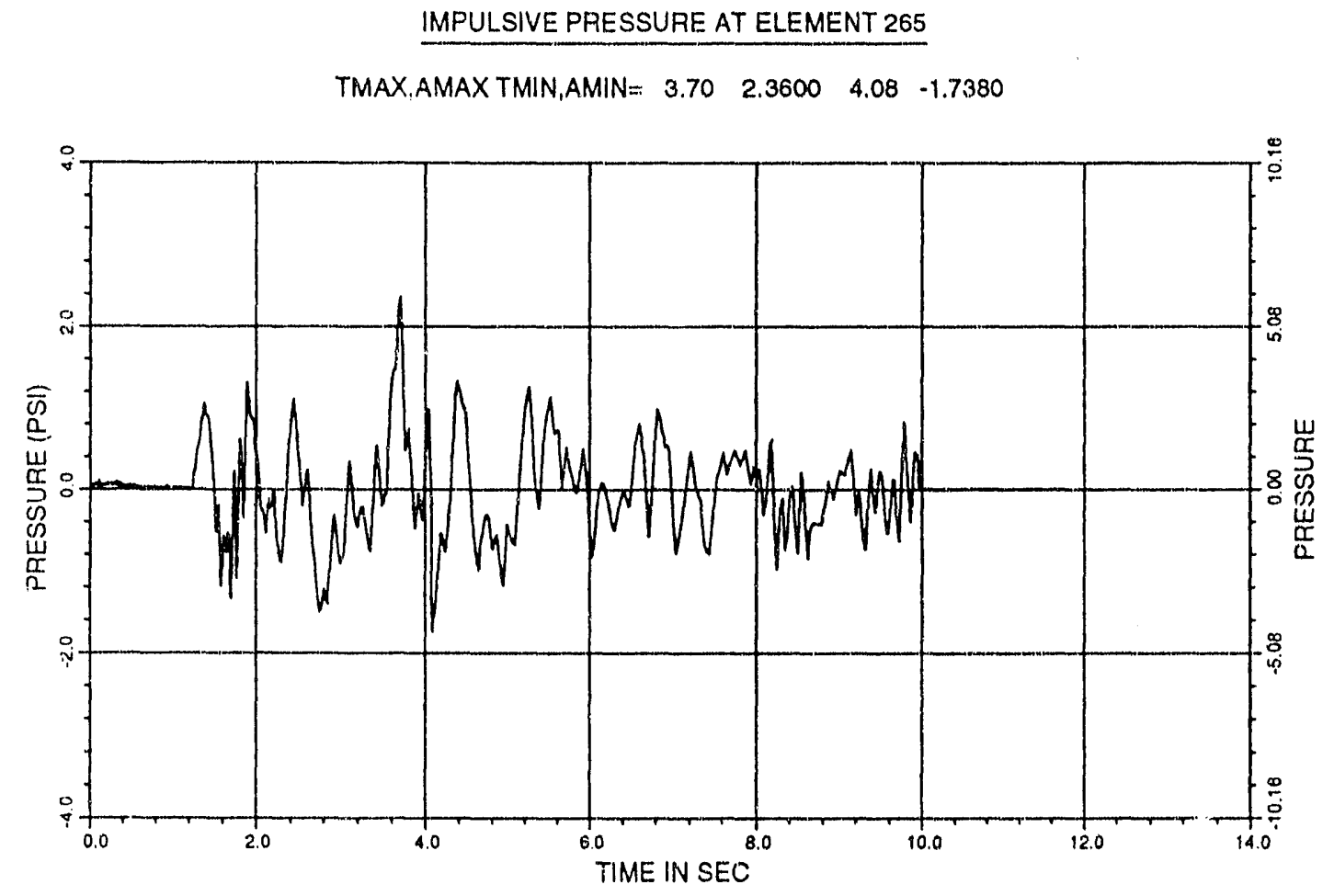

IMPULSIVE PRESSURE AT ELEMENT 265

MAX. FREQUENCY,AMPLITUDE $=0.88 \quad 0.1008$

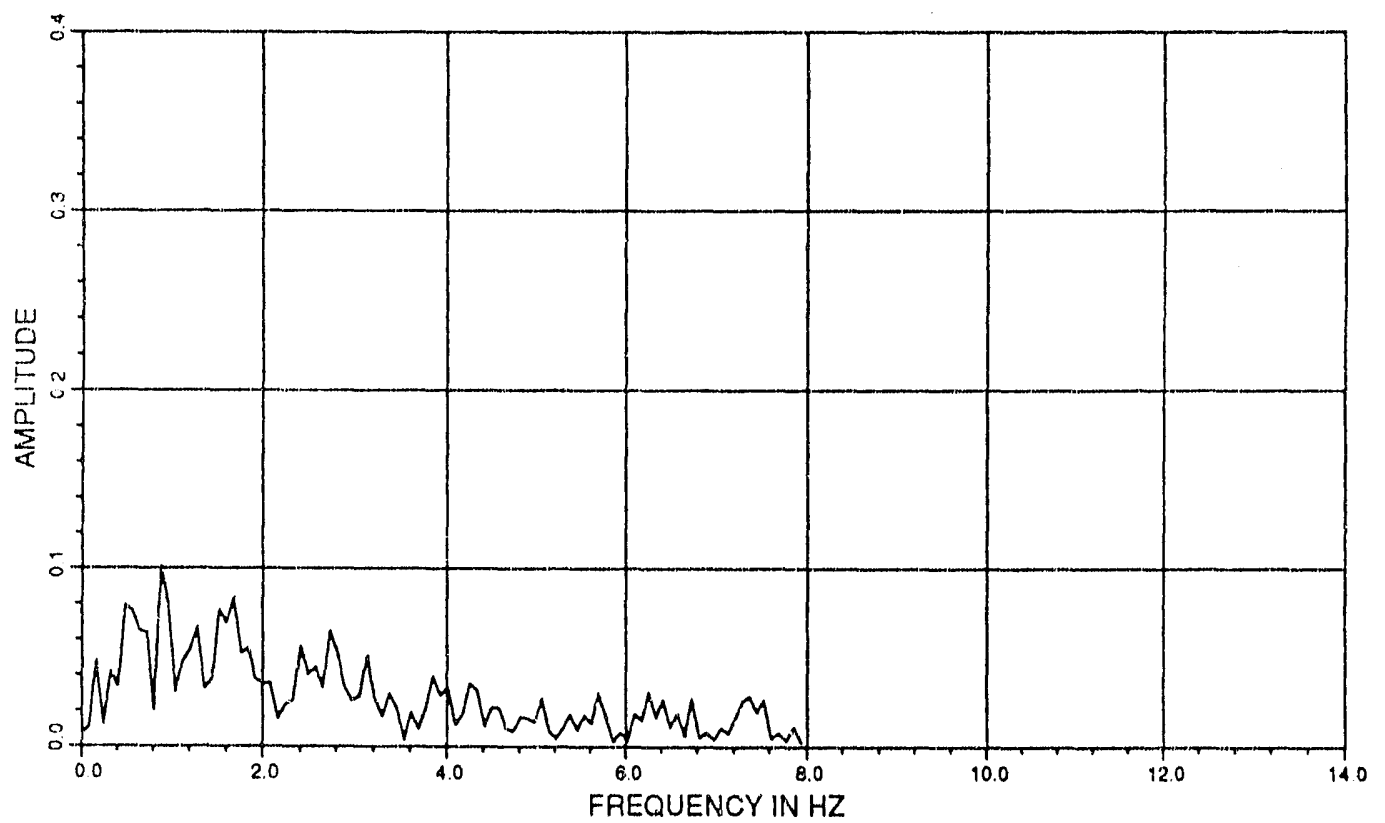

Fig. D-6. Time History of the Impulsive Pressure at Element 265 and its FFT for the Case of $\mu=200 \mathrm{cP}$ 
IMPULSIVE PRESSURE AT ELEMENT 331

TMAX,AMAX TMIN,AMIN $=3.70 \quad 2.4310 \quad 4.08 \quad-1.7900$

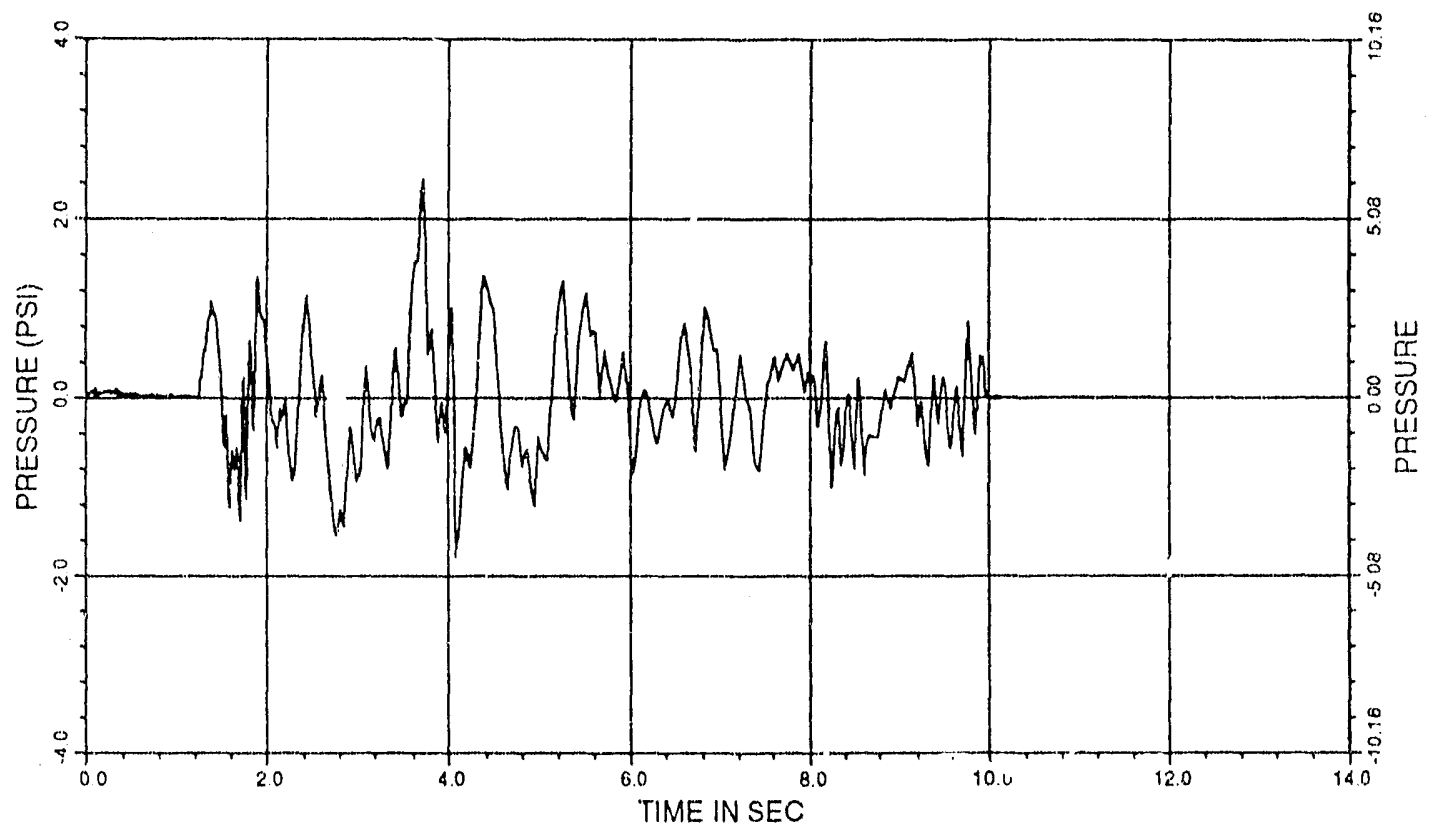

IMPULSIVE PRESSURE A'T EILEMENT 331

MAX. FREQUENCY,AMPLITUDE $=0.880 .1038$

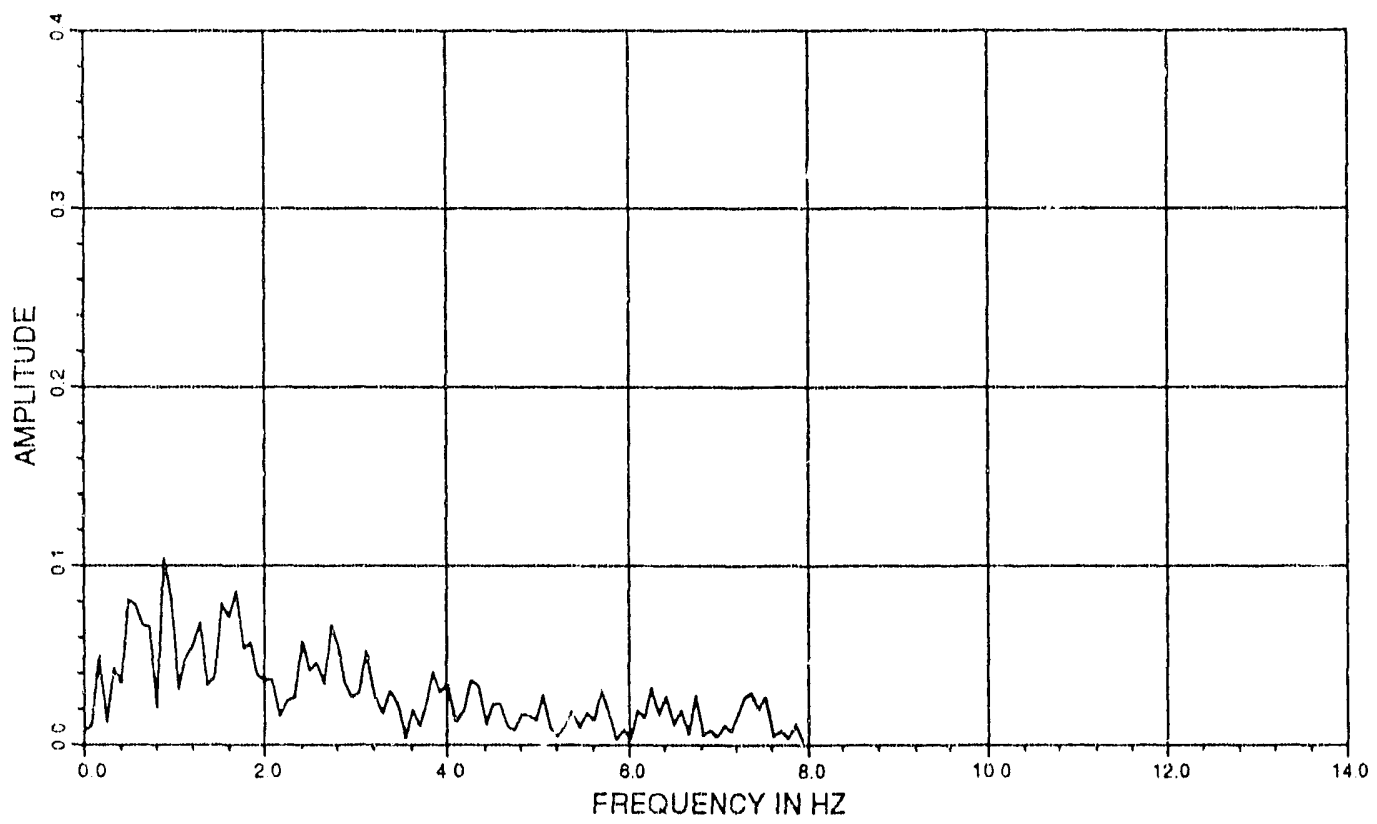

Fig. D-T. Time History of the Impulsive Pressure at Element 331 and its FFT for the Case of $\mu=200 \mathrm{cP}$ 
IMPULSIVE PRESSURE AT ELEMENT 397

TMAX,AMAX TMIN,AMIN $=3.70 \quad 2.4780 \quad 4.08 \quad-1.8250$

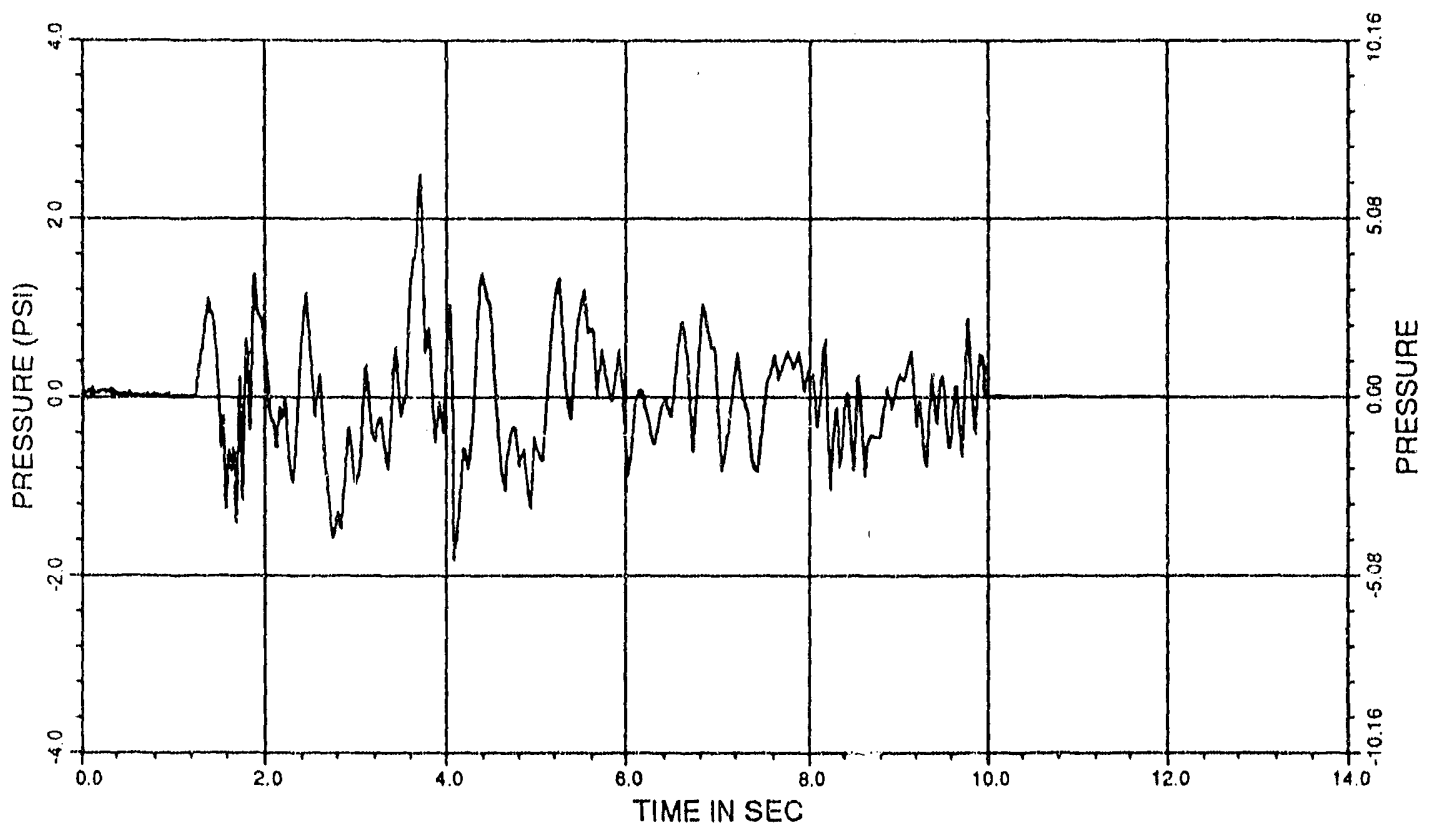

IMPULSIVE PRESSURE AT ELEMENT 397

MAX. FREQUENCY,AMPLITUDE $=0.88 \quad 0.1058$

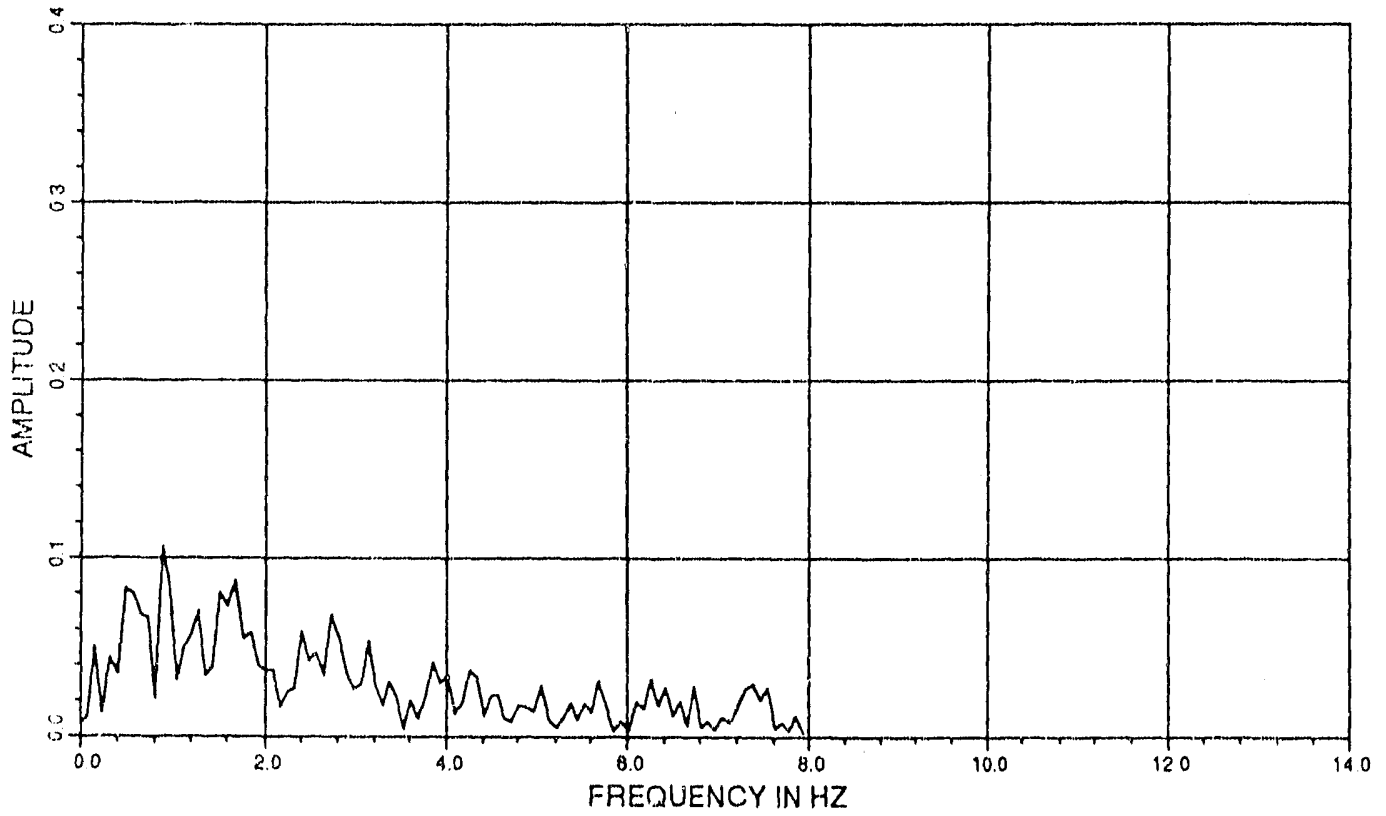

Fig. D-8. Time History of the Impulsive Pressure at Element 397 and its FFT for the Case of $\mu=200 \mathrm{cP}$ 
IMPULSIVE PRESSURE AT ELEMENT 463

TMAX,AMAX TMIN,AMIN $=3.70 \quad 2.5080 \quad 4.08 \quad-1.8460$

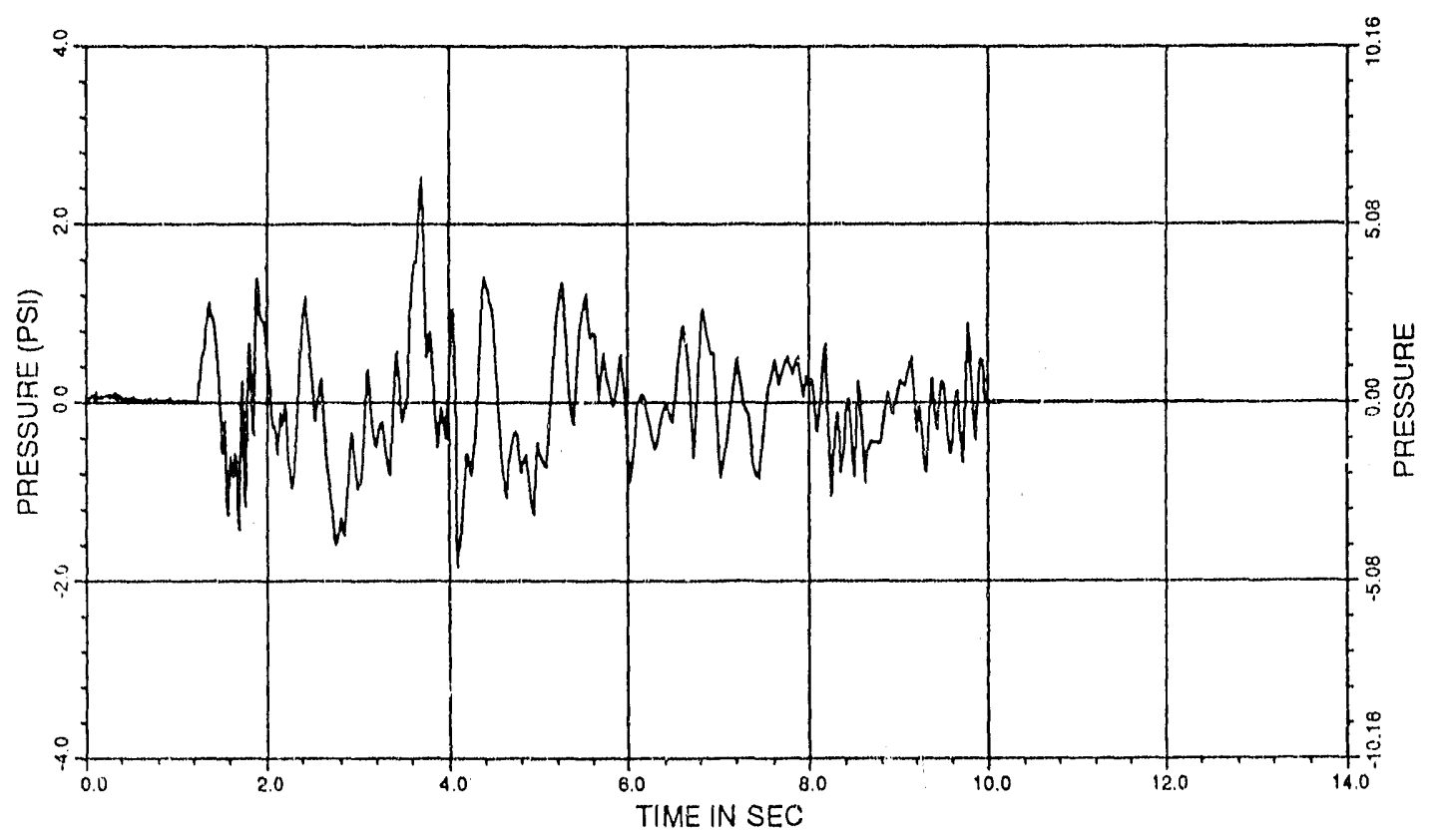

IMPULSIVE PRESSURE AT ELEMENT 463

MAX. FREQUENCY,AMPLITUDE $=0.88 \quad 0.1071$

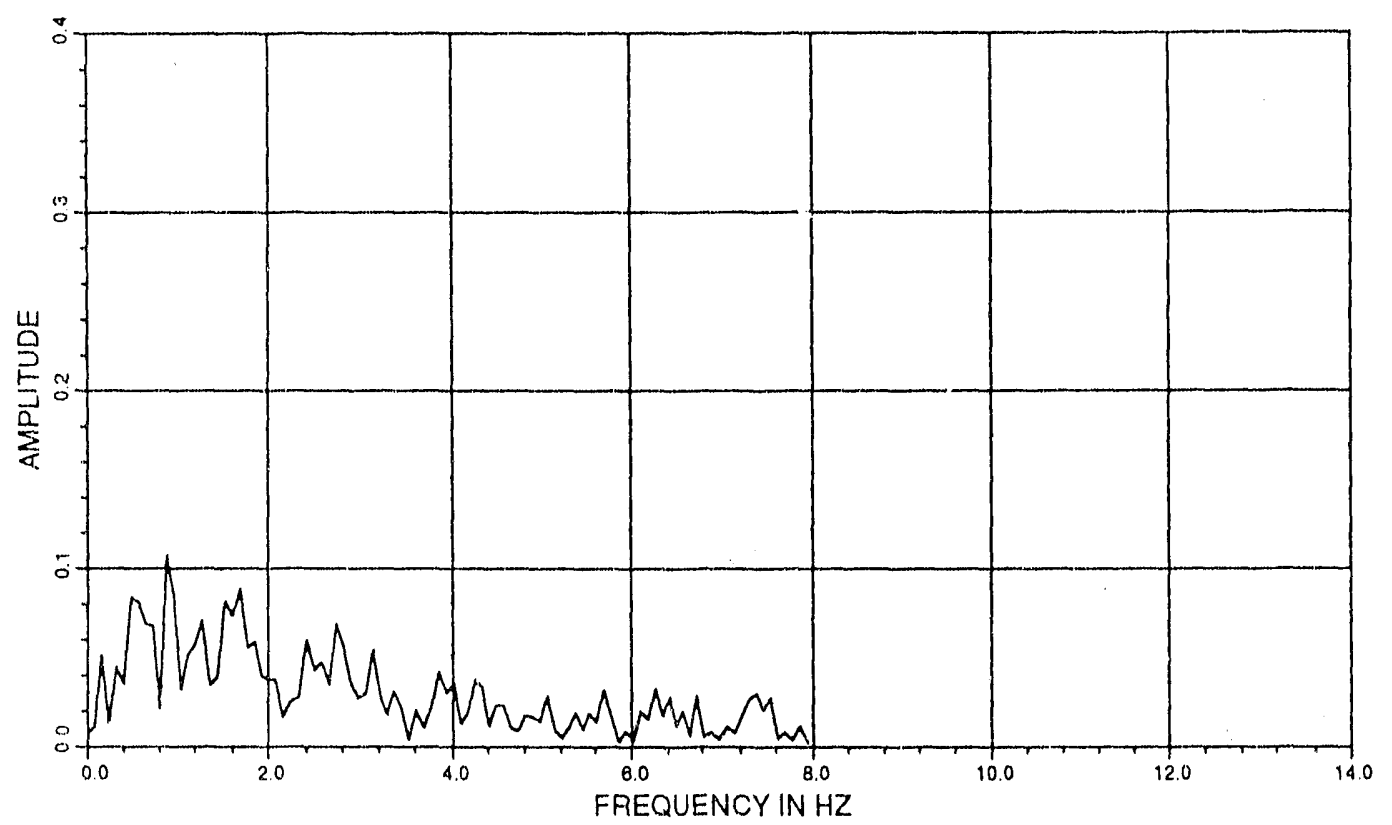

Fig. D-9. Time History of the Impulsive Pressure at Element 463 and its FFT for the Case of $\mu=200 \mathrm{cP}$ 
IMPULSIVE PRESSURE AT ELEMENT 529

TMAX,AMAX TMIN,AMIN $=3.70 \quad 2.5170 \quad 4.08 \quad-1.8540$

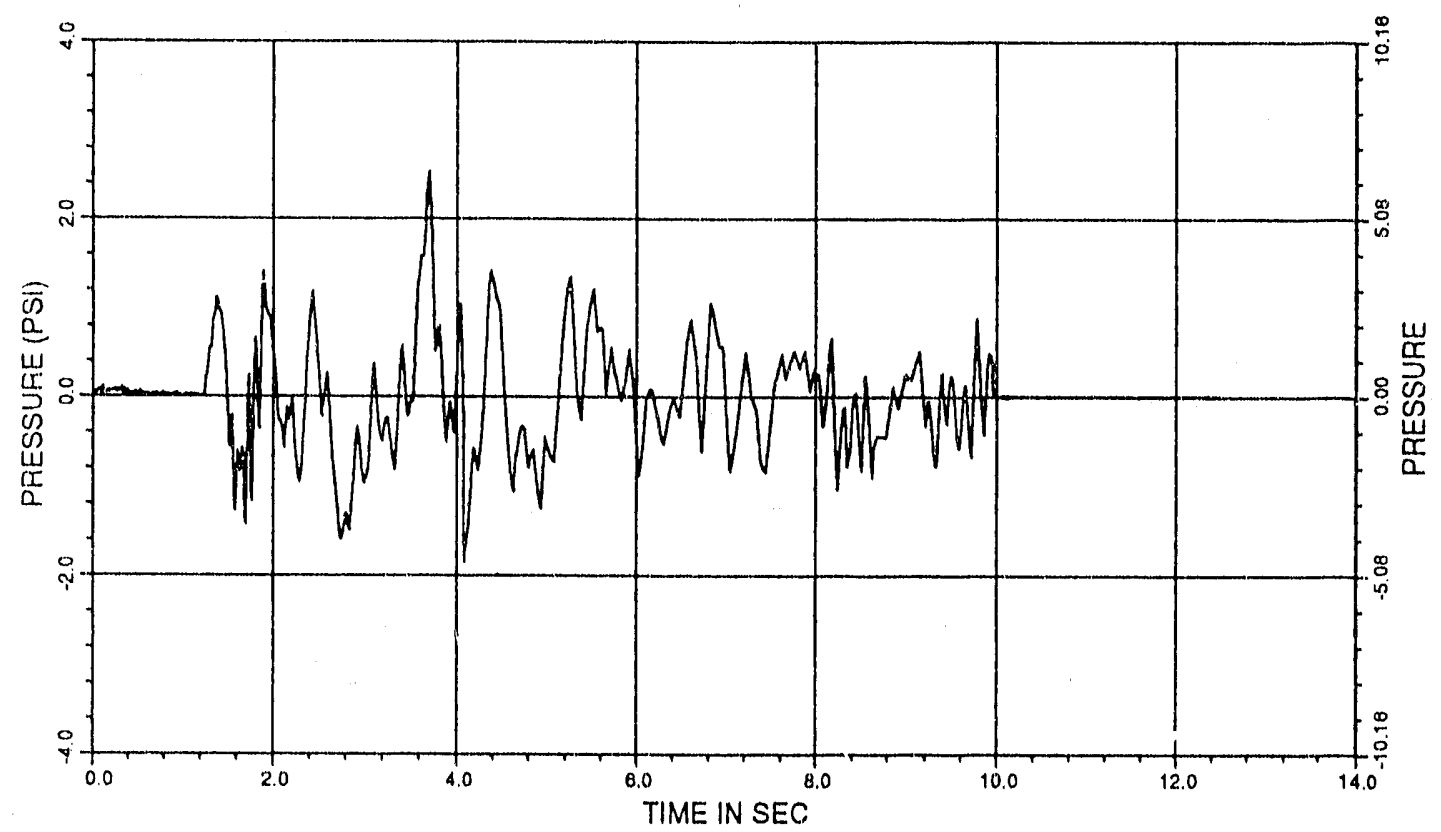

MPULSIVE PRESSURE AT ELEMENT 529

MAX. FREQUENCY,AMPLITUDE $=0.88 \quad 0.1075$

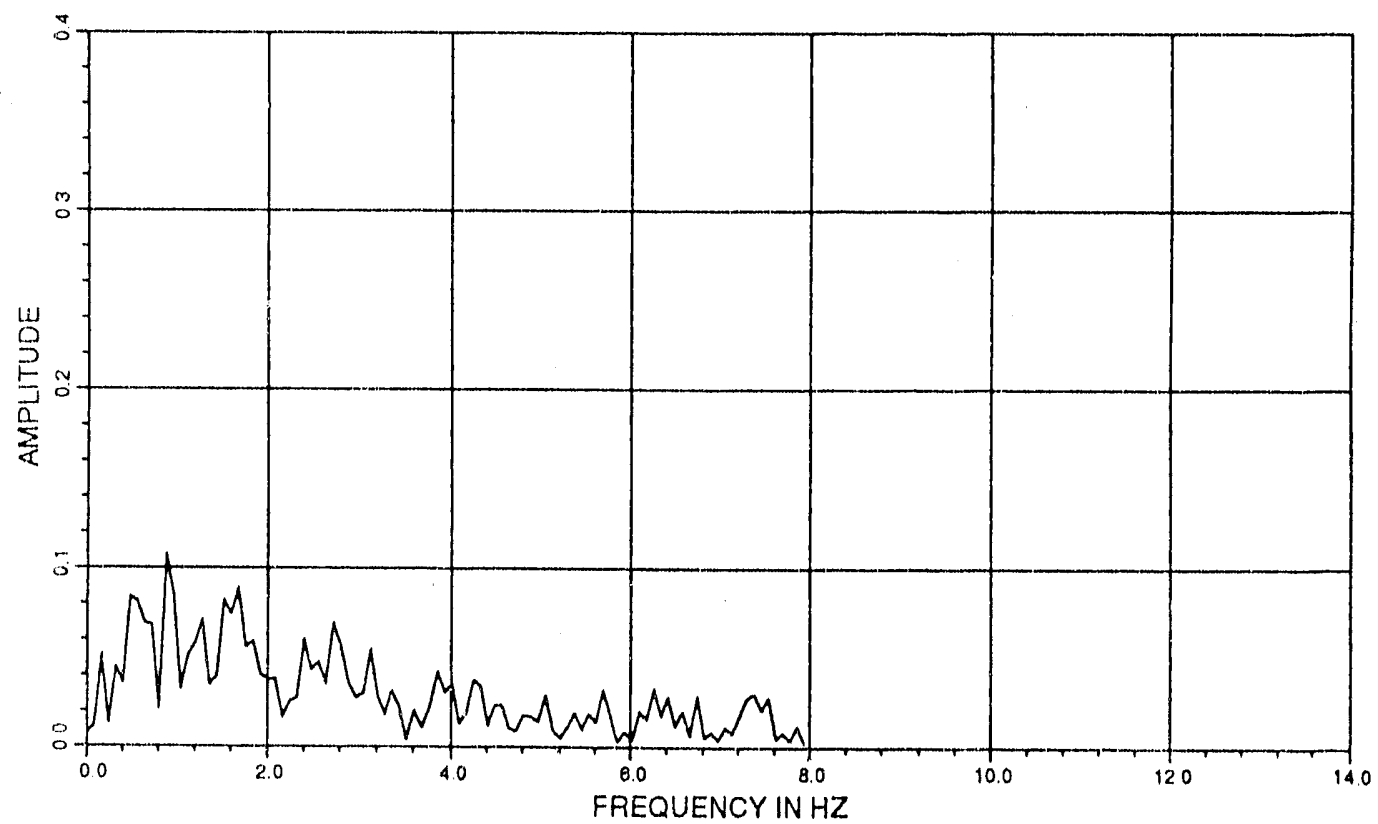

Fig. D-10. Time History of the Impulsive Pressure at Element 529 and its FFT for the Case of $\mu=200 \mathrm{cP}$ 


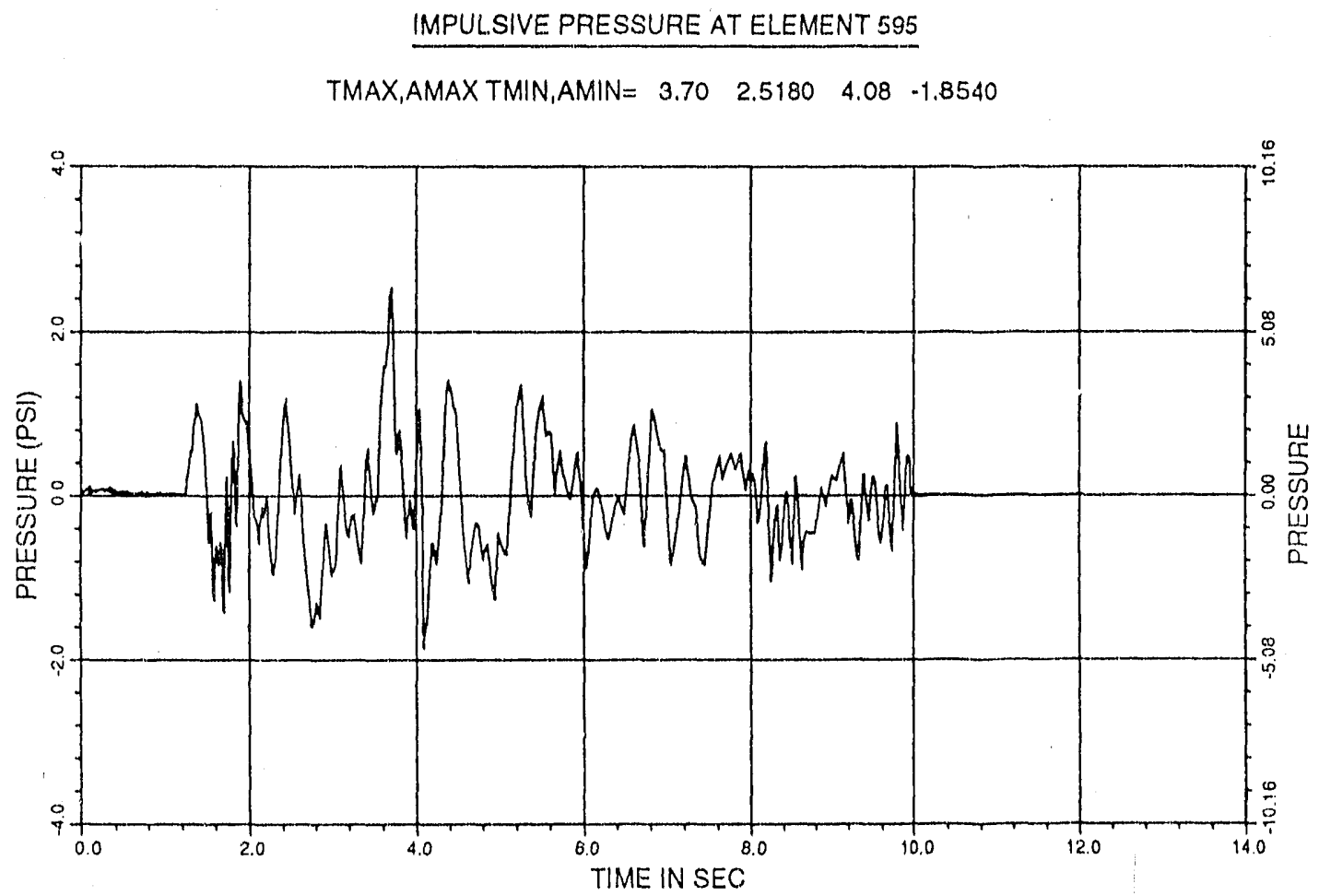

IMPULSIVE PRESSURE AT ELEMENT 595

MAX. FREQUENCY,AMPLITUDE $=0.88 \quad 0.1075$

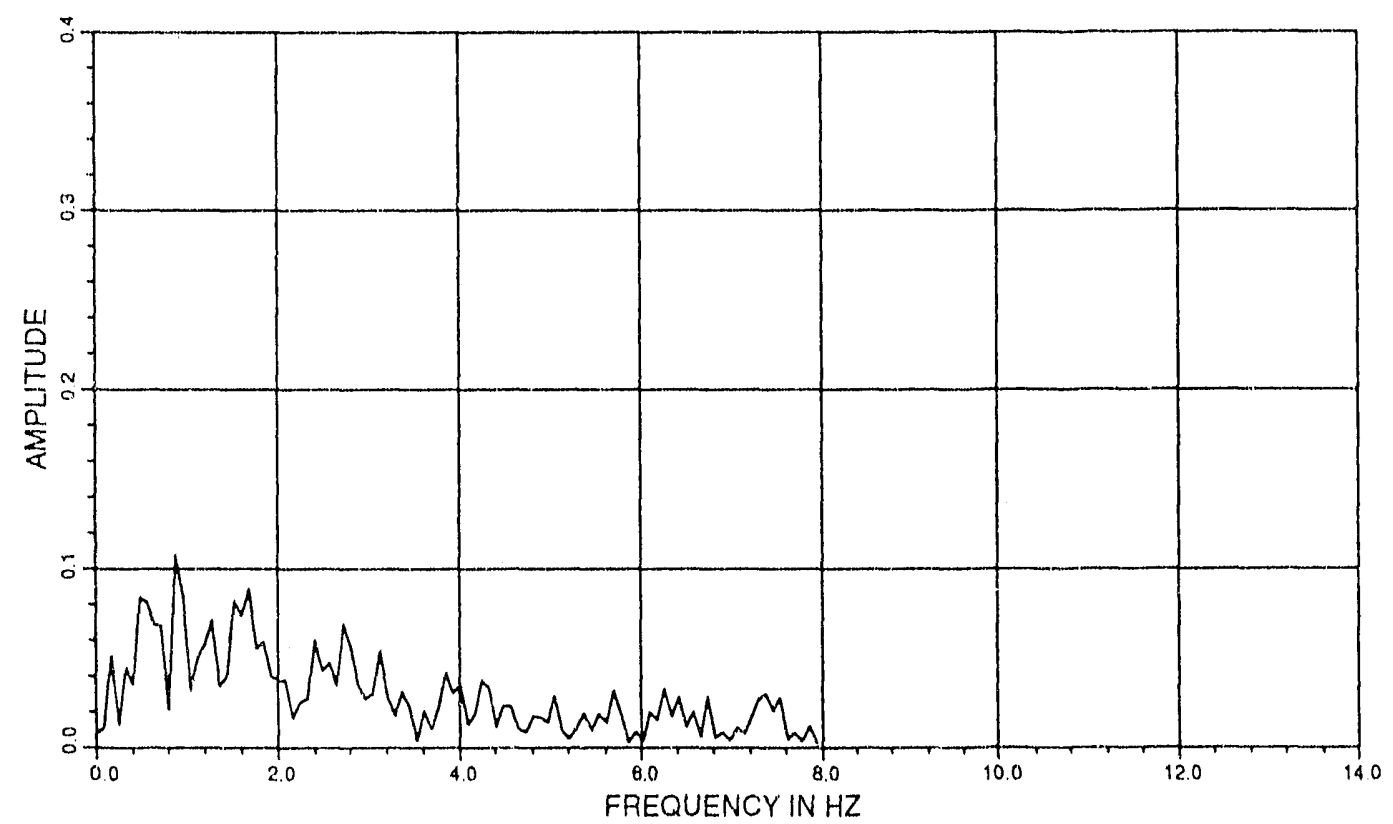

Fig. D-11. Time History of the Impulsive Pressure at Element 595 and its FFT for the Case of $\mu=200 \mathrm{cP}$ 


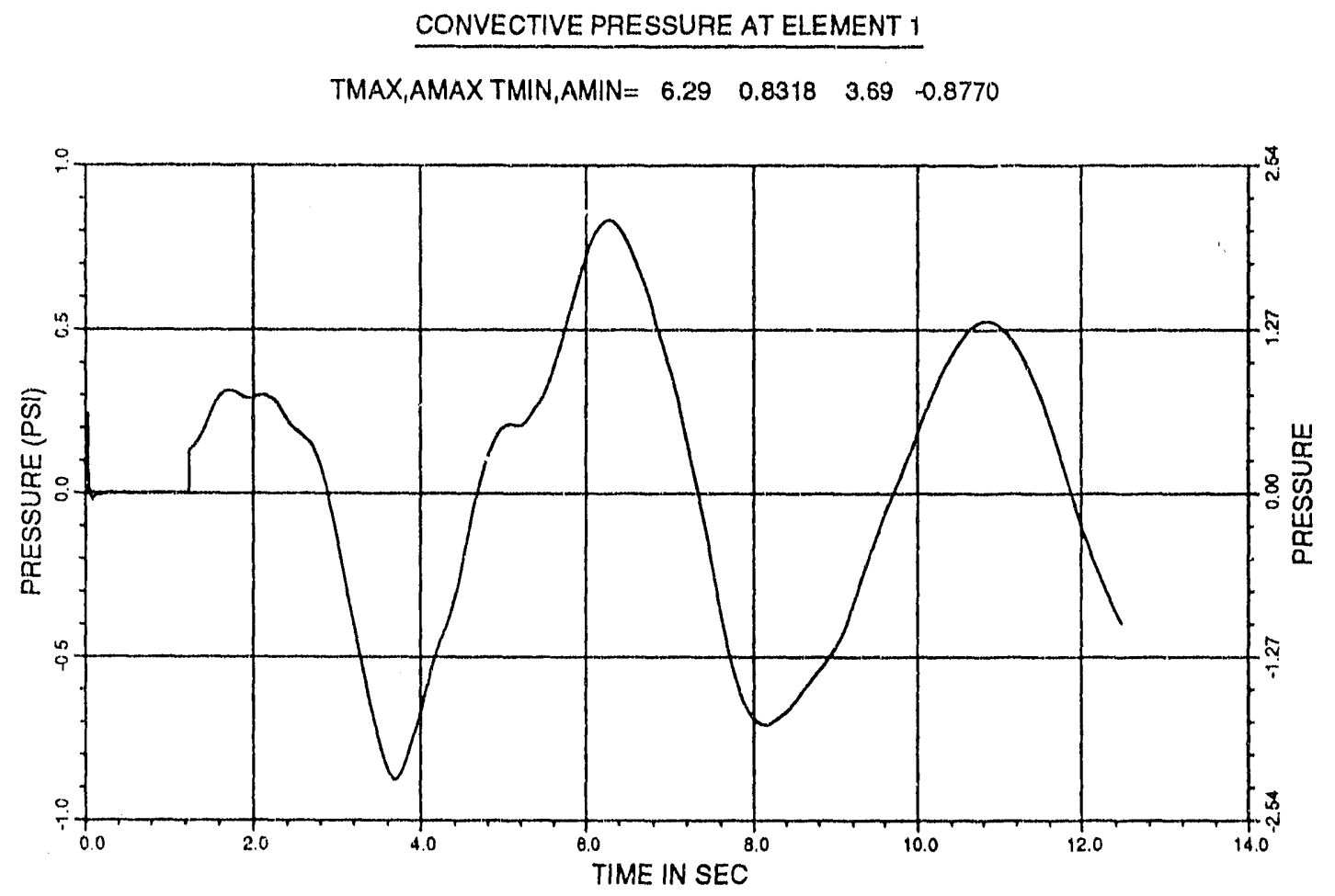

CONVECTIVE PRESSURE AT ELEMENT 1

MAX. FREQUENCY,AMPLITUDE $=0.240 .2438$

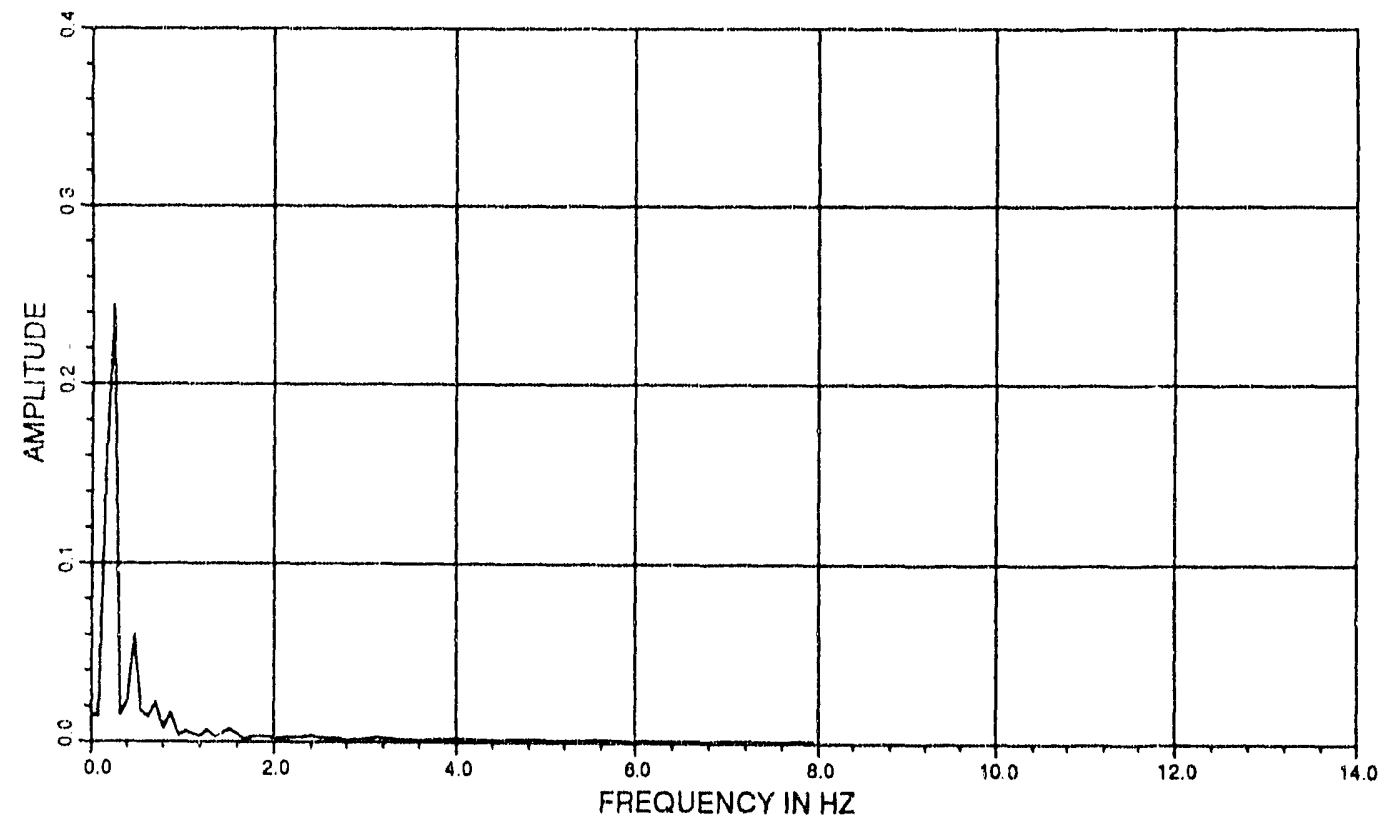

Iig. D-12. Time History of the Convective Pressure at Element 1 and its FFT Eor the Case of $\mu=200 \mathrm{cP}$ 

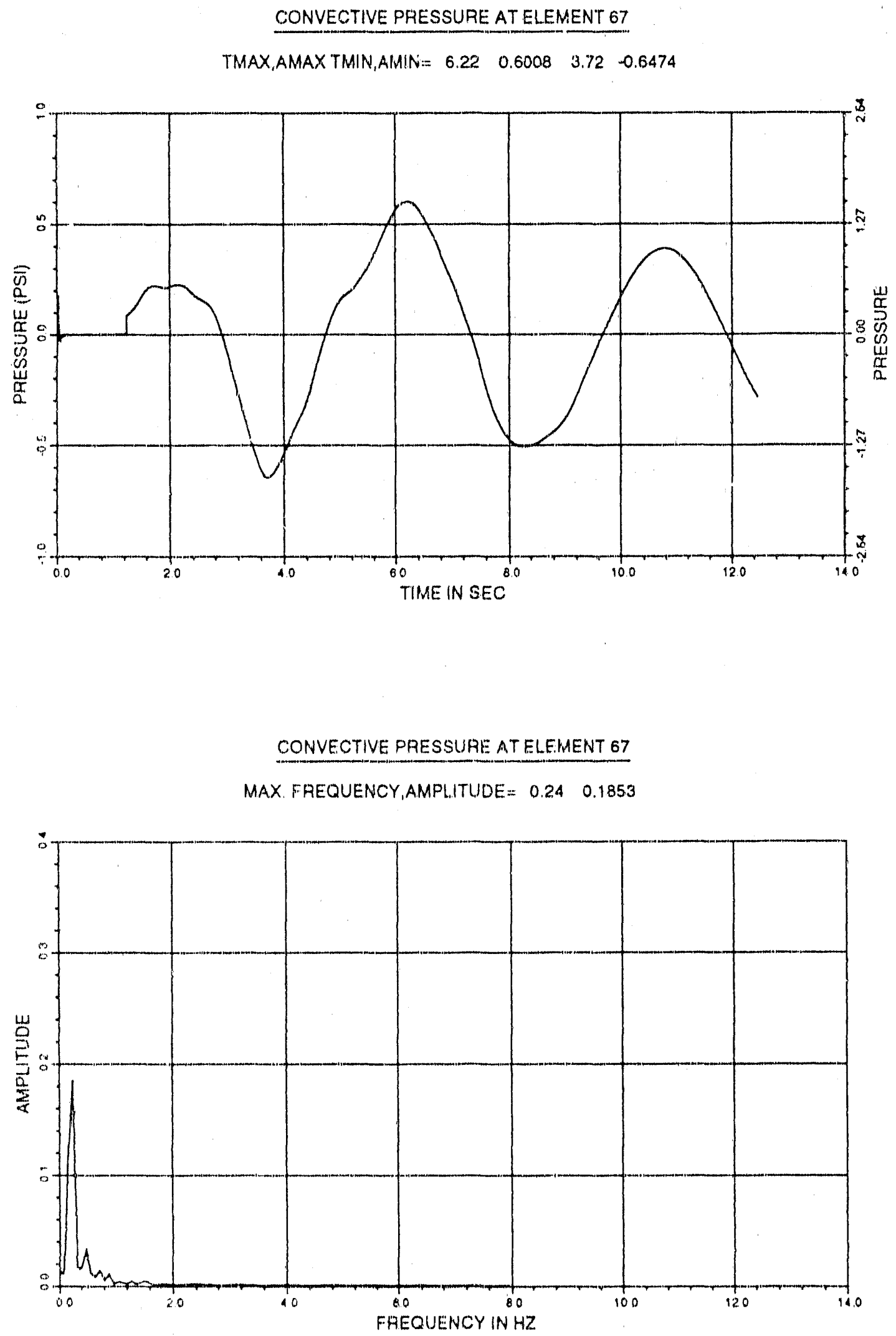

Fig. D-13. Time History of the Convective Pressure at Element 67 and its $\mathrm{FFl}$ for the case of $\mu=200 \mathrm{cP}$ 
CONVECTIVE PRESSURE AT ELEMENT 1;,3

TMAX,AMAX TMIN,AMIN= $6.19 \quad 0.5035 \quad 3.72-0.5350$

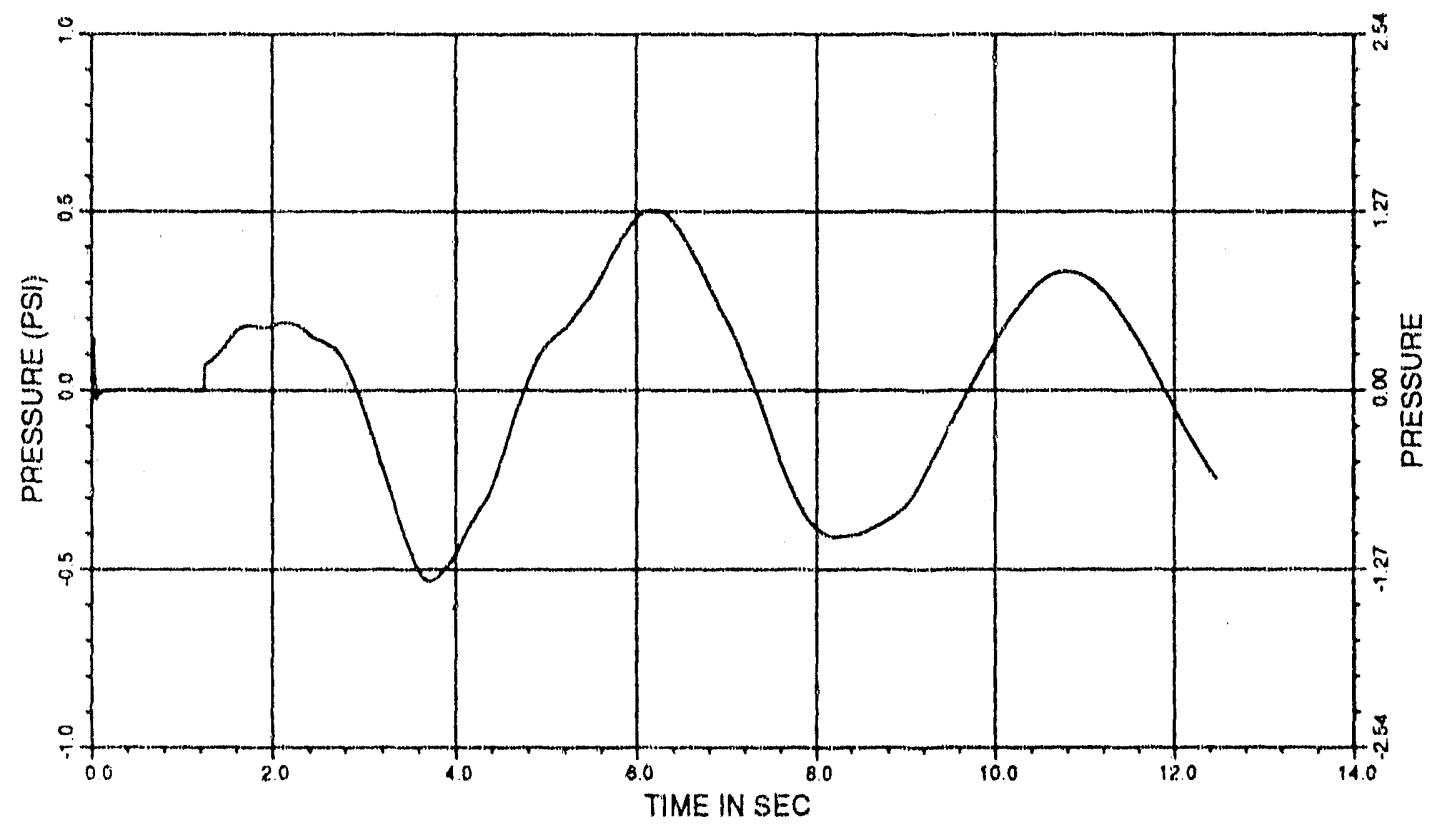

CONVECTIVE PRESSURE AT ELEMENT 133

NIAX. FREQUENCY,AMPLITUDE $=0.24 \quad 0.1548$

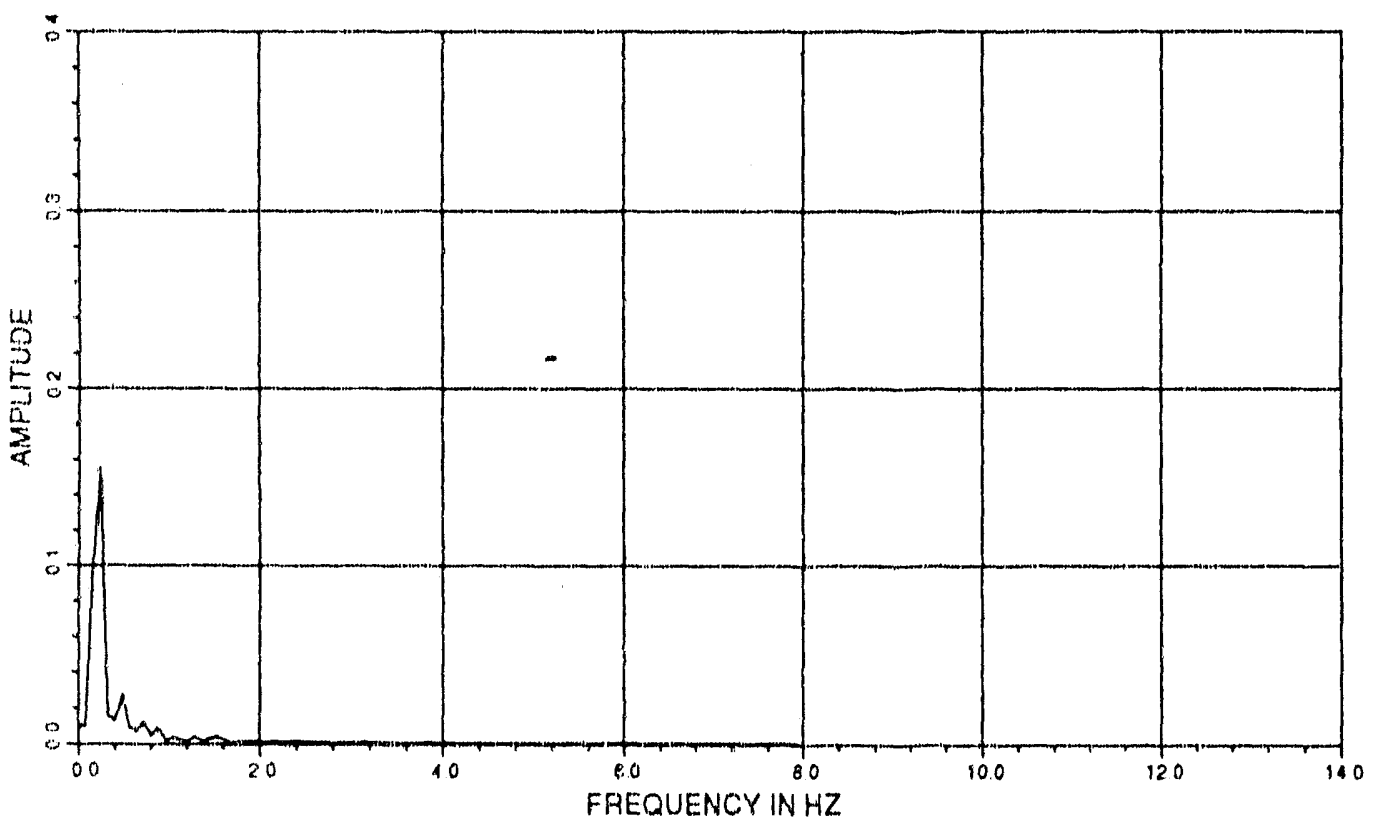

Fig. 1)-14. Time History of the Convective Pressure at Element 133 and its FFT for the case of $\mu=200 \mathrm{cP}$ 

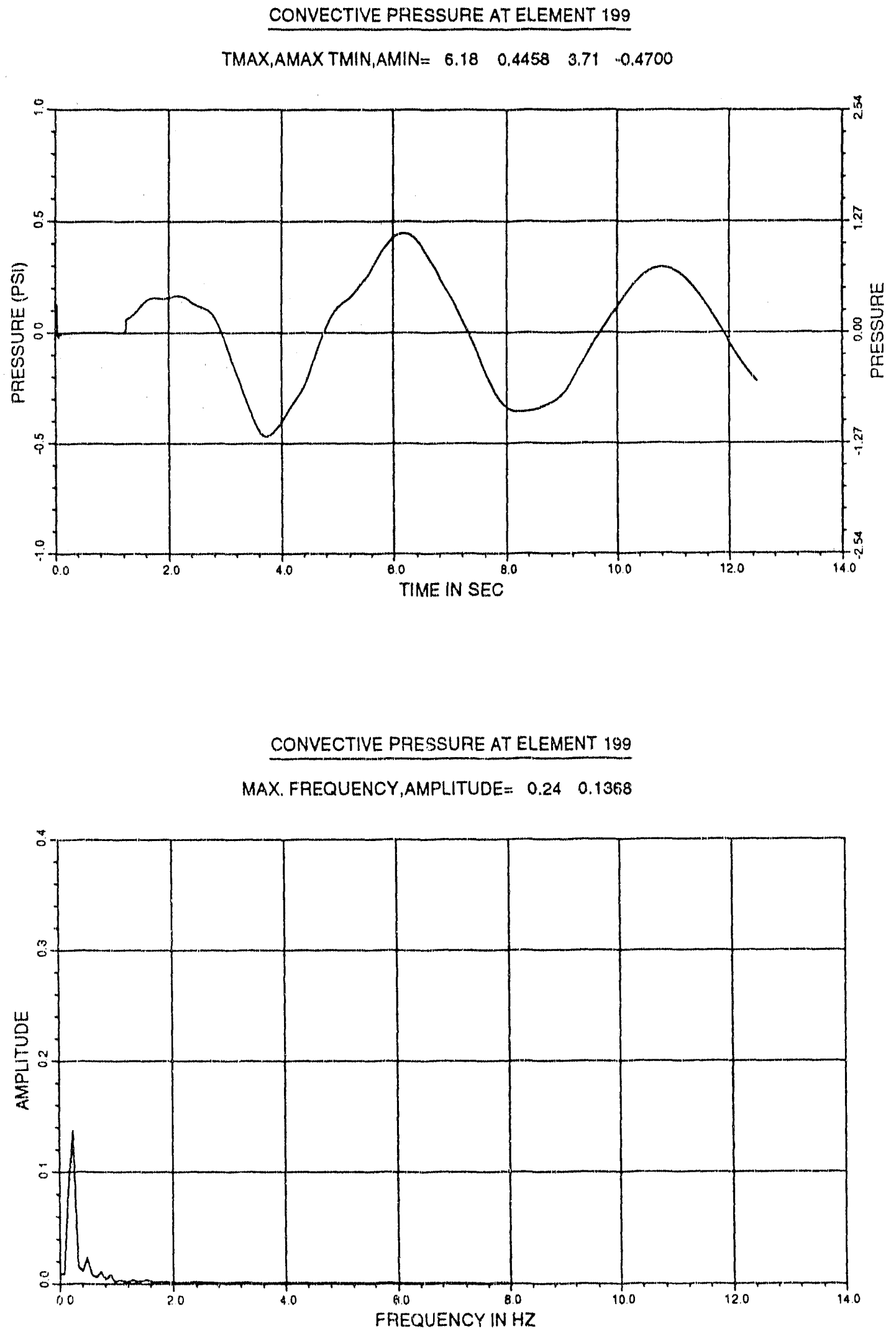

Fig. D-15. Time History of the Convective Pressure at Element 199 and its FFT for the Case of $\mu=200 \mathrm{cP}$ 
CONVECTIVE PRESSURE AT ELEMENT 265

TMAX,AMAX TMIN,AMIN $=6.18 \quad 0.4122 \quad 3.73-0.4330$

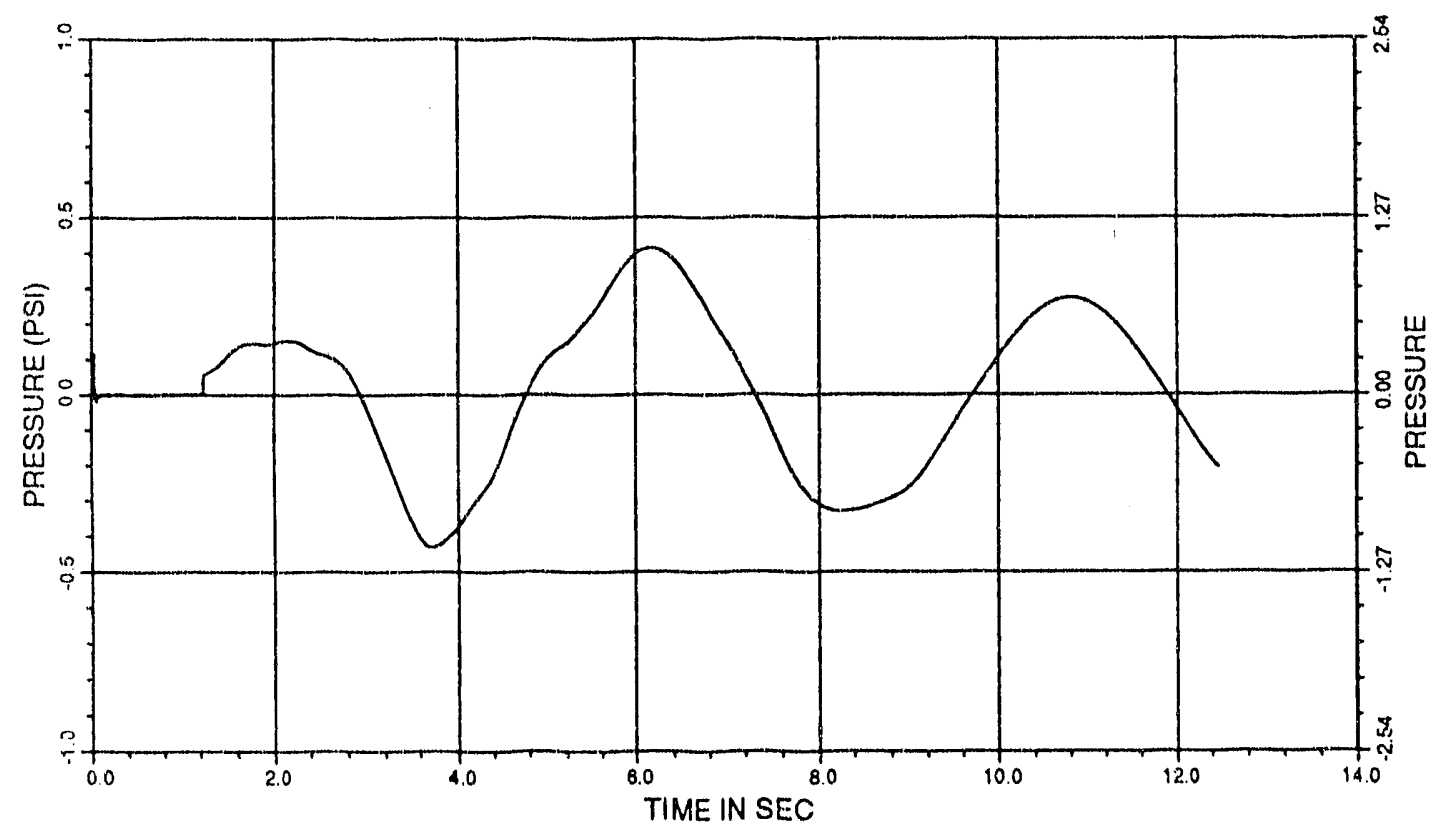

CONVECTIVE PRESSURE AT ELFMENT 265

MAX. FREQUENCY,AMPLITUDE $=0.24 \quad 0.1264$

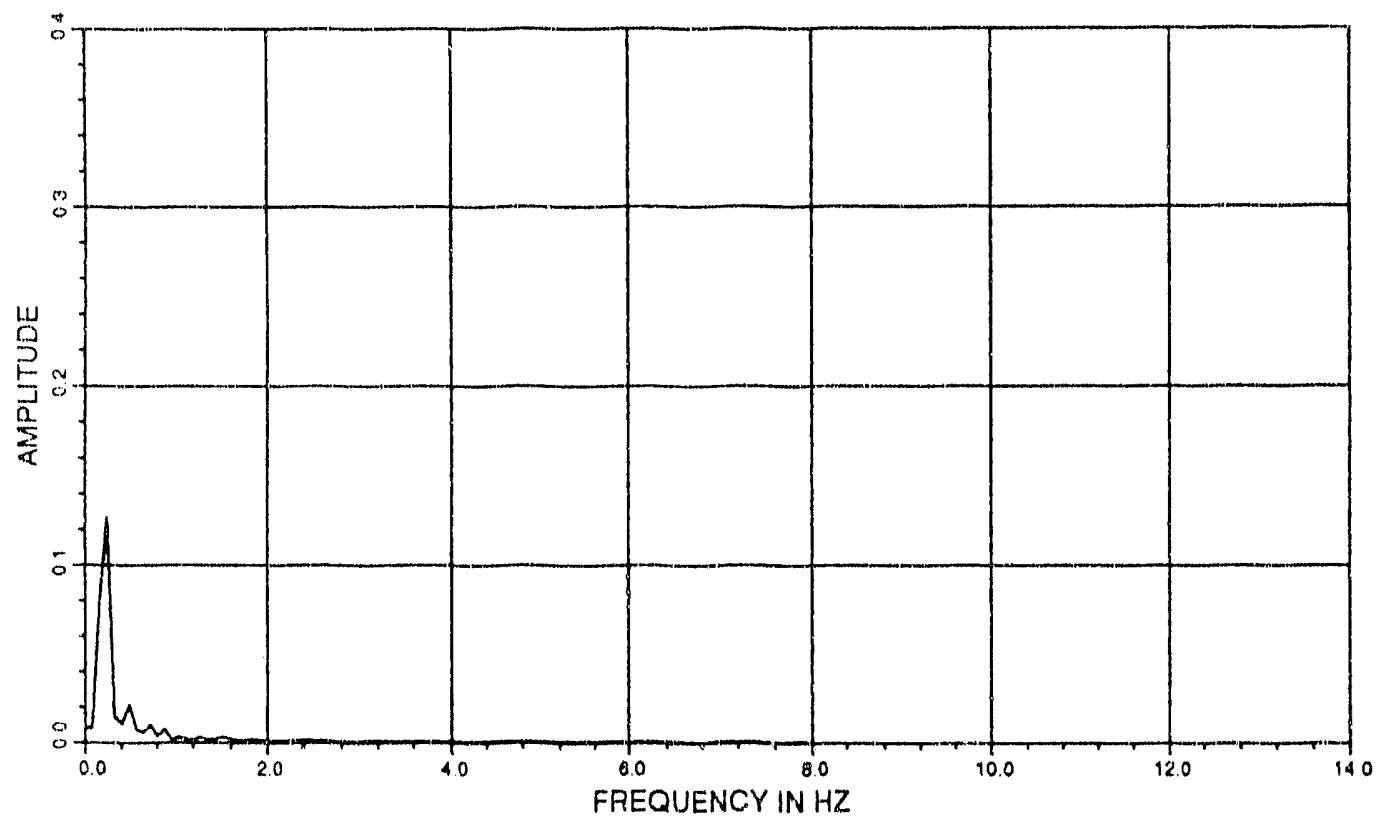

Fig. D-16. Time History of the Convective Pressure at Element 265 and its FFT for the Case of $\mu=200 \mathrm{cP}$ 


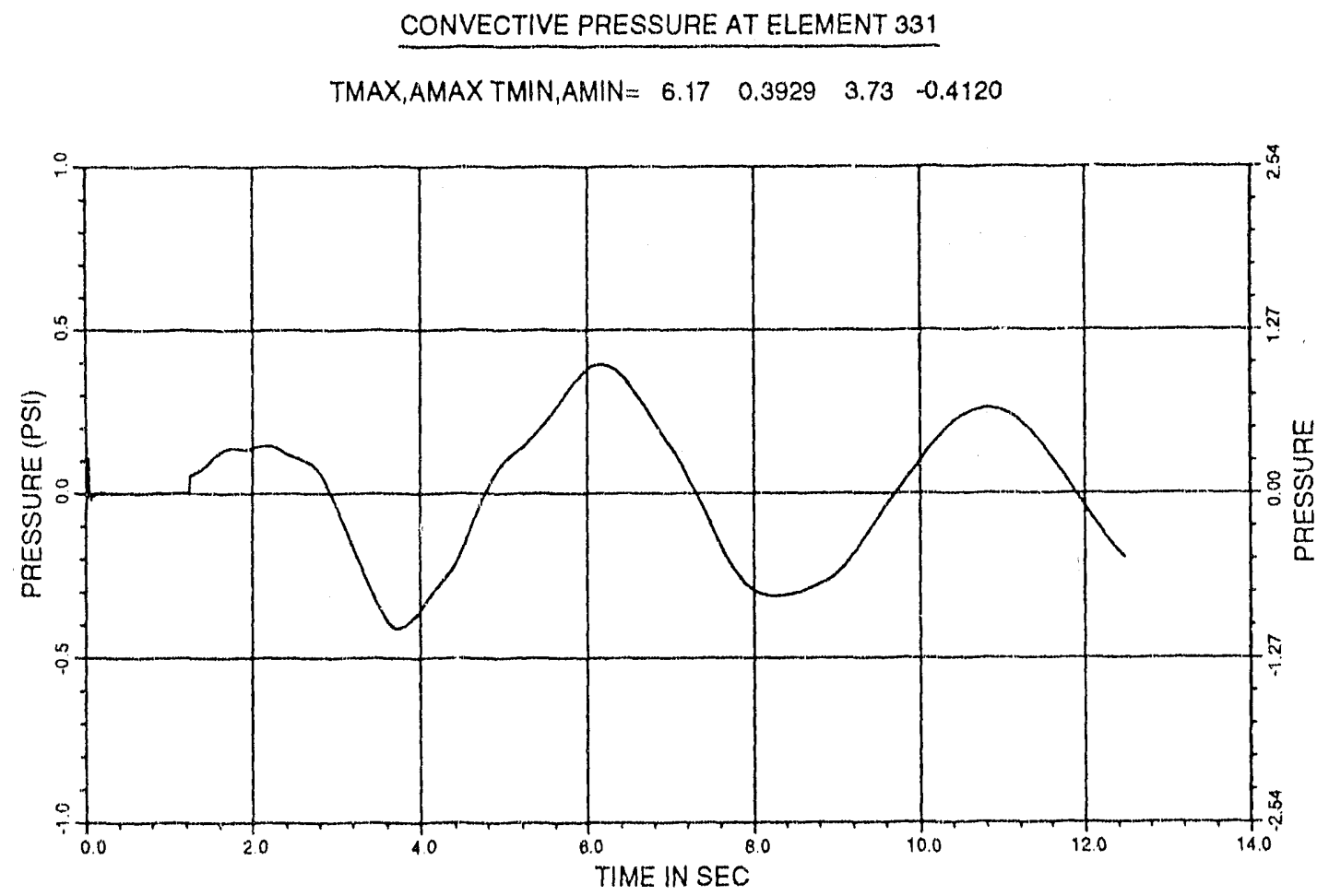

CONVECTIVE PRESSURE AT ELEMENT 331

MAX. FREQUENCY,AMPLITUDE $=0.24 \quad 0.1204$

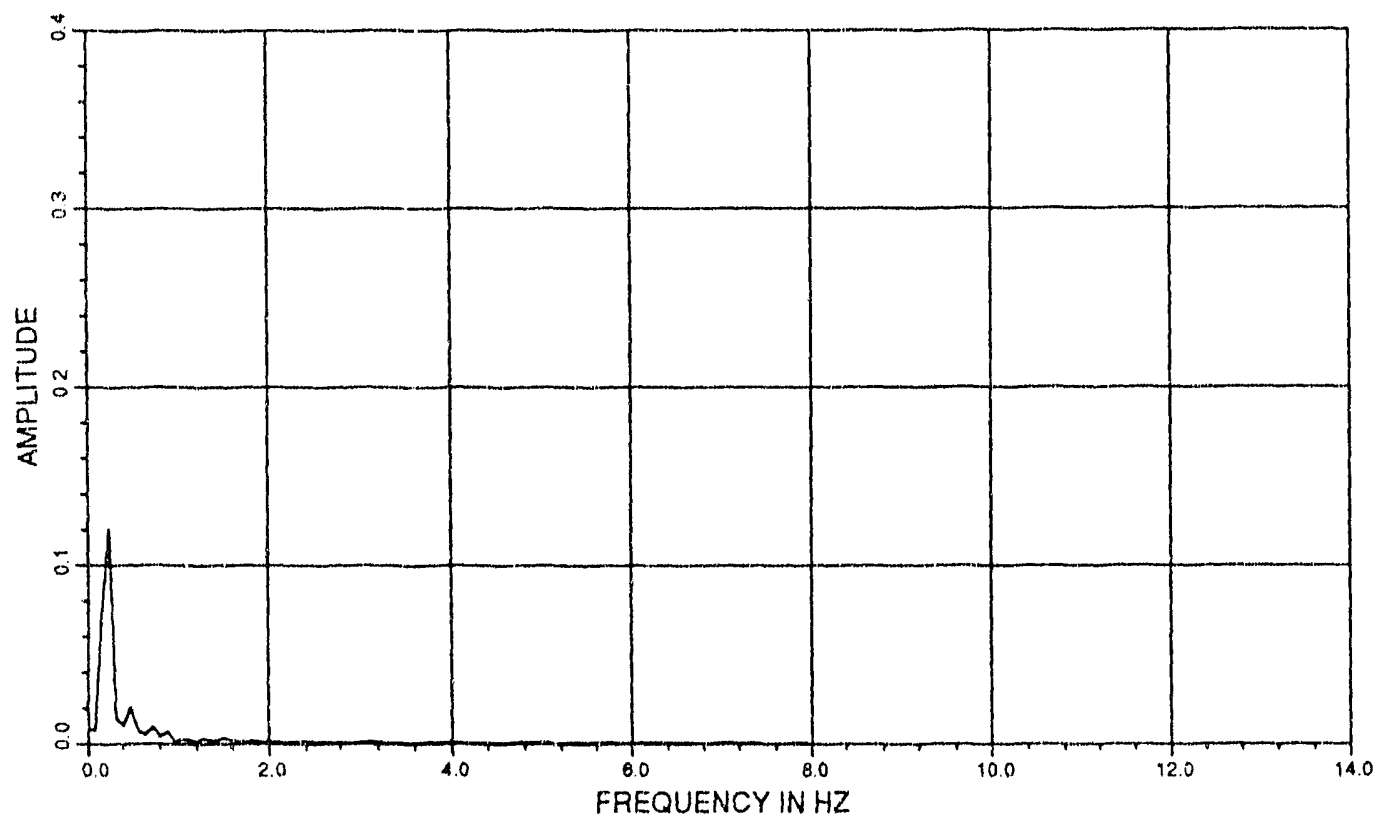

Fig. D-17. Time History of the Convective Pressure at Element 331 and its FFT for the Case of $\mu=200 \mathrm{cP}$ 

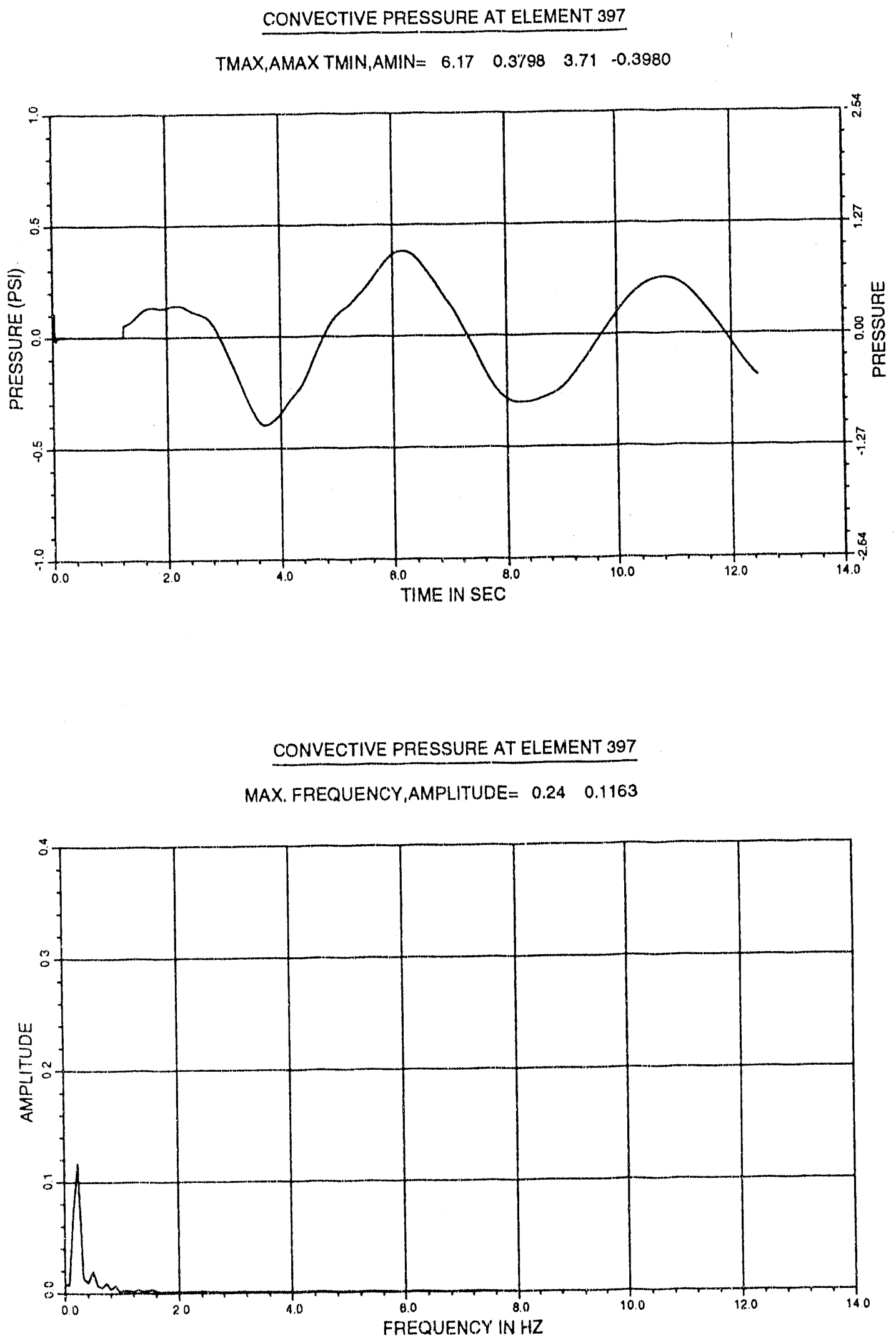

Fig. D-18. Time History of the Convective Pressure at Element 397 and its FFT for the Case of $\mu=200 \mathrm{cP}$ 
CONVECTIVE PRESSURE AT ELEMENT 463

TMAX,AMAX TMIN,AMIN= $6.17 \quad 0.3716 \quad 3.73 \quad-0.3890$

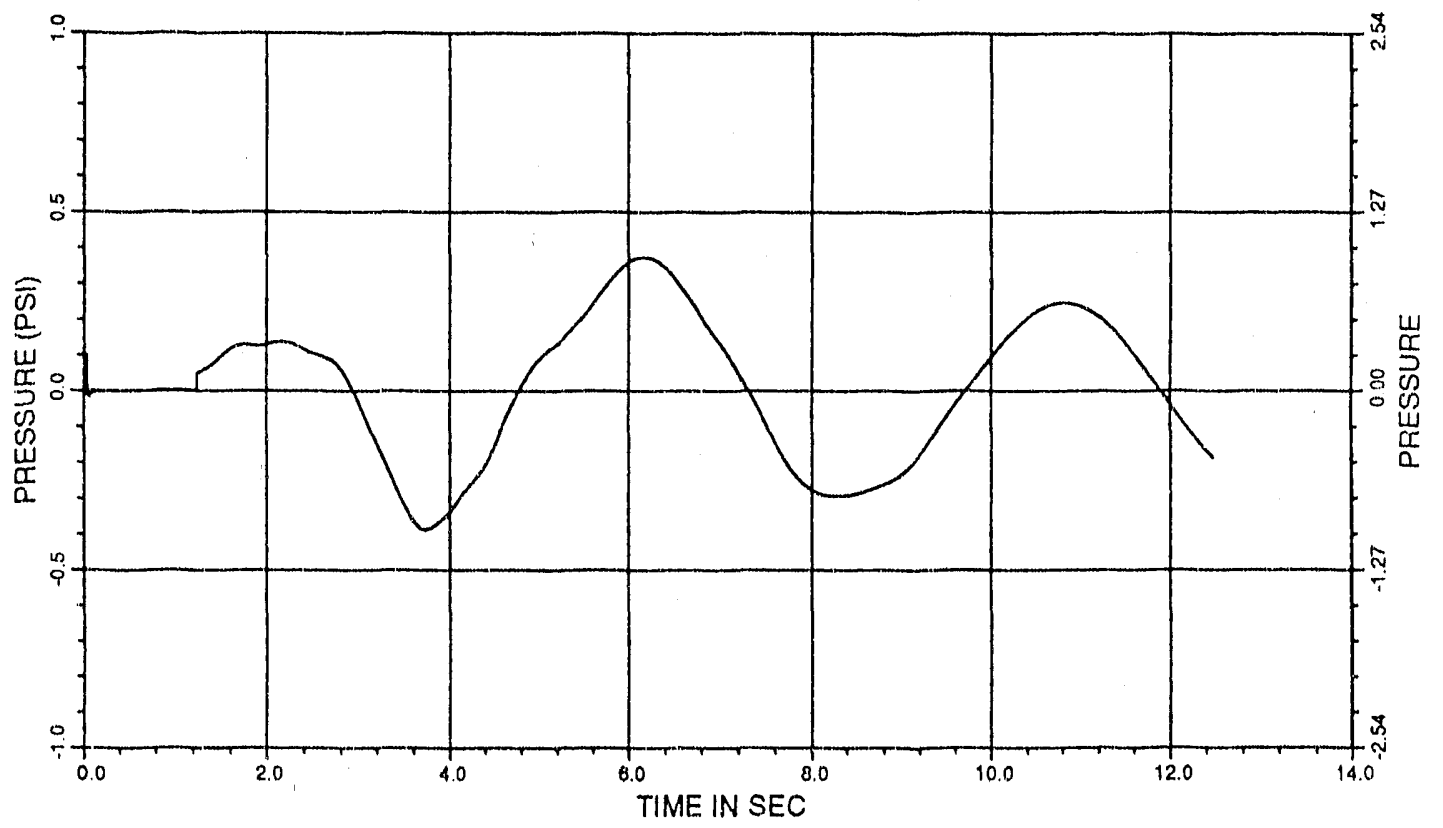

CONVECTIVE PRESSURE AT ELEMENT 463

MAX. FAEQUENCY,AMPLITUDE $=0.24 \quad 0.1138$

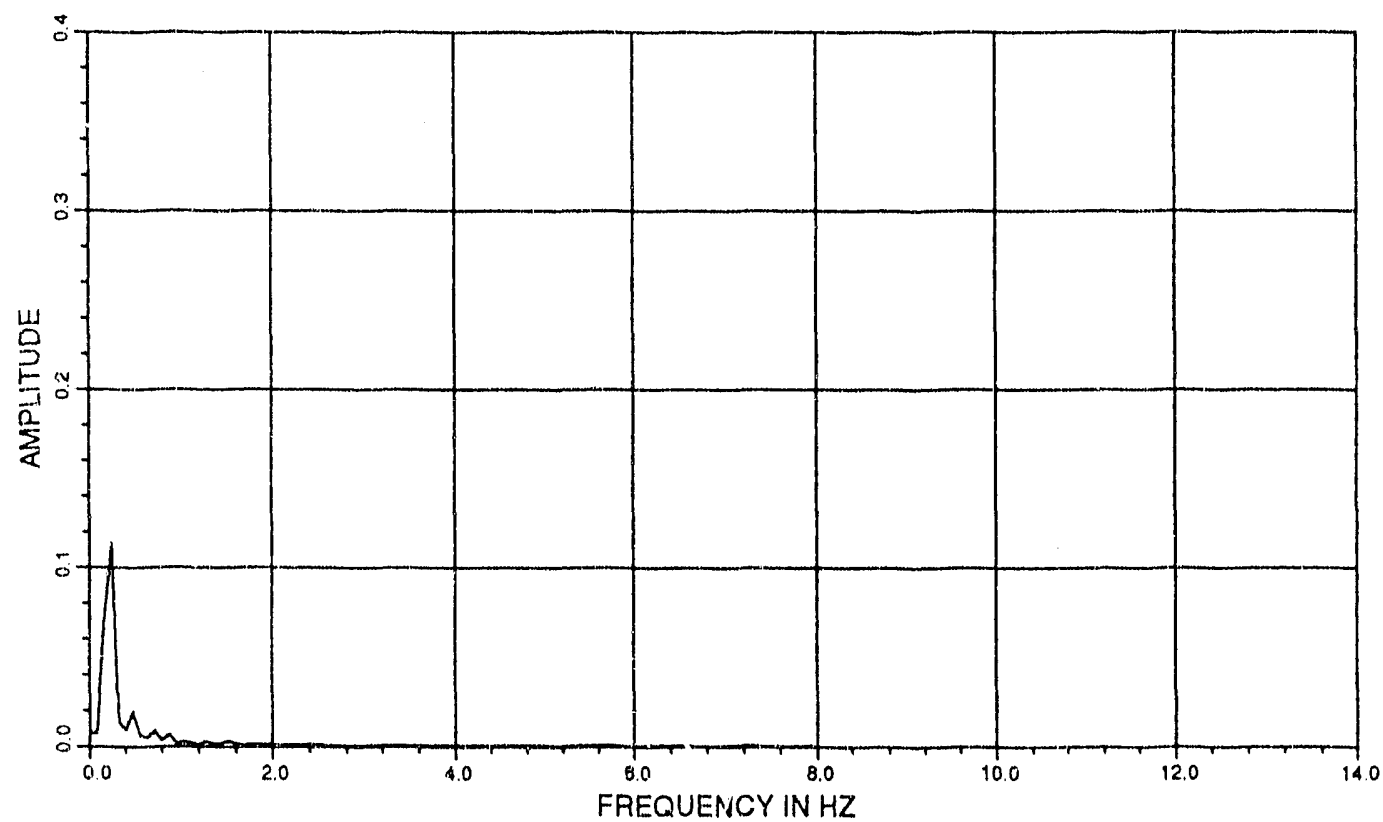

Fig. D-19. Time History of the Convective Pressure at Element 463 and its FFT for the Case of $\mu=200 \mathrm{cP}$ 
CONVECTIVE PRESSURE AT ELEMENT 529

TMAX,AMAX TMIN,AMIN $=6.16 \quad 0.3691 \quad 3.73 \quad-0.3860$

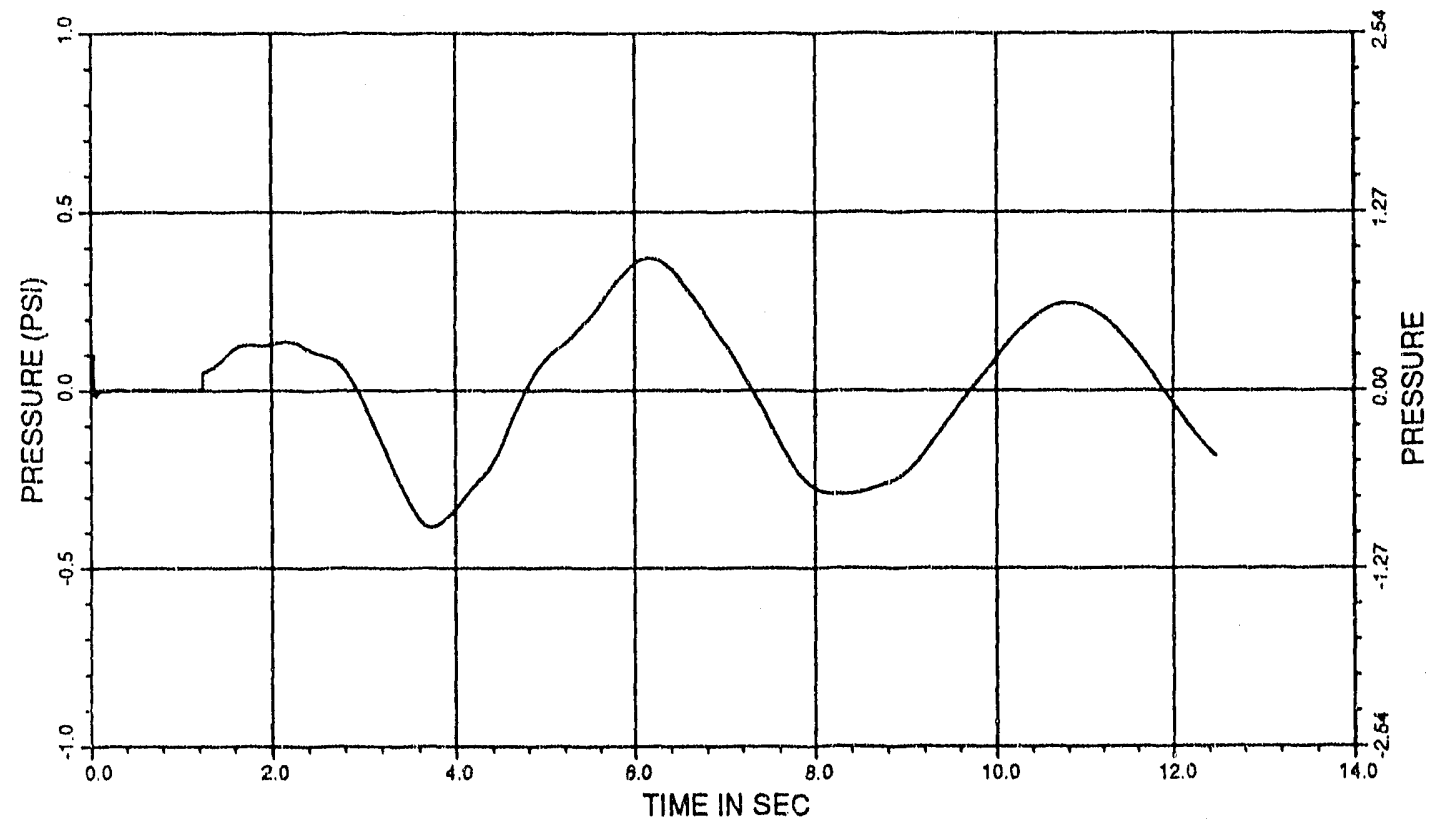

CONVECTIVE PRESSURE AT ELEMENT 529

MAX. FREQUENCY,AMPLITUDE $=0.24 \quad 0.1130$

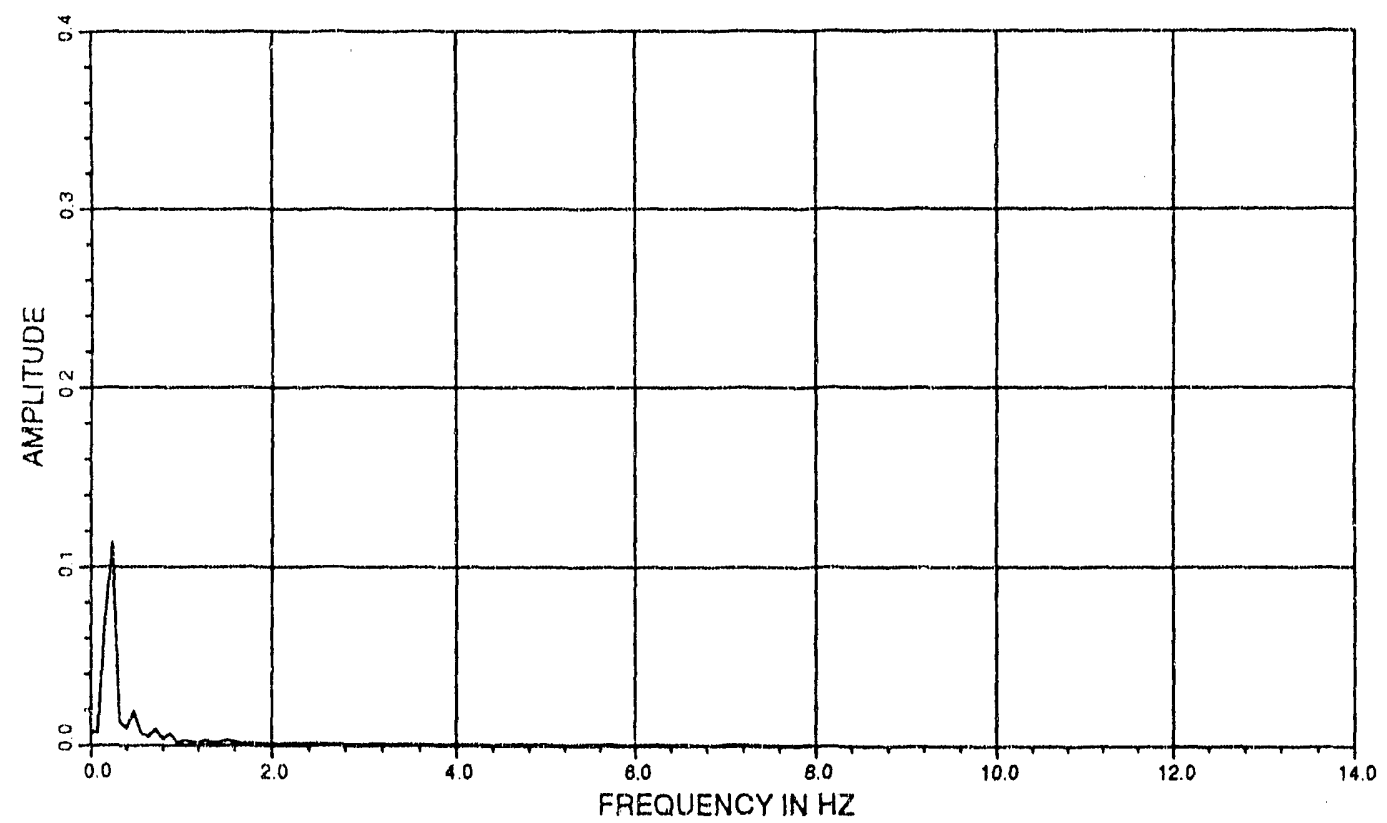

Fig. D-20. Time History of the Convective Pressure at Element 529 and its FFT for the Case of $\mu=200 \mathrm{cP}$ 

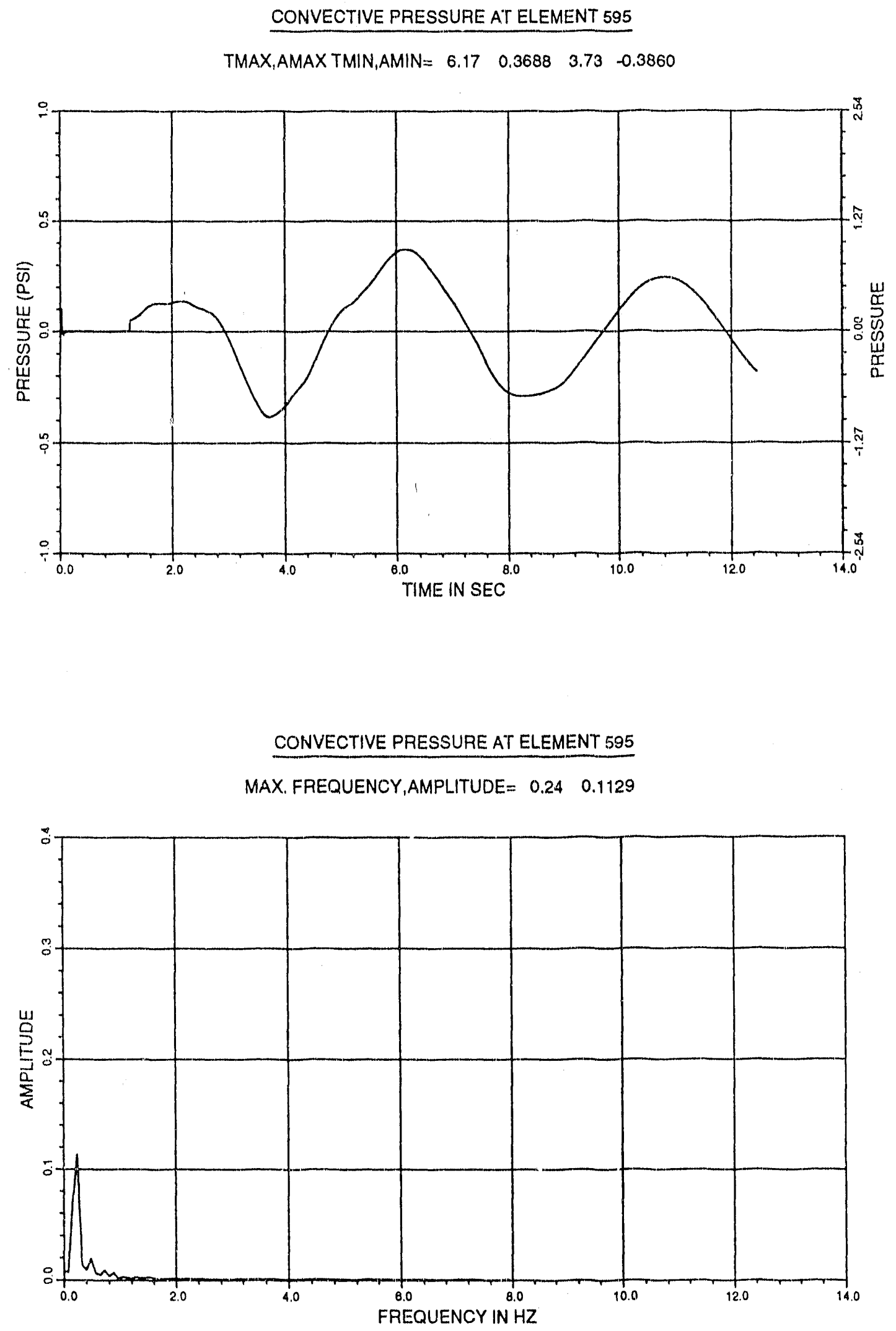

Fig. D-21. Time History of the Convective Pressure at Element 595 and its $\mathrm{FFT}$ for the Case of $\mu=200 \mathrm{cP}$ 
PRESSURE AT ELEMENT 1(waste)

TMAX,AMAX TMIN,AMIN $=6.60 \quad 0.9887 \quad 4.08 \quad \cdot 1.2106$

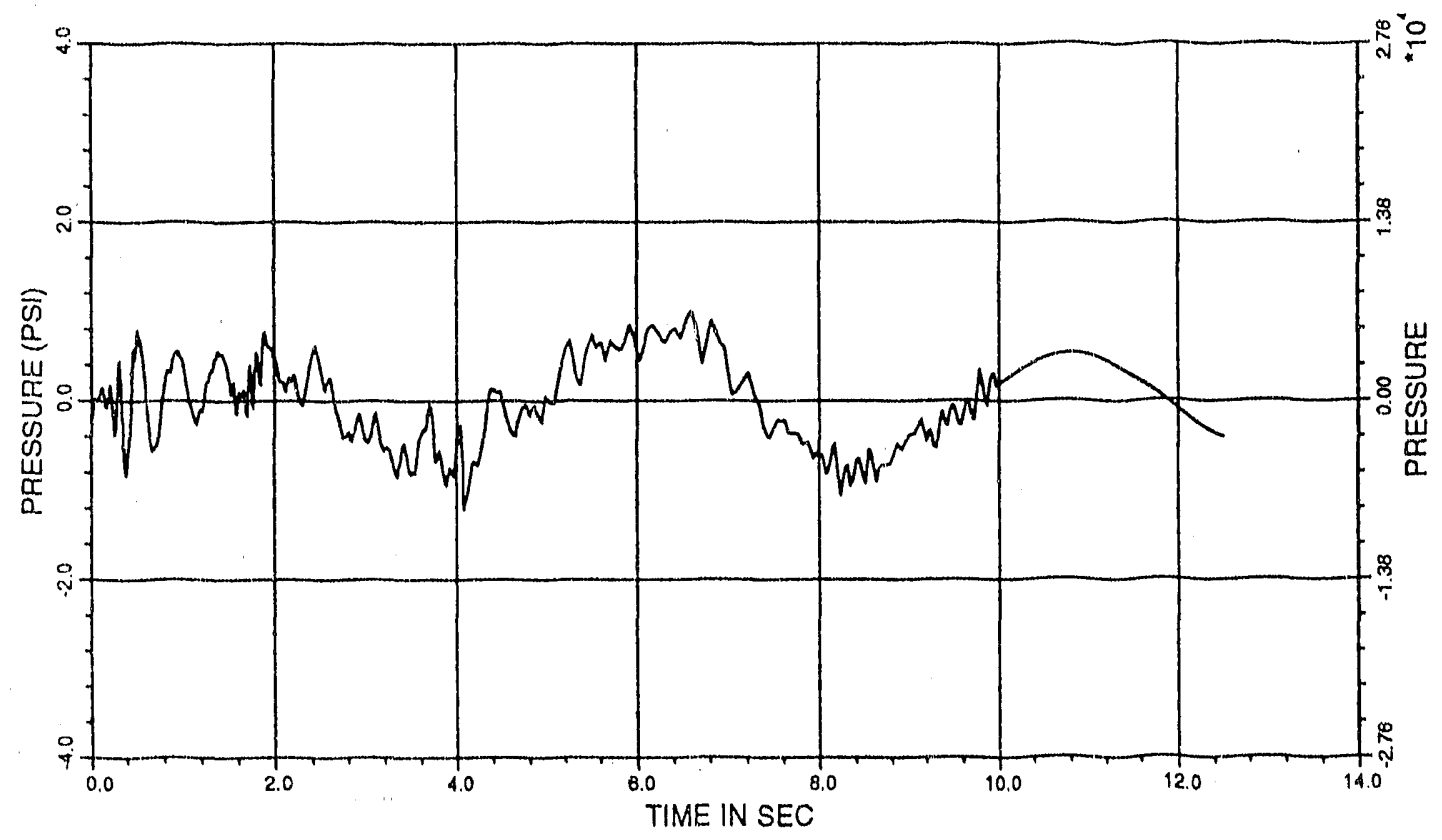

PRESSURE AT ELEMENT 1 (waste)

MAX. FREQUENCY,AMPLITUDE $=0.24 \quad 0.2486$

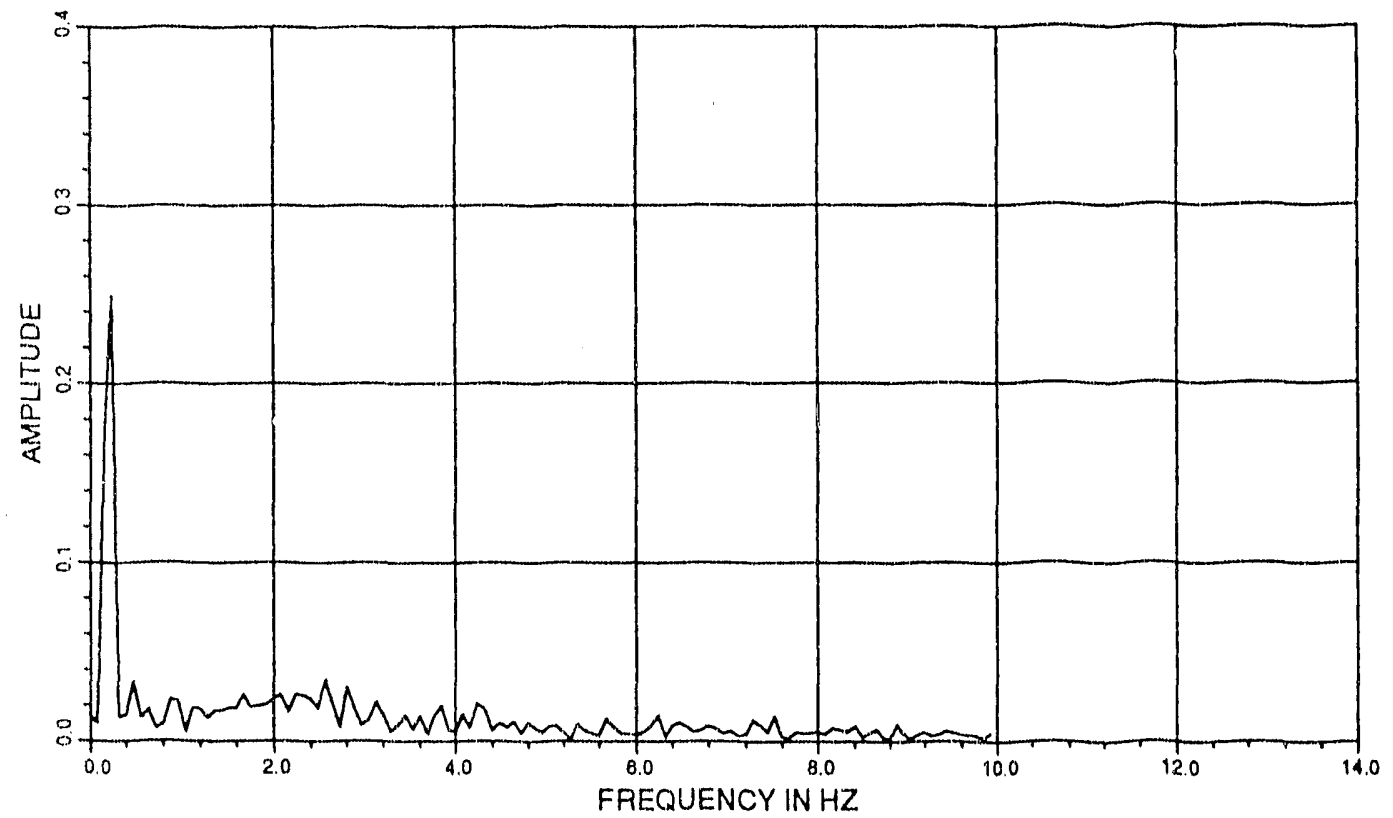

Fig. D-22. Time History of the Total Pressure at Element 1 and its FFT for the Case of $\mu=200 \mathrm{cP}$ 

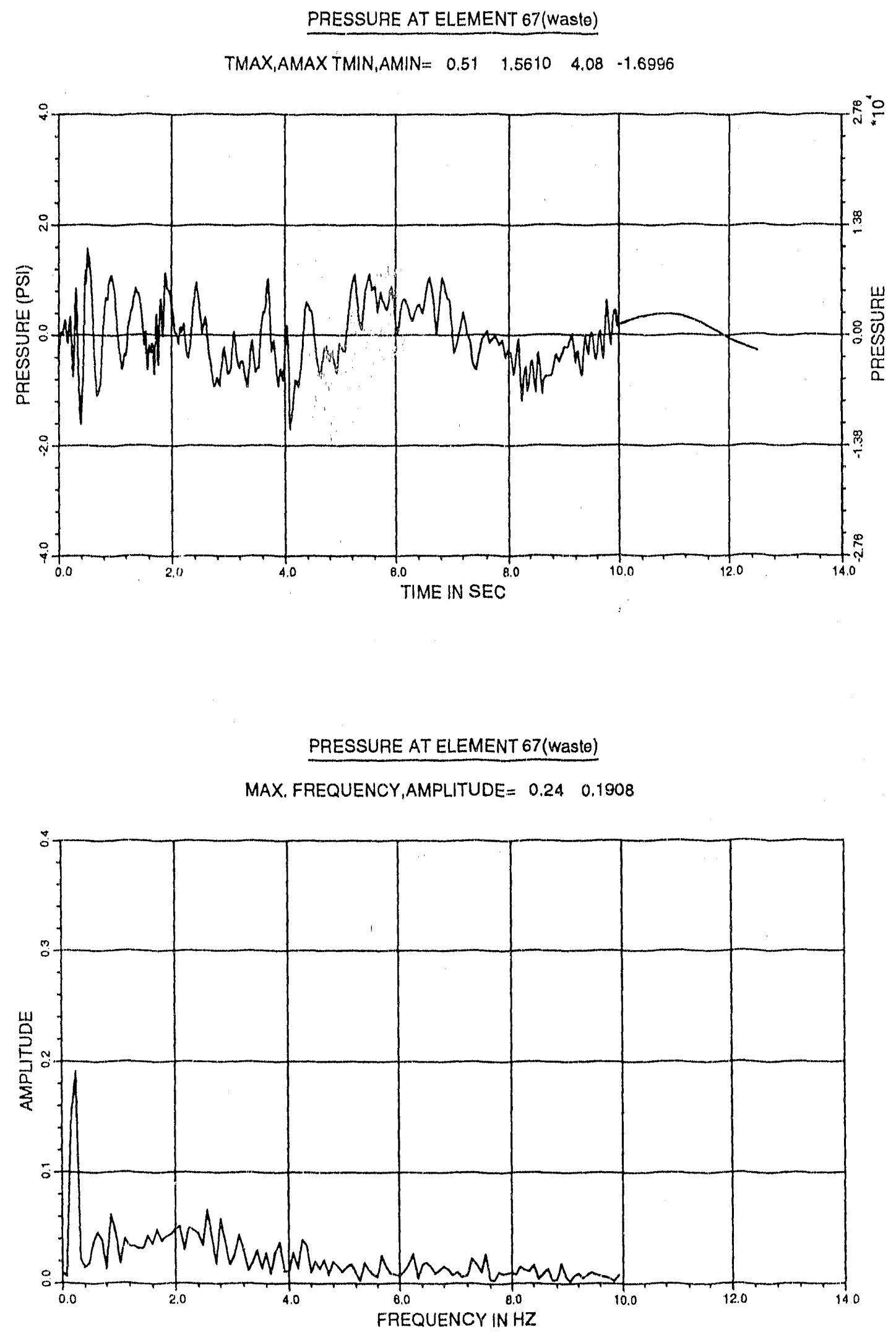

Fig. D-23. Time History of the Total Pressure at Element 67 and its FFT for the Case of $\mu=200 \mathrm{cP}$ 
PRESSURE AT ELEMENT 133(waste)

TMAX,AMAX TMIN,AMIN= $\begin{array}{lllll}0.51 & 1.9311 & 0.39 & -1.9838\end{array}$

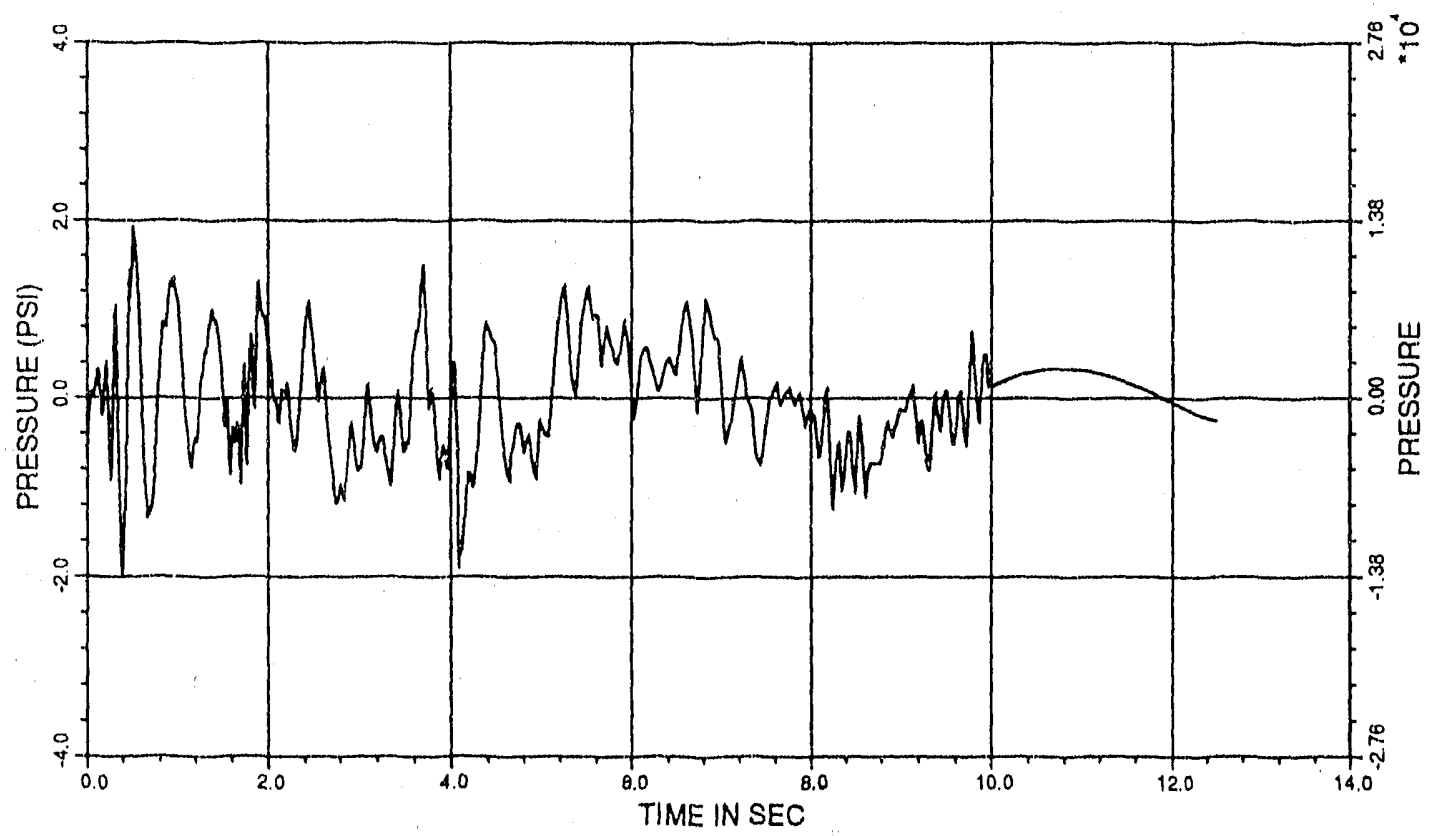

PRESSURE AT ELEMENT 133(waste)

MAX. FREQUENCY,AMPLITUDE $=0.24 \quad 0.1608$

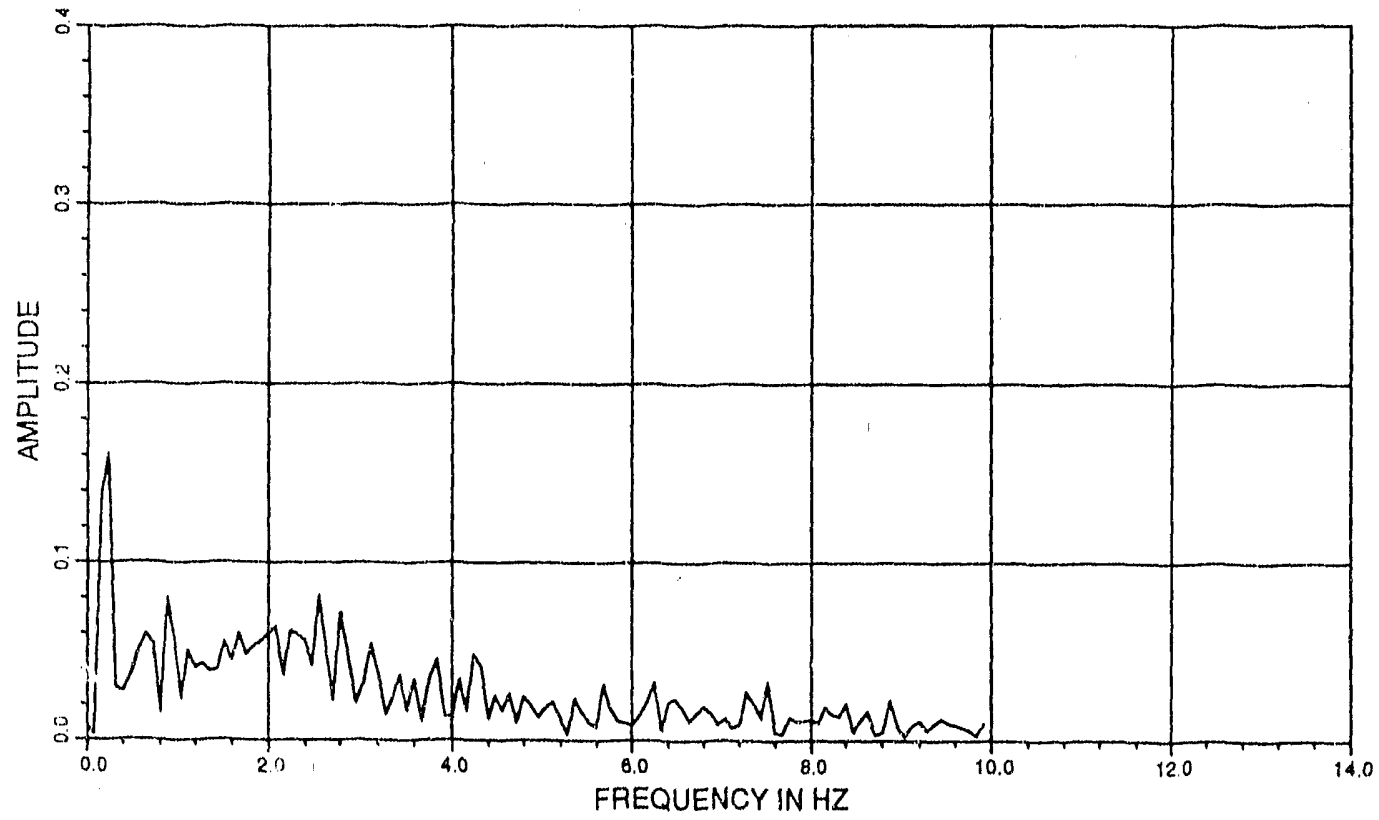

Fig. D-24. Time History of the Total. Pressure at Element 133 and its FFt for the Case of $\mu=200 \mathrm{cP}$ 


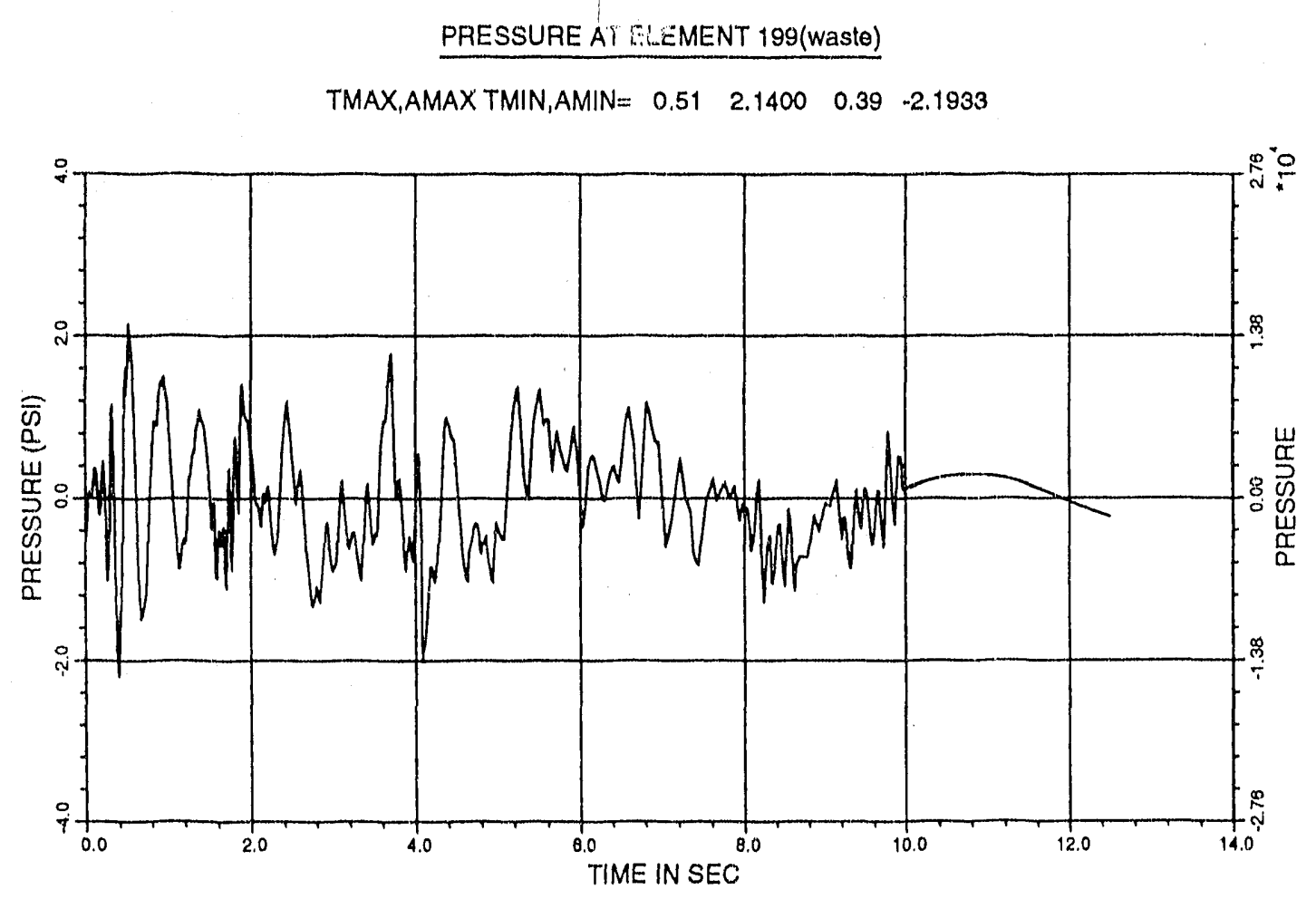

PRESSURE AT ELEMENT 199(waste)

MAX. FREQUENCY,AMPLITUDE $=0.24 \quad 0.1432$

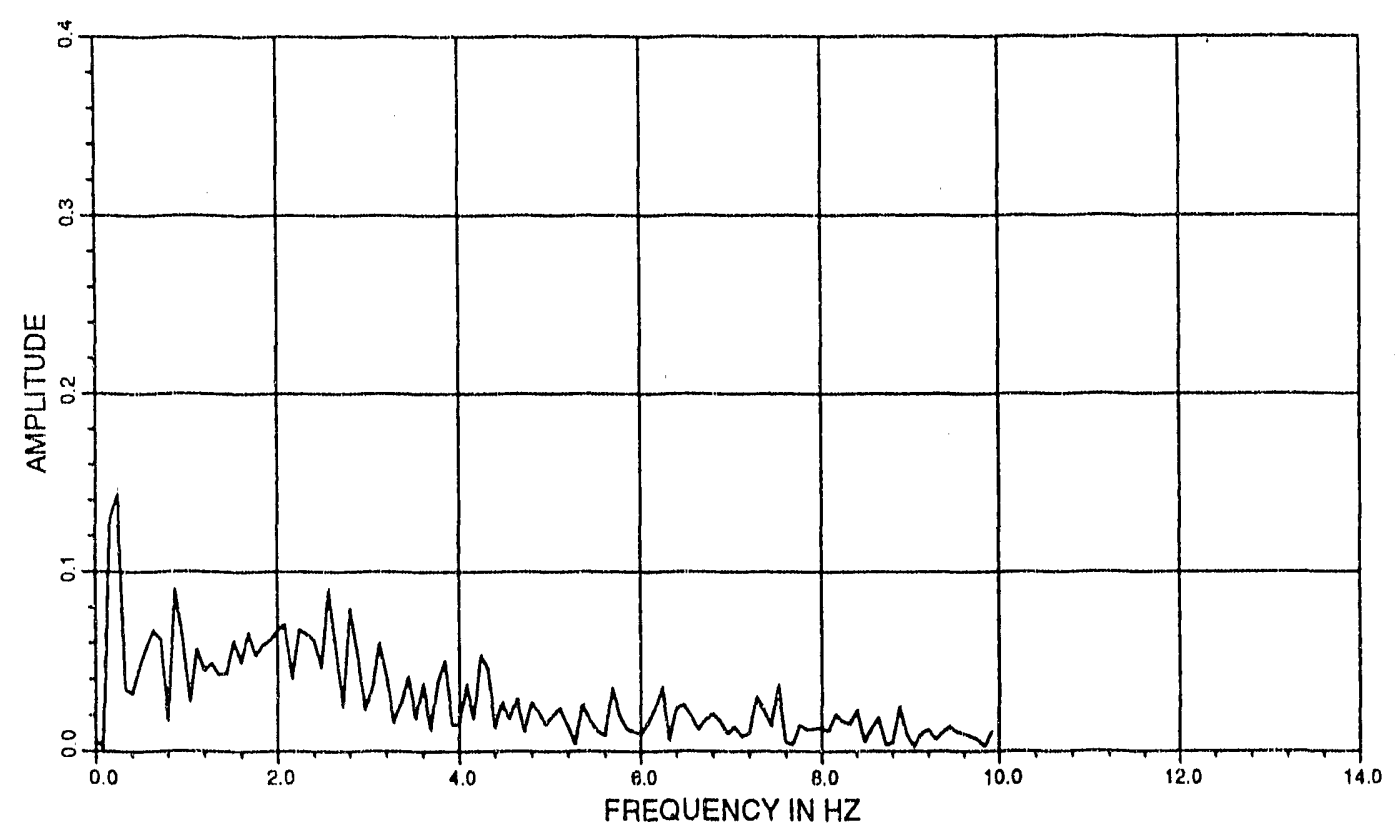

Fig. D-25. Time History of the Total Pressure at Element 199 and its FF'T for the Case of $\mu=200 \mathrm{cP}$ 


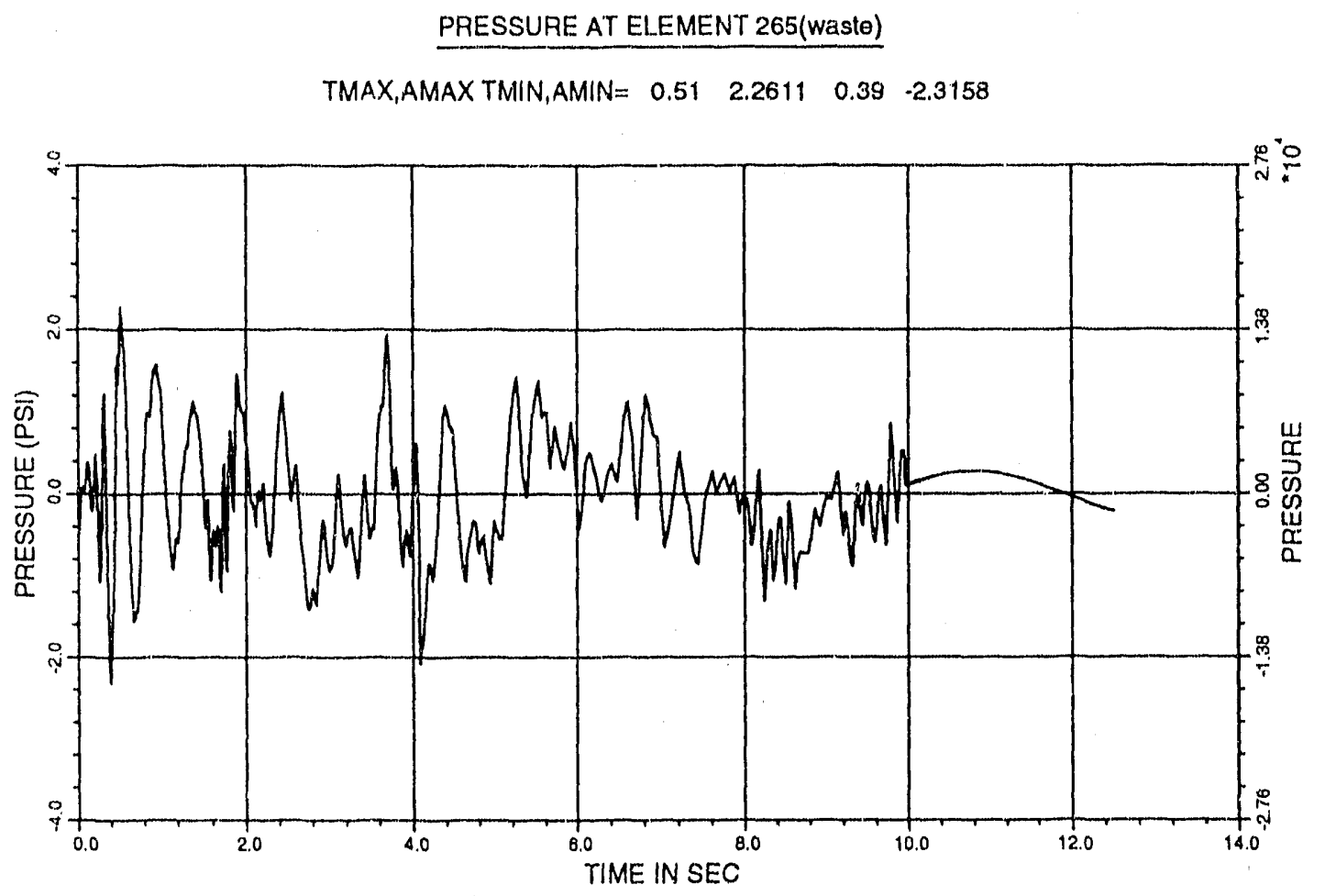

PRESSURE AT ELEMENT 265(waste)

MAX. FREQUENCY,AMPLITUDE $=0.24 \quad 0.1331$

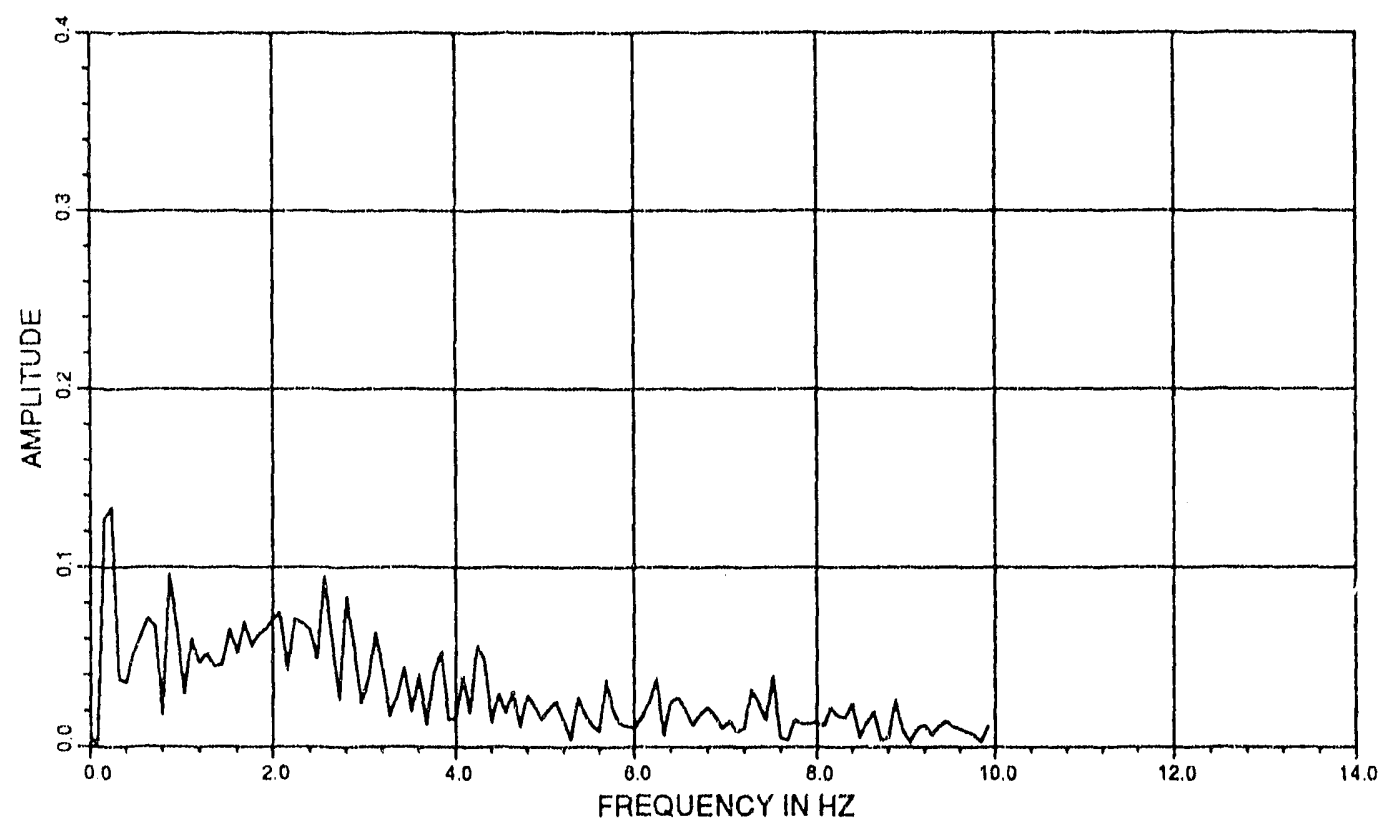

Fig. D-26. Time History of the Total Pressure at Element 265 and its FFl for the Case of $\mu=200 \mathrm{cP}$ 
PRESSURE AT ELEMENT 331 (waste)

TMAX,AMAX TMIN,AMIN $=0.51 \quad 2.3290 \quad 0.39 \quad-2.3832$

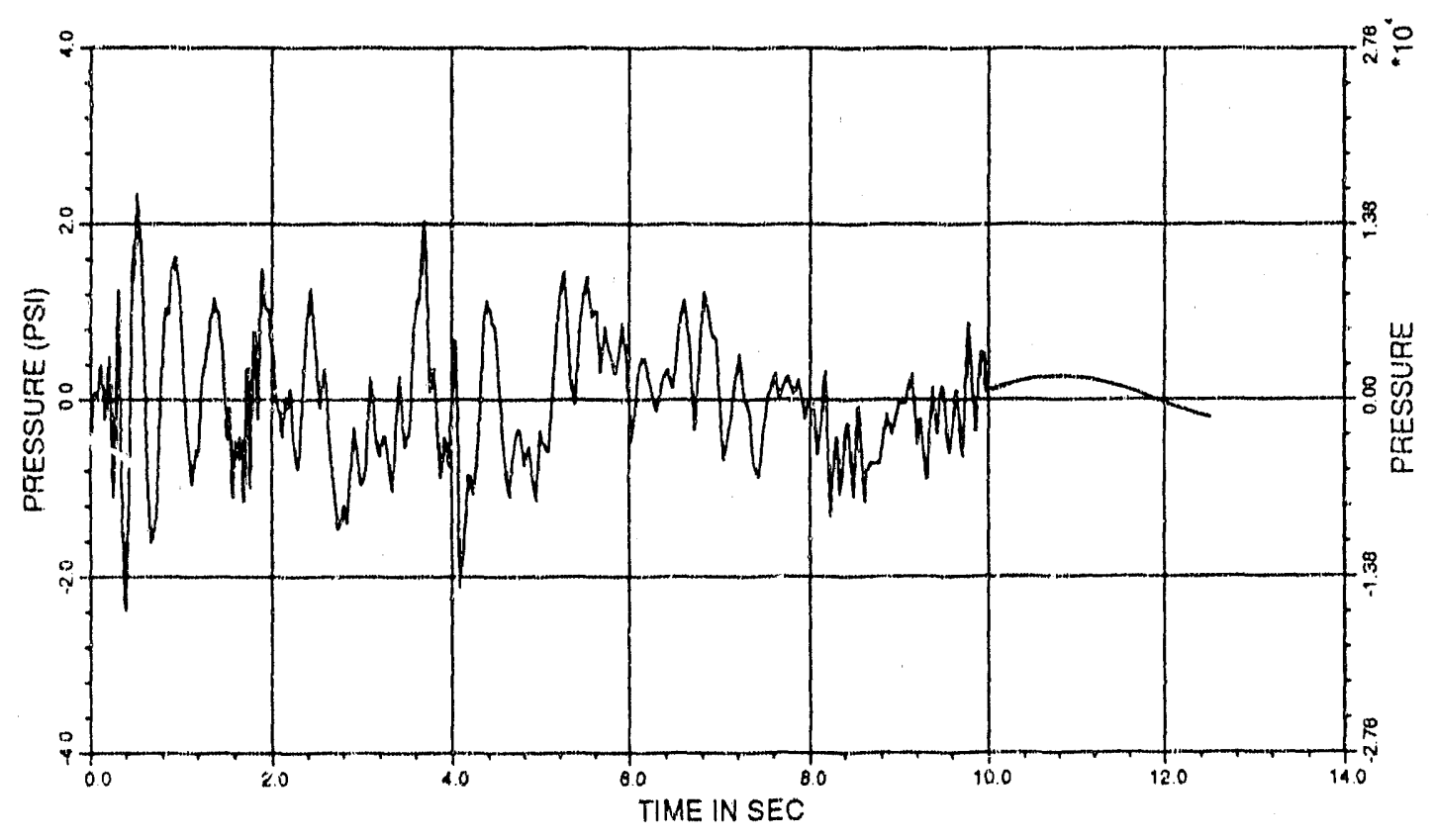

PRESSURE AT ELEMENT 331 (waste)

MAX. FREQUENCY,AMPLITUDE $=0.24 \quad 0.1272$

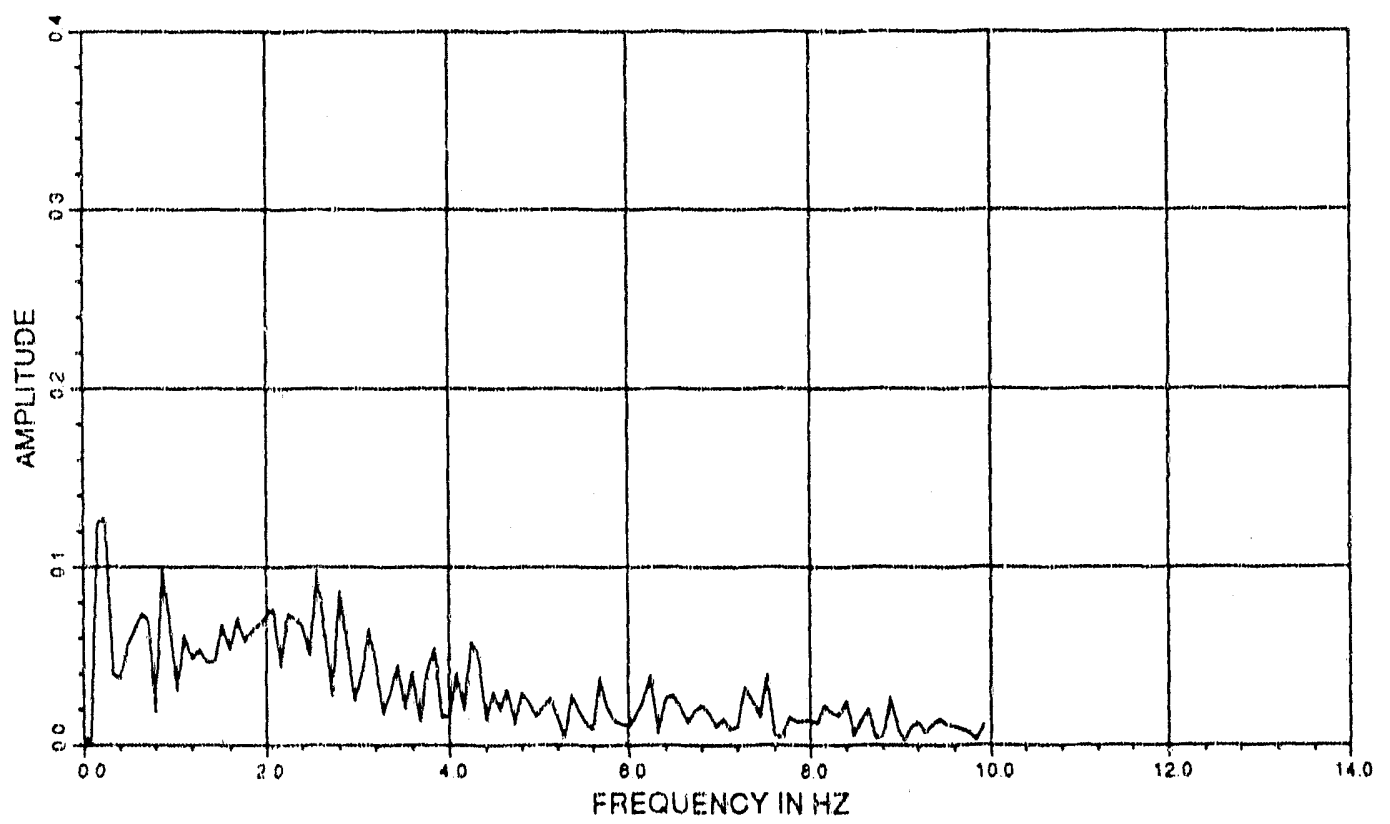

Fig. D-27. Time History of the Total Pressure at Element 331 and its FFT for the Case of $H=200 \mathrm{cP}$ 
PRESSURE AT ELEMENT 397(waste)

TMAX,AMA,X TMIN,ANIN $=0.51 \quad 2.3760 \quad 0.39 \quad-2.4318$

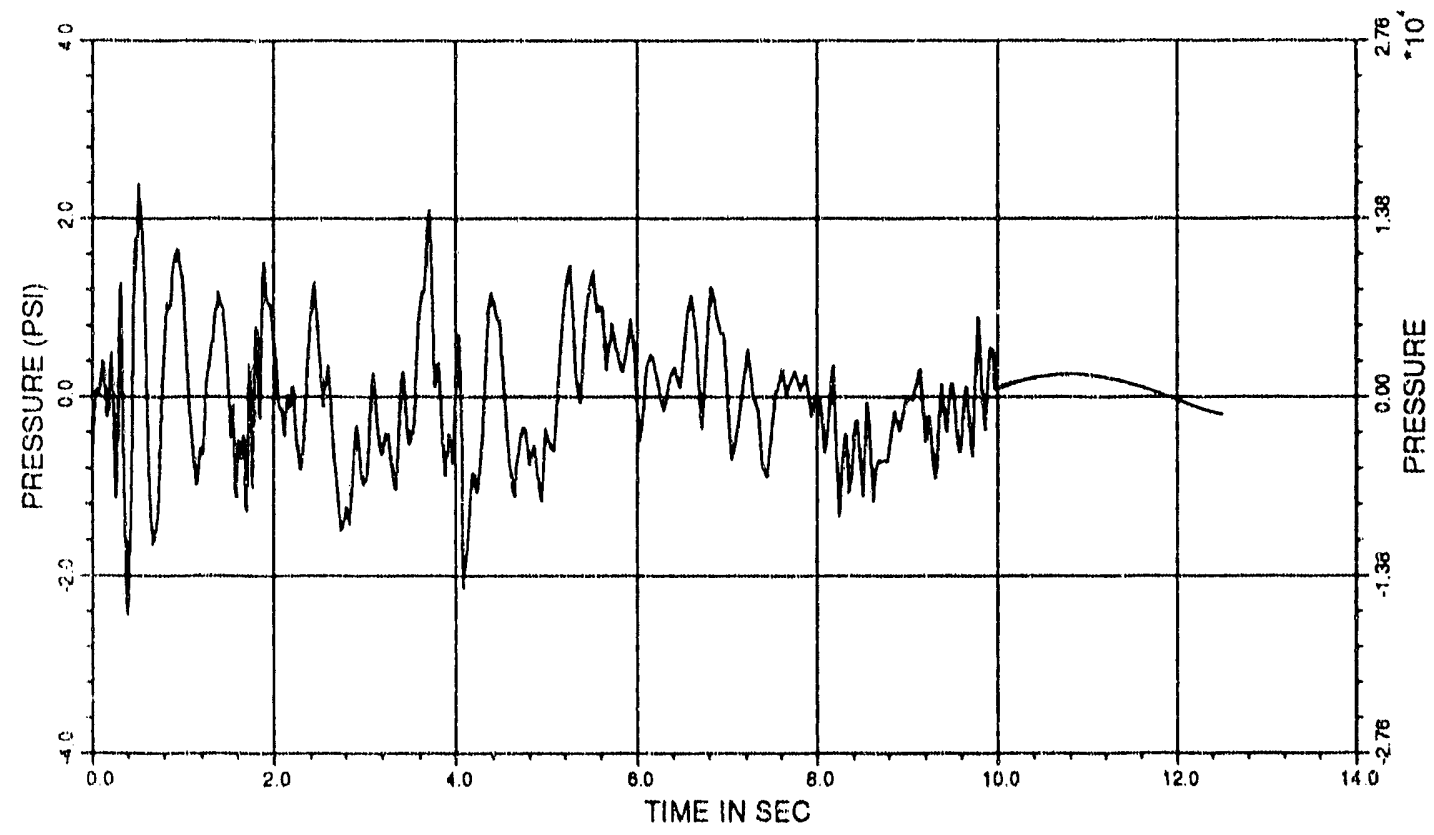

PRESSURE AT ELEMENT 397 (wasto)

MAX. FREQUENCY,AMPLITUDE $=0.24 \quad 0.1233$

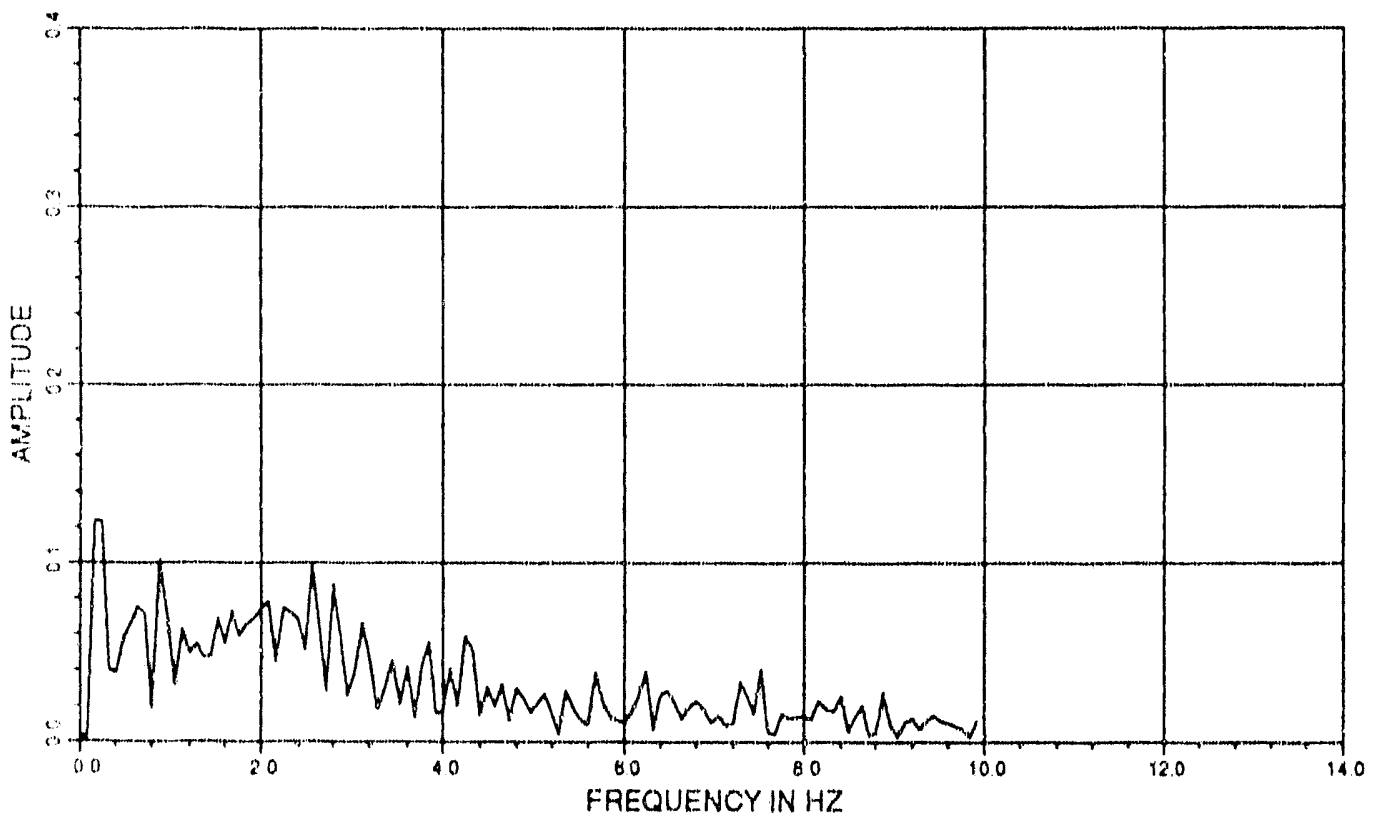

Fig. 1)-28. Time History of the Total Pressure at Element 397 and its FPl for the Case of $\mu=200 \mathrm{cP}$ 
PAESSURE AT ELEMENT 463(wasle)

TMAX,AMAX TMIN,AMIN $=0.51 \quad 2.4040 \quad 0.39 \quad \cdot 2.4587$

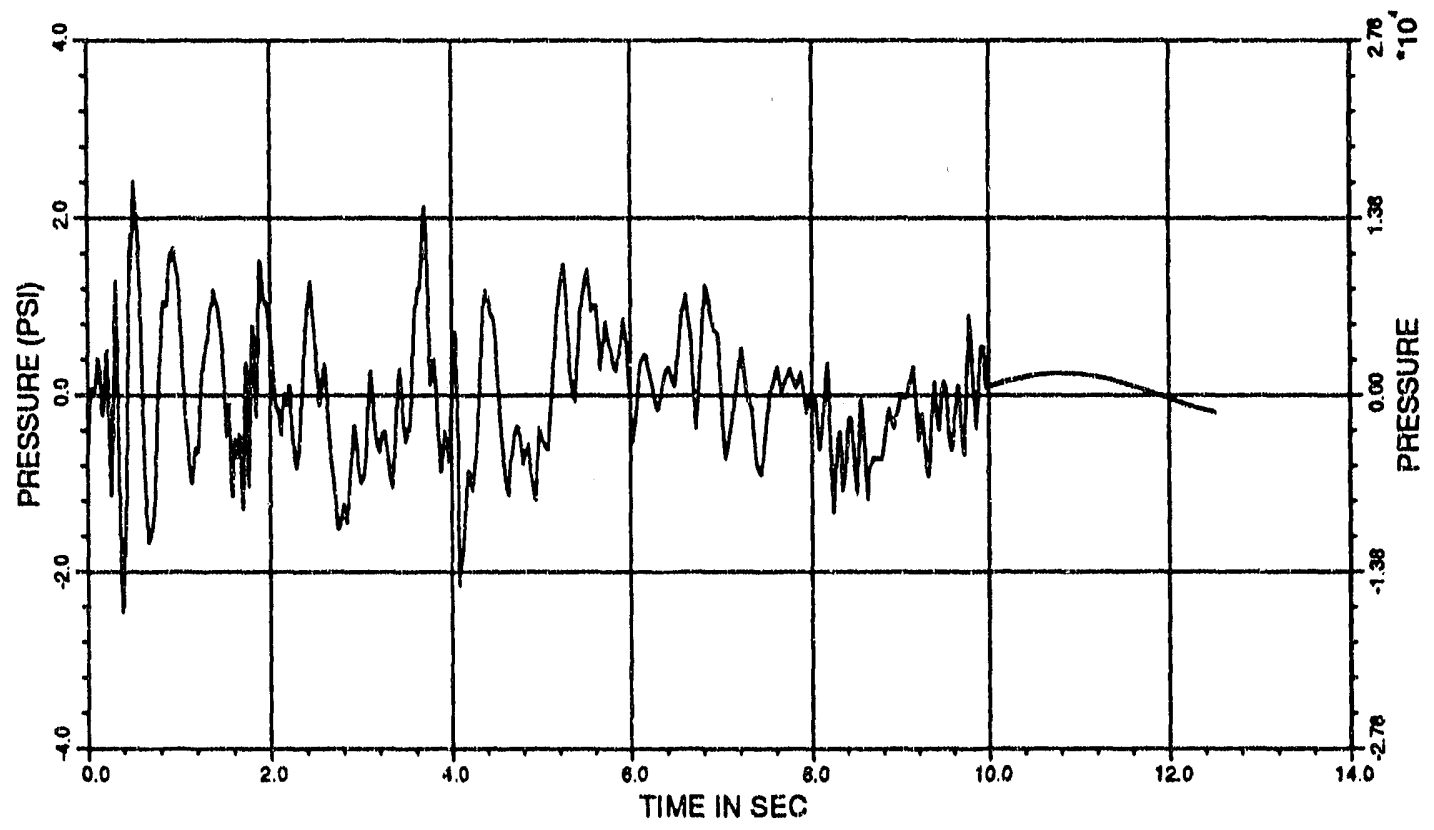

PRESSURE AT ELEMENT 463(wasto)

MAX, FREQUENCY,AMPLITUDE $=0.16 \quad 0.1218$

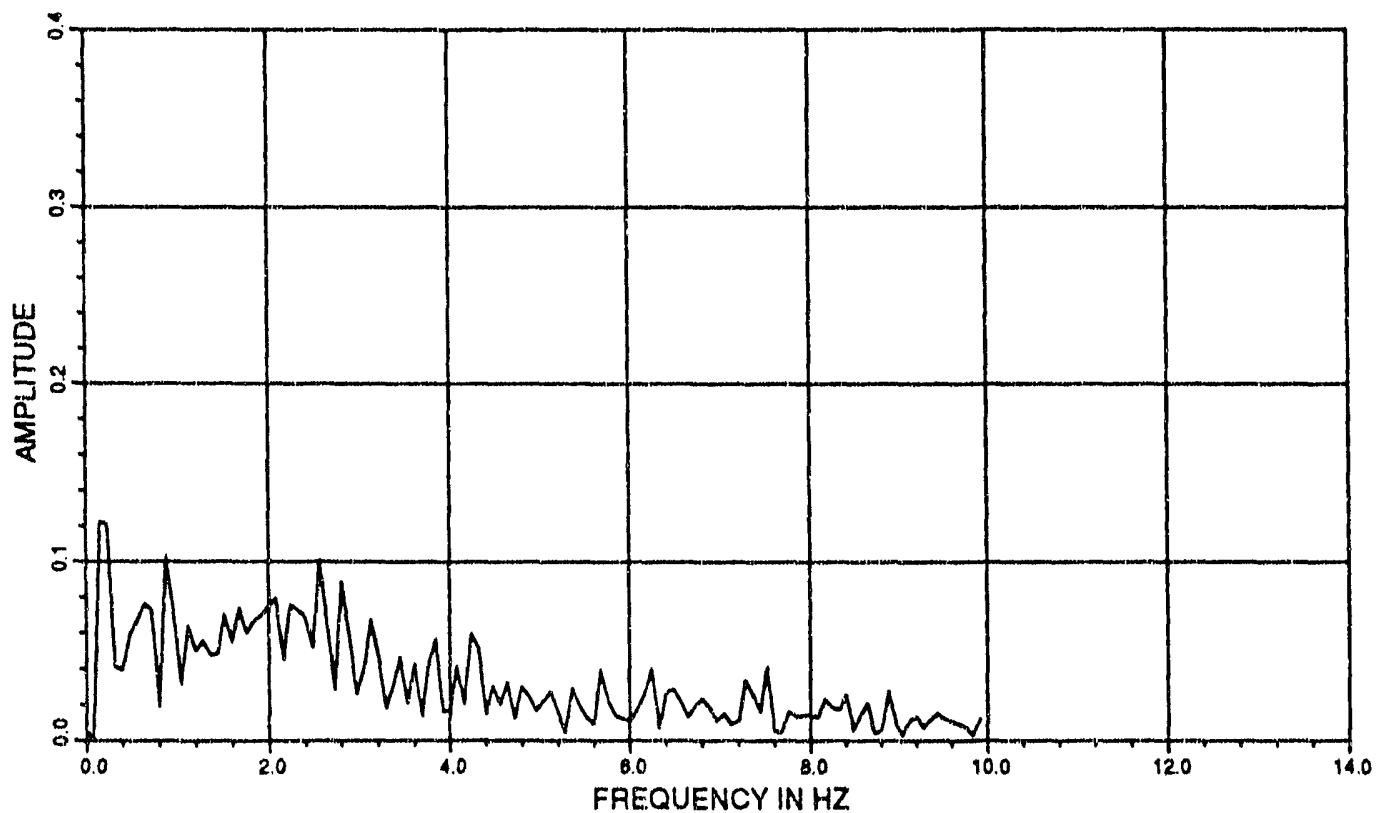

Fig. D-29. Time History of the Total Pressure at Element 463 and its FFT for the Case of $\mu=200 \mathrm{cP}$ 
PRESSURE AT ELEMENT 529(wasto)

TMAX, AMAX TMIN,AMIN $=\begin{array}{llll}0.51 & 2.4141 & 0.39 & -2.4708\end{array}$

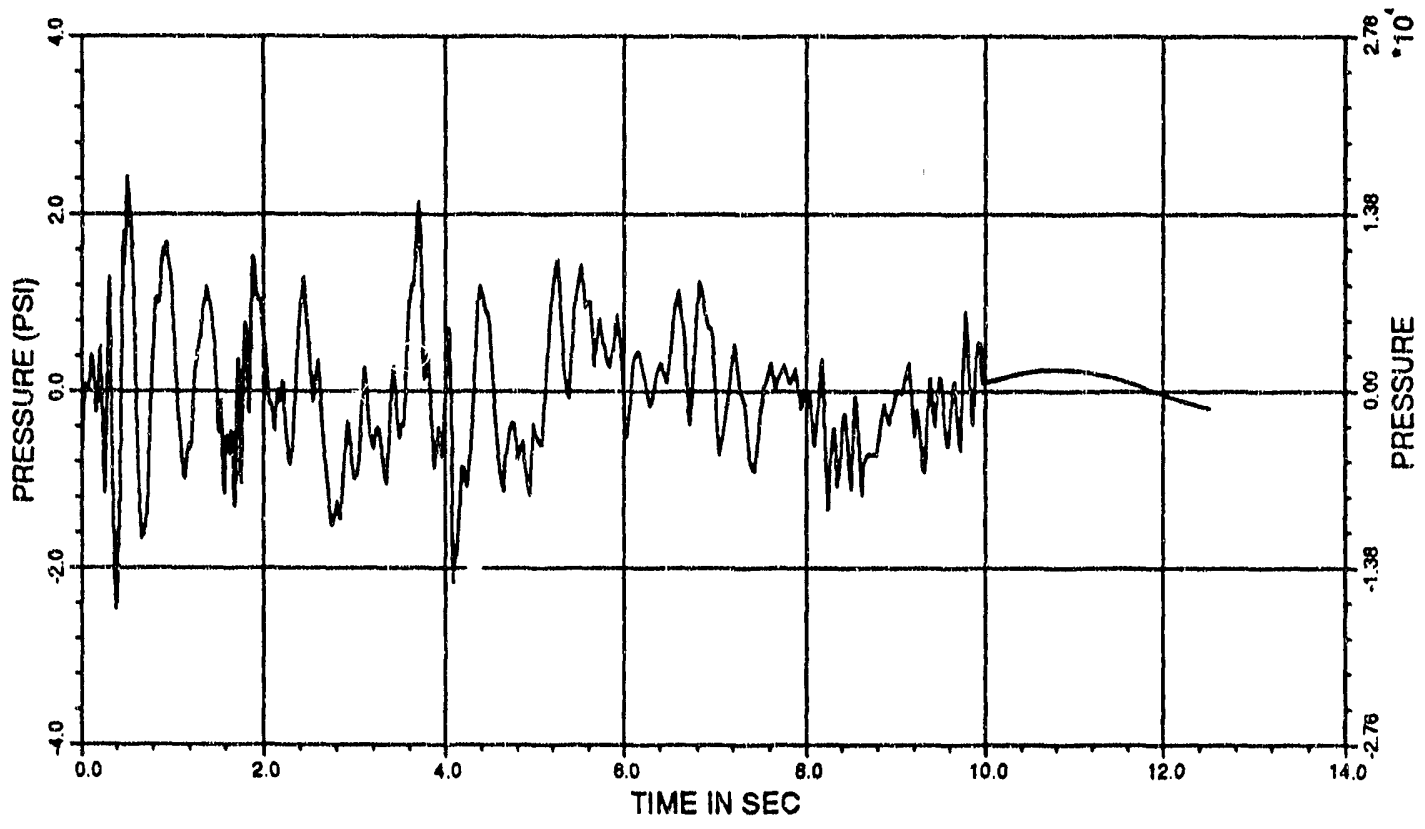

PRESSURE AT ELEMENT 529(wasto)

MAX, FREQUENCY,AMPLITUDE $=0.16 \quad 0.1216$

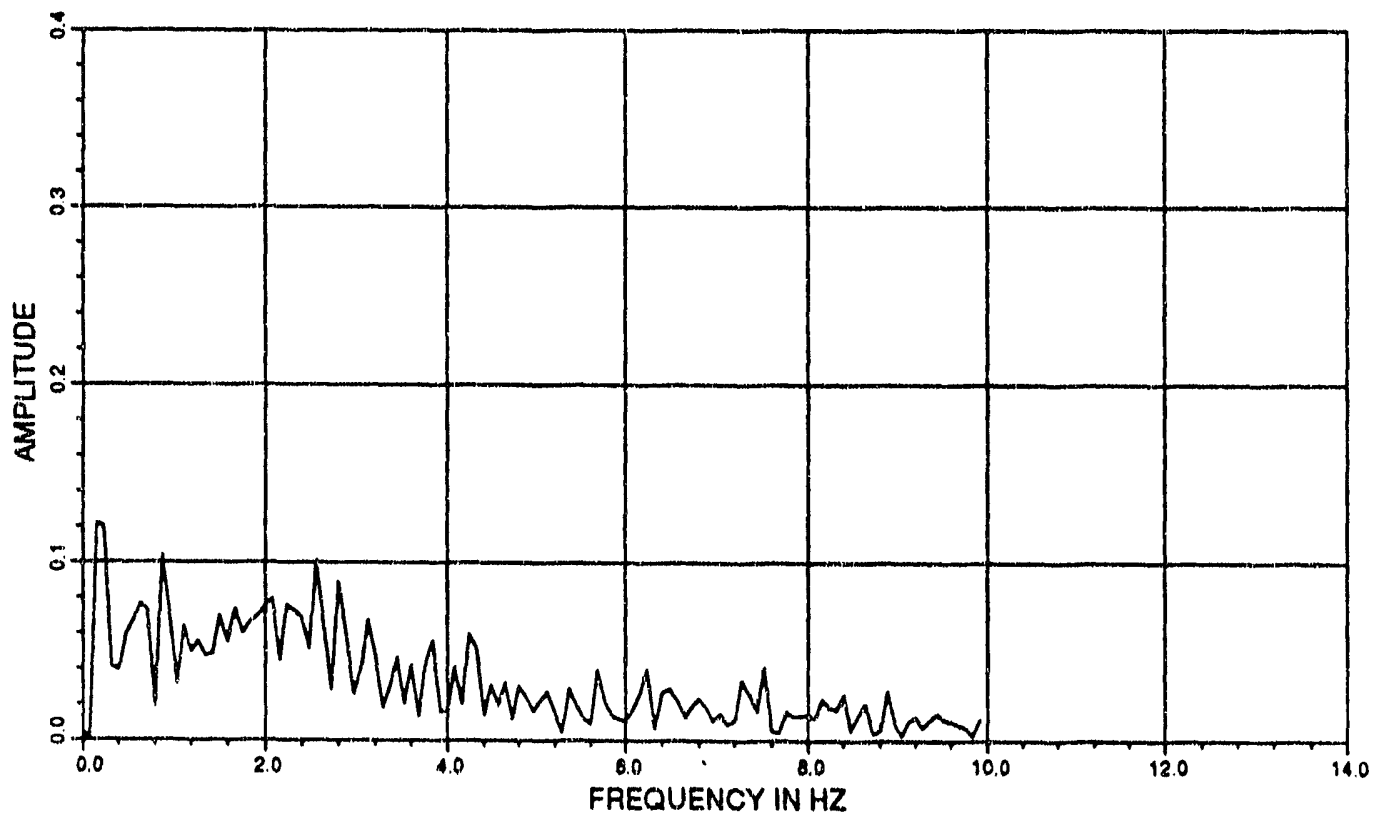

Fig. D-30. Time History of the Total Pressure at Element 529 and its FFT for the Case of $\mu=200 \mathrm{cP}$ 
PRESSURE AT ELEMENT 595(waste)

TMAX,AMAX TMIN,AMIN $=0.51 \quad 2.4130 \quad 0.39 \quad-2.4656$

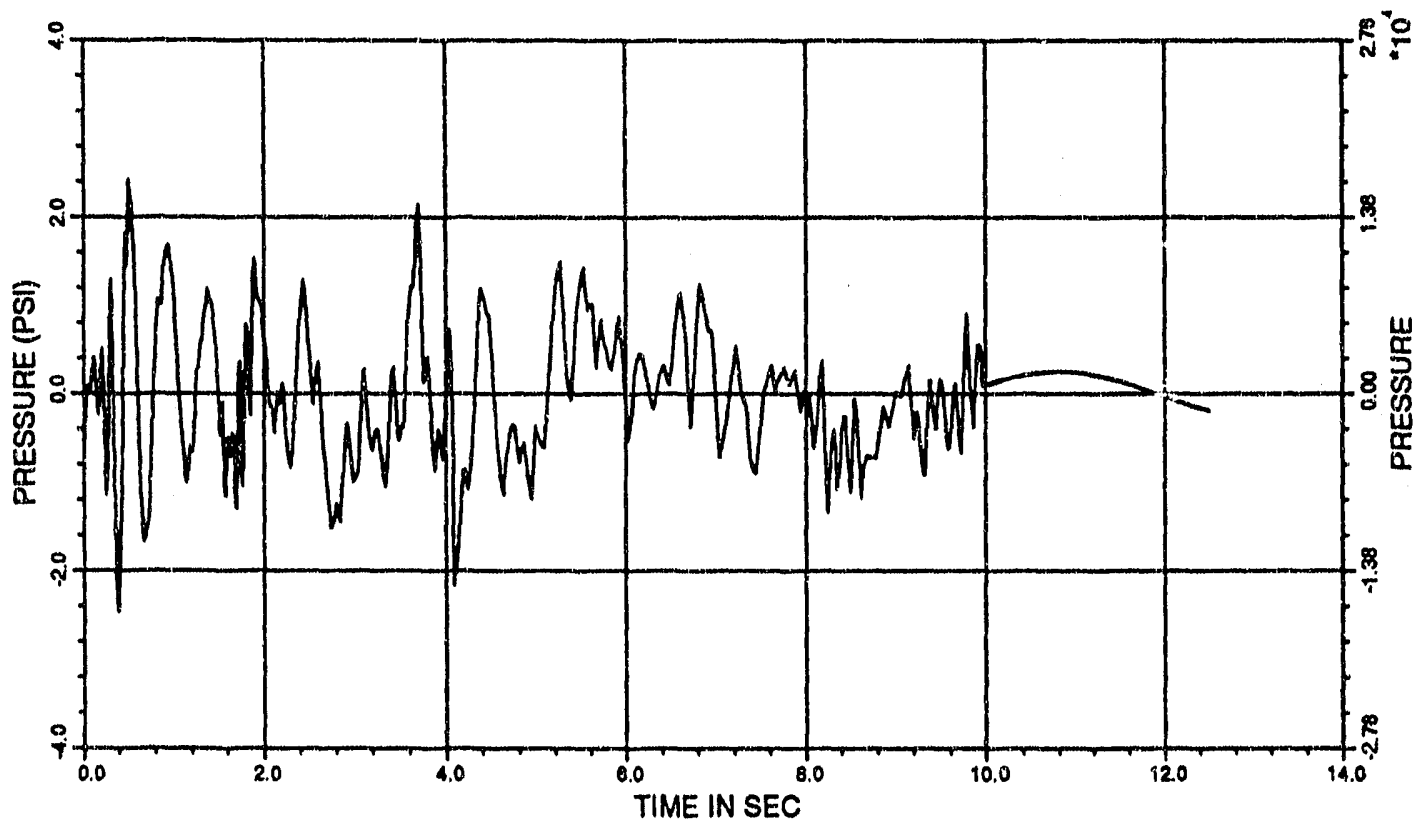

PRESSURE AT ELEMENT 595(waste)

MAX. FREQUENCY,AMPLITUDE $=0.16 \quad 0.1216$

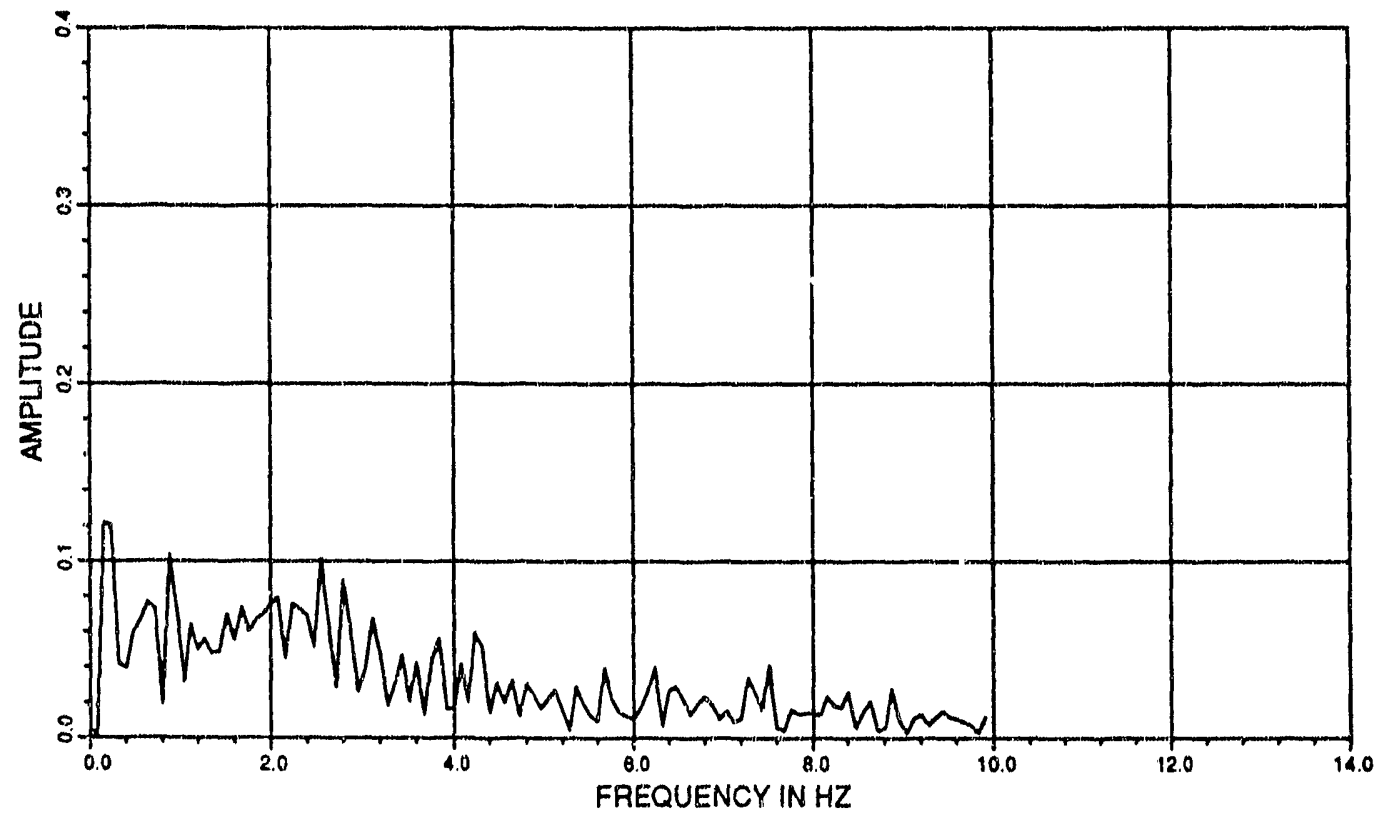

Fig. D-31. Time History of the Total Pressure at Element 595 and Its FFT for the Case of $\mu=200 \mathrm{cP}$ 

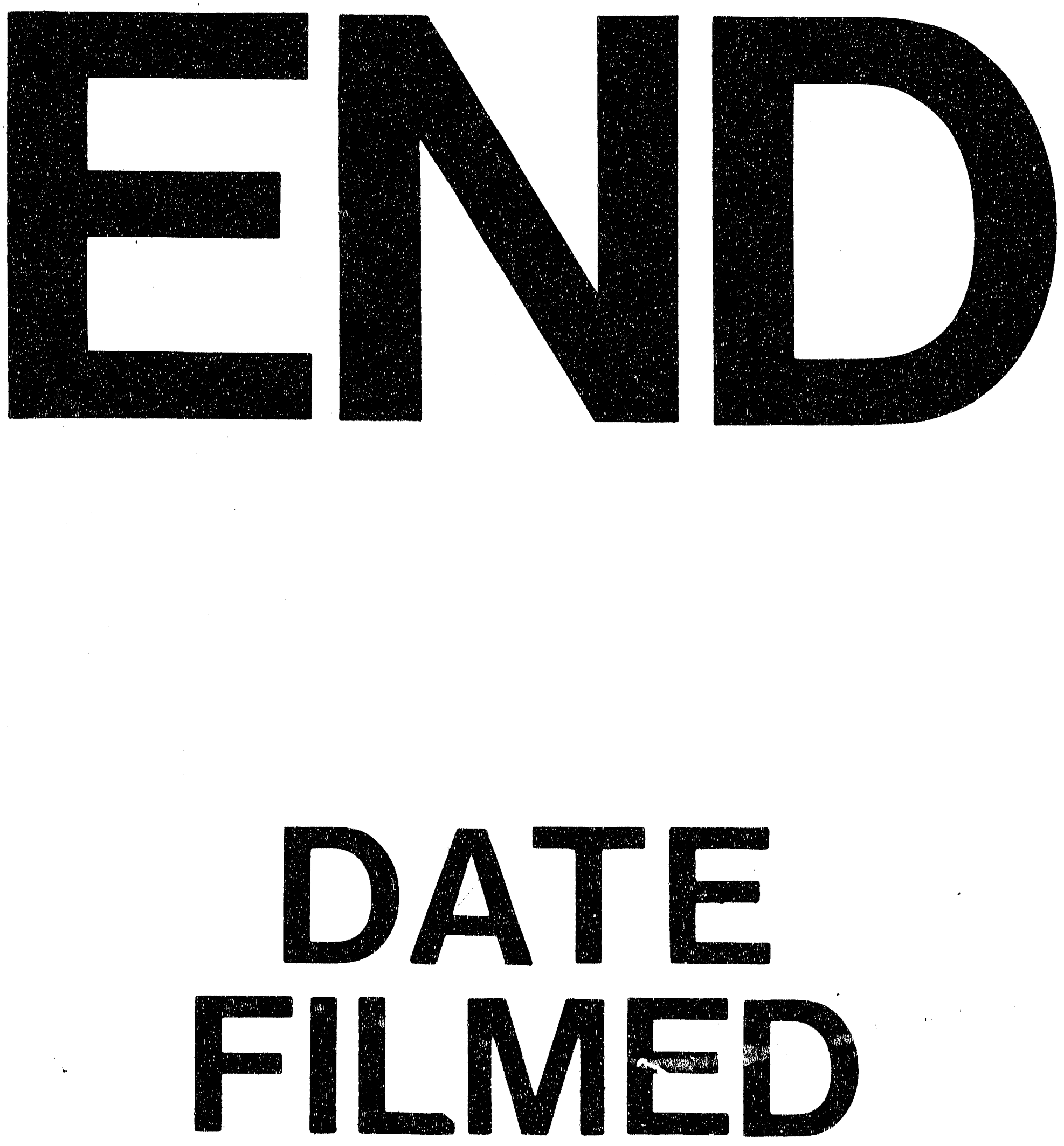

J

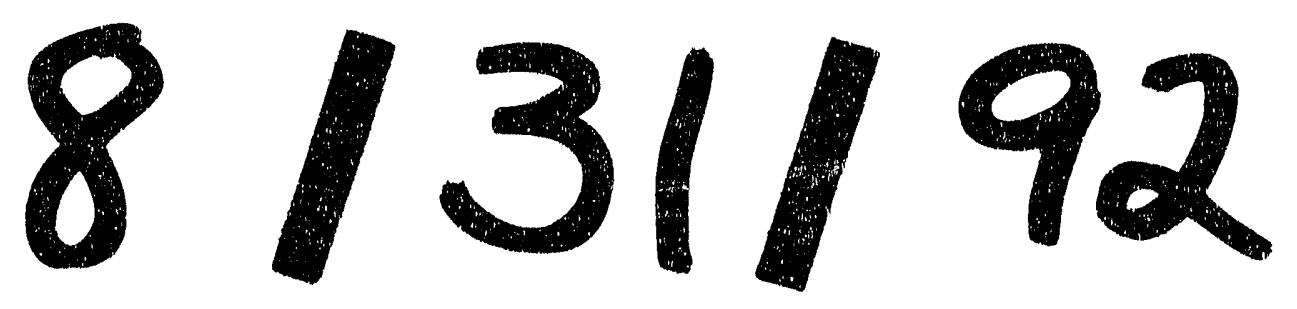


